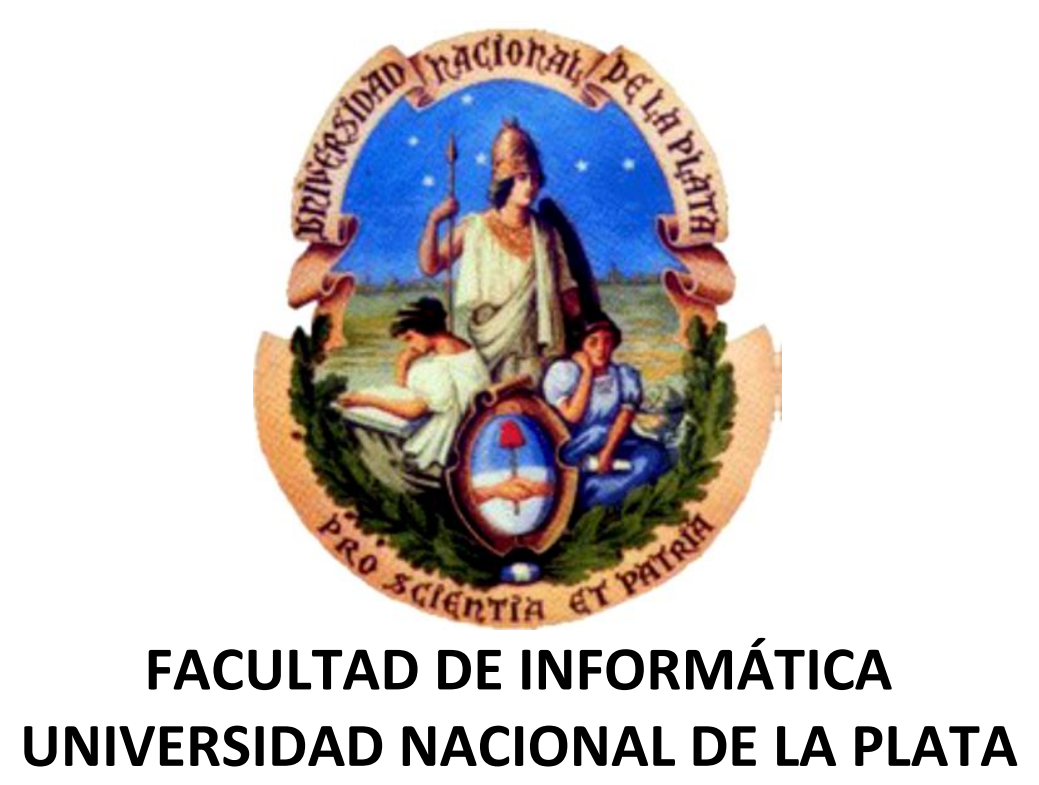

\title{
ANÁLISIS DE LAS REDES SOCIALES ONLINE COMO ENTORNO SEGURO DE COMUNICACIÓN PARA INCLUSIÓN FAMILIAR - SOCIAL GERONTOLÓGICA
}

TESIS PRESENTADA PARA OBTENER EL GRADO DE DOCTOR EN CIENCIAS INFORMÁTICAS

AUTOR (UFA-ESPE): Ramiro Augusto Ríos Paredes

DIRECTOR (UNLP): Lic. Javier Díaz 


\section{RESUMEN}

Este estudio permitió afirmar que la red social Facebook, es una alternativa tecnológica válida, para apoyar la inclusión familiar y social del adulto mayor, y favorecer adicionalmente su salud física y mental, es decir, tiene el potencial para elevar el nivel de la calidad de vida del adulto mayor.

Por otra parte, siendo el entorno de Facebook, una tecnología soportada en Internet, no está exenta de riesgos para sus usuarios. Sin embargo, este estudio evidenció que el nivel de conciencia sobre seguridad y privacidad del usuario adulto mayor de Facebook, es el factor determinante de la exposición al riesgo atribuible al usuario; y concluyó que, mediante ajustes en sus comportamientos psicosociales, y en su cultura de seguridad y privacidad, podría reducir su nivel de exposición al riesgo; haciendo de la red social un entorno más seguro de comunicación.

Frente a los potenciales beneficios que puede tener el adulto mayor con el uso de Facebook, y la posibilidad cierta de reducir la exposición a los riesgos propios de Internet, se concluyó que debería impulsarse el uso de la red social entre los miembros del segmento poblacional mayor a 65 años.

Tomando en cuenta que el estudio giró alrededor del adulto mayor y la red social Facebook, para su desarrollo se seleccionó un enfoque metodológico predominantemente cualitativo, suplementado por análisis cuantitativos de datos cualitativos previamente cuantificados.

Para desarrollar la investigación, se establecieron dos marcos conceptuales derivados de la literatura, el uno relacionado a los potenciales beneficios del uso de Facebook para la calidad de vida del adulto mayor, que fueron parte importante del estado del arte del adulto mayor frente a Facebook; y el otro, respecto de las diversas causas de los ciber-riesgos en el entorno de Facebook, con especial atención a aquellas causas que tienen que ver exclusivamente con los comportamientos psicosociales, y la cultura de seguridad y privacidad del usuario de la red social.

Para aproximarse a la realidad, se recurrió a la observación cualitativa directa; $y$, a la recopilación de datos a través de entrevistas estructuradas, aplicadas a los AM y otros usuarios ecuatorianos de Facebook.

Los aportes generados en el proceso de investigación son: el modelo de sensibilización del adulto mayor hacia el uso y la apropiación de tecnología; el proceso evolutivo de apropiación de tecnología; el modelo integral de apropiación de tecnología (MIAT); el decálogo para moldear una actitud positiva del adulto mayor hacia el uso de la red social Facebook; el modelo conceptual, con perspectiva interdisciplinaria, de las causas de los ciber-riesgos en el entorno de Facebook; los factores determinantes del grado de conciencia sobre privacidad y seguridad de un usuario de Facebook, que fundamentaron, el proceso de estimación del nivel real de conciencia de los usuarios de Facebook respecto a privacidad y seguridad en la red social; y, la propuesta de marco de referencia para conformar en Facebook, un entorno seguro de interacción social virtual que apoye la inclusión familiar y social del adulto mayor.

\section{PALABRAS CLAVES}

Adopción de tecnología, adulto mayor, brecha digital, calidad de vida, comportamientos psicosociales en Facebook; cultura de seguridad y privacidad en el entorno de Facebook, Facebook, inclusión familiar y social. 


\section{DEDICATORIA}

Dedicado a:

Mi esposa Sandra y mis hijos Santiago y Diego, por su amor, comprensión, fortaleza, apoyo, sacrificio y compromiso, fueron el complemento perfecto en esta travesía, sin ellos hubiese sido imposible lograrlo.

A mi querida madre, mi adulta mayor preferida.

A todas las personas adultas mayores, siempre merecedoras de un alto nivel de calidad de vida. 


\section{AGRADECIMIENTOS}

Agradezco profundamente:

A Dios por ser siempre la fuente de mi esperanza.

Al Lic. Javier Díaz, tutor de la tesis, por haber aceptado dirigirme la tesis doctoral, por haberme compartido sus conocimientos, por cada detalle que me mostró y por cada momento que me orientó en el largo camino recorrido.

A la Lic. Claudia Banchoff, por sus conocimientos, paciencia, consejos y apoyo, que me acompañaron para perfeccionar el contenido del documento de tesis.

A todas las personas que hacen la Dirección de Postgrado de la Facultad de Informática de la Universidad Nacional de La Plata por haberme permitido tener el orgullo de ser parte de tan prestigiosa institución y disfrutar de una formación de excelencia.

Al Dr. Ramiro Delgado Rodríguez, docente de la Universidad de las Fuerzas Armadas - ESPE, ante todo un gran amigo, que brindó siempre su respaldo incondicional para el avance de la investigación doctoral.

A mis alumnos de la Universidad de las Fuerzas Armadas ESPE y de la Universidad Central del Ecuador, por su participación voluntaria como encuestadores.

A los AM, actores principales de este estudio, por compartir con confianza y transparencia su realidad. 


\section{INDICE DE CONTENIDOS}

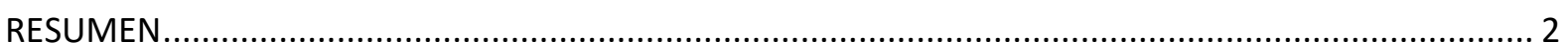

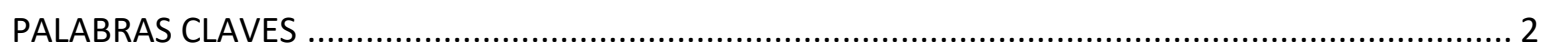

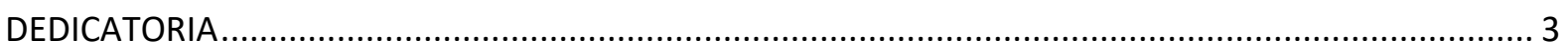

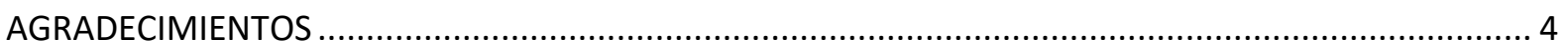

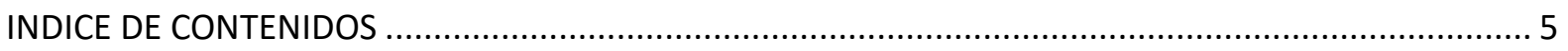

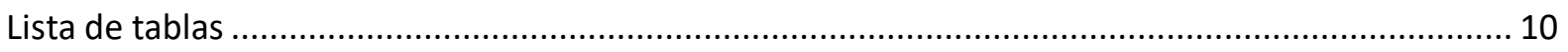

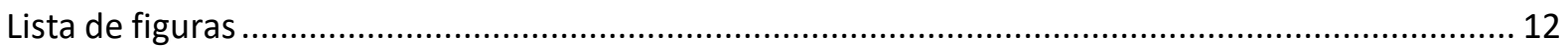

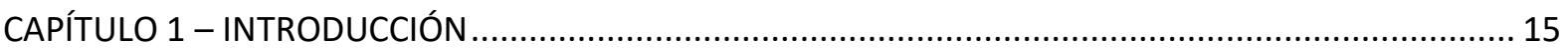

1.1. Antecedentes de la investigación...................................................................... 15

1.2. Planteamiento del problema de investigación ...................................................... 16

1.3. Área de investigación científica a la que pertenece el estudio ........................................ 19

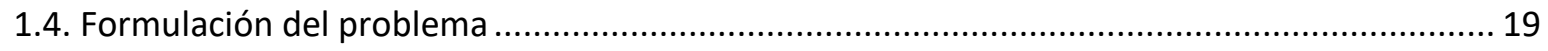

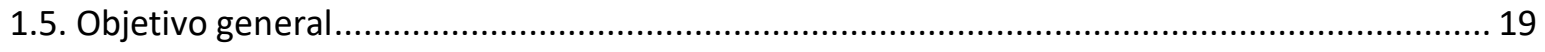

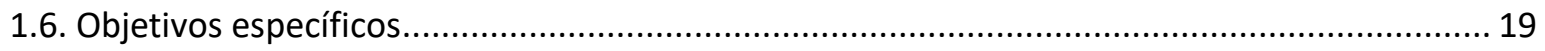

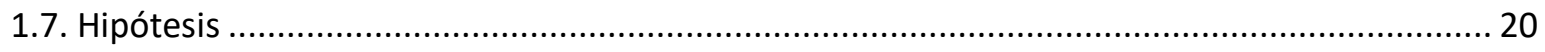

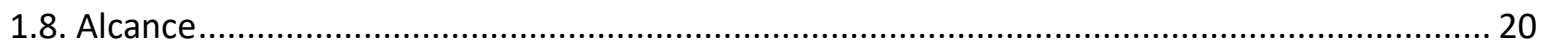

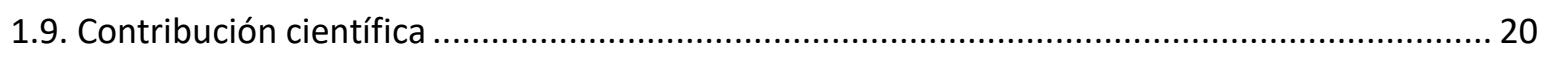

1.9.1. Publicaciones resultantes del proceso de investigación............................................ 20

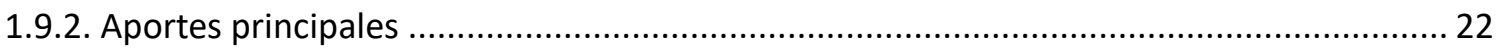

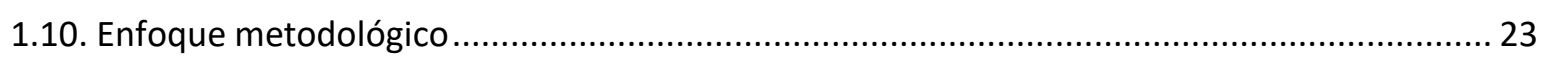

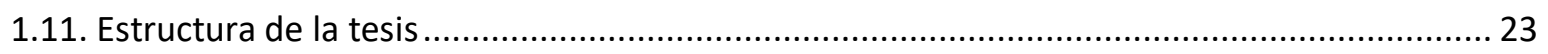

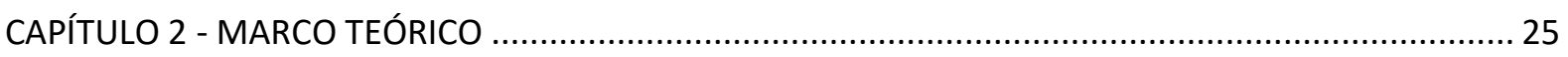

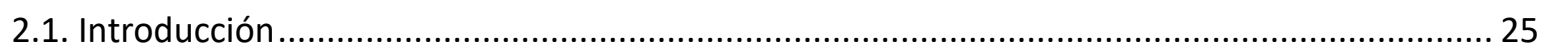

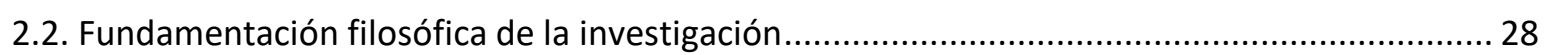

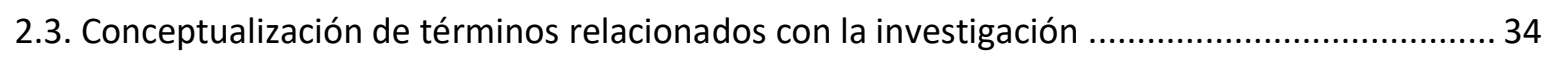

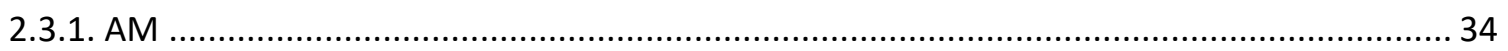

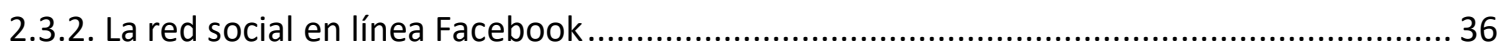

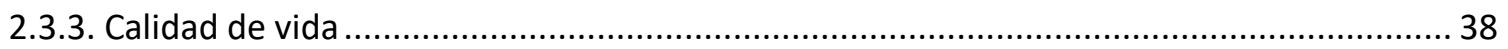

2.4. Aceptación, uso y apropiación de tecnología.............................................................. 42

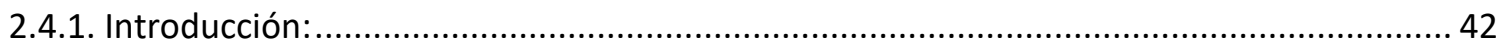

2.4.2. Factores que influyen en la aceptación, adopción - uso, y apropiación de tecnología de

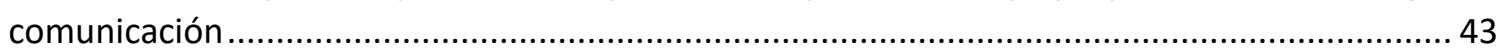

2.4.2.1. Teoría de la presencia social ................................................................ 43 
2.4.2.2. Teoría de usos y gratificaciones

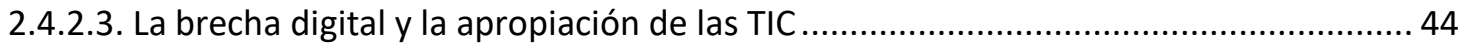

2.4.3. Modelo teorizado de proceso evolutivo hacia la apropiación de tecnología ..................... 46

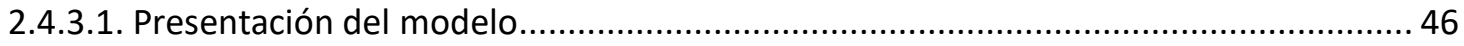

2.4.3.2. Explicación de las etapas del proceso ...................................................................... 49

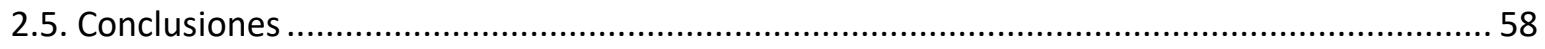

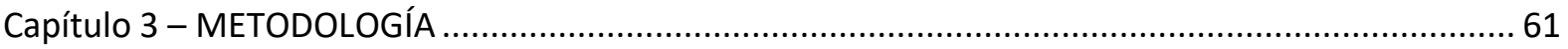

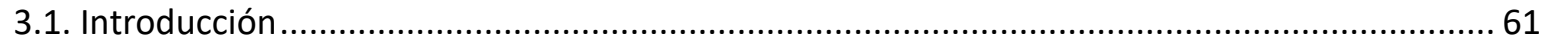

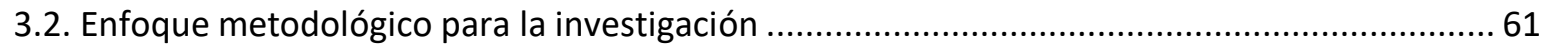

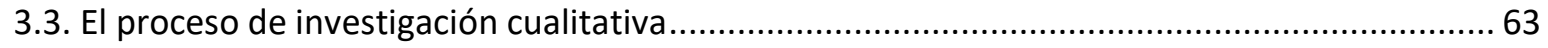

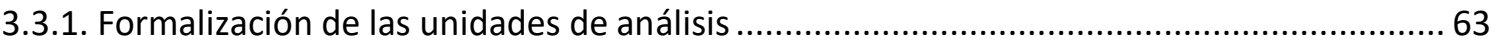

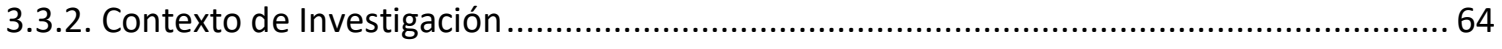

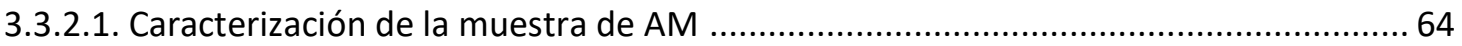

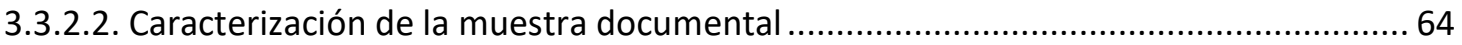

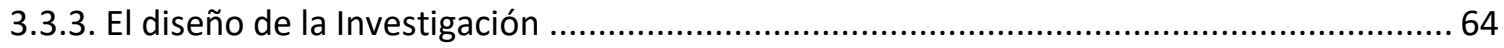

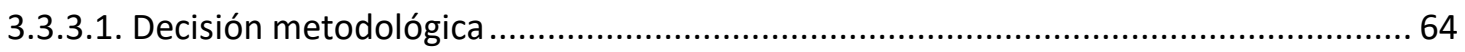

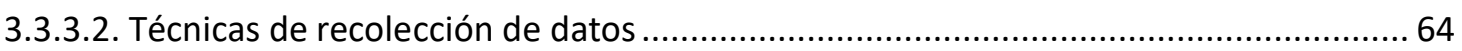

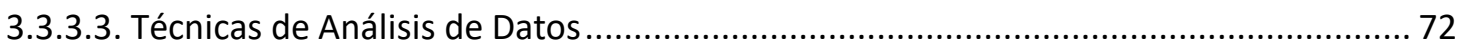

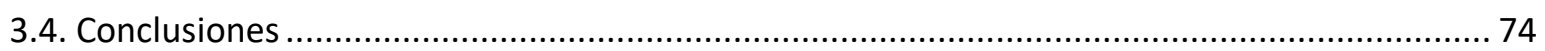

CAPÍTULO 4 - ESTADO DEL ARTE: EL AM FRENTE A LA RED SOCIAL FACEBOOK …............................. 76

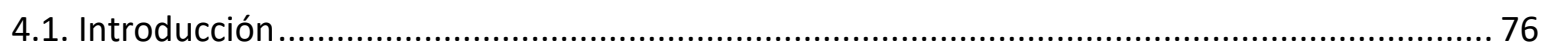

4.2. Modelo de aproximación a la realidad del AM frente a la red social Facebook ........................ 78

4.2.1. Alternativas de modelos de aproximación a la realidad del AM frente a la red social

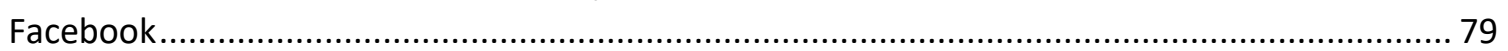

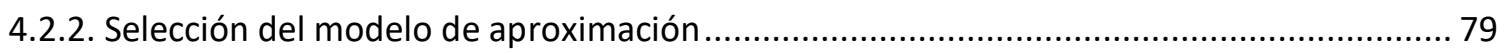

4.2.3. Modelo integral de apropiación de tecnología por el AM (MIAT-AM) .............................. 83

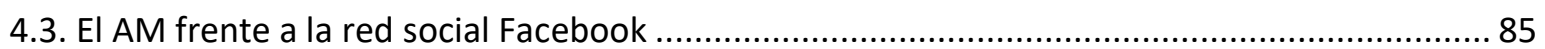

4.3.1. Ámbitos de sensibilización del AM para la reducción de la brecha digital en el acceso

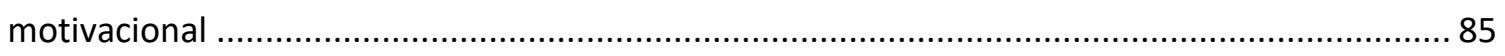

4.3.2. Alternativas para la reducción de la brecha digital en el acceso físico ............................... 87

4.3.3. Ámbitos de sensibilización del AM para la reducción de la brecha digital en el acceso a la

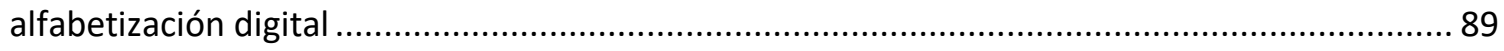

4.3.4. Precauciones a tener en cuenta para evitar efectos adversos con el uso de Facebook .... 91

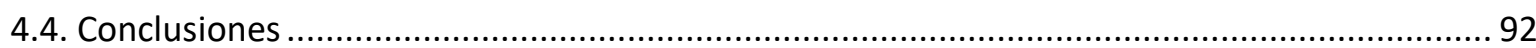


5.1. Introducción

5.2. Investigación No. 1: razones por las que los AM deberían tener una actitud positiva hacia

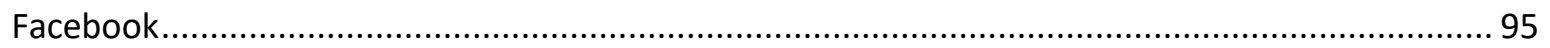

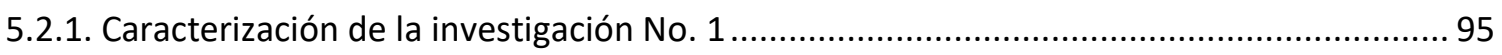

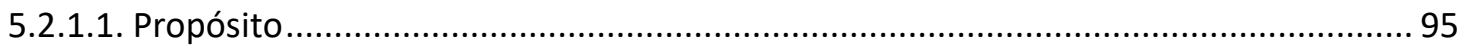

5.2.1.2. Ficha descriptiva de la investigación No. 1 .............................................................. 96

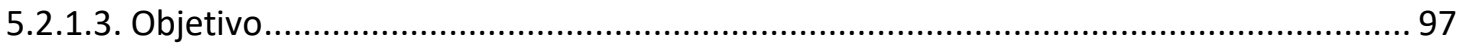

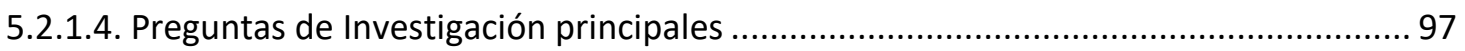

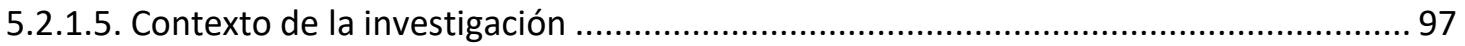

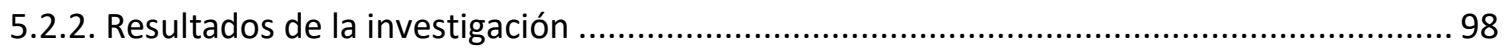

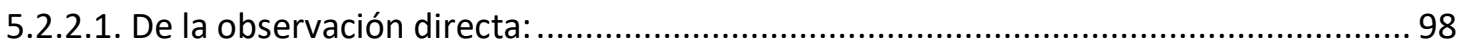

5.2.2.2. De la investigación no experimental transversal: ...................................................... 98

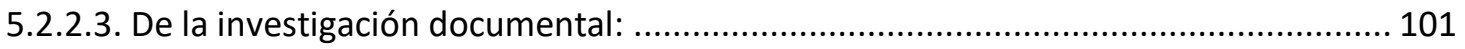

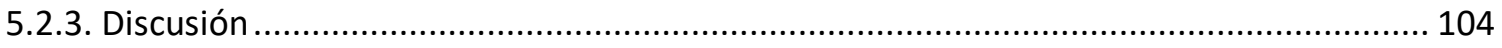

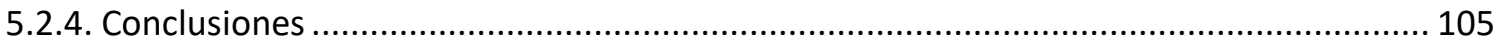

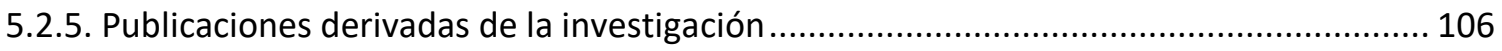

5.3. Investigación No. 2: identificación del contexto tecnológico de las TIC del AM ..................... 107

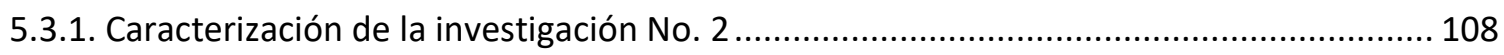

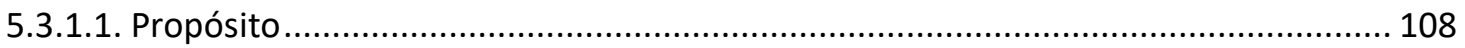

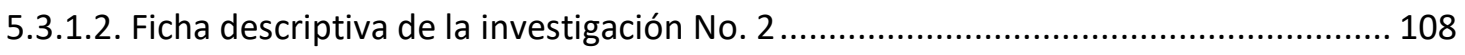

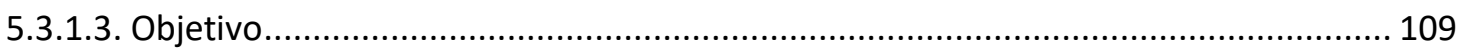

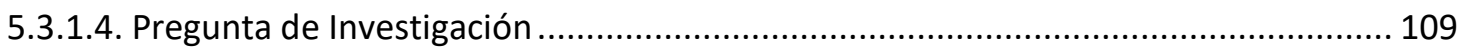

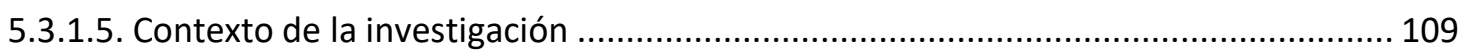

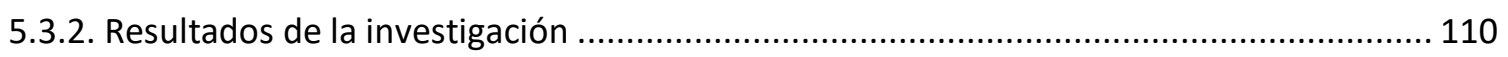

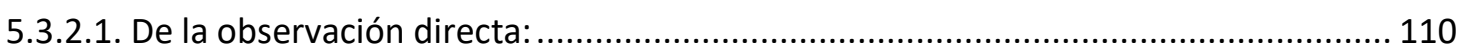

5.3.2.2. De la investigación no experimental transversal: ................................................... 112

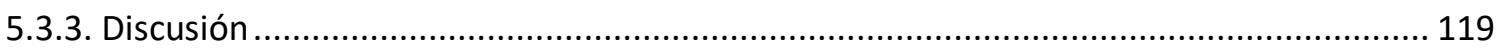

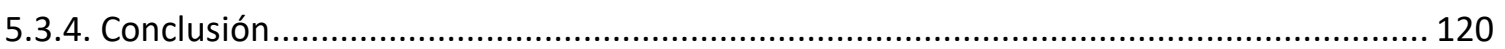

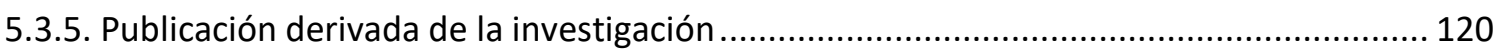

5.4. Investigación No. 3: factores determinantes de la exposición del usuario AM a los ciber-riesgos

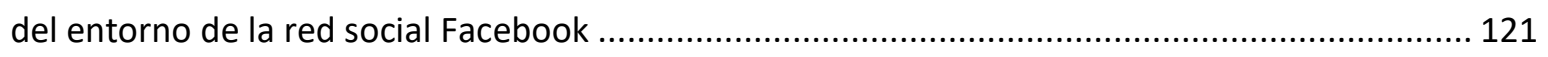

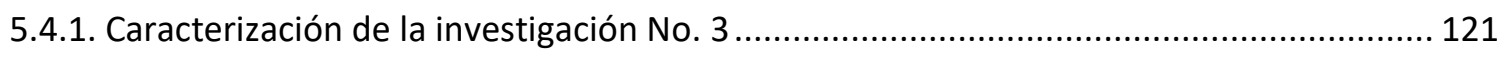

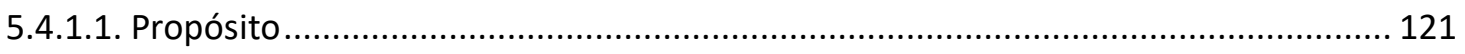

5.4.1.2. Ficha descriptiva de la investigación No. 3 …....................................................... 122 
5.4.1.3. Objetivo.

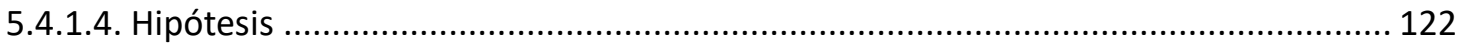

5.4.1.5. Pregunta de Investigación ..................................................................... 122

5.4.1.6. Contexto de la investigación .............................................................. 123

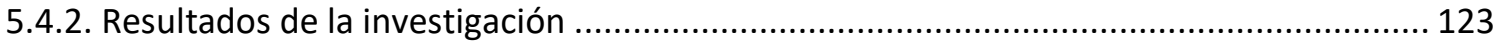

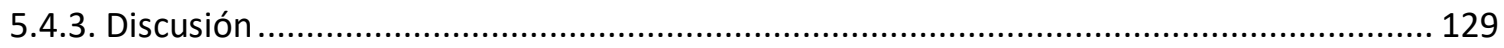

5.4.3.1. Modelo Conceptual de las Causas de los Ciber-riesgos en el Entorno de Facebook 129

5.4.3.2. Factores determinantes del grado de conciencia sobre privacidad y seguridad en Facebook .............................................................................................................. 131

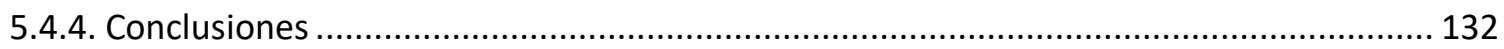

5.5. Investigación No. 4: estimación del nivel real de conciencia de los usuarios de Facebook respecto a privacidad y seguridad en la red social ........................................................... 134

5.5.1. Caracterización de la investigación No. 4 ......................................................... 134

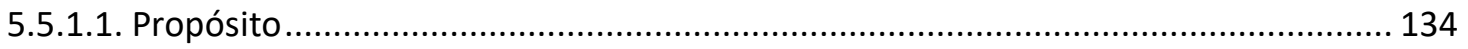

5.5.1.2. Ficha descriptiva de la investigación No. 4 .................................................. 134

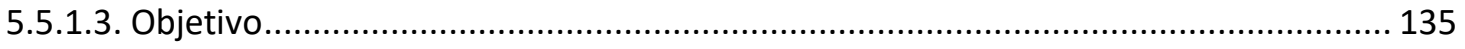

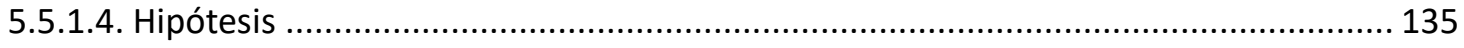

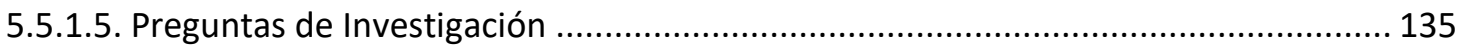

5.5.1.6. Contexto de la investigación .............................................................. 135

5.5.2. Resultados de la investigación ................................................................. 135

5.5.2.1. Entrevista estructurada definitiva para la recopilación de datos limpios ............... 136

5.5.2.2. Reglas para la preparación del conjunto de datos ........................................ 138

5.5.2.3. Proceso propuesto para la estimación del nivel real de conciencia de usuarios de Facebook respecto a privacidad y seguridad en la red social ........................................ 159

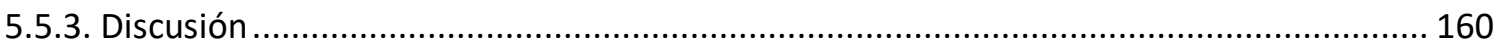

5.5.3.1. Validación del proceso propuesto .............................................................. 160

5.5.3.2. Aportes complementarios del proceso ........................................................ 161

5.5.3.3. Marco de referencia para conformar un entorno seguro en Facebook ................. 165

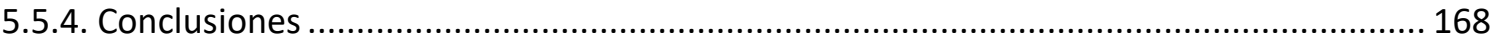

5.5.5. Publicación derivada de la investigación .......................................................... 168

CAPÍTULO 6 - CONCLUSIONES Y TRABAJO FUTURO ........................................................ 170

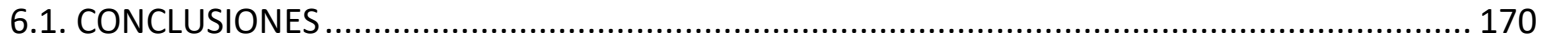

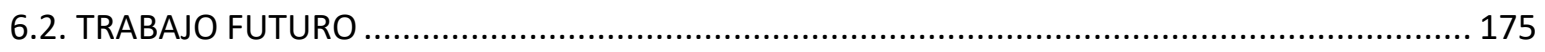

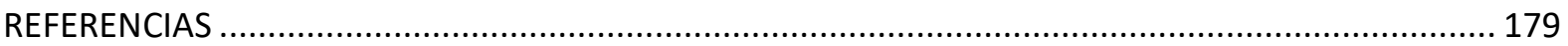

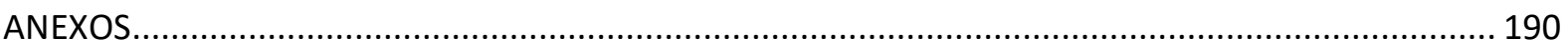




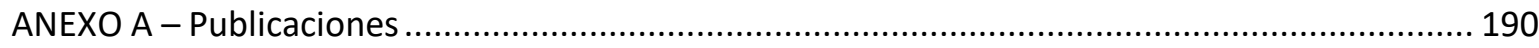

ANEXO B - Ejemplos de registros en las guías de observación cualitativa..................................... 190

ANEXO C - Entrevistas estandarizadas (encuestas) diseñadas para la investigación no experimental

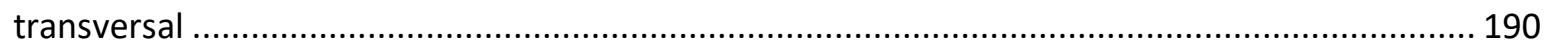

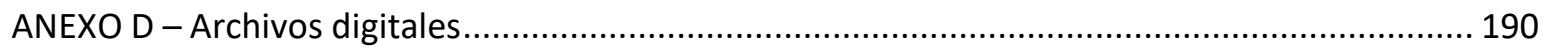




\section{Lista de tablas}

Tabla 1. Publicaciones presentadas en congresos internacionales

Tabla 2. Relación de dimensiones del modelo operativo de calidad de vida frente a factores de

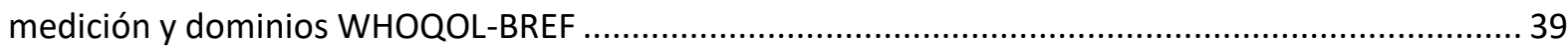

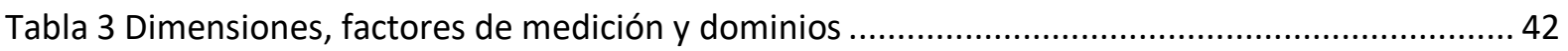

Tabla 4. Características del estudio de la tesis doctoral frente a características de un estudio donde

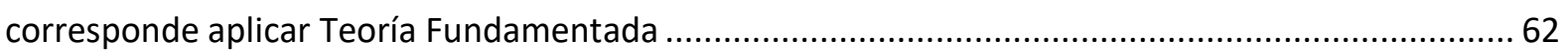

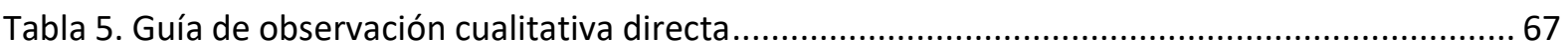

Tabla 6. Combinaciones posibles de niveles de brecha digital en el acceso de un potencial usuario AM

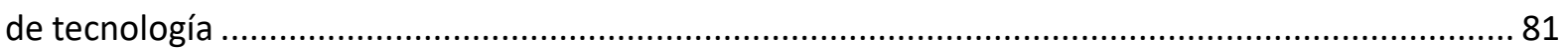

Tabla 7. Síntesis de los ámbitos de sensibilización del AM respecto de los beneficios de las TIC y en

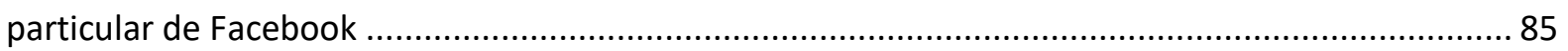

Tabla 8. Síntesis de las propuestas de sensibilización del AM hacia la alfabetización digital .............. 90

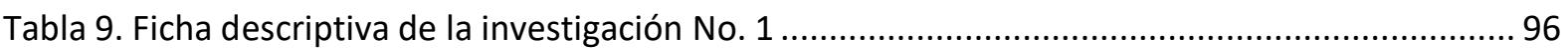

Tabla 10. Publicaciones que sustentan los diferentes beneficios potenciales de las interacciones

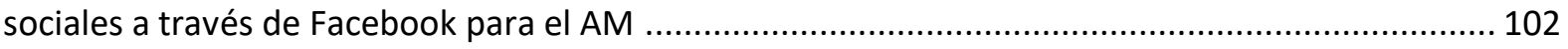

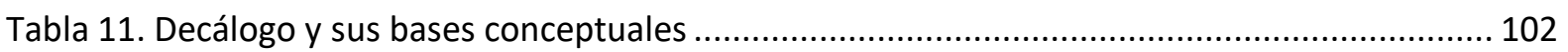

Tabla 12. Detalle de las publicaciones derivadas de la investigación No.1 ..................................... 106

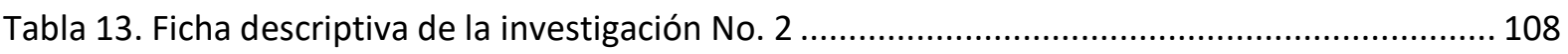

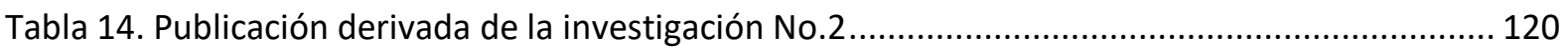

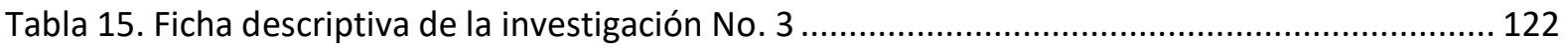

Tabla 16. Organización de las causas de los ciber-riesgos en el entorno de Facebook, en conceptos y

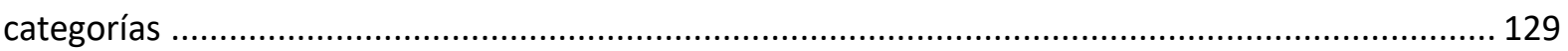

Tabla 17. Publicaciones seleccionadas que soportan los conceptos en que se organizaron las causas de

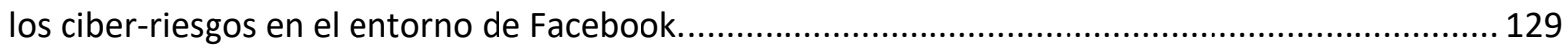

Tabla 18. Factores determinantes del grado de conciencia sobre privacidad y seguridad, características

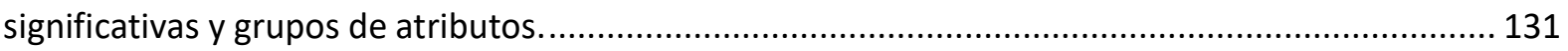

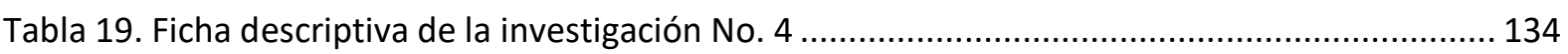

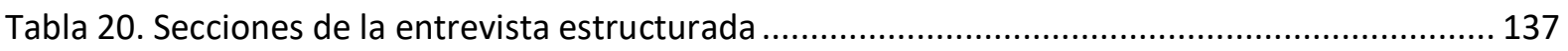

Tabla 21. Estimación del valor del atributo No. 1 de la característica significativa "nivel de conocimientos sobre principios de seguridad y privacidad"........................................................ 139

Tabla 22. Estimación del valor de los atributos No. 2 No. 3 y No. 4 de la característica significativa "nivel de conocimientos sobre principios de seguridad y privacidad". 141 Tabla 23. Estimación del valor de los atributos No. 5 y No. 6 de la característica significativa "nivel de conocimientos sobre principios de seguridad y privacidad"......................................................... 142 Tabla 24. Cálculo del valor de la característica significativa "nivel de conocimientos sobre principios de

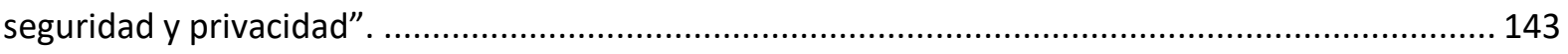

Tabla 25. Estimación del valor de los atributos No. 1, No. 2 y No.3 de la característica significativa "nivel de comprensión de la política de privacidad y datos de Facebook y sus actualizaciones"................ 144 Tabla 26. Estimación del valor de los atributos No. 4, No.5 y No. 6 de la característica significativa "nivel de comprensión de la política de privacidad y datos de Facebook y sus actualizaciones"................ 145 Tabla 27. Cálculo y catalogación de la característica significativa "nivel de comprensión de la política de privacidad y datos de Facebook y sus actualizaciones" ............................................................ 146 
Tabla 28. Estimación del valor de los atributos del No. 1 al No.4 de la característica significativa "nivel de experticia en las configuraciones de privacidad disponibles en la red social".

Tabla 29. Cálculo del valor de la característica significativa "nivel de experticia en las configuraciones de privacidad disponibles en la red social"

Tabla 30. Estimación del valor de los atributos del No. 1 al No.4 de la característica significativa "nivel de conocimiento elemental sobre aspectos jurídicos en el contexto operativo de la red social"..... 149

Tabla 31. Cálculo del valor de la característica significativa "nivel de conocimiento elemental sobre

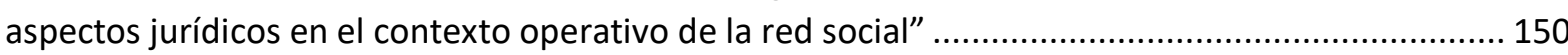

Tabla 32. Método de estimación del nivel de cultura de seguridad y privacidad ............................. 151

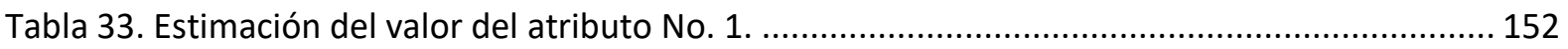

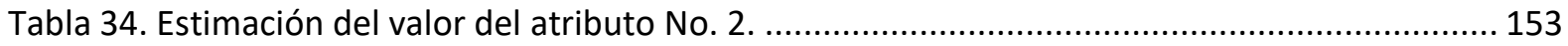

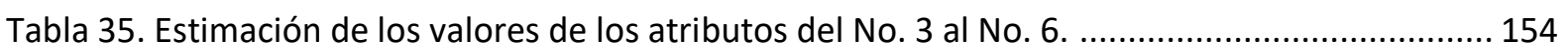

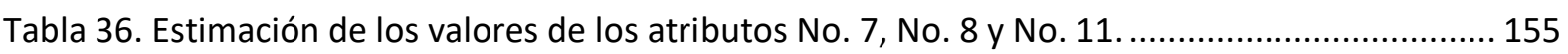

Tabla 37. Estimación de los valores de los atributos No. 9, No. 10 y No. 12 .................................... 156

Tabla 38. Método de estimación del nivel de riesgo por comportamientos psicosociales ............... 157

Tabla 39. Método de estimación del nivel real de conciencia sobre privacidad y seguridad de un usuario

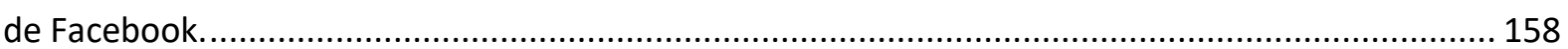

Tabla 40 Etapas del ciclo de vida convencional de minería de datos frente a etapas del proceso

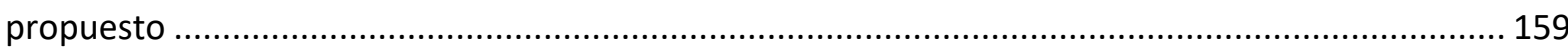

Tabla 41. Temas específicos, que según los resultados deberían reforzarse ..................................... 164

Tabla 42. Marco de referencia para conformar en Facebook, un entorno seguro de interacción social

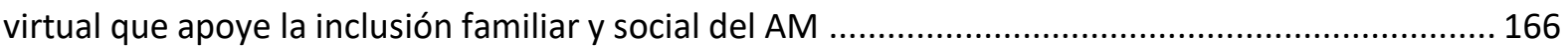

Tabla 43. Publicación relacionada con la investigación No.4 ......................................................... 168 


\section{Lista de figuras}

Fig. 1 Proceso seguido para el planteamiento del problema de investigación

Fig. 2 Reacciones: emoticonos disponibles en Facebook desde el 24 de febrero de 2016 - Fuente: ()37

Fig. 3 Modelo operativo de calidad de vida: Dimensiones y factores para la medición ....................... 39

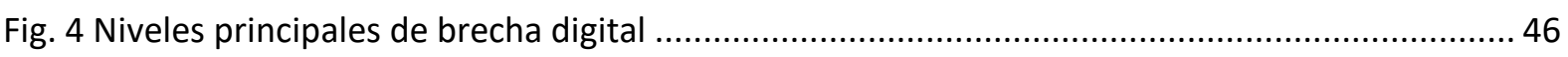

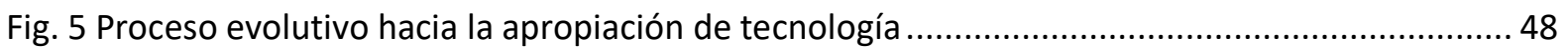

Fig. 6 Etapa previa - Sensibilización hacia la tecnología ................................................................. 49

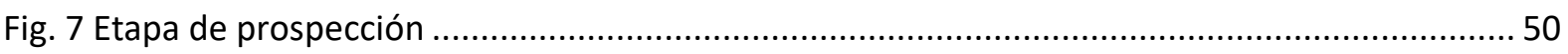

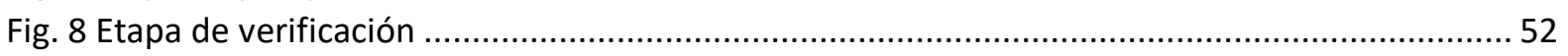

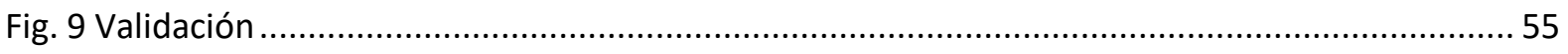

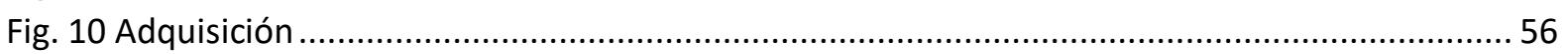

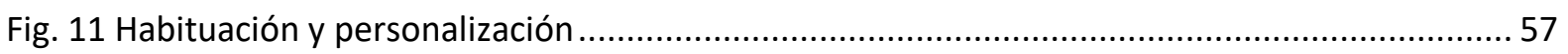

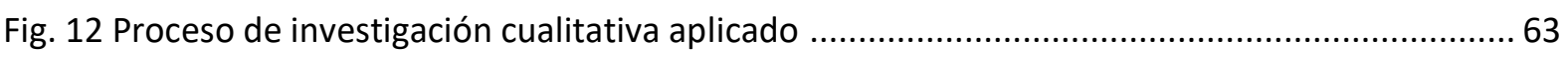

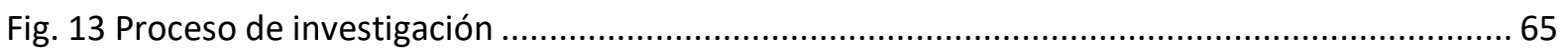

Fig. 14 Métodos de recolección de datos para la fase de Investigación documental .........................66

Fig. 15 Método de recolección de datos para la fase de observación cualitativa directa ....................68

Fig. 16 Método de recolección de datos para la fase de investigación no experimental transversal . 71

Fig. 17 Métodos de análisis de los datos recopilados con las entrevistas estructuradas .................... 73

Fig. 18 Ciclo de vida convencional de minería de datos - Fuente: (Khan et al., 2012) ....................... 74

Fig. 19 Modelo de sensibilización del AM hacia el uso y apropiación de la tecnología ......................... 80

Fig. 20 Modelo integral de apropiación de tecnología del AM (MIAT-AM) ....................................... 84

Fig. 21 Tendencia decreciente de los niveles de analfabetismo digital en Ecuador - Fuente (INEC, 2018)

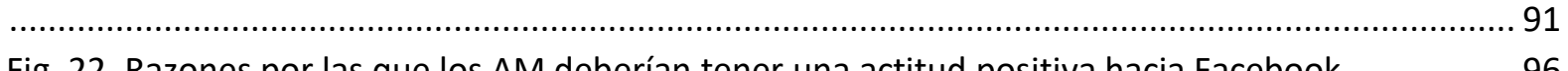

Fig. 22. Razones por las que los AM deberian tener una actitud positiva hacia Facebook .................96 96

Fig. 23 Configuración de la muestra validada de AM por rangos de edad y sexo. ............................. 97

Fig. 24 Medios de comunicación que los AM emplean en sus interacciones sociales. ....................... 99

Fig. 25 Calidad de relaciones interpersonales declaradas frente a desinterés de los AM por aprender

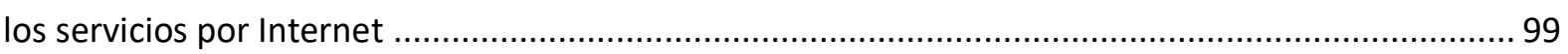

Fig. 26 Calidad de relaciones interpersonales declaradas frente a Interés de los AM por aprender los

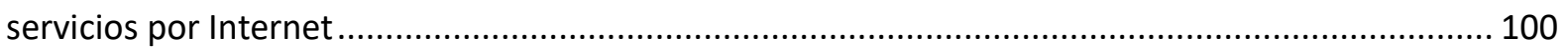

Fig. 27 Nivel de Estudios de los AM frente a medios de comunicación utilizados: (a) tradicionales, (b) virtuales.

Fig. 28 Beneficios potenciales de las interacciones sociales a través de Internet para el AM que vive en su casa 101

Fig. 29 Contexto tecnológico de las TIC: recursos tecnológicos, conocimientos informáticos y

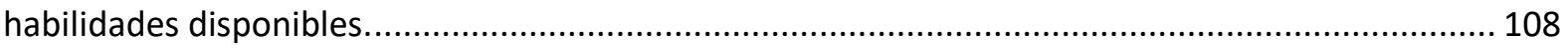

Fig. 30 Configuraciones de las muestras válidas de AM por rangos de edad y sexo: (a) muestra 1, (b)

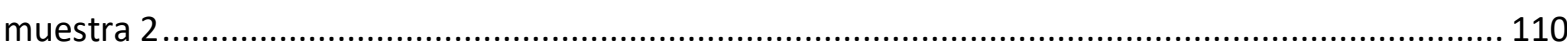

Fig. 31. Medios de interacción social utilizados por los AM:(a) consolidados, (b) detallados........... 112

Fig. 32. Medios de interacción social utilizados por los AM y calidad de relaciones interpersonales 114 Fig. 33. Disponibilidad de acceso a Internet desde la casa y medios de interacción social utilizados por los AM.

Fig. 34. Interés de los AM por aprender los servicios de interacción social por Internet por rangos de edad. 115 
Fig. 35. Interés de los AM por aprender los servicios de interacción social por Internet frente a

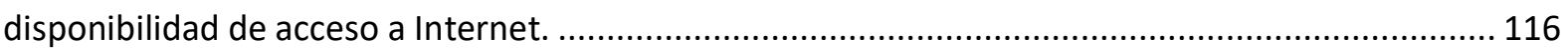

Fig. 36. Principales motivaciones de los AM que alguna vez intentaron utilizar Internet ................ 117

Fig. 37 Percepción del AM respecto al valor de acceso a Internet .............................................. 117

Fig. 38 Disponibilidad del recurso tecnológico para uso personal del AM..................................... 118

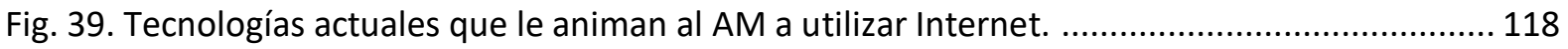

Fig. 40. Frecuencia de acceso a servicios de Internet de los AM................................................... 118

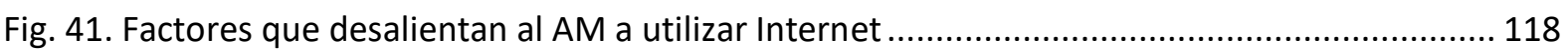

Fig. 42. Nivel de competencias digitales de los AM por rangos de edad........................................ 119

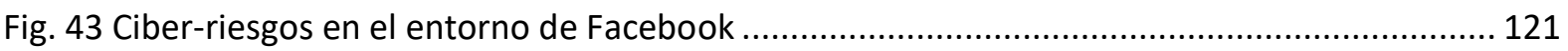

Fig. 44. Disciplinas científicas que conforman el enfoque interdisciplinario de las causas de los ciber-

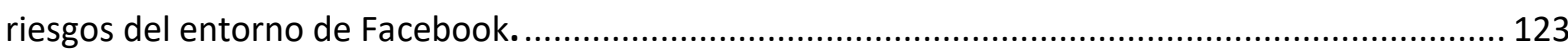

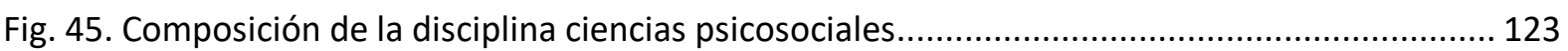

Fig. 46. Factores que conforman el código 1: comportamiento en línea ......................................... 124

Fig. 47. Factores que conforman el código 2: débil cultura de seguridad ...................................... 124

Fig. 48. Factores que conforman el código 3: factores psicosociales ............................................ 124

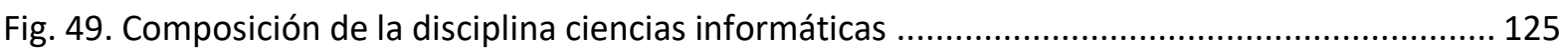

Fig. 50. Códigos del concepto 2: grandes volúmenes de información sensible disponibles por el

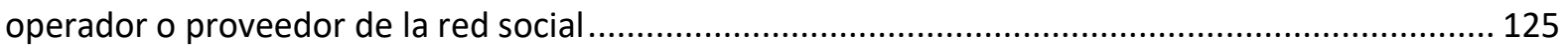

Fig. 51. Factores del código 4: variedad de usuarios; y, del código 5: incremento del número de

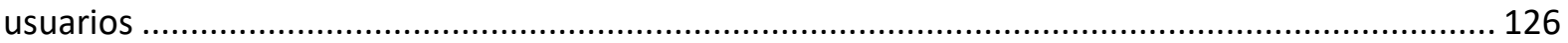

Fig. 52. Factores del código 6: excesiva recopilación de información personal; y, del código 7:

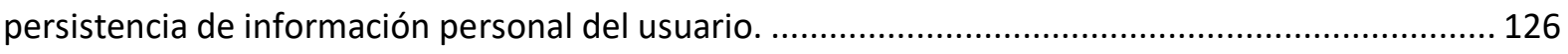

Fig. 53. Códigos del Concepto 3 y factores del código 8: exposición a desconocidos; y, del código 9: facilidades para falsificación y suplantación de identidad ............................................................. 127

Fig. 54. Códigos del concepto 4 y factores del código 10: factores técnicos; y, del código 11: configuraciones - permisos innecesarios o excesivos ................................................................. 127

Fig. 55. Códigos de la categoría 5 y factores del código 12: la plataforma abierta a aplicaciones de terceros; del código 13: acceso por variedad de dispositivos; y, del código 14: mejoras tecnológicas

128

Fig. 56. Códigos del concepto 6 y factores del código 15: normativa legal Internacional; del código 16: normativa legal Nacional; y, del código 17: relativos a los términos de uso del servicio y la política de privacidad de la red social. 128

Fig. 57. Modelo conceptual, con enfoque interdisciplinario, de las causas de los ciber-riesgos en el

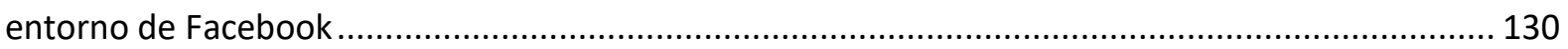

Fig. 58 Pirámide de población por grupo etario de usuarios de Facebook entrevistados ................. 135

Fig. 59 Ciclo de vida convencional de minería de datos - Fuente: (Khan et al., 2012) ...................... 136

Fig. 60. Preparación proactiva de la recopilación de datos limpios .............................................. 136

Fig. 61. Proceso propuesto para la estimación del nivel real de conciencia de usuarios de Facebook

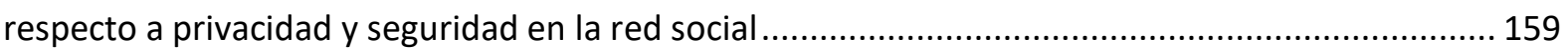

Fig. 62. Resultados obtenidos aplicando el proceso propuesto a la muestra .................................. 161

Fig. 63. Resultados obtenidos de la muestra al comparar los niveles de conciencia real e hipotético 162

Fig. 64. Posibles ubicaciones para el usuario de Facebook resultantes de la comparación del nivel real de conciencia con su nivel hipotético 162 
Fig. 65 (a) Nivel de riesgo debido a comportamientos Psicosociales. (b) Nivel de cultura de seguridad. 163

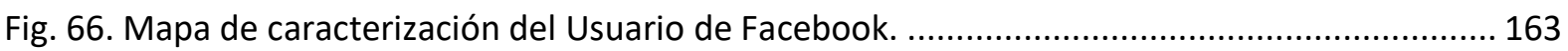

Fig. 67. Nivel de conceptualización de principios de seguridad y privacidad .................................... 164

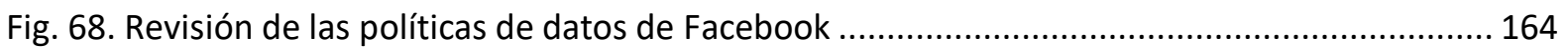

Fig. 69. Nivel de entendimiento de las configuraciones de privacidad y seguridad en Facebook ..... 165

Fig. 70. Nivel de conocimiento respecto a aspectos jurídicos básicos del entorno de Facebook ...... 165 


\section{CAPÍTULO 1 - INTRODUCCIÓN}

\subsection{Antecedentes de la investigación}

En la actualidad, la población adulta mayor (AM), a nivel mundial, está en continuo crecimiento, y en el Ecuador no es una excepción, conforma un segmento poblacional al que se está pretendiendo dar atención con un enfoque en las dimensiones englobadas en los conceptos de calidad de vida y envejecimiento activo.

Precisamente, tomando en cuenta la dimensión bienestar social de la calidad de vida, se ha puesto atención a la forma en que los AM se relacionan con su entorno familiar y de amigos, habiéndose encontrado que ellos utilizan dos esquemas de interacción con los miembros de su red social; por un lado, emplean los medios tradicionales de comunicación como son la comunicación cara a cara; la comunicación de voz a través de la telefonía fija o la telefonía móvil. Por otro lado, están las tecnologías sustentadas en Internet, de ellas, las redes sociales en línea, han cambiado la forma en que las personas se comunican y establecen vínculos con amigos y familiares.

De las redes sociales en línea disponibles, en los años 2015, 2016, 2017, 2018, 2019 y 2020 Facebook se constituyó, en la líder del mercado mundial en el ranking de las redes sociales más populares a nivel global.

Dadas las características funcionales de Facebook, se consideró que esta red social en línea podría constituirse en un medio especialmente apto para apoyar al adulto mayor en la consecución de inclusión social, y disminuir los obstáculos sociales que los aquejan, pudiendo a través de ella aumentar la frecuencia, la cantidad y la diversidad de las interacciones sociales con la familia y amigos, así como también facilitar la solicitud y recepción de apoyos sociales.

Por otra parte, $y$, sin embargo, de todos los beneficios atribuidos a las redes sociales, también se puso atención al hecho de que las redes sociales no están libres de situaciones de peligro, entre otras razones, por la forma de actuar de los usuarios. Los peligros para los usuarios de las TIC en el entorno de las redes sociales, sintetizando lo citado en (Ayuntamiento de Vitoria-Gasteiz, 2010), son: 1) exposición de todo el contenido de su propio computador a cualquier persona malintencionada, debido a la infección por malware; 2) exposición al fraude; 3) delitos contra la privacidad, que se circunscriben generalmente en la utilización y revelación de datos personales del usuario y/o de terceros, sin el consentimiento respectivo y con ánimo de perjudicarles. Además de la privacidad, las redes sociales también se asocian con otros problemas más frecuentes de seguridad, por ejemplo, con la ingeniería social; el spam, los programas maliciosos y el phishing. (Zhan \& Fang, 2011).

Con relación a los ciber-riesgos, se hipotetizó que resultaría más trascendente determinar las causas que originan la exposición de los usuarios de las redes sociales a esos peligros cibernéticos; más que profundizar en el estudio de la forma de concreción de los ciber-riesgos a los que está expuesto el usuario de Facebook, y sus consecuencias.

Con lo expuesto en mente, y siguiendo la propuesta de (Camarinha-matos \& Afsarmanesh, 2011), que alude como un objetivo de investigación alrededor de las TIC y el envejecimiento: explorar formas innovadoras que faciliten, apoyen y aseguren un estilo de vida equilibrado e inclusivo para las personas adultas mayores; se decidió desarrollar la investigación que fue titulada: ANÁLISIS DE LAS REDES SOCIALES ONLINE COMO ENTORNO SEGURO DE COMUNICACIÓN PARA INCLUSIÓN FAMILIAR - SOCIAL GERONTOLÓGICA, para estudiar de forma integrada al AM, la calidad de vida, la red social Facebook, y las causas de los ciber-riesgos en el entorno de la red social Facebook.

Los objetos de estudio específicamente considerados para la investigación, fueron: 
1. Facebook, por ser la red social en línea más representativa de la participación de los AM en redes sociales.

2. Una muestra de $A M$ usuarios o no de Facebook, que no necesariamente sea representativa del universo de AM, que serían seleccionados sin distinción de razas, creencias, pertenecientes a los dos sexos, con diferentes niveles de educación.

3. Las dimensiones que conforman la calidad de vida del AM sobre las que la red social Facebook podría tener potenciales beneficios.

4. Las causas que le expondrían al AM a los ciber-riesgos del entorno de Facebook; especialmente aquellas sobre las que tiene control, y puede actuar para reducir la exposición.

La investigación concebida en esa forma, se refirió a un tema complejo, vigente, importante y necesario, como se afirma en (Nef et al., 2013): "los usuarios mayores y los sitios de redes sociales es un tema interdisciplinario [...] de diferentes campos, incluidas las ciencias médicas, técnicas, psicológicas, gerontológicas y de comunicación [...] el número de estudios que podrían incluirse es bastante pequeño y muchos estudios son de naturaleza cualitativa con un pequeño número de participantes. Sin embargo, reflejan el estado de la investigación, la novedad del tema y enfatiza la necesidad de más investigaciones en este campo."

Y se reafirma, con los pronunciamientos existentes en: 1) (UIT, 2014): "hay relativamente pocos datos recogidos sobre las repercusiones del acceso a las TIC y de su utilización individual y en el hogar, y también son pocos los trabajos analíticos sobre este tema". 2) (D. Quinn et al., 2016): "el impacto de participar en sitios de redes sociales sobre la calidad de vida es un área que ha recibido poca atención. De particular interés es el impacto de las redes sociales en línea en los usuarios mayores, que es un grupo demográfico específicamente vulnerable al aislamiento social."

\subsection{Planteamiento del problema de investigación}

La estructuración del problema de investigación evolucionó desde una idea inicial declarada en forma poco precisa, producto de la observación directa del entorno inmediato del tesista, hacia una mayor especificidad mediante investigación documental.

Es así como al inicio, se realizó una observación cualitativa del entorno inmediato del tesista con la finalidad de registrar las vivencias relacionadas a sus AM; y las vivencias de sus familiares cercanos y las de sus amigos, todos ellos adultos y AM, con relación a los efectos del uso de los medios de comunicación basados en Internet en sus vidas.

La observación directa del entorno inmediato del tesista reveló la consecuencia del paso del tiempo en la vida de sus AM, que se puede resumir, en una palabra: soledad; justificada por sus familiares cercanos con múltiples razones.

Por otra parte, una segunda vivencia se desprendió de la observación personal directa, esta vez relacionada a un familiar muy cercano, quien encontró en la plataforma de la red social Facebook una aliada para reencontrarse con sus condiscípulas del colegio secundario de la ciudad en la que creció y reactivar sus relaciones interpersonales con ellas; por otra parte, le permitió recuperar amistades con las que había dejado de tener contacto cuando salió de la escuela primaria; se observó que Facebook generó un impacto positivo en su vida emocional, y le motivó a interesarse por aprender otras opciones de comunicación basadas en TIC tales como Skype, WhatsApp y además a aprovechar de 
mejor manera otros servicios de Internet, tales como: Netflix para entretenimiento, banca electrónica para revisar sus cuentas y realizar transferencias.

Adicionalmente, la observación directa del entorno del tesista arrojó una tercera vivencia que demostraba un efecto positivo del uso de las TIC en la vida cotidiana, pues a través de Skype se establecía comunicación con los miembros del núcleo familiar que se encontraban en sitios distantes del lugar de residencia; lo interesante de este medio de comunicación, a más de ser gratuito, permitía mirar y escuchar en tiempo real al interlocutor, lo que generaba un estado de emoción y tranquilidad al ver que realmente se encontraba bien y saludable, este medio de comunicación los acercaba a los miembros de la familia y creaba una atmósfera de alegría y calma en el hogar.

Finalmente, mediante observación directa, el tesista pudo evidenciar que sus amigos y excompañeros de trabajo, jubilados, utilizan la red social Facebook para expresar y difundir entre sus contactos, sus estados de ánimo de cada día, su estado de salud, sus opiniones sobre asuntos de variada índole y para compartir archivos con mensajes emotivos y de motivación personal, eso parecía darles una sensación de mantenerse activos socialmente con sus amigos y excompañeros de trabajo. Además, les permitía establecer conexiones privadas con sus familiares cercanos: hijos y nietos.

Frente a estas vivencias, nació el interés por comprender si efectivamente el uso de los servicios basados en las tecnologías de comunicación y telecomunicaciones (TIC) por parte de los AM ecuatorianos podría ciertamente mejorar sus vidas, y se planteó como pregunta de investigación inicial: ¿ podría el uso de las TIC por parte de los AM mejorar su calidad de vida?

Con la declaración de la idea de investigación inicial, se inició la primera etapa de investigación documental, aplicando heurística en la selección de los documentos y análisis hermenéutico para su intelección; se evaluaron, analizaron y revisaron en detalle los contenidos cualitativos de revistas y documentos de conferencias relacionados con el tema las TIC y el AM. Con la primera revisión de literatura ${ }^{1}$, se lograron los siguientes aprendizajes: 1 ) la caracterización del AM; 2 ) las teorías que se enfocan en la vejez; 3) el significado de la calidad de vida del AM y la conceptualización del envejecimiento activo; 4) la capacidad de aprendizaje de las personas adultas mayores.

Con estos aprendizajes, y dado que la calidad de vida abarca varias dimensiones, se hizo necesario acotar el estudio en la dimensión en la cual los medios de comunicación basados en TIC podían tener un efecto directo, planteándose una segunda idea de investigación: ¿̇la calidad de las relaciones interpersonales del AM que vive en su casa puede ser mejorada con el uso de los medios de comunicación basados en TIC?

Con esta segunda idea de investigación se dio inicio a una nueva investigación documental, aplicando los mismos principios de la primera, con la cual se comprendieron los siguientes aspectos:

1) los componentes que determinan la calidad de las relaciones interpersonales del AM;

\footnotetext{
${ }^{1}$ Revisión de la literatura: acto que resume, recapitula, reitera, interpreta y evalúa decisivamente un conjunto de conocimientos existentes (o material publicado o no publicado) para establecer similitudes dentro del conocimiento de un tema. El propósito de hacerlo no es solo expresar la opinión de los expertos en diferentes puntos de vista, sino que, también es pertinente participar en el análisis de contenido al extraer fortalezas, debilidades y lagunas en el cuerpo de conocimiento y ofrecer soluciones apropiadas para cerrar la brecha. (Durodolu, 2016)
} 
2) la conceptualización e importancia de la presencia social de los medios de comunicación utilizados en las relaciones interpersonales;

3) las teorías de la vejez, principalmente la teoría de la actividad, la teoría de la modernidad con su visión dinámica y con su perspectiva de ciclo de vida; que determinaban una condición positiva para el AM, asegurando que es capaz de mantenerse activo como en otras etapas de su vida;

4) la conexión entre la realidad del AM, las TIC, y el envejecimiento activo que se vislumbra en (Camarinha-matos \& Afsarmanesh, 2011), tomando en cuenta que: algunas personas adultas mayores experimentan marginación, pérdida de vínculos sociales, soledad; las TIC son nuevas oportunidades para facilitar la interacción social, y reducir las limitaciones impuestas por la ubicación y el tiempo; el envejecimiento activo es una combinación equilibrada de ocio, de interacción social, y de participación continua, es fundamental para mantener la salud mental y física, por lo tanto las TIC pueden apoyar el envejecimiento activo, evitando la soledad y aumentando los vínculos sociales;

5) la visión amplia sobre las redes sociales, expuesta en (Ayuntamiento de Vitoria-Gasteiz, 2010), que motiva a encontrar maneras correctas de interactuar para integrar: el propósito para el que fueron diseñadas las redes sociales, los beneficios para la vida de las personas, y la presencia de riesgos; $y$,

6) los dos tipos principales de ataques en las redes sociales, que se indica en (Wong, 2014): a) los que aprovechan las vulnerabilidades propias de la plataforma tecnológica y las redes de comunicación para el acceso; $y, b$ ) el abuso de la confianza entre usuarios de la red social, tipo de ataque del cual se dice que es el más fácil de lograr por la forma de ser y actuar de las personas.

Integrando los hallazgos logrados con la observación cualitativa directa inicial, y los conseguidos con las dos fases de la investigación documental, y sabiendo que la red social Facebook, para el momento en que se estaba definiendo la investigación, año 2015, era la plataforma de interacción social y comunicación con más usuarios a nivel mundial, situación que se ha mantenido durante los años 2016, 2017, 2018, 2019 y 2020, se estableció la tercera idea de investigación, alrededor de 3 aspectos: la posible realidad del AM concretada en la palabra soledad y las consecuencias negativas en su calidad de vida; la presunción de la existencia de beneficios de la interacción social a través de Facebook para la calidad de vida del AM que vive en su casa; los ciber-riesgos en el ambiente de Facebook. Estos tres aspectos serían los principios orientadores de la estructuración de un marco de referencia para la creación de un entorno seguro de inclusión familiar y social del AM en Facebook.

Las siguientes interrogantes se concretaron para iniciar la investigación: ¿qué razones habrían para que el AM decidiera ser un usuario habitual de Facebook? ¿qué actitud manifiesta el AM hacia el uso de Facebook? ¿cuál es el contexto tecnológico de las TIC del AM? ¿se pueden cuantificar los aportes de Facebook a la dimensión relaciones interpersonales de la calidad de vida del AM? ¿qué aspectos del AM, usuario de Facebook, se consideran favorecedores de su exposición a los ciber-riesgos presentes en el entorno de la red social? ¿qué factores son determinantes en la estructuración de un entorno seguro de interacción social virtual en la red Facebook que apoye a la inclusión familiar y social del AM?

El proceso seguido para el planteamiento del problema se resume en la Fig. 1. 


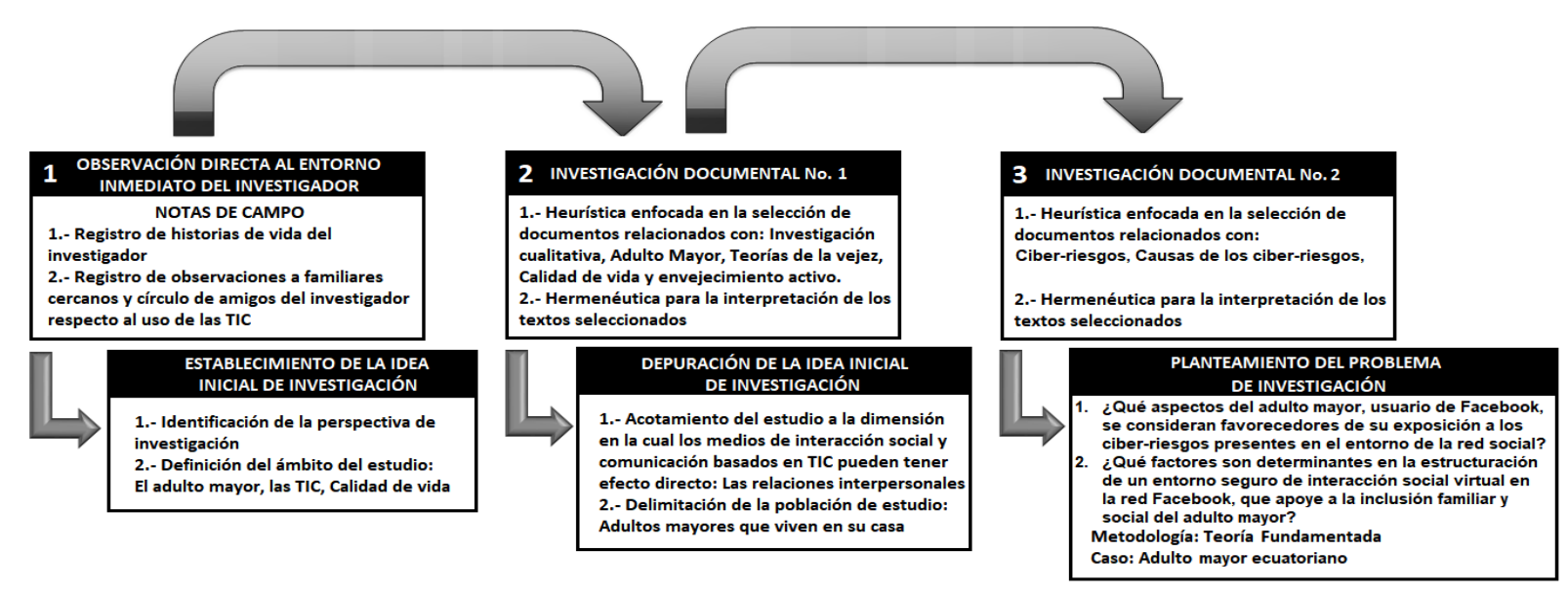

Fig. 1 Proceso seguido para el planteamiento del problema de investigación

\section{3. Área de investigación científica a la que pertenece el estudio}

El estudio se lo ha clasificado dentro del área de investigación científica identificada con el nombre de Computación Social, considerando que se ajusta a lo que (Dasgupta, 2010) señala respecto a esta área de la ciencia informática: "implica dos componentes: un componente de conducta social; y, un sistema computacional o componente técnico, que proporciona el entorno en que las personas interactúan." Para esta investigación, el componente de comportamiento social está constituido por las relaciones interpersonales del AM, que evidencian el nivel de inclusión familiar y social que dispone, cuya calidad se considera, hipotéticamente, que se puede incrementar con el componente técnico correspondiente a la plataforma de red social Facebook, la cual brinda servicios de comunicación con presencia social, permite interacciones sociales ubicuas más frecuentes y más duraderas con familiares y amigos, y admite la administración de diversos factores relacionados con la privacidad y seguridad del usuario.

\subsection{Formulación del problema}

El problema que se investigó en la tesis doctoral fue: ¿Cuáles son los factores determinantes que harían a los AM usuarios de Facebook participar con menos exposición a los ciber-riesgos del entorno de la red social?

Las acciones que los AM tomen sobre las respuestas a esta interrogante, harán que el AM perciba a la red social como un entorno seguro de comunicación para inclusión familiar - social gerontológica.

\subsection{Objetivo general}

Identificar los diferentes aspectos que deben conocer los AM usuarios de Facebook, para percibir a la red social como un entorno seguro de comunicación para inclusión familiar - social gerontológica, y así participar con menos exposición a los ciber-riesgos propios del ambiente virtual, cuando procuran, con actitud positiva, mejorar su calidad de vida mediante la interacción virtual en la red social.

\subsection{Objetivos específicos}

1. Identificar aspectos relevantes del AM frente a Facebook: beneficios, inconvenientes, proceso por el que el AM debe transitar para llegar a un uso significativo de la red social. 
2. Comprender la potencialidad del contexto tecnológico del $A M$ que vive en su casa, para el aprovechamiento de la interacción social a través de Facebook.

3. Estructurar un modelo conceptual de las causas que originan la exposición de los usuarios de la red social Facebook a los ciber-riesgos de ese entorno.

4. Concebir un proceso que permita estimar con fidelidad, el nivel real de conciencia de los usuarios AM respecto a privacidad y seguridad en Facebook.

5. Proponer un conjunto de conceptos, prácticas y criterios que le permitan al AM, usuario de Facebook, percibir a la red social como un entorno seguro de interacción virtual para apoyo de su inclusión familiar y social.

\subsection{Hipótesis}

1. Un marco de referencia de actuación en la red social Facebook, haría que el AM, usuario de Facebook, reduzca su exposición a los ciber-riesgos propios de ese ambiente, y conciba a Facebook como un sistema tecnológico confiable y seguro para su inclusión familiar y social mientras envejece.

La estructuración del marco de referencia de actuación en la red social Facebook debe sustentarse en el conocimiento de los beneficios acreditados a Facebook para la calidad de vida del AM; de las motivaciones, necesidades y características propias del AM; de las características operativas y funcionales de la plataforma tecnológica que ofrece el servicio; de la potencialidad del contexto tecnológico del AM para el aprovechamiento de la interacción social a través de Internet; de las causas que originan la exposición de los usuarios de Facebook a los ciber-riesgos de ese entorno; $y$, del nivel real de conciencia de los usuarios AM respecto a privacidad y seguridad en Facebook.

\subsection{Alcance}

1. La investigación se sustentó en $A M$ que viven en su casa, con edad igual o mayor a 65 años, según la normativa legal vigente en el Ecuador, pertenecientes al área de influencia del tesista.

2. Dado el creciente número de plataformas de redes sociales que pueden accederse a través de Internet, la investigación se centró alrededor de la red social Facebook, por ser la más popular y de mayor crecimiento entre las personas mayores en el año 2015, año en el que se formuló el problema, característica que se ha mantenido durante todo el tiempo en que se desarrolló la investigación, años 2016, 2017, 2018, 2019, 2020.

\subsection{Contribución científica}

\subsubsection{Publicaciones resultantes del proceso de investigación}

Durante el desarrollo de esta tesis se han comunicado los resultados parciales y las diversas aportaciones, a través de artículos presentados en congresos internacionales.

La aceptación por parte de la comunidad científica a cada trabajo de investigación presentado, otorga validez y reconoce la calidad al estudio desarrollado.

La Tabla 1 detalla las publicaciones realizadas: 


\begin{tabular}{|c|c|c|c|c|c|}
\hline No. & Autores & $\begin{array}{l}\text { Título del } \\
\text { artículo }\end{array}$ & $\begin{array}{l}\text { Evento } \\
\text { científico } \\
\text { en que se } \\
\text { presentó }\end{array}$ & $\begin{array}{l}\text { Título de la } \\
\text { publicación }\end{array}$ & $\begin{array}{l}\text { Portada de la } \\
\text { publicación }\end{array}$ \\
\hline 1 & $\begin{array}{l}\text { RIOS, } \\
\text { Ramiro }\end{array}$ & $\begin{array}{l}\text { Decalogue for a } \\
\text { Senior Citizen's } \\
\text { Positive Attitude } \\
\text { towards Facebook. }\end{array}$ & $\begin{array}{l}\text { World } \\
\text { Congress on } \\
\text { Engineering } \\
\text { and } \\
\text { Computer } \\
\text { Science } \\
2017 .\end{array}$ & $\begin{array}{l}\text { Proceedings of the World } \\
\text { Congress on Engineering } \\
\text { and Computer Science } \\
2017 \text { Vol I WCECS } 2017 . \\
\text { ISBN 9789881404756. } \\
\text { p. 153-157. San } \\
\text { Francisco - USA, } 2017\end{array}$ & $\begin{array}{c}\text { WCECS 2017 } \\
\text { World Congress on Engineering } \\
\text { and Computer Science 2017 }\end{array}$ \\
\hline 2 & $\begin{array}{l}\text { RIOS, } \\
\text { Ramiro }\end{array}$ & $\begin{array}{l}\text { Chapter 22: WHY } \\
\text { SHOULD A SENIOR } \\
\text { CITIZEN BE A } \\
\text { FACEBOOK USER? } \\
\text { Reasons for a } \\
\text { Senior Citizen's } \\
\text { Positive Attitude } \\
\text { towards Facebook }\end{array}$ & $\begin{array}{l}\text { World } \\
\text { Congress on } \\
\text { Engineering } \\
\text { and } \\
\text { Computer } \\
\text { Science } \\
2017 .\end{array}$ & $\begin{array}{l}\text { Capítulo del libro } \\
\text { Transactions } \\
\text { Engineering } \\
\text { Technologies: World } \\
\text { Congress on Engineering } \\
\text { and Computer Science } \\
\text { 2017, editado por } \\
\text { Springer. } \\
\text { DOI: } \\
\text { https://doi.org/10.1007/ } \\
\text { 978-981-13-2191-7 }\end{array}$ & $\begin{array}{l}\text { Transactions } \\
\text { on Engineering } \\
\text { Technologies } \\
\text { Wort conpress on Engineening and } \\
\text { computer Science 2017 }\end{array}$ \\
\hline 3 & $\begin{array}{l}\text { RIOS, } \\
\text { Ramiro }\end{array}$ & $\begin{array}{l}\text { Comprensión de la } \\
\text { potencialidad del } \\
\text { contexto } \\
\text { tecnológico del } \\
\text { AM ecuatoriano } \\
\text { que vive en su casa } \\
\text { para el } \\
\text { aprovechamiento } \\
\text { de la interacción } \\
\text { social a través de } \\
\text { Internet. }\end{array}$ & $\begin{array}{l}\text { CIAIQ2017 } \\
\text { Congreso } \\
\text { Ibero- } \\
\text { Americano } \\
\text { en } \\
\text { Investigación } \\
\text { Cualitativa }\end{array}$ & $\begin{array}{l}\text { Actas del Sexto Congreso } \\
\text { Ibero-Americano en } \\
\text { Investigación Cualitativa } \\
\text { CIAIQ2017 } \\
\text { Vol 4. - Investigación } \\
\text { Cualitativa en Ingeniería } \\
\text { y Tecnología } \\
\text { ISBN:978-972-8914-78-3 } \\
\text { [online]. p. 65-74. } \\
\text { Salamanca España, 2017. }\end{array}$ & 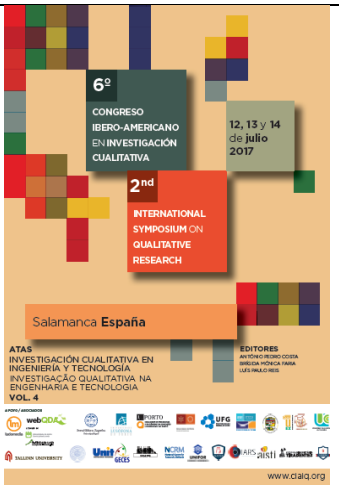 \\
\hline 4 & $\begin{array}{l}\text { RIOS- } \\
\text { PAREDES, } \\
\text { Ramiro } \\
\text { RIOS- } \\
\text { SALGADO, } \\
\text { Diego }\end{array}$ & $\begin{array}{l}\text { Proceso para } \\
\text { estimar el nivel } \\
\text { real de conciencia } \\
\text { de los usuarios de } \\
\text { Facebook respecto } \\
\text { a privacidad y } \\
\text { seguridad en la red } \\
\text { social }\end{array}$ & $\begin{array}{l}\text { CIAIQ } 2020 \\
\text { 9o Congreso } \\
\text { Ibero- } \\
\text { Americano } \\
\text { en } \\
\text { Investigación } \\
\text { Cualitativa }\end{array}$ & $\begin{array}{l}\text { Vol. } 4 \text { (2020): Qualitative } \\
\text { Research in Social } \\
\text { Sciences: advances and } \\
\text { Challenges } \\
\text { ISSN: } 2184-7770 \\
\text { ISBN: } 978-989-54759-3-3 \\
\text { DOI: } \\
\text { https://doi.org/10.3636 } \\
\text { 7/ntqr.4.2020 } \\
\text { Published: } 2020-07-07\end{array}$ & 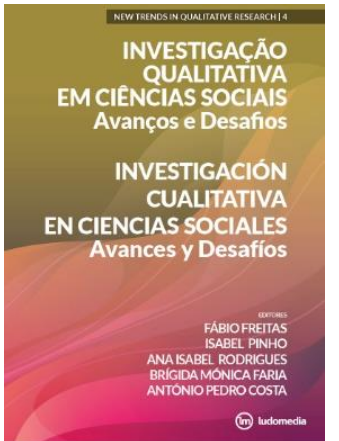 \\
\hline
\end{tabular}




\subsubsection{Aportes principales}

Las principales contribuciones de la presente tesis, que centró su atención en el "análisis de la red social Facebook como entorno seguro de comunicación para integración familiar y social del AM" son:

1. El modelo de sensibilización del AM hacia el uso y la apropiación de tecnología, que sirvió de base para definir el estado del arte del AM frente a la red social Facebook. Se sustenta en el enfoque de la brecha digital desde 3 perspectivas: brecha digital en el acceso motivacional, brecha digital en el acceso físico, y la brecha digital en el acceso a alfabetización digital. Este modelo pone de relieve la necesidad de superar primeramente la brecha digital en el acceso motivacional, para propender a cerrar las otras dos brechas digitales en el acceso.

2. El proceso evolutivo de apropiación de tecnología que, integra varios de los constructos desarrollados en los modelos de aceptación y uso de tecnología, para teorizar las etapas lógicas por las que una persona, con alguna motivación importante, evoluciona hacia el uso significativo de una determinada tecnología.

3. El modelo integral de apropiación de tecnología por el AM (MIAT-AM), que integra los dos aportes antes citados. Describe el proceso complejo que una persona debe seguir para superar la brecha digital y proyectarse hacia la apropiación social de la tecnología para lograr beneficios trascendentes para su vida.

4. El decálogo para moldear una actitud positiva del AM hacia el uso de la red social Facebook, que sintetizó los beneficios posibles de la red social Facebook para la calidad de vida del AM, y las potencialidades del AM para convertirse en usuario activo de Facebook. El decálogo, tuvo como objetivo presentar argumentos que impulsen el cierre de la brecha digital por acceso motivacional, y posibiliten un eventual avance con el proceso descrito en el MIAT.

5. El modelo conceptual de las causas de los ciber-riesgos en el entorno de Facebook, que visualiza la complejidad de los orígenes de los ciber-riesgos desde tres disciplinas científicas diferentes: las ciencias informáticas y las ciencias jurídicas, que enfocan causas que están fuera del control del usuario de la red social Facebook; y las ciencias psicosociales que cubren las causas atribuibles a los usuarios, desde dos aspectos: los comportamientos psicosociales; $y$, la cultura de seguridad y privacidad.

6. El proceso de estimación del nivel real de conciencia de usuarios de Facebook respecto a privacidad y seguridad en la red social, que se fundamenta en un conjunto de reglas que permiten pasar las respuestas cualitativas dadas en la entrevista estructurada sobre privacidad y seguridad en el entorno de la red social, a valores numéricos con los que se determina el nivel real de conciencia sobre privacidad y seguridad del usuario de Facebook. Ese nivel real de conciencia cuantificado se cataloga cualitativamente, para un análisis comparativo con el valor hipotético que cree tener el usuario de Facebook, con el que se generan importantes conclusiones sobre aspectos que debe tomar en cuenta el usuario de Facebook para reducir su exposición a los ciber-riesgos propios del ambiente de la red social.

7. El marco de referencia para la estructuración de un entorno seguro de interacción social virtual en Facebook que apoye la inclusión familiar y social del usuario $A M$, al que debería recurrir el usuario de Facebook, en particular el AM, para propender a reducir su exposición a los ciberriesgos debido a comportamientos psicosociales en la red social y su nivel de cultura de privacidad y seguridad. 


\subsection{Enfoque metodológico}

Se optó por un enfoque metodológico mixto, con énfasis en el paradigma interpretativo, con proceso inductivo e investigación cualitativa, basada en Teoría Fundamentada; complementado con investigación no experimental transversal ${ }^{2}$, para comprender y conceptualizar el caso del AM ecuatoriano como una opción del objeto de estudio.

\subsection{Estructura de la tesis}

Esta tesis ha sido estructurada en 6 capítulos, cuyo contenido de describe de la siguiente manera:

\section{CAPÍTULO 1 - INTRODUCCIÓN}

En este capítulo se revisan de manera sucinta, los antecedentes de la investigación que permitieron establecer el objeto de estudio en la investigación de la tesis doctoral. Adicionalmente se identificó el área de la ciencia a la cual se pertenece la tesis doctoral. Se detallaron aspectos significativos para el desarrollo del proceso de investigación, como son: el planteamiento del problema de investigación; la formulación del problema; el objetivo general y los objetivos específicos; la hipótesis orientadora de la investigación; el alcance que tiene la investigación. Además, se presenta la contribución científica, dividida en dos partes: 1 ) las publicaciones que se realizaron de los resultados parciales de la Tesis, y 2) los principales aportes de la tesis doctoral. Finalmente, se señala el enfoque metodológico que se utilizó en la investigación.

\section{CAPÍTULO 2 - MARCO TEÓRICO}

En la introducción se hace referencia al significado del envejecimiento activo, de la inclusión social de los AM, de la calidad de las relaciones interpersonales del AM. Por otra parte, este capítulo contiene una sección muy importante para toda investigación científica: la fundamentación filosófica. En esta sección se hizo constar temas importantes como las razones corporativas de existir de Facebook que se compatibilizan con las necesidades particulares de los AM; el sustento al hecho que el AM es capaz de desarrollar interacciones virtuales significativas a través de Facebook, para mejorar su calidad de vida; se reconoció la existencia de ciber-riesgos en el entorno de Facebook, y se hizo relieve en la privacidad; se conceptualizaron los términos relacionados con la investigación; y se finalizó con conceptos relacionados a la aceptación, uso y apropiación de tecnología, donde sobresalen dos aspectos importantes para esta tesis: la comprensión de la brecha digital y la apropiación de las TIC; y el modelo teorizado de proceso evolutivo hacia la apropiación de tecnología.

\footnotetext{
${ }^{2}$ Investigación no experimental: (Hernández Sampieri et al., 2010): Es un tipo de investigación cuantitativa, en la cual los estudios se realizan sin la manipulación deliberada de variables y en los que sólo se observan los fenómenos en su ambiente natural para después analizarlos. Mertens (2005) señala que la investigación no experimental es apropiada para variables que no pueden o deben ser manipuladas o resulta complicado hacerlo. En un estudio no experimental no se genera ninguna situación, sino que se observan situaciones ya existentes, no provocadas intencionalmente en la investigación por quien la realiza.

Diseño no experimental transversal o transeccional: la investigación se centra en:

a) analizar cuál es el nivel o modalidad de una o diversas variables en un momento dado;

b) evaluar una situación, comunidad, evento, fenómeno o contexto en un punto del tiempo y/o;

c) determinar o ubicar cuál es la relación entre un conjunto de variables en un momento.
} 


\section{Capítulo 3 - METODOLOGÍA}

En este capítulo, luego de una pequeña introducción que enfocaba el contenido del capítulo, se tiene la sección enfoque metodológico de la Investigación, donde se justifica el enfoque metodológico mixto, con énfasis en el paradigma interpretativo, con proceso inductivo, e investigación cualitativa, soportada como metodología en Teoría Fundamentada, además de la Heurística y la Hermenéutica; complementada con el tipo de investigación cuantitativa no experimental transversal. También se trata el proceso de investigación, la formalización de las unidades de análisis, el contexto de investigación tanto para las investigaciones documentales que generaron los marcos conceptuales necesarios, como para las investigaciones de campo. Este capítulo también contiene el diseño de la investigación, en la que se hizo constar la decisión metodológica, las técnicas de recolección de datos que se emplearían en cada etapa de la investigación: observación directa, investigación documental, e investigación no experimental transversal. También se explica el diseño y aplicación de los instrumentos de recolección de datos; y se finaliza con los métodos de análisis de datos.

\section{CAPÍTULO 4 - ESTADO DEL ARTE: EL AM FRENTE A LAS TIC Y LA RED SOCIAL FACEBOOK}

En la Introducción de este capítulo se resume el procedimiento de 3 fases utilizado para la revisión sistemática de literatura: 1) planeación, 2) ejecución y 3) anuncio de resultados. Seguidamente, se presenta el marco conceptual para el estado del arte. A continuación, los primeros resultados del análisis de la literatura en la sección perspectivas generales desde las cuales se podrían comprender las relaciones existentes entre el AM y las TIC, y se muestra que las TIC han estado presentes en la vida del AM desde distintos enfoques: reducción de la brecha digital, mejoramiento de las interrelaciones personales, juegos virtuales, e-salud. En la tercera sección de este capítulo, se realiza el análisis para escoger el modelo de aproximación a la realidad del AM frente a la red social Facebook y se determina que el estado del arte será desarrollado con el modelo de sensibilización del AM hacia el uso y apropiación de la tecnología, el cual parte de la brecha digital en el acceso. Luego se presenta el análisis del AM frente a la red social Facebook desde la perspectiva del modelo seleccionado; enfocando los tres niveles de brecha digital en el acceso: motivacional, físico y alfabetización digital.

\section{CAPÍTULO 5 - RESULTADOS DE LA INVESTIGACIÓN}

En este capítulo se presentan de forma sistematizada, los hallazgos realizados en el desarrollo de cuatro investigaciones parciales, cuyos resultados principales fueron publicados en eventos científicos.

\section{CAPÍTULO 6 - CONCLUSIONES Y TRABAJO FUTURO}

En este capítulo, se exponen las conclusiones obtenidas tras el desarrollo de la investigación doctoral y se realiza un argumento final regresando la mirada al propósito de la investigación, los objetivos y las hipótesis planteadas. Finalmente, se exponen los ámbitos de trabajos futuros que complementarían el estudio presente.

\section{ANEXOS}

En los anexos se han hecho constar temas que permiten conocer con detalle, aspectos específicos de apoyo al desarrollo de la tesis doctoral. 


\section{CAPÍTULO 2 - MARCO TEÓRICO}

\subsection{Introducción}

La población AM se está incrementando en todos los países del mundo, y es el momento justo en que se hace necesario poner en práctica el paradigma del envejecimiento activo propuesto en el año 2002 por la Organización Mundial de la Salud que, según (del Valle Gómez \& Coll i Planas, 2011) propone: "desarrollar las acciones que les permiten a las personas mantener la autonomía personal y la independencia a medida que se hacen mayores, reconociendo también la existencia de la interdependencia, que tiene que ver con la dinámica de las relaciones que se comparten con los demás $y$ de la que son mutuamente responsables; y que les hace dependientes recíprocamente a las personas en los ámbitos emocionales, éticos, económicos..." Concomitantemente, están los derechos de los ancianos a tener un envejecimiento saludable, tendientes a que alcancen un alto nivel en su calidad de vida, cimentada en su dignidad y su inclusión familiar y social, correspondiéndoles recibir de los miembros jóvenes de la sociedad que ayudaron a construir, todo el respeto, respaldo, ayuda y protección que requieren por ciertas condiciones fisiológicas y funcionales propias del proceso natural de envejecimiento, que se manifiestan en algunos de ellos como limitantes de su accionar.

La inclusión social de los AM antes referida, mediante una adaptación de (Simplican et al., 2015) significa para esta tesis: aceptación social de las personas ancianas dentro de su entorno familiar y de su comunidad (componente subjetivo), para lograr interacción social, relaciones y redes sociales (componentes objetivos).

El grado de inclusión familiar y social del AM se manifiesta a través de una dimensión esencial de su calidad de vida que es la calidad de las relaciones interpersonales, las cuales se originan en la aceptación social, y sobre las que (del Valle Gómez \& Coll i Planas, 2011) apunta: “... las relaciones sociales son fundamentales para el bienestar de las personas, por lo que es necesario la comprensión del valor que tienen a lo largo de la vida, y cómo su ausencia o presencia puede transformarse en un riesgo o en una oportunidad para la calidad de vida"; aportando (Zahava \& Bowling, 2004) en el mismo sentido al decir: "lo fundamental del valor atribuido a las relaciones sociales con familiares, amigos y vecinos fue la prevención de la soledad a través del acceso a compañía y entretenimiento, satisfacción de la necesidad de apoyo emocional recíproco, sentirse cuidado, mantener confianza, tener a alguien con quien hablar, proporcionar consejo, disponer de alguien para acudir todos los días para ayuda y en situaciones de emergencia."

Las relaciones interpersonales en los seres humanos muestran una alta complejidad, que está relacionada con la calidad de la relación interpersonal que, según (Chen et al., 2014), se refiere a: "la cercanía de la relación o la fortaleza de la relación; es un constructo compuesto por al menos dos dimensiones: confianza y satisfacción; [aunque] algunos estudios identifican tres componentes principales en la calidad de las relaciones: confianza, compromiso y satisfacción."

Para entender un sistema complejo como el constituido por las relaciones interpersonales de un AM, primero se necesita representar, sobre un plano físico, la ubicación del AM y su espacio de actividad, formando un mapa ponderado de su diagrama de conexiones, al que se le denomina red egocéntrica del AM. En esta red quedan claramente delimitados y modelados sus componentes estructurales: actores o individuos a través de nodos, y los enlaces denotando las relaciones o interacciones entre los nodos y el AM, caracterizados por una ponderación para representar la intensidad de la relación o la calidad de las relaciones interpersonales, a la que se le ha llamado en esta investigación, como 
fuerza de la conexión o fuerza de las relaciones interpersonales. En la red egocéntrica, las relaciones entre nodos, que no sean con el AM, se consideran sin importancia.

La red egocéntrica del AM es cambiante a lo largo del tiempo, los nodos y los enlaces pueden aparecer, desaparecer y cambiar su fuerza de conexión.

Para comprender la existencia real de la fuerza de las relaciones en la red egocéntrica del AM, resulta oportuno tomar en cuenta lo que (Cornwell et al., 2009) señala: "algunos tipos de vínculos sociales pueden ser más beneficiosos que otros. Es más probable que las relaciones de alta calidad proporcionen a los AM un sentido de pertenencia, y se asocien con una mejor autoestima y bienestar. Del mismo modo, muchos investigadores destacan el valor de las relaciones de parentesco, que es probable que proporcionen apoyo social incondicional".

Por lo tanto, la importancia relativa que los AM dan a los miembros de su red egocéntrica no es siempre la misma, como lo afirmó (Concha et al., 2000), que propuso que para un AM las relaciones familiares más importantes son con sus hijos y nietos, y también con su cónyuge, porque le aportan confianza, seguridad y apoyo real, son las relaciones que le generan una mayor satisfacción en la vida. Le siguen en importancia la relación con sus amigos cercanos, con quienes puede exteriorizar libremente su sentir con los cambios que le van apareciendo con la edad, y realizar una charla amena sin cohibiciones, su relación les da bienestar y satisfacción mientras están juntos. Luego están sus hermanos, con quienes goza de realizar reminiscencias familiares y con los que ubican sus orígenes, y en los momentos necesarios se brindan apoyo y compañía. Es importante tener presente que "la moral de los ancianos suele depender de la frecuencia con que ven a sus amigos e hijos. La fuerza del vínculo entre los padres que envejecen y los hijos muestra la frecuencia de sus contactos." (Concha et al., 2000)

La importancia relativa de las relaciones interpersonales para las personas fue abordada por (Petroczi et al., 2007) en los siguientes términos: "la noción de la fuerza de una relación es un concepto importante en el análisis de redes sociales. La fuerza de la relación es una propiedad cuantificable que caracteriza el enlace entre dos nodos [en una red social]"; e hizo referencia a la definición de la fuerza de un vínculo interpersonal citada en (Granovetter, 1973), como una orientación a la forma de establecer esa cuantificación; cita sobre la cual (Cruz \& Miquel, 2011) afirma: "la tesis sobre la fuerza de los lazos débiles planteada por Mark Granovetter en 1973 y las sucesivas revisiones que se le han hecho, pese a tener más de 40 años, la teoría goza de buena salud, a juzgar por la cantidad de referencias que se le hacen todavía".

En (Granovetter, 1973) se cita: "La fuerza de un vínculo positivo y simétrico es una combinación (probablemente lineal) de la cantidad de tiempo, la intensidad emocional, la intimidad (confianza mutua) y los servicios recíprocos que caracterizan al vínculo."

El significado matemático de la expresión combinación lineal de $x=\left\{x_{1}, x_{2}, x_{3}, \ldots x_{n}\right\}$ y $\omega=$ $\left\{\omega_{1}, \omega_{2}, \omega_{3}, \ldots \omega_{n}\right\}$ es:

$$
x=\sum_{i=1}^{n} x_{i} \omega_{i}=x_{1} \omega_{1}+x_{2} \omega_{2}+x_{3} \omega_{3}+\cdots+x_{n} \omega_{n}
$$

donde $x_{i}$ representarían los componentes y $\omega_{i}$ las ponderaciones de cada componente según la percepción de la persona en análisis. 
Según (Marsden \& Campbell, 1984): "Los factores que determinan la fuerza de una relación interpersonal se clasifican en indicadores y predictores"; cuyas definiciones se encuentran en (Petroczi et al., 2007), en los siguientes términos:

- "Indicadores: son los componentes reales de la fuerza del vínculo (cercanía, duración, frecuencia, amplitud de temas y confianza mutua). Los indicadores aportarán con sus pesos a definir un valor específico para la fuerza de la relación, de conformidad a la definición matemática de media ponderada."

Cabe recordar que la media ponderada para una serie de datos no vacía: $x=\left\{x_{1}, x_{2}, x_{3}, \ldots x_{n}\right\}$ a la que corresponden los pesos $\omega=\left\{\omega_{1}, \omega_{2}, \omega_{3}, \ldots \omega_{n}\right\}$, se obtiene con la ecuación:

$$
\bar{x}=\frac{\sum_{i=1}^{n} x_{i} \omega_{i}}{\sum_{i=1}^{n} \omega_{i}}=\frac{x_{1} \omega_{1}+x_{2} \omega_{2}+x_{3} \omega_{3}+\cdots+x_{n} \omega_{n}}{\omega_{1}+\omega_{2}+w_{3}+\cdots+\omega_{n}}
$$

- "Predictores: son los componentes contextuales (vecindad, afiliación, estatus socio-económico similar, lugar de trabajo). Los predictores están relacionados con la fuerza del vínculo, pero no son componentes de la misma."

(Petroczi et al., 2007) también ofrece una orientación para la catalogación cualitativa del valor que se estime para la fuerza de una relación interpersonal, con la expresión: "Un vínculo dado puede ser fuerte, débil o ausente."

Por otra parte, y retomando la idea de los derechos de los ancianos, (Huenchuan, 2013) describe la realidad opuesta al envejecimiento saludable, que enfrentan algunos AM, diciendo que es "la etapa de la vida donde la persona sufre discriminación, que deviene de actitudes y percepciones sociales negativas u otros factores que originan obstáculos sociales." Esos obstáculos sociales pueden ser: aislamiento social, soledad, ausencia o debilidad de apoyos sociales, falta de compromiso e integración social; todos ellos se pueden considerar consecuencia de una escasa inclusión social.

Todo el análisis anterior, demuestra la importancia para las personas en general, y para el AM en particular, de disponer de relaciones interpersonales de alta calidad, por lo que tomando en cuenta las funcionalidades de Facebook, se planteó, como hipótesis inicial, que la red social Facebook podría ser una alternativa válida que le aporte a la persona mayor las posibilidades de:

1) superar alguna limitación de movilidad que lo haya alejado de sus contactos;

2) mantener activas sus relaciones interpersonales significativas con la red de contactos actuales, principalmente con aquellos que son emocionalmente importantes en la vida de las personas mayores, que por diversas circunstancias, algunas propias de la economía global, se han distanciado geográficamente;

3) de ampliar su red de contactos con personas que fueron parte importante en otras etapas de la vida del AM; y

4) alcanzar otros beneficios colaterales como facilidad de acceso a información de distinta índole, entretenimiento, y más.

La consideración de que Facebook podría ser una alternativa válida para mejorar la calidad de vida de los AM surgió de la observación directa del entorno inmediato del tesista, con la cual se detectó que las características funcionales y operativas de Facebook fortalecen y complementan las relaciones interpersonales reales de las personas, permitiéndoles mejorar la experiencia y calidad de las 
conexiones con sus contactos a través de interacciones virtuales más frecuentes, de mayor duración, con intercambios multimedia, con independencia de tiempo y de ubicación geográfica.

Esta consideración, se vio reforzada con la afirmación de (Ramos et al., 2018) relacionada al número de usuarios AM de Internet y las motivaciones que tienen: “... vale la pena mencionar que el número de usuarios mayores que acceden a Internet también está aumentando. El uso de Internet puede estar motivado por la necesidad de obtener información y establecer una red de contactos; para compartir experiencias y obtener apoyo. Las limitaciones en la movilidad física, características de las personas mayores, conducen a sentimientos de soledad y aislamiento; sin embargo, dicha tristeza puede disminuirse mediante el uso de redes sociales que permiten a las personas obtener ayuda, comunicarse y participar en la comunidad, aumentando así su independencia de la familia. Para los AM, las redes sociales pueden contribuir a una interacción más intensa a través de la participación afectiva con otros usuarios."

Por lo tanto, debía realizarse la fundamentación teórica que respalde la hipótesis inicial que Facebook realmente podría ser un aporte para que el AM alcance una mejor calidad de relaciones interpersonales. También había que fundamentar que el AM dispone de las capacidades intelectuales suficientes para involucrarse con la tecnología de la red social. Y finalmente cimentar otros aspectos relacionados con el entorno de Facebook, que complementarían las expectativas del AM de alcanzar satisfacción plena con el uso de interacciones virtuales con sus familiares y amigos; mediante su desenvolvimiento en un entorno seguro.

\subsection{Fundamentación filosófica de la investigación}

Para comenzar esta sección es necesario comprender la trascendencia de la fundamentación filosófica en toda investigación, que (Beuchot, 1999) la describe con claridad de la siguiente manera: "fundamentar filosóficamente lo que se hace en la práctica es mostrar su conexión con ciertos principios y valores, lo que mejorará mucho el conocimiento general del tema de investigación, y eso mismo ayudará a desarrollarlo de mejor manera, con mayor convicción, siendo de gran ayuda para que se llegue a una aceptación más plena de la importancia y trascendencia de la investigación."

La fundamentación filosófica se inició procurando entender si las razones corporativas de existir de Facebook, se alineaban de alguna manera con las necesidades particulares de los AM. Para lo cual se consideró adecuado hacer la revisión de la visión y misión corporativa actualizada de Facebook, producto de más de 15 años de experiencia de ser uno de los medios de comunicación e interacción virtual más importantes e influyentes a nivel global. Según se cita en (Smithson, 2019): "La misión corporativa de Facebook es dar a las personas el poder de construir una comunidad y acercar el mundo. La visión corporativa de Facebook señala: La gente usa Facebook para mantenerse en contacto con amigos y familiares, para descubrir lo que está sucediendo en el mundo y para compartir y expresar lo que les importa."

Estas declaraciones muestran claramente los principios corporativos que sustentan que la red social Facebook podría apoyarle al AM a elevar la calidad de las relaciones interpersonales, que son las que determinan el grado de inclusión familiar y social que el AM posee. Esto le permitiría superar ciertas limitaciones de comunicación como la distancia geográfica, la movilidad, y le dotaría del poder de la ubicuidad, complementada con la facilidad para la expresión, el acceso a distinto tipo de información y la posibilidad de entretenimiento, todo esto para el mejoramiento integral de su nivel de calidad de vida. Estos principios, (Smithson, 2019) los llama componentes principales de la visión de Facebook: 
"1) alcance mundial; 2) herramienta de comunicación; 3) herramienta de descubrimiento; y, 4) herramienta de autoexpresión."

Una vez que se estableció que Facebook podría contribuirle bienestar al AM, el siguiente paso es encontrar el sustento filosófico y teórico de que el AM es capaz de desarrollar interacciones virtuales satisfactorias a través de Facebook, es decir, posee capacidades para manejar los servicios que la tecnología de Facebook le pone a su alcance para mejorar su calidad de vida.

En este sentido, con fundamentación empírica, se puede asegurar que la mayoría de los AM jóvenes, definitivamente están capacitados para el manejo de herramientas tecnológicas como la red social Facebook, por haber desarrollado sus actividades productivas recientes justamente alrededor de las TIC, y porque les resulta muy familiar el uso de teléfonos inteligentes y sus aplicaciones; todo esto independientemente del nivel socioeconómico, del nivel académico, y del sexo de las personas.

Para el caso de los AM de más edad, especialmente aquellos que en sus años de juventud y adultez no tuvieron la oportunidad de estar en contacto cercano con la tecnología es necesario encontrar fundamentos que los acerquen a la tecnología de las redes sociales y a lo mejor les hagan cambiar de forma de pensar respecto a ideas equivocadas o pesimistas, que les limitan y podrían hacerles perder una oportunidad, en este caso de índole tecnológica, de mejorar su autosatisfacción con la vida. Ejemplos de pensamientos y concepciones pesimistas se han señalado en (Casamayou \& Morales González, 2018) en los siguientes términos: "hay emociones y percepciones negativas de los AM para con las TIC, como son: sentir que no está diseñada para sus necesidades; no tener el impulso de involucrarse activamente en la tecnología, actitudes negativas derivadas del miedo la ansiedad, la falta de motivación e interés, y la falta de beneficios percibidos." O lo que (Meymo \& Nyström, 2017) indica: "suponen que es más difícil aprender asuntos relacionados con tecnología a una edad tan avanzada, cuando comienzan a enfrentar problemas de envejecimiento como la cognición, la memoria, la vista, etc.; además tienen necesidad de apoyo técnico - humano en el entorno local; o simplemente porque sienten que pueden sobrevivir sin usar tecnologías".

Para fundamentar la lucidez mental y capacidades intelectuales suficientes del AM, y así sustentar lo equivocadas que son esas ideas pesimistas del AM hacia la tecnología, y aportarle argumentos al AM para que, si es su decisión, llegue a utilizar la tecnología de red social Facebook, se acudió a tres fuentes principales:

1. Los pensamientos de importantes filósofos de la historia de la humanidad: Platón, Cicerón Hermann Hesse y Simone de Beauvoir, que propusieron una alta consideración y admiración por las capacidades y virtudes morales que ostentan las personas mayores; y, que descartaron cualquier pensamiento negativo hacia los ancianos, según se describen con suficiente detalle en (Alfaro, 2015). 
2. Las teorías enfocadas en la vejez, citadas en (Aranibar, 2001): de la modernidad - visión dinámica de la modernidad - perspectiva de ciclo de vida ${ }^{4}$, de la actividad ${ }^{5}, y$ del labeling ${ }^{6}$; que permiten afirmar que los AM actuales están sometidos a la influencia de uno de los acontecimientos tecnológicos que mayor transformación ha ocasionado en la forma de comunicarse e interactuar de las personas en el mundo, las redes sociales; el mismo que se ha unido a otros acontecimientos de la época tales como la globalización de la economía, la migración; que han traído como consecuencia el hecho particular que las familias se separen geográficamente, pero de ninguna manera, se alejen emocionalmente.

Frente a los diversos acontecimientos acaecidos en forma paralela en la época actual en el mundo, al no ser la vejez una etapa de exclusión social, el AM que cuente con una aceptable condición de salud; con recursos económicos, y apoyo de confianza, podría disponer de los elementos necesarios para acceder a Internet y a los servicios de Facebook.

Ese AM tendría la capacidad de decidir sobre el uso de los diversos recursos tecnológicos ofrecidos por Facebook: de comunicación, de compartición de materiales multimedia, de expresión, de entretenimiento, y de descubrimiento de información de interés; con los cuales podría: mantener e inclusive mejorar sus conexiones con familiares y amigos; ampliar su red de contactos; retomar relaciones interpersonales con personas que dejaron de ver; recibir apoyo social cuando lo necesite; lo que conllevaría un mejoramiento de la calidad de sus relaciones interpersonales y su calidad de vida en general.

Esa experiencia le conduciría a construir una conducta positiva hacia la red social, y ser un elemento que podría influir en otros AM de su comunidad.

3. Publicaciones de investigaciones científicas que citan estudios que evidencian o resultados que destacan las capacidades para el aprendizaje que aún mantienen los AM, así, por ejemplo:

a. Según (Agudo Prado \& Fombona Cadavieco, 2013): "no está demostrado que las personas mayores sean incapaces de realizar actividades intelectuales. Los estudios del National Institute of Aging de los Estados Unidos sobre el cerebro de las personas mayores demuestran

\footnotetext{
${ }^{3}$ Teoría de la modernidad - visión dinámica, que plantea: “... la historia moldea a los individuos de diferente manera en función a su año de nacimiento, sometiéndolos a la influencia de distintos acontecimientos, ofreciéndoles determinadas combinaciones de recursos para desarrollar sus vidas y dotándolos incluso de una forma propia y única de entender e interpretar la realidad ..." (Aranibar, 2001)

${ }^{4}$ Teoría de la modernidad - perspectiva de ciclo de vida: "la vejez no implica necesariamente una ruptura en el tiempo ni el ingreso a una etapa terminal, sino que es parte de un proceso (y un proceso en sí misma) donde el individuo continúa "dialogando" con la sociedad, al igual que como lo hacía en etapas anteriores. La situación y la posición social experimentada en la vejez están determinadas por los acontecimientos, decisiones y conductas de los individuos en etapas anteriores de su vida; y no tendría razón para ser una etapa de exclusión social." (Aranibar, 2001)

5 Teoría de la actividad: "cuyo fundamento central se basa en que el envejecimiento normal implica el mantenimiento de las actitudes y actividades habituales de la persona por el máximo tiempo posible y que, por lo tanto, un envejecimiento satisfactorio consiste en permanecer como en la edad adulta." (Aranibar, 2001)

${ }^{6}$ Teoría del labeling - subcultura de la vejez: "propuso que la edad - o el agrupamiento por edades - conduce inevitablemente hacia la formación de una subcultura, que es la que define y dirige la conducta de sus miembros. Esta teoría considera que el grupo de AM desarrolla un grado de actividad social de acuerdo a tres factores: su condición de salud, su situación económica y el apoyo social que reciba; y que el control de uno o todos estos factores permite modificar la realidad social de la vejez. Esta perspectiva ha demostrado, que la desvinculación social no es causada por la edad sino por otras circunstancias asociadas, como la mala salud, la pérdida de relaciones y la merma en los ingresos." (Aranibar, 2001)
} 
que éste es tan activo y eficiente como el de una persona joven. La vejez mantiene una elevada capacidad para el aprendizaje, favorecida por la riqueza y la sabiduría de la experiencia."

b. En (Aldana González et al., 2012) se afirma que: "la capacidad de aprendizaje se conserva en el envejecimiento normal hasta más allá de los ochenta años; uno de los aprendizajes que se puede desarrollar con la estimulación de los procesos cognitivos es el uso y manejo de las TIC."

Por lo tanto, el AM tiene suficientes facultades intelectuales para operar, o aprender el manejo, o capacitarse para manejar ese fenómeno tecnológico positivo llamado Facebook; lo único que tiene que hacer es tomar la decisión de convertirse en usuario. Sin embargo, se debe hacer notar, que esa decisión solo le será posible adoptar si posee razones particulares poderosas, que le motiven a utilizar activamente la tecnología de la red social, haciéndole superar la brecha digital y limitaciones contraídas con la edad. Para despertar el interés, se considera necesario que el AM llegue a conocer todos los beneficios potenciales que le ofrece la red social Facebook, y los compatibilice con sus necesidades, para así determinar la motivación.

Existe un aspecto complementario importante para el AM, como es su necesidad de mantener sus actividades reales y/o virtuales en el contexto de un entorno seguro. Esta necesidad tiene su asidero en la realidad del ambiente de Internet, que al igual que todo ambiente del mundo físico real creado por el ser humano, tiene riesgos a los que se exponen sus habitantes, que en el mundo virtual se conocen como ciber-riesgos, causados por la ciberdelincuencia, es decir, personas con un cierto dominio de la tecnología, que utilizan sus conocimientos y destrezas para cometer delitos tecnológicos. Estos ciber-riesgos, atentan a la seguridad de los distintos componentes que el usuario utiliza para participar en Internet: recursos tecnológicos donde se almacenan datos, recursos económicos, personales, y privacidad; muy semejantes a aquellos riesgos existentes en el mundo físico.

Diversas publicaciones se refieren a los ciber-riesgos, como por ejemplo, (Instituto de Auditores Internos de España, 2016) y (Me Conecto Sin Clavos, 2017), de las que se han sintetizado las siguientes definiciones de los tipos de ciber-riesgos a los que están expuestos los usuarios de Facebook:

- Tipo 1.- Contra la información: aquellos cuya materialización provocan una pérdida, manipulación, publicación o uso inadecuado de la información. Se destacan: 1) robo y publicación de información clasificada, confidencial o sensible; 2) robo de identidad digital suplantación de identidad: consiste en el uso de información personal, a través de las redes, por parte de una tercera persona con el fin de obtener un beneficio propio, con el perjuicio para el titular de la identidad, a quien le serán atribuidos los actos cometidos; 3 ) fraude dinerario o estafa económica.

- Tipo 2.- Contra el ser humano: "1) ciber-acoso o ciberbullying: consiste en utilizar los medios en línea para dispersar una campaña de insultos y descalificaciones contra una determinada persona. 2) El grooming: supone el conjunto de técnicas de engaño y persuasión a través del internet, ejercido deliberadamente por un adulto, para ganarse la confianza y disminuir las inhibiciones de un menor y así establecer una relación y un control emocional, con el fin de obtener de él un beneficio de índole sexual. 3) El sexting: es la difusión o publicación de imágenes o videos de tipo sexual, producidos por personas cuando se conectan a Internet. 4) Tecnoadicciones: cuando los abusos de la tecnología le quitan a la persona la libertad, influyendo gravemente en las actividades particulares, o relaciones familiares y de amigos. 5) Amenazas a la privacidad." (Me Conecto Sin Clavos, 2017) 
- Tipo 3.- Contra los recursos tecnológicos: infecciones con malware $; y$, botnet ${ }^{8}$.

Para el caso específico de Facebook y los ciber-riesgos propios de ese entorno, la sustentación es la siguiente:

1. Es importante tener clara a la visión de privacidad en los momentos actuales en que la tecnología ha penetrado profundamente en la forma de vida de las personas. Para la comprensión necesaria del tema, considerando la perspectiva de uso de Internet y las redes sociales por parte del AM, se acudió a (UNESCO, 2012), de la cual se extrajo la siguiente afirmación:

"Con relación a una persona usuaria de los servicios de Internet, la privacidad tiene dos dimensiones: la primera relacionada con salvaguardar su identidad; $y$, la segunda tiene que ver con la forma en que se maneja su información personal. En este último sentido, la privacidad se ha definido actualmente como el derecho de las personas a determinar cuándo, cómo y en qué medida la información sobre ellas se comunica a otros."

2. Con respecto a cómo Facebook puede afectar negativamente en la privacidad de los usuarios, en (UNESCO, 2012) se expresó un comentario, que aún sigue tan vigente como entonces:

"Si es verdad que Facebook puede haber tenido éxito en convertirse en insustituible para muchos de sus usuarios, esto tiene implicaciones sustanciales para la privacidad en Internet. Los usuarios se hacen vulnerables a los cambios unilaterales realizados por Facebook y otras redes sociales en sus políticas de privacidad y prácticas de privacidad. Los usuarios están lo suficientemente encerrados en la red social que, incluso si están fundamentalmente en desacuerdo con las políticas de privacidad de las redes sociales, es poco probable que abandonen la red.

Si bien las personas a menudo se preocupan por la privacidad en abstracto, en la práctica parecen menos preocupadas; las personas no se dan cuenta de las implicaciones de publicar en línea, de cómo estarán disponibles sus publicaciones hacia todo el mundo y que no podrán ser recuperadas por ellos."

3. (Algarni et al., 2014) afirma: "la información está siempre bajo amenaza; puede ser interceptada, modificada o expuesta. Tales riesgos configuran los retos de proporcionar usabilidad y sociabilidad, que son los principales propósitos de los servicios de redes sociales y a su vez, de asegurar la integridad, confidencialidad y disponibilidad, que son principios estándares de seguridad."

4. (Cornejo \& Tapia, 2011) hace alusión al gran volumen de datos personales que los usuarios de redes sociales difunden voluntariamente: "en las redes [sociales] se comparten muchos datos personales (intereses, gustos, fotos, videos, etc.). En la página de inicio, cada usuario hace su construcción pública del yo, siendo este perfil un conjunto de datos de diversa naturaleza, un

\footnotetext{
7 Malware: "código malicioso, archivos con fines dañinos que, al infectar una computadora, realizan diversas acciones, como el robo de información, el control del sistema o la captura de contraseñas." (Esset, 2011)

"Abarca virus, gusanos, troyanos, rootkits, spyware, keyloggers, etc." (Instituto de Auditores Internos de España, 2016)

${ }^{8}$ Botnet: "Es una red de computadoras comprometidas (es decir, bots) que están bajo el control de un atacante remoto (es decir, botmaster) a través de algún canal de comando y control (C\&C)." (Gu, 2011)

"Conjunto de ordenadores infectados (conectados a Internet) que se ejecutan y controlan de manera autónoma y automática. Estas redes son usadas principalmente para aumentar la capacidad de procesamiento necesaria para perpetrar un ataque, así como para ocultar el origen y autoría del mismo." (Instituto de Auditores Internos de España, 2016)
} 
collage de texto e imágenes que componen un reflejo de sí mismo, pero maleable, cambiante, flexible."

5. El comportamiento de las aplicaciones de redes sociales con los datos provistos voluntariamente por los usuarios, es definido por el modelo de negocio detrás de esos productos de comunicaciones.

En el caso particular de Facebook, en (Facebook - Condiciones del servicio, 2020), se revela el modelo de negocio que aplica, y la necesidad de recopilar la mayor cantidad de datos de los usuarios a través de todos los servicios de comunicaciones que ofrece.

El modelo de negocio aplicado por Facebook establece que sus productos de comunicaciones presentarán a los usuarios "servicios gratuitos", y "con la mejor experiencia de uso".

Para viabilizar ese modelo, Facebook capta recursos económicos de negocios y organizaciones, a cambio de mostrar anuncios de los productos y servicios que comercializan, acorde a los intereses particulares de los usuarios de Facebook.

Facebook, para asegurar su capacidad de captación de recursos económicos de negocios y organizaciones de todo el mundo, requiere:

a) Incorporar la mayor cantidad de usuarios alrededor del mundo.

b) Que el usuario acepte que Facebook le muestre anuncios que considera que le resultarán relevantes para sus intereses.

c) Recopilar una inmensa cantidad de datos de cada uno de los usuarios

d) Garantizar a sus usuarios que NO venden ni comparten a los anunciantes, sus datos personales o información que les identifique directamente (como su nombre, dirección de correo electrónico u otra información de contacto), a menos que el usuario haya dado su permiso expreso.

e) Brindar a sus usuarios facilidades para que configuren aspectos relacionados con su privacidad y seguridad en los productos y servicios.

6. Los ciber-delincuentes pretenden perjudicar económicamente a los usuarios de Facebook, para lo cual emplean diversos modus operandi, que resumiendo a (Gómez Blanco, 2019), son:

a) Publicación de sorteos, cupones de descuento u ofertas tentadoras para los usuarios, casi siempre ofreciendo un enlace a un formulario en el que el usuario de la red social debe rellenar sus datos y compartir la publicación con sus amigos.

b) Difusión de publicidad no legítima que se anuncia en la red social, relacionada con tiendas de artículos sorprendentemente baratos.

c) Creación de usuarios con perfiles falsos para realizar estafas, mediante la publicación de comentarios en grupos y publicaciones ofreciendo préstamos irresistibles que nunca llegarán, pero por los cuales hay que ofrecer un adelanto.

d) Creación de usuarios con perfiles falsos, elaborados con fotografías y publicaciones habitualmente robadas de otras personas, que le dan credibilidad al perfil. Este tipo de usuarios se dedica a contactar con personas para labrar una amistad, a veces incluso relaciones románticas. Cuando el cibercriminal tiene la confianza de su víctima, se dedica a pedir dinero con pretextos totalmente creíbles, utilizando sus dotes de engaño o seducción para que la víctima acceda. 
e) Sextorsión: Usuarios con perfiles falsos que logran entablar una relación romántica con su víctima, y que la perjudicarán económicamente, extorsionándole a través del 'sexting, bajo la amenaza de hacer públicos los materiales eróticos o pornográficos enviados voluntariamente por la víctima, si no reciben una cierta cantidad de dinero.

f) Anuncios de nuevas funcionalidades para la red social, alegando que son exclusivas y que se logran con la descarga de una aplicación o extensión del navegador.

g) Enlaces en 'Fake news': noticias, fotos o vídeos sensacionalistas sobre famosos; que redirigen a portales con 'malware'.

h) Anuncios de supuestas aplicaciones que responden curiosidades del usuario, con los que se le motiva a instalar aplicaciones o extensiones que infectarán el dispositivo del usuario con 'malware' para robar datos. Curiosidades como, por ejemplo: “¿Quieres saber quién visita tu Facebook?” “¿Quieres saber quién te ha eliminado de su lista de contactos de redes sociales?"

En este contexto, nació la hipótesis de que no es suficiente el conocimiento detallado de la existencia de los ciber-riesgos y sus consecuencias, sino que es necesario identificar, estructurar y catalogar plenamente los orígenes de los ciber-riesgos, para determinar los factores que el AM debe tomar en cuenta en el ambiente de Facebook, para concretar un entorno seguro de comunicación donde pueda apoyarse para conseguir o mantener su inclusión familiar y social. Es justamente esta hipótesis la que orientó el desarrollo de algunas de las investigaciones parciales descritas en el capítulo 5, con las que se encontraron argumentaciones para orientar el comportamiento del AM hacia la conformación de un entorno seguro en Facebook, que le brinde seguridad y satisfacción en sus interacciones virtuales con sus contactos.

\subsection{Conceptualización de términos relacionados con la investigación}

2.3.1. AM

El término AM lleva consigo distintos aspectos: cronológico, fisiológico, cognitivo, sociológico, económico.

Desde el punto de vista cronológico, no existe una edad estandarizada para que una persona sea considerada AM, varían entre los países y las organizaciones internacionales. Así, según la Organización Mundial de la Salud (OMS), AM es toda persona mayor de 60 años; la Organización Panamericana de la Salud emplea el término para las personas de 65 o más años de edad; en el Ecuador, la Constitución de la República del Ecuador declara que pertenecen a este grupo etario las personas que hayan cumplido los 65 años de edad.

Con relación a lo fisiológico, el AM presenta "la pérdida de capacidades funcionales y la disminución gradual de densidad ósea, tono muscular y fuerza" (Huenchuan, 2013).

Respecto a las capacidades cognitivas, algunos investigadores, tales como (Aldana González et al., 2012), señalan como algo estereotipado de las personas adultas mayores el deterioro en sus procesos cognitivos. Sin embargo, aclara que, desde la perspectiva gerontológica, el estado de los procesos cognitivos en los AM no son solo el resultado de factores orgánicos que participan en la recepción de estímulos del entorno, sino también de aspectos sociales y psicológicos experimentados a lo largo de su vida, por lo que el estado de los procesos cognitivos de las personas adultas mayores no necesariamente coincide.

La intelección del aspecto sociológico en el AM, se enfoca desde las justificaciones de la conformación de la estructura de las redes sociales, y la necesidad de la inclusión familiar y social, que encuentran 
su sustento en dos teorías orientadoras del comportamiento humano de las personas adultas mayores: la teoría de selectividad socioemocional (SST por sus siglas en inglés), y la teoría de pertenencia.

La teoría de selectividad socioemocional justifica la reducción del tamaño de las redes sociales de los $\mathrm{AM}$, al punto de quedarse con un reducido número de contactos significativos, constituidos especialmente por sus familiares cercanos: cónyuge, hijos, nietos; hermanos; y, amigos cercanos. La propuesta de SST, se expone con un resumen de lo señalado en (English \& Carstensen, 2015):

"SST es una teoría del comportamiento social humano que se basa en la idea de que los horizontes temporales definen los objetivos. Plantea que cuando el tiempo de vida se percibe como extenso, las personas priorizarán objetivos centrados en la información, asignan recursos para explorar el entorno, reúnen todo tipo de información que pueda ser útil para el futuro lejano e incierto, invierten en actividades que puedan permitir nuevos aprendizajes y oportunidades futuras. Al contrario, cuando el tiempo de vida se percibe como limitado, las personas priorizarán los objetivos relacionados con los aspectos emocionales más importantes de la vida, viven el presente, dan mayor relevancia a las relaciones cercanas y las interacciones emocionalmente significativas, por lo tanto, las preferencias sociales y la composición de las redes sociales se ven modificadas, los AM mantienen sus relaciones cercanas más significativas y dejan de lado a los interlocutores sociales periféricos menos satisfactorios."

Por otro lado, con la teoría de pertenencia se entiende la importancia para el AM de su inclusión familiar y social, mediante relaciones interpersonales significativas; y las consecuencias adversas de no disponer de ella. (Sinclair \& Grieve, 2017) anota respecto a esta teoría lo siguiente:

"Ia teoría de la pertenencia propone que las personas están motivadas a experimentar membresía social con el fin de obtener una vida óptima, [...] que no solo la compañía de otros satisface las necesidades de pertenencia, sino que importa la calidad y el significado del contacto, es decir, la conexión social significativa con otros define la pertenencia, [...] que, en el AM, la pérdida de conexiones sociales puede ocurrir por diversas circunstancias, tales como: cambios en el estilo de vida (por ejemplo, por jubilación o duelo), restricciones de movilidad (por ejemplo, como resultado de una artritis debilitante); deterioro de la salud física; y mayores comorbilidades ${ }^{9}$. Aquellas personas con niveles más bajos de pertenencia sufren niveles altos de enfermedades psicológicas y físicas, tienen niveles más altos de soledad y, a su vez, niveles más bajos de bienestar."

Con relación al aspecto económico, se debe destacar la seguridad económica que debe tener el AM, definida en (Madrigal-Martínez, 2010) como: "[...] la capacidad de disponer y usar de forma independiente una cierta cantidad de recursos económicos regulares y en montos suficientes para asegurar una buena calidad de vida."

La seguridad económica es fundamental para los AM, les permite tener independencia y vivir con dignidad. Puede originarse de tres fuentes: aportes familiares, la seguridad social, y el trabajo. Aunque los apoyos de la familia, concretados en dinero en efectivo, y/o alimentos y medicinas, no son específicos ni periódicos, representan un aporte importante para la economía de la persona AM; más aún si se consideran los bajos valores de las pensiones de jubilación que reciben los ancianos que

\footnotetext{
${ }^{9}$ Comorbilidades: la presencia simultánea de dos enfermedades o afecciones crónicas en un paciente. La comorbilidad es un término médico, que se refiere a dos conceptos: La presencia de uno o más trastornos (o enfermedades) además de la enfermedad o trastorno primario. El efecto de estos trastornos o enfermedades adicionales
} 
gozan de esos beneficios; y más todavía para aquellos que no tienen la protección de la seguridad social. Con respecto a la posibilidad de alguna remuneración debido a la realización de algún tipo de trabajo por parte del AM, no es una situación común, es posible para aquellos que puedan trabajar independientemente, normalmente en actividades artesanales. Más bien es posible que dispongan de algún tipo de ingreso debido a las regalías que recibe por los bienes que logró acumular durante su época de juventud y adultez; pero tampoco es una situación que se pueda generalizar para todos los AM. (Madrigal-Martínez, 2010)

Finalmente, para cerrar la caracterización del AM, resulta interesante tomar en cuenta que los AM constituyen una población en la que no se permite establecer características de uniformidad, según lo propuesto por (Casamayou \& Morales González, 2018):

"Considerando que existen múltiples formas de envejecer y la importancia de condiciones que se han ido construyendo a lo largo de todo el ciclo vital, distintos autores establecen la imposibilidad de considerar la población de AM como un colectivo homogéneo. En ese sentido se señalan diferentes variables que responden tanto a condiciones estructurales como a otras que se han ido construyendo a lo largo del ciclo vital, que determinan, intervienen o explican la relación con las tecnologías, las motivaciones, los tipos de uso y las formas de apropiación."

\subsubsection{La red social en línea Facebook}

Según (Ayuntamiento de Vitoria-Gasteiz, 2010): "Ias redes sociales son sistemas de interacción social que facilitan, a través de un sistema informático, un intercambio entre personas, invitan a la participación activa, a compartir contenidos y, en general, a la comunicación y el encuentro; a los usuarios se les permite crear una página personal, expresarse libremente y establecer vínculos con amigos."

De las distintas redes sociales en línea existentes en Internet, Facebook sobresale, para ser tomada en cuenta en esta investigación doctoral, por las siguientes razones:

1. En el ranking de las redes sociales más populares a nivel global en los años 2015, 2016, 2017, 2018, 2019 y 2020, apareció como líder del mercado mundial.

2. En (Jung \& Sundar, 2016) se afirma: "Facebook es el sitio de redes sociales más popular. Más del $70 \%$ de los adultos en línea que usan las redes sociales visitan Facebook".

3. Las estadísticas sobre Facebook en el año $2020^{10}$, señalan:

"Las personas mayores representan el grupo demográfico de edad más pequeño de Facebook, pero también [...] representan el grupo demográfico con el crecimiento más acelerado dentro de la plataforma. De acuerdo al Centro de Investigación Pew, la proporción de estadounidenses mayores en la plataforma se ha más que duplicado desde el 2012. Cuando se trata de datos demográficos sobre los rangos de edad de Facebook, es probable que esta tendencia aumente a medida que la población de mediana edad ingrese al sector mayor.

Facebook es la red social más popular entre las personas mayores. Las personas mayores podrán ser el grupo de edad más pequeño en Facebook en los Estados Unidos. Sin embargo, Facebook es la red social que más utilizan. Entre los estadounidenses mayores de 65 años, el

${ }^{10}$ https://blog.hootsuite.com/es/datos-demograficos-facebook-cm/

27 datos demográficos sobre usuarios de Facebook que necesitas saber en 2020 - Fecha de último ingreso: 4 de septiembre de 2020 
46\% usa Facebook. Ahora, compare esta cifra con el 38\% que usa YouTube, el 15\% que está en Pinterest y el 11\% que utiliza Linkedin."

Según (Jung \& Sundar, 2016), las diversas prestaciones de los sitios de redes sociales (SNS por sus siglas en inglés), se puntualizan de manera resumida de la siguiente manera:

1. "Permiten a las personas formar nuevas relaciones y mantener relaciones existentes, así como generalmente participar en una amplia red de conexiones sociales.

2. Brindan a sus usuarios diversos recursos tecnológicos para una comunicación efectiva: capacidad para conectarse entre usuarios; elementos multimedia (es decir, gráficos, audio, video, texto) como contenido informativo y emocional.

3. Admiten que los usuarios sean tanto receptores de contenido como proveedores.

4. Las características principales de interacción del usuario de Facebook son actualización de estado, mensajes privados, comentarios, chat y uso compartido de medios. $Y$, las actividades posibles gracias a estas características del SNS: comunicarse con amigos, mirar o publicar fotos y videos, conocer o planificar eventos, enviar y recibir mensajes, publicar o leer información o historias en los muros, conocer mejor a las personas, encontrar información de contacto y perfil.

5. Facebook también proporciona una característica de retroalimentación, el botón "Me gusta". Este botón es una señal visible con efectos similares a los de los comentarios. El botón "Me gusta" ayuda a los usuarios a responder activamente a las publicaciones de otros haciendo clic en el botón, así como a recibir apoyo social de otros usuarios."

Como consecuencia de la gran acogida del botón me gusta, Facebook amplió esta prestación creando Reacciones, emoticonos con los que los usuarios tienen más opciones para reaccionar rápida y fácilmente. Las Reacciones disponibles, con sus respectivos significados se muestran en la Fig. 2.

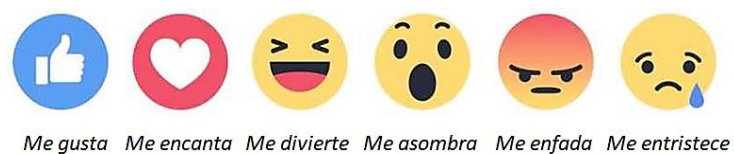

Fig. 2 Reacciones: emoticonos disponibles en Facebook desde el 24 de febrero de 2016 - Fuente: (11)

A las prestaciones anteriores de los SNS, (Finn \& Ph, 2010) agregan:

6. "Interacción no limitada por el horario comercial u otros horarios

7. Ampliamente disponible; no requiere capacitación especial o equipo costoso.

8. Las redes sociales no son un canal de comunicación lo suficientemente rico como para reemplazar por completo la necesidad de las personas de tener interacciones cara a cara significativas."

Como una característica adicional y para ampliar sus prestaciones, Facebook acepta aplicaciones de terceros, en la que el usuario tiene acceso gratuito luego de registrarse.

${ }^{11}$ https://about.fb.com/es/news/2017/02/primer-aniversario-de-reacciones-en-facebook/

Primer aniversario de Reacciones en Facebook - Fecha de último ingreso: 04 de septiembre de 2020 


\subsubsection{Calidad de vida}

No existe una única definición de calidad de vida de las personas. Lo que si se ha consensuado es que se trata de un concepto multidimensional, constituido por componentes objetivos y subjetivos relacionados con diferentes ámbitos de la vida como la salud física, el estado psicológico, el nivel de independencia, las relaciones sociales, las creencias personales y la percepción del individuo de su posición en la vida en el contexto de la cultura y los sistemas de valores en los que vive y en relación con sus objetivos, expectativas, estándares y preocupaciones. Ámbitos que son desarrollados en el sistema social en el que se desenvuelve la persona, como son: la familia, la escuela, el trabajo, la comunidad, el medio ambiente; que han sido clasificados en distintos bienestares de la vida como son el bienestar emocional, el bienestar físico, el bienestar espiritual, el bienestar intelectual, el bienestar social, y el bienestar material; los que pueden ser considerados más importantes para un individuo que para otro. (León et al., 2011) (Esteban et al., 2012)

La calidad de vida no tiene que considerarse como un estado absoluto, en este sentido se manifestó (Esteban et al., 2012) de la siguiente forma: "debe quedar claro que la calidad de vida no es algo que una persona puede tener o no, es necesario considerarla como algo en una escala; una persona puede tener baja o alta calidad de vida. La calidad de vida se puede evaluar e incrementar." Esta afirmación es reforzada por (Zahava \& Bowling, 2004) cuando señala: "cualquier estímulo puede modificar la construcción individual de su calidad de vida."

\section{Modelo operativo de la calidad de vida}

El modelo mostrado en la Fig. 3 se fundamenta en el modelo operativo de calidad de vida con enfoque multidimensional, citado en (M. Á. Verdugo Alonso, 2004). 


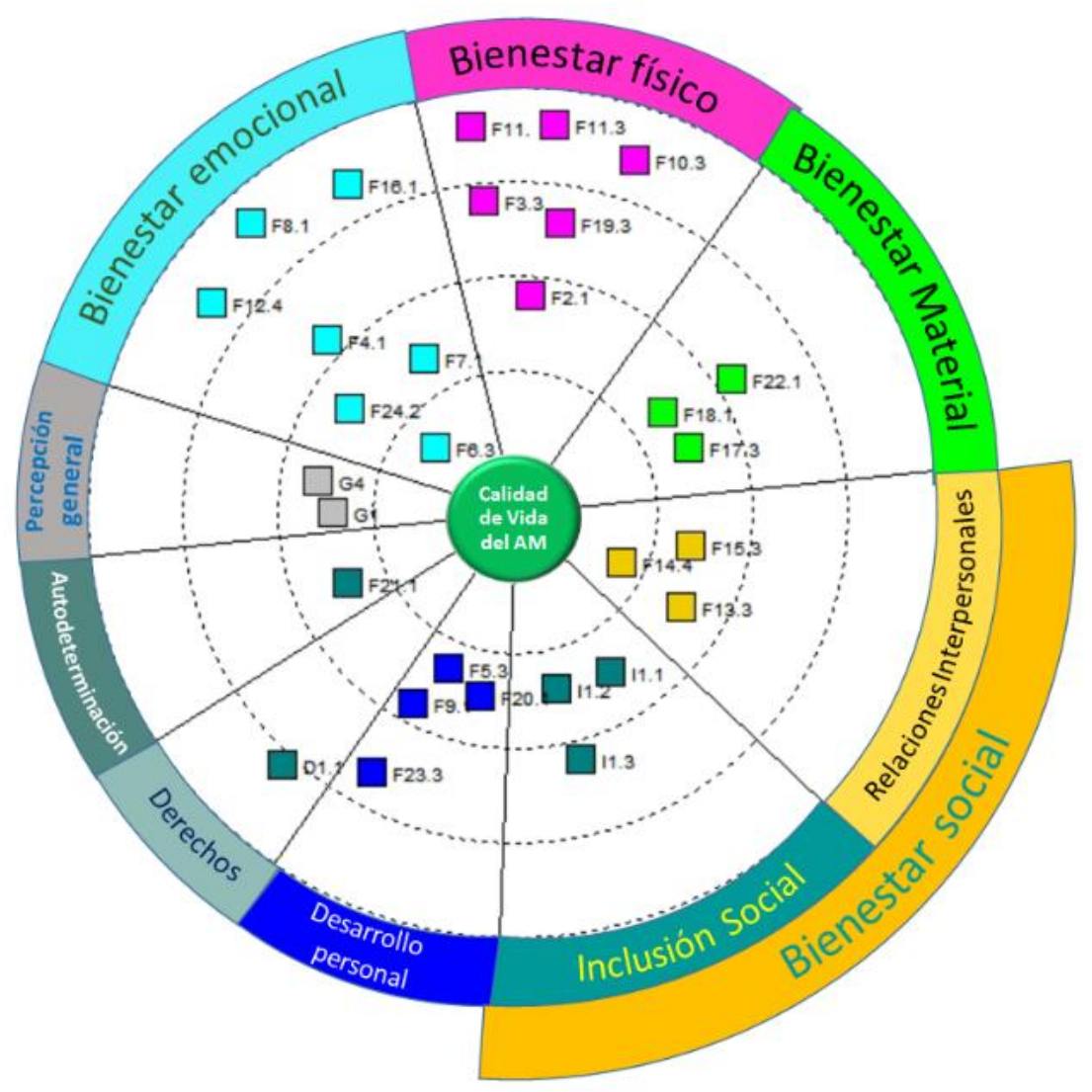

Fig. 3 Modelo operativo de calidad de vida: Dimensiones y factores para la medición

El modelo se complementa con la Tabla 2, en la que se describen los factores que deben tomarse en cuenta para cuantificar cada una de las dimensiones señaladas en el modelo, valores parciales que integrados permitirán otorgarle un valor total a la calidad de vida de la persona; valor que servirá para catalogar cualitativamente la calidad de vida en: excelente, muy buena, buena, regular, mala. Este modelo, permitiría identificar las dimensiones que menos valor alcanzan, para proponer acciones específicas sobre ellas, tendientes a mejorarlas, y como consecuencia, elevar el nivel de vida de la persona en estudio. Esta visión es la que permite, considerar que Facebook podría ayudar a mejorar la calidad de vida, en algunos AM, específicamente en el dominio bienestar social, compuesto por las dimensiones inclusión social y relaciones interpersonales, mediante el incremento de la frecuencia, la duración, la cantidad, la facilidad de las interacciones con familiares cercanos y amigos.

Tabla 2. Relación de dimensiones del modelo operativo de calidad de vida frente a factores de medición y dominios WHOQOLBREF

\begin{tabular}{|c|c|c|}
\hline $\begin{array}{l}\text { Dimensiones } \\
\text { consideradas en el } \\
\text { modelo operativo de } \\
\text { Calidad de Vida } \\
\end{array}$ & $\begin{array}{l}\text { Factores que se consideran en la medición } \\
\text { de cada una de las dimensiones }\end{array}$ & $\begin{array}{l}\text { Dominios del Instrumento } \\
\text { WHOQOL-BREF }{ }^{12} \text { diseñado } \\
\text { por la Organización } \\
\text { Mundial de la Salud }\end{array}$ \\
\hline $\begin{array}{ll}\text { Bienestar general } & - \\
\text { Percepción general } & \end{array}$ & $\begin{array}{l}\text { G1 ¿Cómo calificaría su calidad de vida? } \\
\text { G4 ¿Qué tan satisfecho está usted con su salud? }\end{array}$ & $\begin{array}{l}\text { Bienestar general } \\
\text { Percepción general }\end{array}$ \\
\hline
\end{tabular}

${ }^{12}$ EI WHO Quality of Life-BREF (WHOQOL-BREF) es un cuestionario genérico para medir la calidad de vida creado por el Grupo de Estudio sobre Calidad de Vida de la Organización Mundial de la Salud (WHO por sus siglas en inglés). Es una versión abreviada del WHOQOL-100. (Espinoza et al., 2011) (WHO, 1996) 


\begin{tabular}{|c|c|c|}
\hline \multirow{7}{*}{ Bienestar emocional } & $\begin{array}{l}\text { F4.1 ¿Cuánto disfruta de la vida - Satisfacción con } \\
\text { la vida afectiva? }\end{array}$ & \multirow{4}{*}{ Bienestar emocional } \\
\hline & $\begin{array}{l}\text { F6.3 ¿Qué tan satisfecho está usted con usted } \\
\text { mismo?, ¿Cuánto grado de autonomía tiene en su } \\
\text { vida o capacidad para el cuidado de sí mismo en } \\
\text { tareas domésticas, en actividades básicas, para } \\
\text { levantarse y acostarse, para cambiar de posición } \\
\text { el cuerpo? ¿Es capaz de defender sus derechos } \\
\text { cuando no son respetados, disfruta de todos sus } \\
\text { derechos legales (ciudadanía, voto, procesos } \\
\text { legales, etc.) ¿; ¿percibe un sentimiento de } \\
\text { respeto y aceptación por la sociedad, tiene } \\
\text { satisfacción con el trato que recibe? }\end{array}$ & \\
\hline & F7.1 ¿Es capaz de aceptar su apariencia física? & \\
\hline & $\begin{array}{l}\text { F8.1 ¿Con qué frecuencia usted tiene } \\
\text { sentimientos negativos tales como estado de } \\
\text { nerviosismo, intranquilidad, desesperación, } \\
\text { ansiedad, depresión? }\end{array}$ & \\
\hline & $\begin{array}{l}\text { F16.1 ¿Qué tan seguro se siente en su vida diaria } \\
\text { - tiene buen control personal: tiene dificultades } \\
\text { para manejar el dinero de forma autónoma } \\
\text { (cheques, alquiler, facturas, ir al banco, etc.), su } \\
\text { vida (y su tiempo libre) es organizada por usted o } \\
\text { por otras personas, ha elegido el lugar donde vive } \\
\text { actualmente, usted ha escogido con quien vivir o } \\
\text { lo han decidido otras personas, otras personas } \\
\text { toman las decisiones que son importantes para su } \\
\text { vida? }\end{array}$ & Bienestar material \\
\hline & $\begin{array}{l}\text { F24.2 ¿Hasta qué punto siente usted que su vida } \\
\text { tiene sentido, hace planes sobre su futuro, tiene } \\
\text { metas y objetivos para el resto de su vida? }\end{array}$ & Bienestar emocional \\
\hline & $\begin{array}{l}\text { F12.4 ¿Qué tan satisfecho está usted con su } \\
\text { capacidad para el trabajo? }\end{array}$ & Bienestar físico \\
\hline \multirow{6}{*}{ Bienestar físico } & $\begin{array}{l}\text { F2.1 ¿Tiene suficiente energía para la vida } \\
\text { cotidiana? }\end{array}$ & \multirow{5}{*}{ Bienestar físico } \\
\hline & F3.3 ¿Qué tan satisfecho está usted con su sueño? & \\
\hline & $\begin{array}{l}\text { F10.3 ¿Qué tan satisfecho está usted con su } \\
\text { capacidad para realizar sus actividades de la vida } \\
\text { diaria: ser responsable de la toma de su } \\
\text { medicación, recordar información importante } \\
\text { para la vida cotidiana (caras familiares, nombres, } \\
\text { etc.) ¿ }\end{array}$ & \\
\hline & $\begin{array}{l}\text { F11 ¿Cuánto necesita de algún tratamiento } \\
\text { médico para desenvolverse en su vida diaria? }\end{array}$ & \\
\hline & $\begin{array}{l}\text { F11.3 ¿Hasta qué punto siente usted que alguna } \\
\text { dolencia física le impide hacer lo que hay que } \\
\text { hacer: si oye mal no puede seguir una } \\
\text { conversación, si tiene dificultades de visión tiene } \\
\text { impedimento para realizar sus tareas habituales ¿ }\end{array}$ & \\
\hline & $\begin{array}{l}\text { F19.3 ¿Qué tan satisfecho está usted con su } \\
\text { acceso a los servicios de salud y los apoyos que } \\
\text { recibe? }\end{array}$ & \multirow[t]{2}{*}{ Bienestar material } \\
\hline Bienestar material & $\begin{array}{l}\text { F17.3 ¿Qué tan satisfecho está usted con la } \\
\text { condición de su lugar de residencia? }\end{array}$ & \\
\hline
\end{tabular}




\begin{tabular}{|c|c|c|}
\hline & $\begin{array}{l}\text { F18.1 ¿Tiene suficiente dinero para satisfacer sus } \\
\text { necesidades, dispone de las cosas materiales que } \\
\text { necesita - vivienda propia? }\end{array}$ & \\
\hline & $\begin{array}{l}\text { F22.1 ¿Qué tan saludable es su entorno físico - } \\
\text { Satisfacción con el ambiente en que vive? }\end{array}$ & \\
\hline \multirow[t]{3}{*}{$\begin{array}{l}\text { Relaciones } \\
\text { interpersonales }\end{array}$} & $\begin{array}{l}\text { F13.3 ¿Qué tan satisfecho está usted con sus } \\
\text { relaciones personales? ¿Se siente querido por las } \\
\text { personas importantes para usted? ¿Tiene } \\
\text { satisfacción con el apoyo y las relaciones } \\
\text { familiares: su familia respeta sus decisiones, le } \\
\text { apoya, le cuida, se mantienen en contacto y le } \\
\text { visitan, se preocupan por usted? }\end{array}$ & \multirow[t]{3}{*}{ Bienestar Social } \\
\hline & $\begin{array}{l}\text { F14.4 ¿Qué tan satisfecho está con el apoyo que } \\
\text { recibe de sus amigos, o sus relaciones de amistad? }\end{array}$ & \\
\hline & $\begin{array}{l}\text { F15.3 ¿Qué tan satisfecho está usted con su vida } \\
\text { sexual? }\end{array}$ & \\
\hline \multirow{4}{*}{ Desarrollo personal } & $\begin{array}{l}\text { F5.3 ¿Qué tan bien es capaz de concentrarse para } \\
\text { resolver con eficacia los problemas que se le } \\
\text { plantean, manejar conceptos matemáticos } \\
\text { básicos, útiles para la vida cotidiana (sumar, } \\
\text { restar, etc.), comprender la información que } \\
\text { recibe, tomar decisiones sobre cuestiones } \\
\text { cotidianas? }\end{array}$ & Bienestar emocional \\
\hline & $\begin{array}{l}\text { F9.1 ¿Qué tan capaz es de moverse (tener } \\
\text { movilidad)? }\end{array}$ & Bienestar físico \\
\hline & $\begin{array}{l}\text { F20.1 ¿Cuan disponible está para usted la } \\
\text { información que usted necesita en su vida diaria } \\
\text { (revistas, periódicos, etc.), información adecuada } \\
\text { y suficiente sobre los tratamientos e } \\
\text { intervenciones que recibe? }\end{array}$ & \multirow[t]{2}{*}{ Bienestar material } \\
\hline & $\begin{array}{l}\text { F23.3 ¿Qué tan satisfecho está usted con su modo } \\
\text { de transportación? }\end{array}$ & \\
\hline Autodeterminación & $\begin{array}{l}\text { F21.1 ¿Hasta qué punto tiene usted la } \\
\text { oportunidad para (elegir) actividades de ocio, de } \\
\text { realizar ejercicio físico o actividad deportiva? }\end{array}$ & Bienestar material \\
\hline
\end{tabular}

Para comprender la Tabla 2 es importante señalar que la Organización Mundial de la Salud (WHO por sus siglas en inglés) elaboró un primer instrumento para la medición de la calidad de vida aplicable en distintas partes del mundo, al que se lo llamó WHOQOL-100, que era un cuestionario genérico que contenía 100 preguntas, organizadas en 24 facetas con 4 preguntas por cada una, más 4 preguntas generales sobre una percepción global de la calidad de vida y la salud de la persona en estudio. El instrumento cubría 6 grandes áreas o dominios de la calidad de vida. Los códigos incluidos junto a las preguntas, hacen relación a las facetas a las que corresponden; y el número de pregunta dentro de esa faceta. Un segundo instrumento fue el WHO Quality of Life-BREF (WHOQOL-BREF), que es una versión abreviada del WHOQOL-100.

Por otro lado, siguiendo lo propuesto en (M. A. Verdugo Alonso et al., 2009), se han considerado las dimensiones Inclusión social y Derechos en el modelo operativo de calidad de vida, que no existen en WHOQOL, pero que aportan para comprender la situación del adulto mayor. Los códigos para identificar los factores considerados en la medición han sido creados por el tesista. 


\begin{tabular}{|c|c|c|}
\hline $\begin{array}{l}\text { Dimensiones consideradas en } \\
\text { el modelo operativo de calidad } \\
\text { de vida }\end{array}$ & $\begin{array}{l}\text { Factores que se consideran en } \\
\text { la medición de cada una de las } \\
\text { dimensiones }\end{array}$ & $\begin{array}{l}\text { Dominios del instrumento } \\
\text { WHOQOL-BREF diseñado por la } \\
\text { Organización Mundial de la } \\
\text { Salud }\end{array}$ \\
\hline \multirow{3}{*}{ Inclusión social } & $\begin{array}{l}\text { I1.1 ¿Qué tan satisfecho está con } \\
\text { su integración y participación en la } \\
\text { comunidad? }\end{array}$ & \multirow{4}{*}{ No existen dominios } \\
\hline & $\begin{array}{l}\text { I1.2 ¿Hasta qué punto siente usted } \\
\text { que es una persona útil y valorada } \\
\text { por los grupos comunitarios en los } \\
\text { que participa? }\end{array}$ & \\
\hline & $\begin{array}{l}\text { I1.3 ¿Dispone de redes de apoyo y } \\
\text { ayuda necesaria de grupos y } \\
\text { servicios cuando lo necesita? }\end{array}$ & \\
\hline Derechos & $\begin{array}{l}\text { D1.1 ¿Hasta qué punto siente } \\
\text { usted que le han tratado con } \\
\text { discriminación, desconociendo e } \\
\text { irrespetando sus derechos } \\
\text { humanos y legales? }\end{array}$ & \\
\hline
\end{tabular}

\subsection{Aceptación, uso y apropiación de tecnología}

\subsubsection{Introducción:}

Las TIC han penetrado actualmente en casi todos los aspectos de la sociedad, y las personas las usan en diversos contextos. Sin embargo, la realidad evidencia que no todos los AM han tenido la oportunidad de estar en contacto directo con las tecnologías actuales; y que existen circunstancias particulares de cada uno que determinarían su posición y actitud inicial frente a ellas. Para comprender que aspectos determinan la actitud frente a las tecnologías basadas en Internet, la decisión de usar esas tecnologías y el llegar a hacerlas parte de su vida como medios de comunicación efectivos, se ha considerado que las teorías y modelos de adopción y aceptación de tecnología proveerían las pautas a tomar en cuenta para aproximarse a la comprensión antes señalada.

Hay varias posturas que pueden adoptar las personas frente a la tecnología, conceptualizadas por varios autores:

- Resistencia a la tecnología: según (Durodolu, 2016): "a pesar de todos los beneficios del uso de las nuevas tecnologías, un gran número de investigadores atestigua el hecho de que las personas han desarrollado una resistencia al uso de tecnología moderna [...] la resistencia a la tecnología ilustra una reticencia a adoptar una iniciativa, percepción, idea y acción u oponerse a circunstancias adversas. Por lo tanto, es importante que se comprenda la razón de la resistencia de los individuos para comprender el comportamiento resistente y encontrar una salida... los diversos niveles culturales, tecnológicos, pueden ayudar a la adopción y el rechazo de nuevas tecnologías. Una posible solución es ofrecer instrucción y capacitación adecuadas sobre el uso de la tecnología y la aplicación a situaciones de la vida real orientadas a superar la causa de la resistencia."

- Tecnofobia: (Durodolu, 2016) se refiere a esta disposición emocional de la siguiente forma: "El miedo a las nuevas tecnologías es un sentimiento de ansiedad relacionado con la 
introducción de nuevas tecnologías. Aquellos que están abrumados por un sentimiento de angustia o ansiedad cognitiva les resulta difícil adoptar el uso de la tecnología moderna, que es común en el siglo XXI debido a la popularidad de la tecnología aplicada a todos los aspectos de la vida humana. Este sentimiento de insuficiencia se refleja en nerviosismo y sentimiento constante de insatisfacción y aprensión."

- Aceptación de la tecnología: según (Renaud \& Van Biljon, 2008): “La aceptación es una actitud hacia una tecnología." (Venkatesh, 2003) precisa: "La actitud hacia el uso de la tecnología se define como la reacción afectiva general de un individuo a usar un sistema [...] tiene que ver con el gusto, el disfrute, la alegría y el placer de un individuo asociado con el uso de la tecnología."

Una actitud, puede ser positiva o negativa, y puede predecir la intención de conducta de uso de la tecnología. No significa una seguridad absoluta que se dé la conducta de uso de la tecnología cuando la actitud es positiva; ni tampoco representa una decisión absoluta de no uso de la tecnología, si la actitud es negativa. Esto se debe a que una actitud puede ser modificable, debido a la influencia de factores externos, durante el período de tiempo que transcurre desde que se construye la actitud hasta el momento en que se ejecuta la conducta.

- Adopción y uso efectivo de la tecnología: para (Renaud \& Van Biljon, 2008) "la adopción de tecnología es un proceso: comienza con que el usuario toma conciencia de la tecnología, la acepta y termina abrazando la tecnología y haciendo uso completo de ella."

(Durodolu, 2016) señala que "el uso efectivo de la tecnología requiere una integración adecuada para hacerla más productiva y fomentar su desarrollo, lo que también implica la utilización adecuada de los recursos y la tecnología que promueve su uso."

- Apropiación de la tecnología: según (Casamayou \& Morales González, 2018): “apropiarse de las TIC implica para personas o colectivos hacer propias, incorporar de acuerdo a las propias necesidades e intereses las tecnologías en la vida cotidiana produciendo transformaciones".

\subsubsection{Factores que influyen en la aceptación, adopción - uso, y apropiación de tecnología de comunicación}

Para iniciar la comprensión de los factores que influyen en el uso de tecnologías por parte de las personas, se presentan a continuación, tres elementos a considerar: la teoría de la presencia social, la teoría de usos y gratificaciones, y, la brecha digital y la apropiación de las TIC.

\subsubsection{Teoría de la presencia social}

Esta teoría es la base para comprender el éxito de la red social Facebook, y de muchas otras aplicaciones que permiten la interconexión ubicua entre las personas mediante múltiples medios: visuales, auditivos, imágenes, textos; de formas sincrónicas y asincrónicas, y más.

En estas aplicaciones interactivas, las personas perciben a sus interlocutores cerca y con influencia directa sobre su estado emocional, en muchas ocasiones les hace vivir, con naturalidad, la espontaneidad de las manifestaciones que aparecen durante los momentos en que se desarrolla la comunicación. Esto es lo que se conoce como presencia social del medio de comunicación.

Procurando encontrar una definición formal de la presencia social, se revisaron las publicaciones de (Achilleos et al., 2013), (Animesh et al., 2011), (Lu \& Fan, 2016), (Chen et al., 2014), (Dasgupta, 2010) y (Keil \& Johnson, 2000), encontrándose que no existe una definición única, por lo que, integrando y 
sintetizando las diversas definiciones y comentarios encontrados en esas publicaciones, se plantea la siguiente caracterización en la que la mayoría de los investigadores coincidirían:

1. La presencia social de un medio de comunicación es un atributo que determina el grado en que permite que las personas que se comunican e interactúan a distancia perciban un comportamiento humano realista, mediante la transmisión del lenguaje acústico - verbal; y el lenguaje visual - no verbal para observar expresiones faciales, posturas, gestos; con los cuales los interlocutores tienen la sensación de contacto humano o proximidad psicológica, sociabilidad y sensibilidad; es decir, como si estuvieran presentes.

2. Los medios de comunicación no tienen los mismos niveles de aportación de presencia social. Aquellos que incluyen video en el servicio de comunicación ofrecen mayor presencia social a los interlocutores que si la comunicación solamente emplea audio; y mucho más que si la comunicación se cumple a través de textos.

3. El nivel de presencia social ofrecida por los medios de comunicación, así como el acceso ubicuo, son factores determinantes del uso cotidiano por parte de las personas. En el caso particular de los AM, tomando en cuenta su sensibilidad ante la presencia de sus familiares y amigos; los dos factores señalados adquieren gran interés.

4. La presencia social, provee lo que (Moser et al., 2011) llama "implicación psicológica", esto es el conocimiento de las emociones y actitudes que revelan, con mayor fidelidad, los pensamientos exteriorizados verbalmente por la otra persona con la que establece comunicación, alcanzando lo que el mismo autor señala como "co-presencia", es decir, un contacto cálido y emotivo, que le aporta un sentimiento de pertenencia a alguien, les aleja de la sensación de soledad, y validan su inclusión familiar y social; para finalmente sentir que los participantes en la conexión virtual mutuamente afectaron sus comportamientos, lo que (Moser et al., 2011) nombra como "compromiso de comportamiento".

\subsubsection{Teoría de usos y gratificaciones}

El enfoque de la teoría de usos y gratificaciones (U\&G) según plantea (Bosch \& Currin, 2015): "es apropiado cuando el propósito es comprender por qué y cómo la gente elige medios específicos para satisfacer necesidades especificas"; y se ha aplicado con las redes sociales, según (Jung \& Sundar, 2016) "para explicar por qué las personas usan ciertas redes sociales y qué gratificaciones reciben de dicho uso. Especificamente, la teoría de U\&G asume que los usuarios tienen libre albedrío para seleccionar los medios de su elección, y la gratificación que buscan impacta su uso real de los medios."

Integrando las propuestas de la teoría de U\&G y de la teoría de selectividad socioemocional, se concluye que el AM haría uso de la tecnología solo si con ello satisface una necesidad emocional. Por lo tanto, en esta investigación, es importante identificar las necesidades particulares de los AM que podrían ser satisfechas con el uso de Facebook, más otros beneficios potenciales que la red social le podría brindar a la calidad de vida del AM; para con esos hallazgos sensibilizarles a los AM hacia el uso de la red social Facebook.

\subsubsection{La brecha digital y la apropiación de las TIC}

La brecha digital es la desigualdad que experimentan las personas, en las oportunidades de acceso a las TIC, lo que les dificulta o impide su aprovechamiento.

En el caso de los AM, las causas que pudieron haberlos mantenido al margen del contacto con la tecnología son diversas. Por ejemplo: su año de nacimiento, el lugar en que desarrolló su juventud y 
adultez, su nivel de educación, su estatus socio-económico, el tipo de actividades productivas en que se desempeñó; sus creencias; y otras más como las expuestas por(Casamayou \& Morales González, 2018): "la ausencia de una necesidad que dé impulso motivacional; el desconocimiento de ese tipo de tecnología y la falta de ayuda."

Con relación a la brecha digital, (Gómez Navarro et al., 2018) presenta un análisis interesante con una perspectiva hacia la apropiación de tecnología, en el que considera que la brecha digital se exhibe en tres niveles principales:

1) El acceso propiamente dicho, que engloba tres componentes:
a. acceso motivacional,
b. acceso físico o de infraestructura tecnológica,
c. acceso a habilidades digitales.

2) El uso simple de la tecnología, que tiene que ver con los primeros contactos con las TIC disponibles, o el análisis de las posibilidades de adquirir otras, probar los equipos para acceso a los servicios en procura de desarrollar habilidades y destrezas, y descubrir las afinidades reales con la tecnología.

3) La apropiación social de la tecnología, que se vislumbra cuando el uso de la tecnología se presenta en actividades cotidianas que fomentan el desarrollo social, económico y cultural del usuario, e inciden en su calidad de vida.

Esta propuesta que se ha esquematizado en la Fig. 4, resulta atrayente en la forma y el orden en que se proponen los tres componentes de la brecha digital de acceso, porque se entiende más como una propuesta de ruta para dejar atrás la brecha digital, y lograr el acercamiento necesario que induce hacia un contacto inicial de uso de las TIC, que posteriormente puede hacerse significativo y transformador cuando alcance la apropiación social de la tecnología.

Aprovechando la perspectiva del primer nivel de brecha digital planteada por (Gómez Navarro et al., 2018), y con la mente puesta en el proceso evolutivo de apropiación de tecnología que se propone en la siguiente sección, se puede conformar una etapa de sensibilización hacia la tecnología, muy necesaria como etapa previa al proceso propiamente dicho de apropiación de tecnología. 


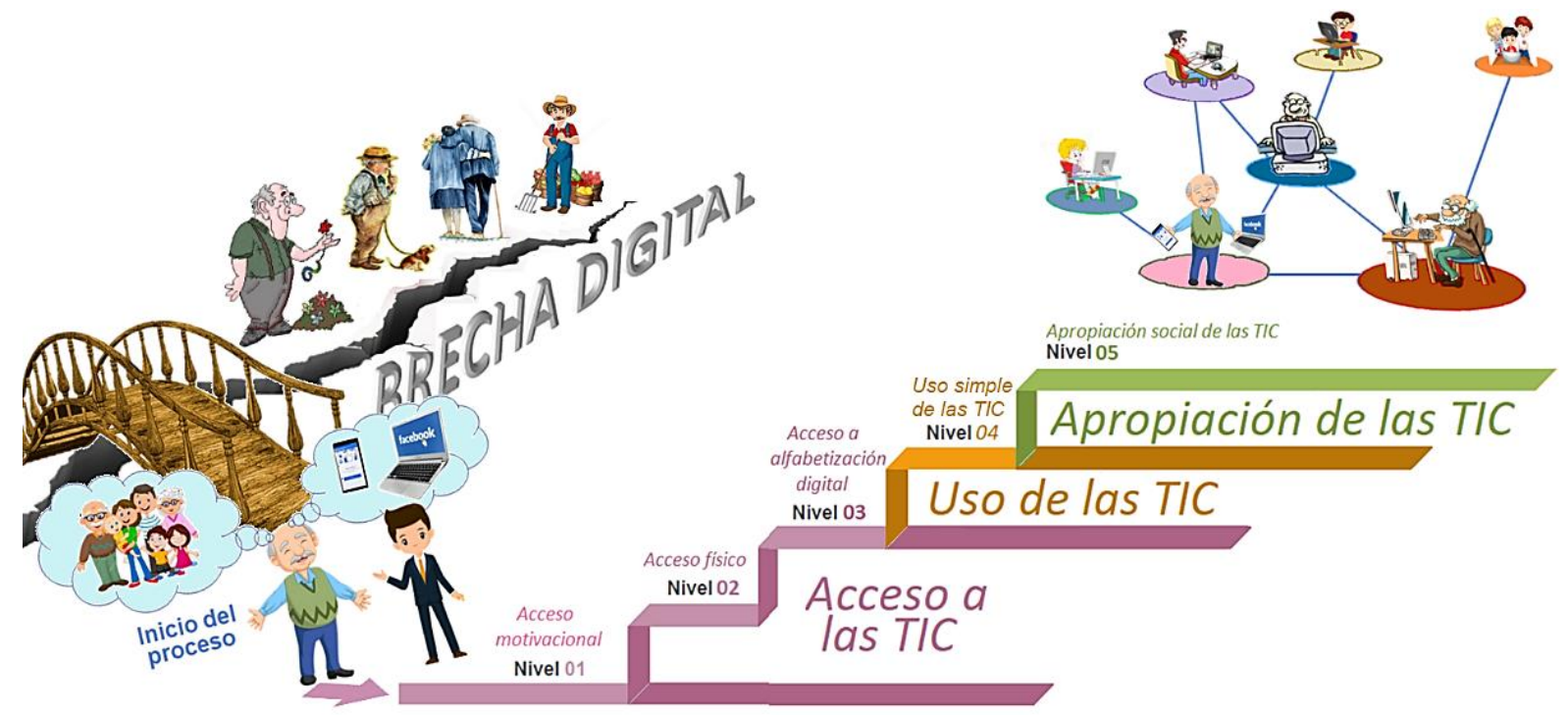

Fig. 4 Niveles principales de brecha digital

Esta etapa de sensibilización, transcurre por influencia familiar y social. En primera instancia, la persona debe recibir estimulación hacia el uso de la tecnología, en la que se le proveería de todos los beneficios potenciales para su calidad de vida, contrastando con la situación actual particular, es decir se le ayuda a identificar al menos una motivación significativa.

A continuación, el AM debe recibir una descripción del proceso de acceso físico completo, incluyendo la tecnología propia y contratada que debería disponer. También, se le debe informar de los costos que conlleva el acceso físico, y las alternativas para cubrirlos. Finalmente, se le tiene que brindar una explicación de carácter informativa, con visión optimista sobre las habilidades, destrezas y conocimientos que debería disponer, procurando no crearle barreras mentales.

El proceso y la información manejada en esta etapa de sensibilización, bien puede llamarse Modelo de sensibilización del AM hacia el uso y apropiación de la tecnología.

\subsubsection{Modelo teorizado de proceso evolutivo hacia la apropiación de tecnología}

\subsubsection{Presentación del modelo}

A continuación, se propone un modelo de proceso evolutivo hacia la apropiación de tecnología, que una persona seguiría fuera de un contexto organizacional, que se ha teorizado a partir de la comprensión de los diferentes significados y alcances que les corresponden a los términos aceptación de tecnología, adopción de tecnología, y apropiación de tecnología; que se expusieron en los párrafos anteriores.

Este modelo teórico, integra conceptualizaciones de los siguientes modelos de aceptación de tecnología:

1. TAM (Technology Acceptance Model - Modelo de aceptación de tecnología), descrito en (Venkatesh \& Bala, 2008) y (Durodolu, 2016);

2. UIT (Modelo de Utilización de la Tecnología de la Información), analizado en (López-Bonilla \& López-Bonilla, 2011)

3. TAM2, presentado en (Bradley, 2009); 
4. TAM3, desarrollado en (Venkatesh \& Bala, 2008) y (Oturakci \& Oturakci, 2018);

5. STAM (Senior Technology Acceptance \& Adoption Model - Modelo de adopción y aceptación de tecnologías por el AM), explicado en (Renaud \& Van Biljon, 2008);

6. UTAUT (Unified Theory of Acceptance and Use Of Technology - Teoría Unificada de Aceptación y Uso de Tecnología para el contexto empresarial), detallado en (Ahmad, 2014), (Venkatesh et al., 2016), (Venkatesh, 2003);

7. UTAUT2 (Teoría Unificada de Aceptación y Uso de Tecnología para el contexto del consumidor), propuesto en (Venkatesh, 2012);

8. LUM (Lazy User Model - Teoría del Usuario Perezoso), descrito en (Tétard \& Collan, 2009); y,

9. el modelo de apropiación de tecnología expuesto en (Casamayou \& Morales González, 2018) y (Casamayou, 2016).

En el modelo de proceso evolutivo hacia la apropiación de tecnología, esquematizado en la Fig. 5, se muestran las distintas etapas, y se identifican por figuras y colores, los constructos tomados de los diferentes modelos de aceptación y uso de tecnología, así como también los aportes propios del tesista. Las definiciones de los constructos del modelo propuesto se corresponden con aquellas definiciones de los respectivos modelos originales que los contenían. 


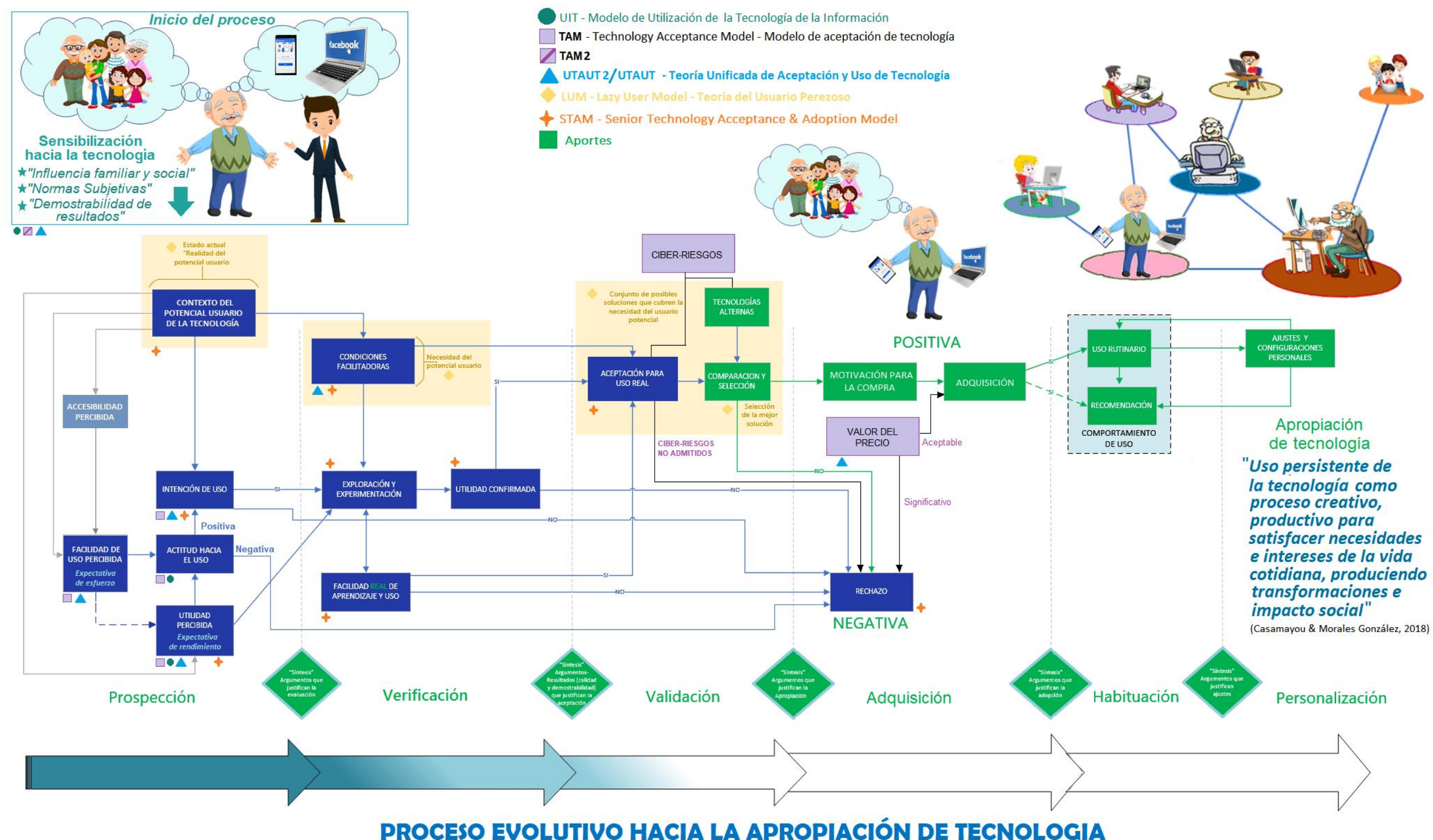

Fig. 5 Proceso evolutivo hacia la apropiación de tecnología 


\subsubsection{Explicación de las etapas del proceso}

Las explicaciones de cada una de las etapas del proceso evolutivo hacia la apropiación de tecnología que se presentan a continuación, se basan en las definiciones de cada uno de los constructos dados en los respectivos modelos que apoyaron el desarrollo del proceso propuesto, que para una mayor comprensión, son ejemplificadas con algunas situaciones hipotéticas, correspondientes al caso de un AM que pretenda desarrollar el proceso evolutivo hacia la apropiación de la tecnología de Facebook.

\subsection{Sensibilización hacia la tecnología}

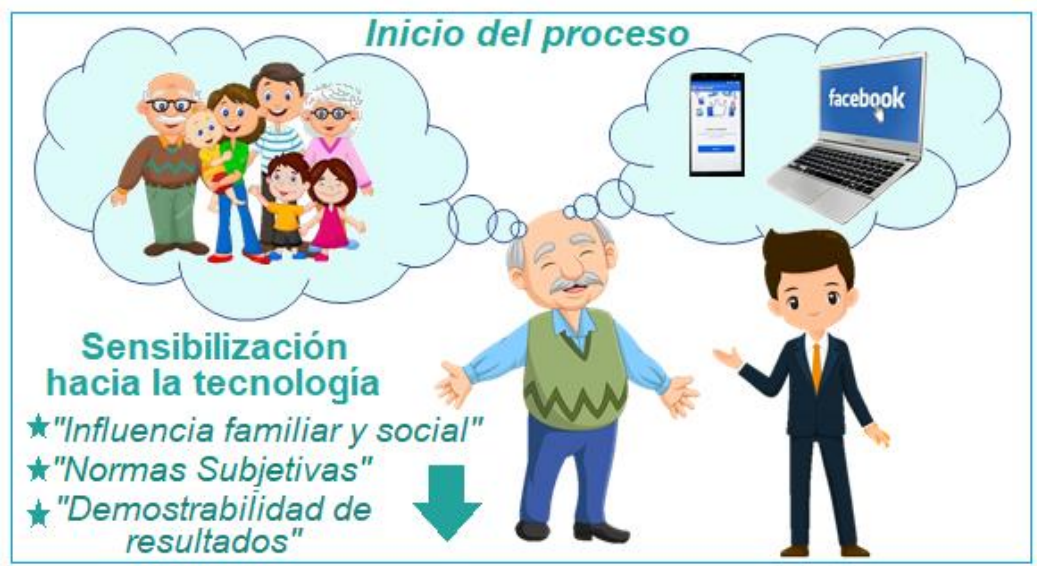

Fig. 6 Etapa previa - Sensibilización hacia la tecnología

En esta etapa, Fig. 6, previa al proceso evolutivo de apropiación de tecnología, el AM recibiría de personas de su confianza, que comprenden su situación de vida actual y que tienen claros los beneficios potenciales que el uso de la tecnología de red social Facebook le puede acarrear a la calidad de vida del AM, la información necesaria para sensibilizarle al AM hacia el uso de esa tecnología en su beneficio.

Comenzarán por señalarle que se verá favorecida su inclusión familiar y social, con contactos más frecuentes, con compartición de diversos tipos de materiales multimedia, con la posibilidad de que se le facilitaría encontrar información variada, que podrá compartir su información e inquietudes aprovechando el acceso ubicuo (sin limitaciones de tiempo, horario y distancia geográfica), con servicios que le favorecerían el acceso a entretenimiento en su tiempo libre así como de actividades de ocio; correlacionando su actual situación con la nueva situación posible con el uso de la tecnología, pretendiendo despertar el interés del AM por la tecnología y la identificación de una motivación clara que le decida al AM a tomar el reto de superar sus limitaciones actuales por los beneficios descubiertos en esta sensibilización.

Se tratará de eliminar las creencias que le podrían estarle creando barreras mentales al AM para acercarse al uso de la tecnología, como creer que tiene una edad muy avanzada como para aprender el manejo de tecnología, o que hasta ahora ha vivido sin tecnología y puede continuar viviendo así el tiempo que le quede por vivir, ayudándole a mejorar su autopercepción.

En esta etapa el AM recibe, lo que en TAM 2 se conoce como las normas subjetivas, es decir, la opinión de las personas cercanas a él, respecto a cómo lo verían los demás utilizando la tecnología. Y así también se verifica, lo que se muestra en UTAUT, que la influencia familiar y social, tiene que ver con la intención de uso. 


\subsection{Prospección}

Esta etapa, está conformada por 6 fases como se observa en la Fig. 7.

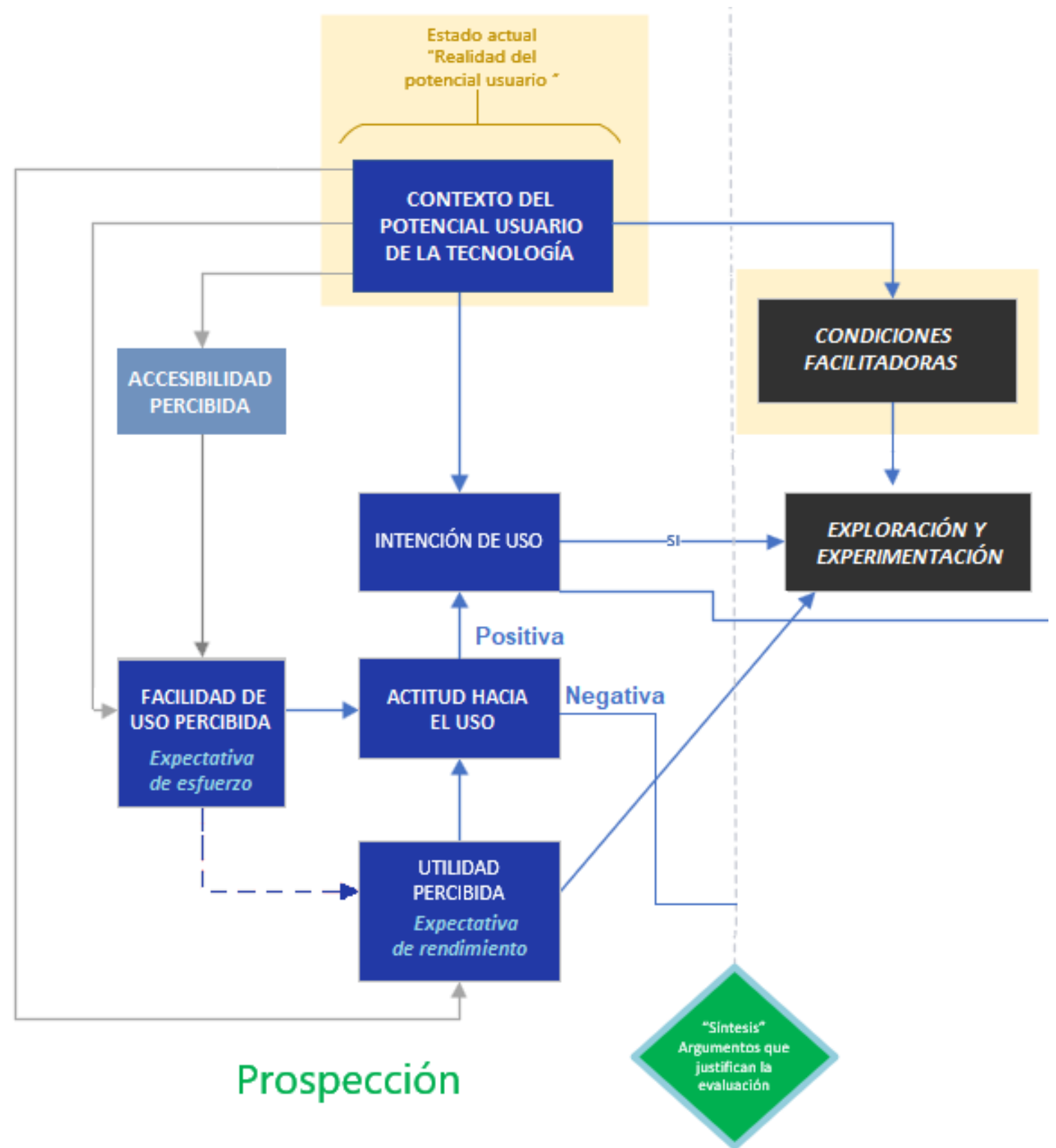

Fig. 7 Etapa de prospección

1. Identificación del estado actual o de la realidad del potencial usuario de la tecnología - Análisis del contexto

En esta fase, el AM, hace un análisis de sus contextos fisiológicos, cognitivos, sociológico y económico, su nivel de alfabetización informática, para identificar las circunstancias de su realidad: nivel de conocimientos, experiencia previa con el manejo de tecnología, determina sus necesidades actuales, y las motivaciones que tiene para iniciar con la exploración de la tecnología que se le está proponiendo que use. 


\section{Accesibilidad percibida}

En esta instancia se analiza la posibilidad de acceso que el AM tiene, deberá considerar la disponibilidad de todo lo que requiere para acceder al servicio tecnológico de Facebook: acceso a Internet mediante contrato con un ISP; un computador o teléfono inteligente; nivel de conocimiento requerido, disponibilidad de ayuda de confianza para la solución de problemas, disponibilidad de recursos económicos.

3. Facilidad de uso percibida

Basado en sus reales facultades cognitivas y orgánicas, en su nivel de conocimientos disponibles y su experiencia previa con tecnologías, estima subjetivamente la facilidad de uso de la tecnología en análisis, considerando la complejidad o simpleza del manejo del equipo con el que se conecta a Internet y de la interface de usuario con que se accede al servicio; $y$, la sencillez o dificultad de solucionar problemas.

4. Utilidad percibida

En esta fase, hace una valoración subjetiva sobre sus necesidades actuales frente a las funciones, presencia social y beneficios que le ofrece la tecnología que se le está proponiendo, para estimar el grado posible de satisfacción de las necesidades actuales que lograría con la tecnología si se decidiera a usar, sin dejar de lado el nivel de esfuerzo que le significaría alcanzar el dominio necesario para realmente alcanzar los resultados esperados.

Además, para que el AM tenga una percepción completa de la utilidad, conviene que conozca también todos los beneficios potenciales que le puede brindar el uso de Facebook, más allá de los que cubren sus necesidades inmediatas, por ejemplo: mejora de sus funciones cognitivas y motoras finas, opciones de entretenimiento para mejor aprovechamiento de su tiempo libre, acceso fácil a información variada, capacidad de generar y difundir su propio material.

Estos beneficios potenciales adicionales a los que se ha hecho referencia, es lo que en TAM se conoce como motivaciones extrínsecas, es decir, resultados extras que se presentan luego de satisfacer la necesidad primaria, que en TAM se le llama motivación intrínseca. Estos beneficios deben ser evidenciados de manera que el AM se convenza de la existencia real de tales beneficios, para lo cual se pueden acudir a publicaciones resultantes de investigaciones, a experiencias y observaciones en personas cercanas; con lo cual se estaría poniendo en práctica la variable demostrabilidad de resultados y la calidad de los resultados que según TAM 2 influye en la utilidad percibida.

5. Actitud hacia el uso

El AM, teniendo siempre presente su situación actual y el claro deseo de mejorarla con apoyo de la tecnología que se le está ofreciendo, se forma un criterio, basado en las percepciones in iciales alcanzadas respecto a utilidad y facilidad de uso, que puede ser positiva o negativa. Si es positiva, entonces, se genera la intención o predisposición para el uso de la tecnología; caso contrario, se descarta la tecnología.

6. Intención de uso

En esta fase, se realiza la síntesis de la etapa de prospección; y se establecen los argumentos que justifican entrar en la siguiente etapa. 


\subsection{Verificación}

Esta etapa de 4 fases como muestra la Fig. 8, tiene como objetivo confirmar la utilidad de la tecnología para solventar la necesidad específica que le motivó a la persona a acercarse a dicha tecnología.



Fig. 8 Etapa de verificación

1. Condiciones facilitadoras

Las condiciones que facilitan al AM a convertirse en usuario de Facebook, incluyen aspectos del contexto tecnológico, y del contexto personal del AM que le ayudan a superar barreras mentales; entre las que se pueden incluir:

a) Ubicación geográfica de su residencia para disponer potencialmente del acceso a Internet.

b) Tiempo para invertir en el aprendizaje del uso de la tecnología.

c) Disponibilidad económica para solventar el acceso a Internet.

d) Disponibilidad de computador o teléfono inteligente, o la posibilidad económica de adquirir alguno de esos equipos.

e) Experiencia en el uso de la tecnología.

f) Una motivación o gratificación esperada.

g) Disponibilidad de ayuda y soporte de confianza para contrarrestar las limitaciones cognitivas y físicas asociadas con la edad.

h) Influencia familiar - social positiva.

i) Compromiso familiar - social que asegure la interacción frecuente con respuestas permanentes a los comentarios e inquietudes del AM. 
2. Exploración y experimentación

Tiene que ver con la demostración de la satisfacción de alguna necesidad actual del AM a través del uso de la tecnología en análisis, principalmente que tenga que ver con un aspecto emocional significativo; realizada por parte de alguna persona de confianza del AM, que le da una evidencia inicial de las posibilidades básicas que le ofrece Facebook; y le animan a la experimentación.

Esta fase es importante porque "el usuario comienza a usar la tecnología por primera vez y forma las primeras impresiones de la facilidad [real] de uso. Tenga en cuenta que la experiencia obtenida aquí retroalimentará la utilidad confirmada." (Renaud \& Van Biljon, 2008)

En esta etapa de exploración es conveniente no abrumarle al AM con funcionalidades complejas, que le confundan y le generen rechazo a realizar la experimentación individual.

También será importante demostrarle al AM, las opciones de equipos que tiene para usar la red social Facebook; para que él determine con cual siente mayor comodidad y percibe mayor facilidad de uso.

3. Facilidad real de aprendizaje y uso

Una vez que el AM se decide por la experimentación en el equipo que percibió mayor comodidad y facilidad, en esta fase evalúa el nivel real de esfuerzo personal que le corresponde hacer para lograr satisfacer la necesidad actual con el uso de la tecnología, se centra en aprender únicamente las funciones básicas del servicio con las que resuelve su necesidad y emite un criterio de valor personal respecto de la facilidad real de aprendizaje y uso.

Es importante notar que la facilidad o dificultad que el AM tenga con el uso del equipo con que accede al servicio de Facebook, así como con la interface de usuario que ofrece Facebook, son determinantes en la decisión final de confirmar la utilidad, y en la aceptación o el rechazo de la tecnología.

4. Utilidad confirmada

Es la determinación que el equipo escogido para acceder al servicio de Facebook y el servicio propiamente dicho, cubrieron las expectativas de satisfacción emocional y esfuerzo con la forma de cubrir la necesidad actual y reconoce que le puede seguir sirviendo en los días venideros.

En esta fase el AM confirmó que aprendió a utilizar las diferentes funciones básicas, y mantiene expectativa por el uso de otras funciones aún no empleadas, que podrían brindarle otras emociones y satisfacciones.

\subsection{Validación}

La ubicación de esta etapa en el proceso evolutivo hacia la apropiación de tecnología, está influenciada por la cultura de consumo ecuatoriana. Haciendo una síntesis a (Ron Revelo, 2016), se puede afirmar que el consumidor ecuatoriano, en lo que va del siglo XXI, se caracteriza por:

1. Preferir realizar sus gastos de contado.

2. Ser un consumidor tradicional que tiene una conducta de consumo determinada por las necesidades básicas. Demanda con mayor frecuencia en la canasta de compra, los bienes y servicios que se encuentran en tres sectores: la vestimenta, el calzado y los alimentos que incluye bebidas no alcohólicas. 
3. No poseer un conocimiento perfecto de sus necesidades, ni tampoco conocer aquellos productos que servirían para satisfacerlas, excepto los de la canasta básica de compra.

4. Incorporar a la influencia de la familia en la toma de decisiones, en sustitución a la antigua costumbre de hacerlo individualmente.

5. Tener una nueva conducta en la que incide la presencia de la información. Ha dejado de ser impulsivo y se ha convertido en alguien más moderado y reflexivo. Esta actitud se desarrolló al inicio de este siglo, a raíz de la dolarización, los avances tecnológicos, sobre todo el acceso al internet, y otros factores económicos como los precios petroleros.

6. Ser un consumidor más exigente y con mayores habilidades para conectarse y conseguir cualquier producto.

7. Consumir en función de la mayor utilidad que proporcionan los distintos bienes y servicios al satisfacer sus necesidades y sus expectativas.

8. Estar envuelto en el conflicto de saber cuándo tomar la decisión acertada de gasto. Sus temores de errar en la compra son cada vez más frecuentes. En consecuencia, solo desea obtener un mayor beneficio percibido por su consumo. Al enfrentar mayores razones de utilidad tarda más en elegir. Lo cual es connatural al acertado proceso de valoración antes de comprar.

9. Dejarse llevar por la opción que surge como mejor oferta, aun cuando se trate de un producto sin experiencia de consumo histórico.

10. No saber manejar el dólar, redondear precios, dar poco interés al cambio en centavos.

La validación es una etapa de 3 fases, representada en la Fig. 9, en la que se analizan todas las alternativas tecnológicas existentes para satisfacer la misma necesidad actual del AM. Toma en cuenta que todas las alternativas están sujetas a ciber-riesgos, y se compara con la tecnología que la persona acaba de verificar la utilidad.

1. Aceptación para uso real

Es la fase donde se recopilan las experiencias positivas de la etapa de exploración: se ha confirmado la utilidad, realmente hay facilidad de aprendizaje y de uso, y efectivamente existen condiciones facilitadoras.

En esta etapa es conveniente que se consciencie al AM de los ciber-riesgos (Variable externa), sus causas, sus consecuencias, y se oriente la forma de evitar su exposición. Si el AM acepta su participación en un entorno con amenazas, tomando las precauciones necesarias, entonces se acepta para uso real.

2. Tecnologías alternas

El AM indaga por las otras opciones tecnológicas del conjunto universo de soluciones que podrían ser aplicadas para satisfacer la misma necesidad actual, en lo que tiene que ver a las características operativas, los equipos complementarios que se requieren para acceder al servicio, los ciberriesgos que les amenazan, y las contrasta con sus circunstancias particulares actuales de vida, para conformar el subconjunto de posibles soluciones que se ajustan a su estado actual; de las cuales seleccionará la solución que exija el menor esfuerzo. 
La estimación subjetiva del esfuerzo se hace en base a: el tiempo utilizado en alcanzar un manejo satisfactorio de las funciones de la tecnología, el dinero requerido para acceder al servicio, el esfuerzo mental necesario, y el conocimiento mínimo necesario; coincidiendo con lo planteado en la teoría del usuario perezoso. El esfuerzo será menor si el AM tiene experiencia en el uso de tecnología, o ya dispone de dispositivos para acceder al servicio.

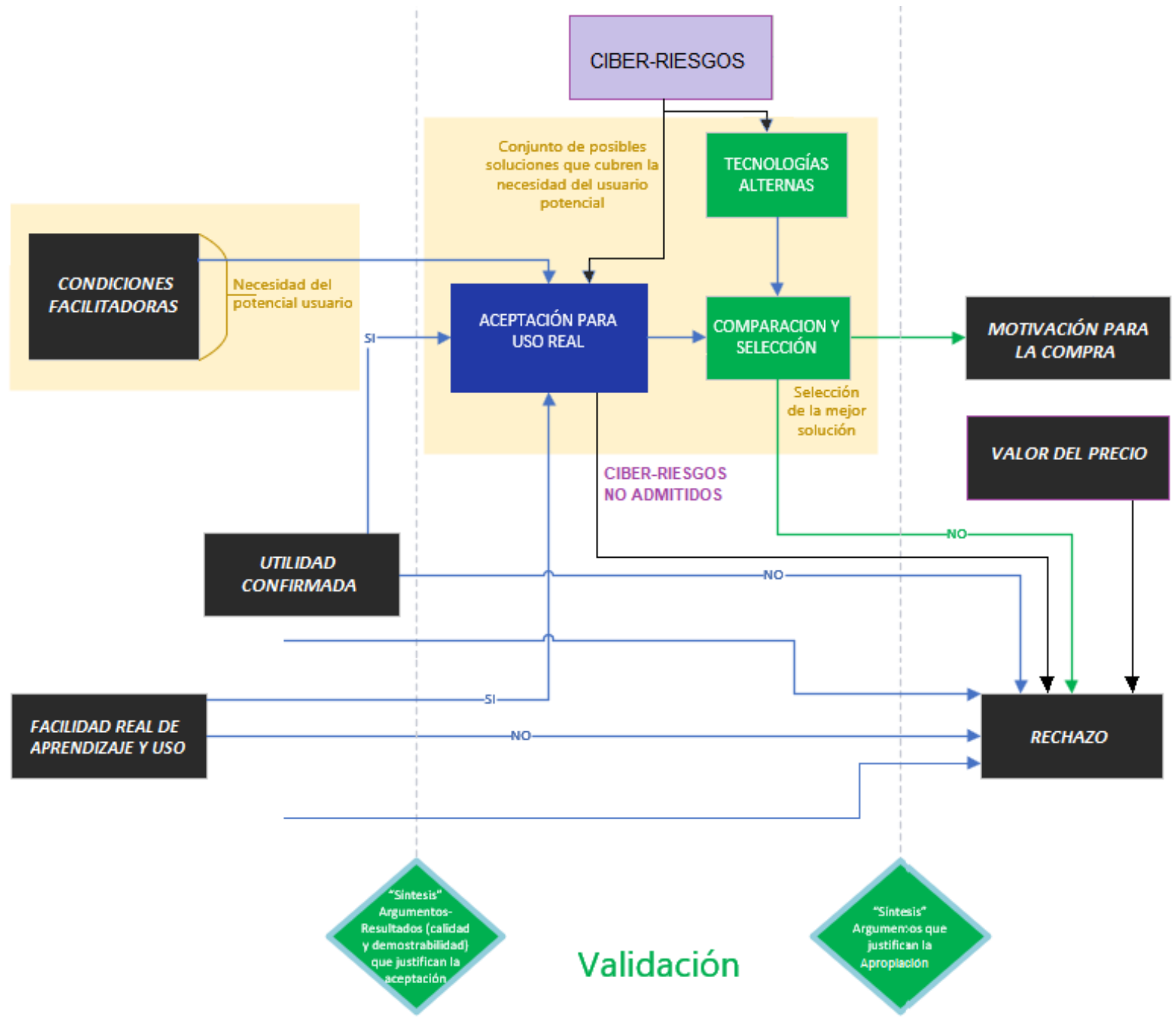

Fig. 9 Validación

3. Comparación y selección

Se realiza la comparación de la tecnología experimentada con la información de las otras tecnologías alternas. Pero en esta fase no solamente se debe realizar un análisis de corto alcance, sino que es importante tomar en cuenta otros aspectos del entorno, como por ejemplo, el AM debe conocer que la red social Facebook es la red más utilizada por miembros de su grupo etario, y que por la tanto, hay altas probabilidades que personas con las que el AM quisiera contactarse o retomar contacto podrían ser usuarias de Facebook y no de otras redes sociales semejantes.

Una vez que se realiza la comparación de amplio espectro, y se reconoce que la tecnología considerada es la mejor opción, incluyendo el análisis de los ciber-riesgos, entonces se pasa a la siguiente etapa. 


\subsection{Adquisición}

En esta etapa de 3 fases como exhibe la Fig. 10, el AM toma la importante decisión respecto a realizar o no la inversión económica en los componentes necesarios para el uso efectivo del servicio tecnológico.

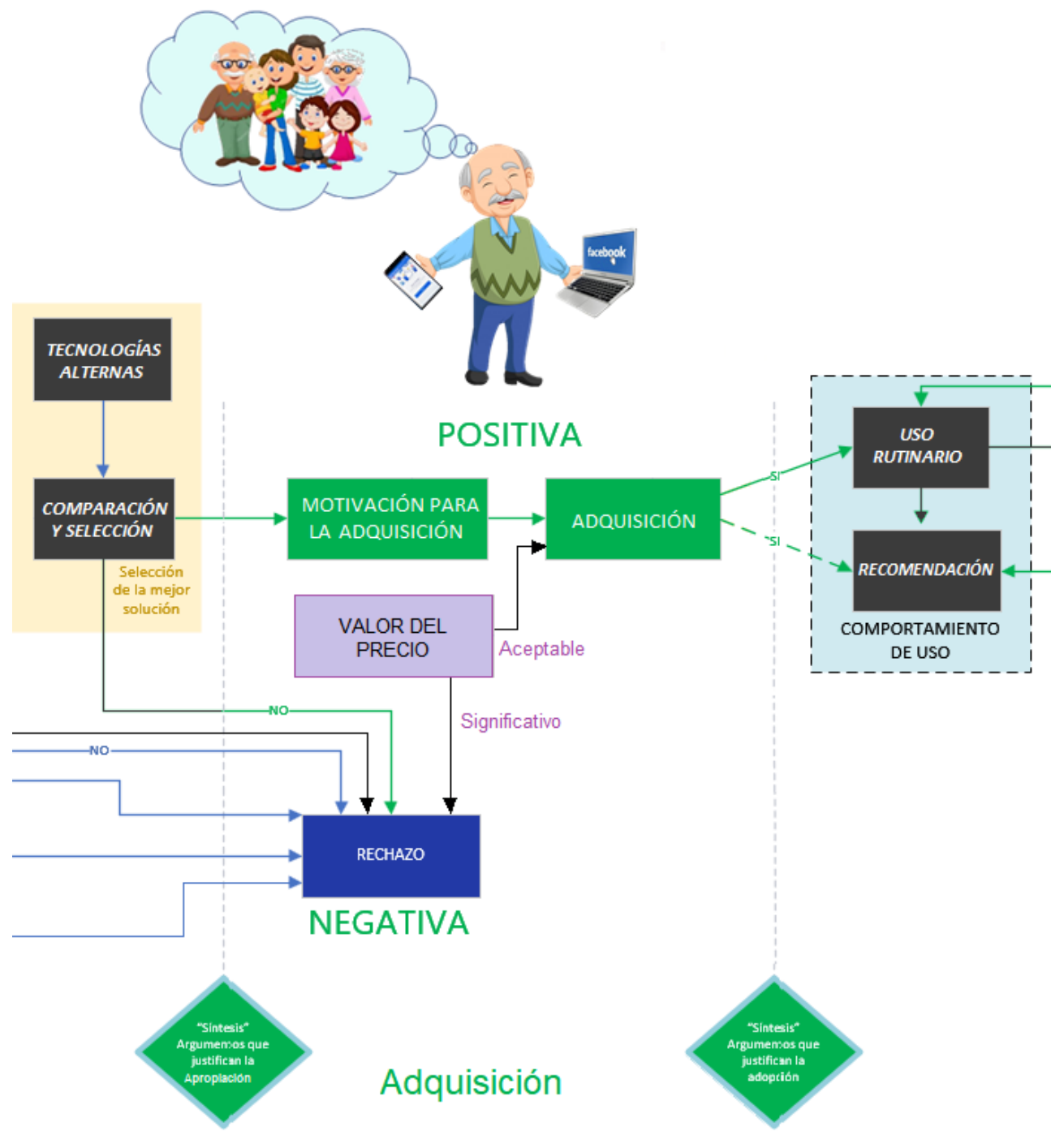

Fig. 10 Adquisición

1. Motivación para la adquisición

Con la certeza que la tecnología seleccionada es la mejor opción para satisfacer su necesidad actual, entonces se tienen claras las razones para realizar la inversión económica necesaria para la adquisición de todos los componentes requeridos para hacer uso efectivo de la tecnología.

2. Valor del precio

"Es bien sabido que las personas mayores consideran gastar con mucho cuidado y el precio de un dispositivo o servicio es un diferenciador para su uso." (Renaud \& Van Biljon, 2008)

Se deben tener claros los siguientes costos: el contrato mensual indefinido de acceso a Internet con el ISP debido a que el acceso a Internet debe ser permanente; el equipo con el que accede al servicio, en caso de no disponerlo, deberá ser comprado una sola vez; $y$, que puede ser necesaria alguna capacitación. 
Con la definición de los costos antes citados, y tomando en cuenta el contexto económico y el contexto tecnológico actual de las TIC del AM, es necesario determinar si el valor del precio (Variable externa) de lo que se requiera para definitivamente acceder al servicio tecnológico está dentro de los alcances económicos de la persona AM, sin el quebranto de su seguridad económica.

Si el valor del precio es aceptable, se continua con la adquisición; caso contrario, se rechaza el uso efectivo de la tecnología y se finaliza el proceso de apropiación de tecnología por falta de recursos económicos del AM.

3. Adquisición

Se legaliza el contrato con el ISP, y, de ser necesario, la compra del equipo: PC y/o teléfono inteligente.

\subsection{Habituación}

En la Fig. 11 se muestran las dos últimas etapas con las que se espera alcanzar la apropiación de la tecnología: la habituación compuesta de las fases: uso rutinario, y recomendación; y la personalización.



Fig. 11 Habituación y personalización 
1. Uso rutinario

El AM, ya disponiendo de la tecnología de acceso al servicio, inicia la etapa de uso rutinario, con el uso de las funciones básicas, con ayuda de alguna persona de confianza, y con el compromiso familiar de ser receptivos a las pruebas y participaciones que el AM desee hacer.

Poco a poco, irá adquiriendo la confianza requerida, ampliando su participación con otras personas fuera del entorno cercano.

Posteriormente empezará a intentar usar otras funciones para lograr mayores beneficios y participaciones.

2. Recomendación

A la par que se habitúa al uso de la tecnología, comienza a recomendar a sus amigos y pares conocidos, para establecer interacciones por ese medio tecnológico.

\subsection{Personalización}

1. Ajustes y configuraciones personales

Cuando el AM tiene el dominio suficiente de las funciones básicas del servicio, inicia la etapa de adecuación a sus intereses particulares, formando grupos de contactos, restringiendo ciertos accesos y comparticiones de información, configurando a su gusto sus niveles de privacidad y seguridad. Al personalizar va creando una mejor experiencia de uso con el servicio, lo que le permite alcanzar la apropiación de la tecnología.

\subsection{Apropiación}

Cuando el AM alcance un suficiente dominio del servicio de Facebook, entonces podrá iniciar la etapa de apropiación de la tecnología de red social Facebook, aportando a los suyos y a su entorno, generando transformación e impacto familiar y social, generando su contenido muy particular con el que proyectará su experiencia y sabiduría.

\subsection{Conclusiones}

En este capítulo se ha enfocado un amplio conjunto de conocimientos que se los ha compilado y organizado para sustentar teóricamente el desarrollo de esta tesis doctoral, que se resumen en los siguientes aspectos:

1. La importancia creciente del segmento poblacional de los AM, prácticamente en todo el mundo, debido al fenómeno del incremento permanente de su cantidad, y su consecuencia en el crecimiento del número de usuarios de Internet y sus servicios de comunicación por parte de miembros pertenecientes a este grupo etario.

2. Existen suficientes razones que fundamentan filosóficamente las investigaciones relacionadas a los AM y la apropiación de la tecnología de red social Facebook, tales como las concepciones históricas optimistas, positivas hacia la vejez; así como también varias de las teorías que enfocan la vejez, las cuales proyectan la idea de las capacidades intactas del AM para continuar con una vida normal, manteniendo contactos sociales significativos con sus familiares cercanos y amigos, a través de las diferentes alternativas que les ofrece el momento histórico en que viven.

Para los AM actuales, el momento histórico en que viven está caracterizado por la presencia de la red social Facebook en el ámbito de las vidas de gran parte de la población mundial de todas las 
edades. Esta red social, según su visión empresarial y la proyección que se puede hacer hacia el bienestar de los usuarios, permitiría a las personas, establecer interacciones sociales virtuales significativas con los miembros de su red familiar-social. En particular a los AM, les podría proveer la riqueza del contacto familiar intergeneracional; lo que traería como consecuencia, el mantenimiento e inclusive elevación de su calidad de vida, un envejecimiento en mejores condiciones emocionales, evitando los múltiples efectos negativos que condiciones de aislamiento social y soledad generan en la persona AM: afecciones a la salud física, a la salud mental y emocional, la reducción de los niveles de apoyo social.

3. Frente a la realidad histórica en que se desenvuelve el $A M$, se ha objetivado la necesidad de promover en el AM, el uso de la tecnología actual como entorno seguro para impulsar su inclusión familiar y social, tomando en cuenta las características de las plataformas tecnológicas de comunicación e interacción virtual, que Internet pone al alcance de todos; de las dimensiones de la calidad de vida de las personas que pueden verse favorecidas con el uso de las TIC; y, de la concepción de la calidad de vida como algo que puede ser mejorado a través de estímulos, como por ejemplo el uso de las redes sociales, en particular Facebook.

4. También, en este capítulo no se ha desestimado el tema de privacidad y seguridad en el entorno de la red social Facebook, porque se ha considerado necesario que el AM tenga conocimiento de los ciber-riesgos a los que están expuestos los usuarios de Facebook, y se proyecte la idea de que no es suficiente solamente el conocimiento de los ciber-riesgos, sino que también es necesario, desentrañar las diversas causas que los originan, e identificar aquellas que son atribuibles a las personas usuarias, con el fin de actuar sobre ellas para mantenerlas bajo control, reducirlas o eliminarlas.

5. Por otra parte, se han analizado algunas teorías tendientes a dar luz sobre las características de las relaciones interpersonales del AM, que permitirían orientar la forma real en que se puede enfocar el aprovechamiento de las características operacionales y funcionales de las plataformas tecnológicas de redes sociales disponibles actualmente, para apoyar el mejoramiento de la calidad de las relaciones interpersonales, mediante interacciones virtuales que pueden darse con mayor frecuencia, mayor duración, con libertad de horarios, con diversidad de medios, y desde la comodidad del hogar de los participantes en la interacción.

Así, la teoría teoría de selectividad emocional permite comprender, que no debería ser una preocupación que el AM, debido a sus horizontes de tiempo, posea un tamaño reducido de sus redes sociales, por cuanto el AM otorga más sentido a las relaciones significativas que le proveen satisfacción emocional, como puede ser el contacto intergeneracional con sus hijos, sus nietos y sus amigos más cercanos. Este tipo de preferencias sociales y relaciones pueden ser mantenidas e incrementadas a través de la tecnología de redes sociales; satisfaciendo también la necesidad de experimentar membresía social con conexión social, postulada en la teoría de pertenencia, y que en el contexto de esta tesis se la llama inclusión familiar y social.

Además, la teoría de usos y gratificaciones permite reflexionar con relación a que el AM usaría le tecnología actual para interacciones virtuales, solamente si a cambio existen gratificaciones por el esfuerzo que representa la superación de algunas de las limitaciones que sufre a causa de la vejez, por lo que induce a la realización, en esta tesis, de una búsqueda exhaustiva de potenciales beneficios de la tecnología de redes sociales para la calidad de vida del AM, procurando abarcar más allá de la dimensión relaciones interpersonales, para que el impacto sea mayor. 
$\mathrm{Y}$, finalmente dentro del contexto en análisis, la teoría de presencia social, aclara las razones por las que estas modernas plataformas de redes sociales han tenido tanto éxito, pues proveen al usuario con diferentes esquemas para compartir mensajes, más las nuevas posibilidades de la persona AM de convertirse en protagonista de sus producciones propias que pueden ser distribuidas a todos los miembros de la plataforma de red social, lo que también proyecta nuevos beneficios de las redes sociales para el bienestar emocional y calidad de vida del AM.

6. Por último, en este capítulo se teorizó un modelo, al que se lo ha denominado, proceso evolutivo hacia la apropiación de tecnología, que partió de la comprensión del significado y alcance de los términos: aceptación de tecnología, adopción de tecnología, y apropiación de tecnología; que sintetiza los conceptos analizados en los diferentes modelos existentes de aceptación de tecnología; más las perspectivas de sistematización propias del tesista; por lo que las definiciones de los constructos del modelo se corresponden con aquellas definiciones de los respectivos modelos originales que los contenían, pero que se los integra con la perspectiva propia del tesista, probablemente influenciada por su cultural nacional, para exponer un proceso evolutivo hacia la apropiación de tecnología que seguirían las personas. 


\section{Capítulo 3 - METODOLOGÍA}

\subsection{Introducción}

Con fundamento en las orientaciones conceptuales encontradas en (Neergaard \& Ulhøi, 2006), en este capítulo se hace referencia a la metodología, el método y las técnicas de investigación que se aplicaron para abordar el estudio de la red social Facebook como entorno seguro de comunicación para inclusión familiar - social del usuario AM para el mejoramiento de su calidad de vida; y siguiendo a (Hernández Sampieri et al., 2010) sobre los diferentes aspectos con que se estructura una investigación cualitativa, también se describe el proceso de investigación cualitativa cumplido.

\subsection{Enfoque metodológico para la investigación}

El enfoque metodológico se seleccionó considerando que un mejor y mayor entendimiento de la realidad se logra cuando la investigación cualitativa se complementa con la investigación cuantitativa y viceversa, criterio que se basó en la reflexión planteada por (Arribas Macho, 1998): "la cualidad no está reñida con la cantidad - nunca lo estuvo -, sino que la precede. La cantidad nunca debió separarse de la cualidad, pues cuando lo hace cae en los mayores absurdos... las cualidades sensibles preceden la cuantificación y tal vez sean lo único que puede darle sentido".

Con apego al criterio anterior, para la investigación de tesis doctoral se estableció, desde el principio, un enfoque metodológico mixto, aunque también se podría considerar que se trata de una metodología de investigación cualitativa llamada en (Gasson, 2009), como Teoría multifundamentada, en la cual el análisis de datos cualitativos puede ser realizado mediante técnicas cualitativas, y/o cuantitativas con la conversión de datos cualitativos en cuantitativos; o suplementando datos cualitativos con datos cuantitativos.

En cualquier caso, el enfoque metodológico se correspondió, por un lado, con la investigación cuantitativa no experimental transversal, debido a que el estudio cubierto en la tesis cumple con las características señaladas en (Hernández Sampieri et al., 2014) para aplicar este tipo de investigación: 1) se observan situaciones ya existentes, no provocadas intencionalmente por quien realiza la investigación. En la investigación, las situaciones existentes que se observaron fueron: las relaciones interpersonales del AM, que reflejan su nivel de inclusión familiar y social; el impacto de la red social Facebook en la forma de comunicarse e interactuar de las personas en el mundo; así como los comportamientos actitudinales de los usuarios de Facebook. 2) Se evalúan variables en un determinado momento, como las relacionadas con el contexto tecnológico de las TIC del AM para determinar el potencial del AM para acceder al servicio de la red social Facebook; y, el nivel de conciencia sobre privacidad y seguridad que posee el AM como usuario del entorno de Facebook, para proponer acciones que le permitan al usuario AM crear la percepción de estar participando e interactuando en un entorno seguro o al menos de ciber-riesgos controlados.

Por otro lado, por las particularidades de la investigación y la compatibilidad exhibida en la Tabla 4, se optó por el paradigma interpretativo, con proceso inductivo, e investigación cualitativa, soportada como metodología en Teoría Fundamentada, con el método de codificación propio de la Teoría Fundamentada, con asistencia de la Hermenéutica, para establecer marcos conceptuales y explicar los resultados de las investigaciones. 
Tabla 4. Características del estudio de la tesis doctoral frente a características de un estudio donde corresponde aplicar Teoría Fundamentada

\begin{tabular}{|c|c|}
\hline $\begin{array}{l}\text { Características del estudio en el que } \\
\text { se recomienda la aplicación de la } \\
\text { Teoría fundamentada como } \\
\text { metodología de investigación }\end{array}$ & Características del estudio de la tesis doctoral \\
\hline $\begin{array}{l}\text { 1. "los investigadores cualitativos a } \\
\text { menudo estudian los fenómenos } \\
\text { en su entorno natural, intentando } \\
\text { darle sentido o interpretar sus } \\
\text { objetos de investigación en } \\
\text { términos de los significados que } \\
\text { las personas les aportan" } \\
\text { (Neergaard \& Ulhøi, 2006) }\end{array}$ & $\begin{array}{l}\text { El entorno natural en el que se desempeña la investigación está } \\
\text { constituido por: } \\
\text { - la realidad del AM, } \\
\text { - las características de los servicios de comunicación e interacción } \\
\text { virtual ofrecidos por la red social Facebook a sus usuarios, } \\
\text { - las causas de los ciber-riesgos existentes en el entorno de Facebook. } \\
\text { Se procura comprender los factores que componen la calidad de las } \\
\text { relaciones interpersonales del AM, como característica } \\
\text { representativa del nivel de inclusión familiar-social que posee, y } \\
\text { como una dimensión de la calidad de vida; los beneficios potenciales } \\
\text { que el uso de la red social Facebook podrían tener para la calidad de } \\
\text { vida del AM; la posibilidad de la integración del uso de la red social } \\
\text { Facebook en la vida cotidiana del AM para el mejoramiento de la } \\
\text { calidad de sus relaciones interpersonales, basado en el análisis del } \\
\text { contexto real de las TIC del AM. } \\
\text { Además, se pretende desvelar las causas que originan los ciber- } \\
\text { riesgos en el entorno de Facebook, en particular aquellas asignables } \\
\text { a los usuarios de la red social. Con la conceptualización de las causas } \\
\text { específicas antes señaladas, realizar la estimación del nivel real de } \\
\text { conciencia sobre privacidad y seguridad que exhiben los usuarios, } \\
\text { para proponer acciones que les permitan crear la percepción de estar } \\
\text { actuando en un entorno seguro de comunicación que favorece su } \\
\text { inclusión familiary social. }\end{array}$ \\
\hline $\begin{array}{l}\text { 2. "El enfoque de la teoría } \\
\text { fundamentada (GT por sus siglas } \\
\text { en inglés) se utiliza para generar } \\
\text { una teoría sustantiva, una teoría } \\
\text { que se basa en mecanismos, } \\
\text { contextos o entornos } \\
\text { específicos." (Gasson, 2009) }\end{array}$ & $\begin{array}{l}\text { Interés por construir explicaciones claras y detalladas que encajan } \\
\text { con la realidad del contexto de los AM de ambos sexos, de diferentes } \\
\text { niveles de educación, que viven en su casa ubicada en áreas } \\
\text { residenciales con acceso a Internet; y, enfocan el entorno específico } \\
\text { de la red social Facebook relacionadas con: } \\
\text { a) Mejorar la inclusión familiar y social del AM. } \\
\text { b) Orientar la percepción del usuario AM hacia Facebook como } \\
\text { entorno seguro de comunicación, basado en los datos } \\
\text { recopilados de los factores determinantes del nivel de conciencia } \\
\text { sobre seguridad y privacidad de los usuarios de Facebook como } \\
\text { son el nivel de riesgo debido a los comportamientos } \\
\text { psicosociales del usuario; y, el nivel de cultura de seguridad y } \\
\text { privacidad que posee. }\end{array}$ \\
\hline $\begin{array}{l}\text { 3. "Un análisis de teoría } \\
\text { fundamentada puede emplear } \\
\text { análisis estadísticos de casos y } \\
\text { puede basarse en datos } \\
\text { recolectados usando una } \\
\text { encuesta." (Neergaard \& Ulhøi, } \\
\text { 2006) }\end{array}$ & $\begin{array}{l}\text { Para la investigación no experimental transversal, que apoyaría el } \\
\text { estudio cualitativo, se contempló el uso de encuestas estructuradas } \\
\text { para recopilar datos, y el análisis estadístico para esos datos. }\end{array}$ \\
\hline $\begin{array}{l}\text { 4. "En estudios cualitativos e } \\
\text { interpretativos, el diseño de la } \\
\text { investigación tiende a emplear } \\
\text { un marco conceptual derivado } \\
\text { de la literatura para guiar la }\end{array}$ & $\begin{array}{l}\text { Para el estudio propuesto, es necesario establecer un marco } \\
\text { conceptual de: 1) los potenciales beneficios del uso de la red social } \\
\text { Facebook en la calidad de vida de los usuarios AM, para encontrar } \\
\text { razones o motivaciones que puedan sensibilizar al AM hacia la } \\
\text { apropiación de la tecnología de Facebook; y } 2 \text { ) las diversas causas de }\end{array}$ \\
\hline
\end{tabular}


recopilación y el análisis de datos. Cuando se emplea un enfoque de $G T$, se realiza una revisión de la literatura principalmente con el propósito de identificar las preguntas de investigación que quedan por responder." (Gasson, 2009) los ciber-riesgos en el entorno de Facebook, para identificar aquellas que tienen que ver exclusivamente con el usuario de la red social, debido a sus comportamientos psicosociales y cultura de seguridad y privacidad, para establecer un proceso para estimar el nivel de conciencia; y a través de él, finalmente explicar las acciones a tomar para crear la percepción de Facebook como entorno seguro de comunicación para inclusión familiar y social del AM.

Para concretar el estudio, fue necesario siempre realizar la estructuración de un marco conceptual en base a investigación documental; y conocer la realidad de los objetos de estudio, por observación directa y/o por declaraciones de los AM ecuatorianos como una opción del objeto de estudio.

\subsection{El proceso de investigación cualitativa}

Tomando en cuenta que se ha llegado a este punto, habiendo realizado 1) la elección del tema de investigación; 2) la formulación del problema, los objetivos, la hipótesis, y el enfoque metodológico; en las próximas secciones se muestra la concepción del diseño de la investigación y en los capítulos siguientes se explicitará el reporte de resultados cualitativos; partes del proceso de investigación cualitativa que se siguió, Fig. 12, conforme a la propuesta de (Hernández Sampieri et al., 2010).

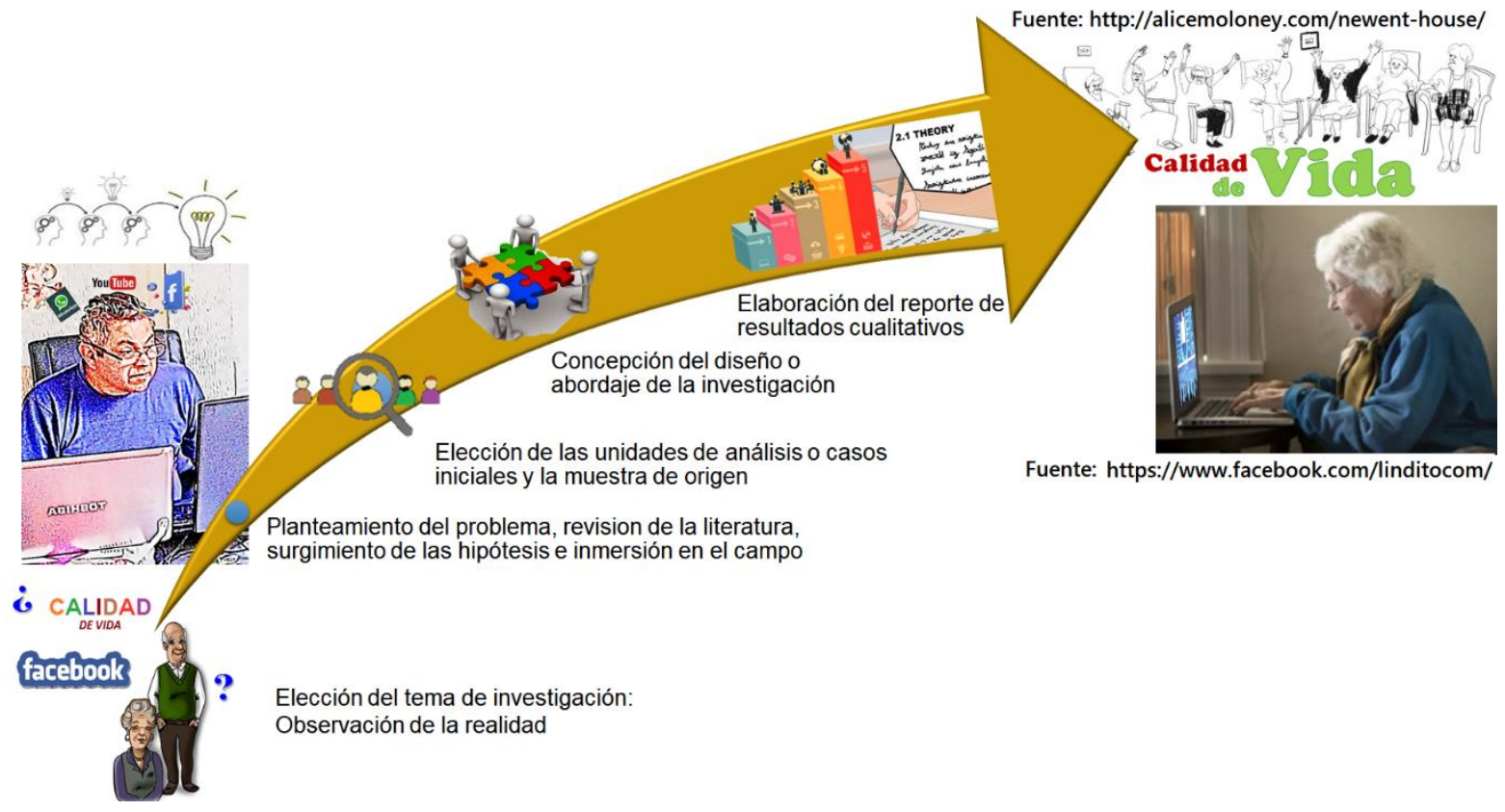

Fig. 12 Proceso de investigación cualitativa aplicado

\subsubsection{Formalización de las unidades de análisis}

Los análisis previos determinaron que las unidades de análisis en la investigación son: 1) la plataforma de red social Facebook; 2) el AM que vive en su casa como usuario de la red social, 3) Los efectos potenciales del uso de Facebook sobre la calidad de vida del AM, principalmente sobre la dimensión relaciones interpersonales, y 4) las causas de los ciber-riesgos en el entorno de Facebook; particularmente las que se le atribuyen al usuario. 


\subsubsection{Contexto de Investigación}

Dado que para esta investigación se seleccionó predominantemente el enfoque cualitativo, las muestras para la investigación se establecieron siguiendo las consideraciones expuestas en (MartínezSalgado, 2012) y (Quinn Patton \& Cochran, 2007) para estudios cualitativos; por lo que, atendiendo al contexto de estudio: AM y la red social Facebook, la muestra fue intencional, no habiéndole dado importancia al tamaño de la muestra. Así, para la investigación cuantitativa no experimental transversal, se buscaron personas adultas mayores que pudieran aportar con datos respecto a dos ámbitos: su comportamiento psicosocial mientras usan Facebook, y su cultura de privacidad y seguridad en el entorno en línea. Y para establecer las conceptualizaciones, se buscaron documentos que incorporaban los temas de interés.

Así, se establecieron las siguientes muestras que conformaron el contexto de la investigación:

\subsubsection{Caracterización de la muestra de AM}

Personas, según la normativa legal vigente en el Ecuador, con edad igual o mayor a los 65 años, de los dos sexos, con distintos niveles de formación académica, sin distinción de razas o religión, que viven en su residencia ubicada en la zona urbana de la ciudad de Quito, capital del Ecuador (sector donde está garantizado el acceso a Internet desde cualquier vivienda), y que pertenezca al área de influencia del investigador.

Se ha considerado al AM que vive en su casa, debido a que las condiciones que él puede tener en esa circunstancia, difieren de aquellas que puede tener cuando vive asilado en una institución de cuidado, pública o privada. Así, 1) la disponibilidad de las tecnologías habilitantes para el acceso a los servicios de comunicación basados en TIC desde el domicilio del AM, dependen de él o de sus familiares cercanos; 2) el acceso a Internet desde la casa, le permite al AM tener libertad de tiempo y horario para su uso; 3) el uso de los servicios de comunicación que ofrece Internet depende de que el AM cuente con las competencias informáticas necesarias, o en su defecto, disponga de ayuda competente de confianza.

\subsubsection{Caracterización de la muestra documental}

Para la estructuración de cada uno de los marcos conceptuales de las investigaciones que fueron desarrolladas, el contexto de investigación documental estuvo constituido por publicaciones científicas que constan en revistas indexadas o en actas de eventos científicos; $y$, documentos elaborados por Organismos Nacionales e Internacionales reconocidos; difundidos a través de Internet.

\subsubsection{El diseño de la Investigación}

\subsubsection{Decisión metodológica}

Para cumplir con el objetivo de la investigación, se decidió aplicar dos métodos de investigación:

1) Investigación Documental

2) Investigación de campo

\subsubsection{Técnicas de recolección de datos}

La investigación doctoral se apoyó en las siguientes técnicas: 
1. La investigación documental se desarrolló a través de dos técnicas de investigación documental ${ }^{13}$ :

a) Heurística para la selección de documentos.

b) Hermenéutica para la interpretación de los documentos, orientada por el método de codificación de la metodología de Teoría Fundamentada, como fue planteado por (Gasson, 2009), realizando ciclos iterativos de codificación y análisis, y terminando con notas teóricas de las relaciones discernidas en los datos en términos de categorías conceptuales abstractas, propiedades de categorías conceptuales y relaciones entre categorías y/o sus propiedades.

2. La investigación de campo para recopilar datos de los AM del entorno de estudio, se apoyó en los dos tipos de técnicas indicados en (Rojas Crotte, 2011) ${ }^{14}$ :

a. Observación cualitativa directa, para complementar las ideas iniciales de las investigaciones y orientar la búsqueda de documentos.

b. Entrevistas estandarizadas

El proceso evolutivo e iterativo de investigación, se esquematiza en la Fig. 13.

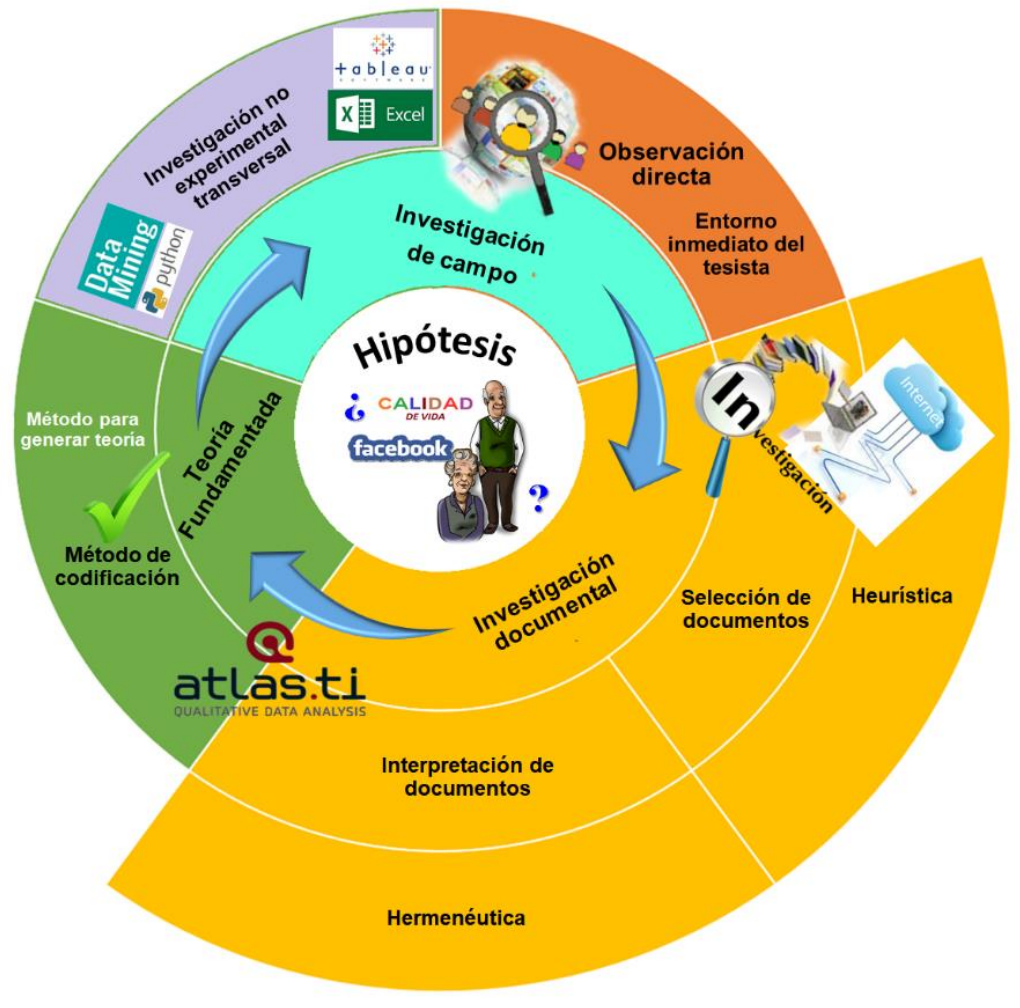

Fig. 13 Proceso de investigación

13 Técnicas de investigación documental: procedimientos orientados a la aproximación a, procesamiento y recuperación de información contenida en documentos, independientemente del soporte documental en que se hallen. (Rojas Crotte, 2011)

14 Técnicas para la obtención de información en campo: procedimientos del tipo sujeto-objeto como la observación directa, o sujeto-sujeto como la entrevista, que se aplican a procesos sociales u objetos. (Rojas Crotte, 2011) 


\section{Diseño y aplicación de los instrumentos de recolección de datos}

El diseño de los instrumentos de recolección de datos en esta investigación fue orientado por el objetivo y las distintas fases del proceso de investigación, obteniéndose los siguientes:

\section{Para la investigación documental:}

La estrategia que se planteó para recorrer los distintos documentos publicados en Internet fue ser selectivo, interpretativo, y crítico para extraer conclusiones propias y mantener la atención sobre los aspectos que resultaban atinentes al problema de investigación establecido. La estrategia se desarrolló con la aplicación de selección heurística de documentos, para posteriormente aplicar el análisis hermenéutico, Fig. 14.

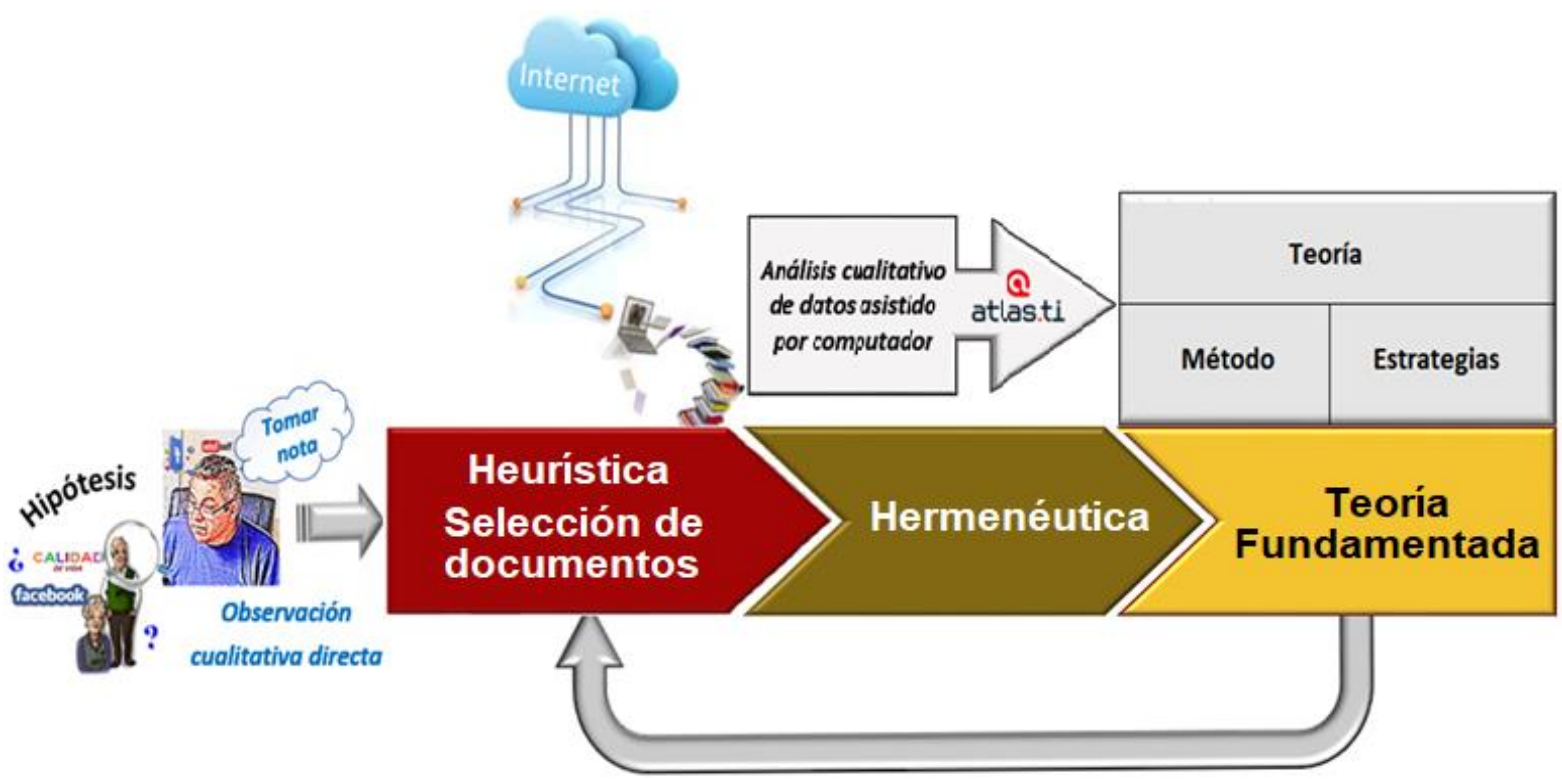

Fig. 14 Métodos de recolección de datos para la fase de Investigación documental

Guía de selección heurística de documentos: este instrumento orientó la selección de material documental a través de las siguientes heurísticas (reglas de tanteo):

1. Pertenecer al grupo de material documental desplegado como resultado de las palabras clave establecidas para la búsqueda de investigaciones relevantes.

Las palabras clave utilizadas fueron: Investigación cualitativa, teoría fundamentada, AM, calidad de vida, teorías de la vejez, las TIC y el AM, ciber-riesgos, principios de privacidad y seguridad, privacidad en Facebook, seguridad en Facebook, modelos de aceptación de tecnología.

2. Materiales documentales difundidos a través de Internet, publicados por organismos nacionales e internacionales reconocidos; o, publicaciones científicas existentes en revistas indexadas o en actas de congresos.

3. Documentos publicados preferentemente en la última década, exceptuándose los que enfoquen conceptualizaciones del uso de la tecnología por los AM o que caractericen al AM.

4. Los documentos deben estar escritos en idioma español o inglés.

5. Solo en casos excepcionales se considerarán publicaciones de fechas anteriores al año 2005 . 


\section{Para la investigación de campo:}

\section{Aspectos éticos considerados para la investigación}

Tomando en cuenta que la investigación tiene que ver con personas, en particular, con los AM; se consideró relevante utilizar, para el diseño y aplicación de los instrumentos de recolección de datos, los tópicos enfocados en los artículos de la sección Principios de la Declaración Universal sobre Bioética y Derechos Humanos de la UNESCO del 19 de octubre de 2005, que consta en el ANEXO 1 de (Keyeux et al., 2006), en particular los siguientes: Artículo 3 - Dignidad humana y derechos humanos; Artículo 4 - Beneficios y efectos nocivos; Artículo 5 - Autonomía y responsabilidad individual; Artículo 6 - Consentimiento - numeral 2; Artículo 9 - Privacidad y confidencialidad; Artículo 11 - No discriminación y no estigmatización.

Para la observación cualitativa directa:

Todos los sentidos del investigador fueron considerados instrumentos de recolección de datos, apoyados por dispositivos para registro de observaciones: 1) Plantilla impresa para registro de datos observados; 2) Dispositivos de grabación de voz y vídeo (teléfono celular).

La plantilla impresa empleada para la observación cualitativa directa es expuesta en la Tabla 5.

Tabla 5. Guía de observación cualitativa directa

\begin{tabular}{|c|c|c|c|}
\hline \multicolumn{4}{|c|}{ GUIA DE OBSERVACIÓN CUALITATIVA DIRECTA } \\
\hline Observación No. & & Fech & \\
\hline Nombre del AM observado: & & $\begin{array}{l}\text { Eda } \\
\text { (años }\end{array}$ & \\
\hline \multicolumn{4}{|l|}{ Lugar: } \\
\hline \multicolumn{4}{|l|}{ Espacio - Situación: } \\
\hline Aspectos Observados & \multicolumn{3}{|c|}{$\begin{array}{l}\text { Consideraciones interpretativas/analíticas } \\
\text { con respecto al aspecto observado }\end{array}$} \\
\hline \multicolumn{4}{|l|}{ 1. Composición de la red egocéntrica del AM } \\
\hline \multicolumn{4}{|l|}{$\begin{array}{l}\text { 2. Medios utilizados para establecer } \\
\text { conexiones con los miembros de la red } \\
\text { egocéntrica. }\end{array}$} \\
\hline \multicolumn{4}{|l|}{$\begin{array}{l}\text { 3. La motivación que le hizo ingresar a la red } \\
\text { social Facebook. }\end{array}$} \\
\hline \multicolumn{4}{|l|}{$\begin{array}{l}\text { 4. Disponibilidad de acceso a Internet por } \\
\text { parte del AM. }\end{array}$} \\
\hline \multicolumn{4}{|l|}{$\begin{array}{l}\text { 5. Disponibilidad tecnológica del AM para } \\
\text { aprovechar los servicios de Internet. }\end{array}$} \\
\hline \multicolumn{4}{|l|}{$\begin{array}{l}\text { 6. Nivel de dominio de la tecnología } \\
\text { disponible. }\end{array}$} \\
\hline $\begin{array}{l}\text { 7. Estado de ánimo del sujeto de } \\
\text { observación con relación a su ingreso a la } \\
\text { red social Facebook. }\end{array}$ & ANTES & DURANTE & DESPUÉS \\
\hline
\end{tabular}




\begin{tabular}{|l|l|}
\hline $\begin{array}{l}\text { 8. Cómo se percibe el impacto de Facebook } \\
\text { en la vida de la persona. }\end{array}$ & \\
\hline Observaciones adicionales: & \\
\hline Nombre del observador & \\
\hline
\end{tabular}

Ejemplos de cómo fueron llenadas estas guías de observación constan en el ANEXO B.

La Fig. 15, esboza las estrategias aplicadas en el procedimiento para la recolección de datos en observación cualitativa directa:

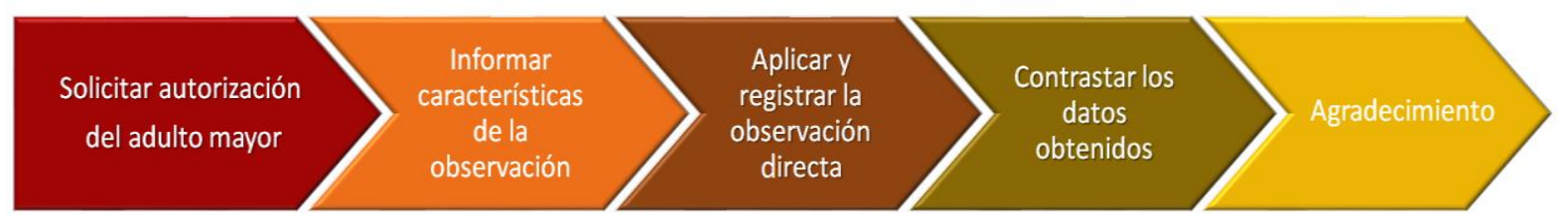

Fig. 15 Método de recolección de datos para la fase de observación cualitativa directa

El procedimiento se puede describir de la siguiente forma:

1. Solicitar la autorización del AM para ser observado respecto al uso de los servicios basados en TIC, particularmente, Facebook.

2. Informar a los AM que iban a ser observados, respecto de:

a. Las razones para la observación, (¿el por qué?)

b. Los objetivos de la observación, (¿el qué?)

c. Aspectos éticos de la observación tales como: confidencialidad de lo observado, el respeto a lo que la persona observada desee mantener en reserva; el uso exclusivo de lo observado para los propósitos de la presente investigación académica; el compromiso del observador de no realización de juicios de valor sobre lo observado.

d. Período de observación: a partir de la autorización del AM para ser observado por el investigador, el proceso de observación se iniciaba, y se mantenía hasta que el investigador llenara la plantilla de observación; no existía un tiempo específico de observación aplicable a todos los casos de observación de AM.

3. Contrastar lo observado con el AM.

4. Agradecimiento por la participación voluntaria del AM en la observación directa, y manifestación por el interés para que siga participando en otras etapas de la investigación, bajo las mismas circunstancias de consideración y respeto.

Para la investigación no experimental transversal

Con el propósito de conocer de fuente directa, fueron diseñadas entrevistas estandarizadas (encuestas) especializadas para aplicarse a los AM del contexto de investigación. Se plantearon cuestionarios estructurados con los componentes generales que se detallan a continuación:

1. Un título en el cual se sintetizaba y enunciaba el objetivo de la encuesta.

2. Un mensaje constituido de cuatro partes: 
1. Un agradecimiento al AM por su participación voluntaria.

2. Un anuncio de confidencialidad sobre los datos entregados.

3. El compromiso de que serían utilizados únicamente para efectos de una INVESTIGACIÓN ACADÉMICA.

4. El tiempo aproximado que le tomaría completar la encuesta.

3. Las preguntas, fueron elaboradas con las orientaciones de (UIT, 2014), pertenecientes a los siguientes tipos:

- Generales: para registrar datos sociodemográficos del entrevistado.

- De antecedentes.

- De conocimiento.

- De sentimientos.

- Filtro.

Se conformaron tres encuestas con distintos objetivos y componentes:

1. Encuesta para adultos mayores que viven en su casa referida a sus relaciones interpersonales Componentes:

a) Datos sociodemográficos: esta sección contemplaba la recopilación de los datos de identificación del AM (nombre, edad, sexo, estado civil, nivel de estudios).

b) De antecedentes:

a. Medios de comunicación que utiliza para comunicarse con sus familiares y amigos (comunicación tradicional, comunicación por Internet).

b. Identificación del interés por aprender comunicaciones por Internet.

c. Percepción de los entrevistados sobre la seguridad en el entorno de Internet.

d. Disponibilidad de acceso a Internet en su lugar de residencia.

e. Percepción de la calidad de sus relaciones interpersonales.

c) Filtro:

a. Contactos Activos: para clasificar a los contactos activos en grupos de contactos activos (familia nuclear, familia extendida, amigos), determinar existencia de contactos intergeneracionales, identificar ciertas características de la calidad de las relaciones interpersonales como: frecuencia de interacción, razón de la interacción, grado de satisfacción con la conexión, la confianza que siente con el contacto, la percepción del aporte que las comunicaciones por Internet le han hecho a la calidad de sus relaciones interpersonales, cuáles redes sociales utiliza.

b. Contactos Pasivos: para conocer el interés por recuperar contacto perdidos.

d) De sentimientos:

a. Universo de contactos: para identificar la fuerza de la conexión que siente por sus contactos, y la percepción del grado de emotividad que posee de participar en actividades grupales con familiares, amigos, y su comunidad en general.

2. Encuesta para adultos mayores que viven en su casa referida a la forma en que utilizan Internet y Facebook

a) Datos sociodemográficos: esta sección contemplaba la recopilación de los datos de identificación del AM (nombre, edad, sexo, nivel de estudios).

b) De antecedentes:

a. Percepción del nivel de conocimientos informáticos. 
b. Medios de comunicación que utiliza para comunicarse con sus familiares y amigos que viven en la misma ciudad (comunicación tradicional, comunicación por Internet).

c. Medios de comunicación que utiliza para comunicarse con sus familiares y amigos que viven lejos de su ciudad residencia (comunicación tradicional, comunicación por Internet).

d. Disponibilidad de acceso a Internet en su lugar de residencia.

e. Disponibilidad de algún equipo de uso personal para acceso a los servicios de Internet.

f. Frecuencia de uso y tiempo que se mantiene en Internet.

g. Percepción del valor del precio de acceso a Internet.

h. Identificación de ser usuario de Facebook.

i. Tecnologías que le permiten acceso a Facebook.

j. Facilidad de uso de la red social Facebook y necesidad de ayuda.

k. Frecuencia de uso, horario y tiempo que se mantiene en Facebook.

I. Manejo de la característica básica: enviar/aceptar solicitudes de amistad.

m. Percepción del aporte de Facebook a la calidad de vida.

c) De conocimiento:

a. Conocimiento de las amenazas a la que se expone por ser usuario de Facebook.

b. Conocimiento de las acciones a tomar frente a la concreción de un ciber-delito.

d) Filtro:

a. Identificación de las actividades en que utiliza Internet.

b. Actividades preferidas que realiza en Facebook y elementos que gusta compartir.

c. Identificación de la importancia personal que revisten algunas de las características que Facebook ofrece al usuario.

d. Tipos de personas a las que acepta solicitudes de amistad.

e. Objetivos que fortalece con Facebook.

f. Para las personas que no utilizan Internet y Facebook, saber si alguna vez intentaron usar y cuáles fueron las razones que le motivaron al intento, y qué factores le desalentaron.

3. Encuesta para AM, usuarios de Facebook, referida a su seguridad y privacidad en línea.

a) Datos sociodemográficos: esta sección contemplaba la recopilación de los datos de identificación del AM (nombre, edad, sexo, nivel de estudios).

b) De antecedentes:

a. Percepción del nivel de conocimientos informáticos.

b. Percepción del nivel de conocimientos sobre seguridad y privacidad.

c. Años de uso de Facebook.

d. Necesidad de ayuda para el uso de la red social Facebook.

e. Frecuencia de uso, horario y tiempo que se mantiene en Facebook.

f. Tecnologías utilizadas para acceder a Facebook.

g. Número de cuentas activas en Facebook.

c) Filtro:

a. Beneficios que le contribuye Facebook.

b. Actividades preferidas que realiza en Facebook y elementos que gusta compartir.

c. Comportamientos psicosociales.

d) De conocimiento:

a. Manejo de opciones de Facebook para configuración de privacidad e interacción.

b. Comprensión de los principios de seguridad y privacidad. 
c. Entendimiento de la política de privacidad y la política de datos de Facebook.

d. Nivel de conocimientos jurídicos relacionados a la seguridad y privacidad en Facebook.

El detalle de cada una de las encuestas elaboradas para el desarrollo de esta investigación, se encuentra en el ANEXO C.

El método seguido para la recopilación de datos directamente desde los $A M$, se encuentra representado en la Fig. 16.

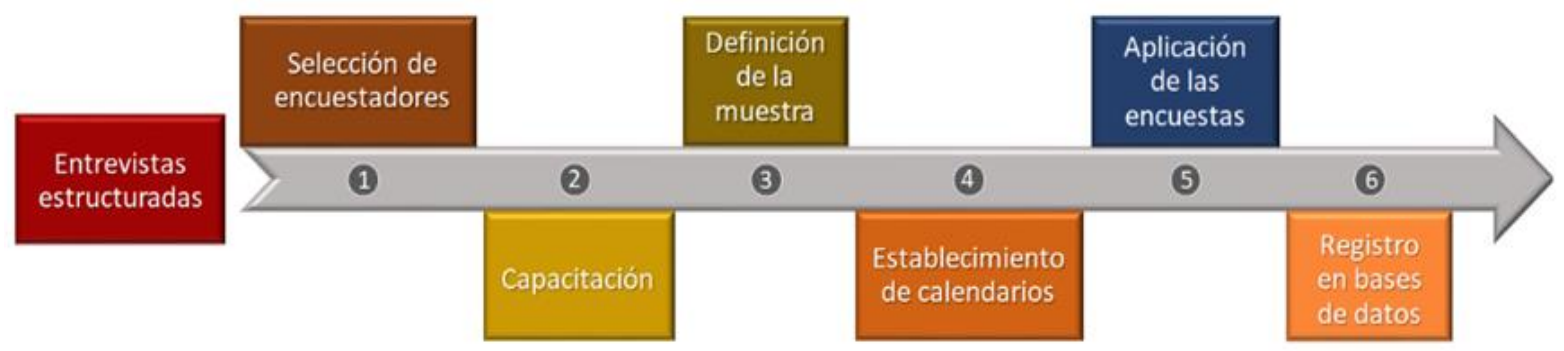

Fig. 16 Método de recolección de datos para la fase de investigación no experimental transversal

Para la aplicación de las encuestas diseñadas, se siguieron los lineamientos que se detallan a continuación:

1. Tomando en cuenta que muchas de las preguntas involucraban un cierto carácter técnico relacionadas con el acceso y la utilización de las TIC; era necesario emplear como encuestadores, personas familiarizadas con las TIC.

Por esta razón, se requirió la ayuda voluntaria, en calidad de encuestadores, de estudiantes universitarios de las carreras técnicas en Informática y Electrónica en las que participa como docente el tesista. De entre los estudiantes que se ofrecieron voluntariamente como encuestadores, se seleccionaron a aquellos que tenían abuelos AM.

2. Se previó una capacitación para los encuestadores, en relación con la confidencialidad de los datos a ser recolectados, los propósitos y objetivos de los cuestionarios, la forma de aplicación de los cuestionarios, y los conceptos y términos TIC utilizados.

La capacitación tenía como objetivo primario que los encuestadores entiendan todas y cada una de las preguntas y alternativas de respuesta para proveer explicaciones y absorber inquietudes.

Y como objetivo final que las preguntas se transmitan claramente para que el entrevistado pueda responder con conocimiento y confianza, en procura de lograr tasas de respuesta más elevadas y datos de mejor calidad.

3. La selección de los AM sobre los que se iba a aplicar la encuesta se hizo, una vez que se tuvo el compromiso de los estudiantes que decidieron participar voluntariamente como encuestadores, y aplicando los siguientes criterios:

a. Facilitar a los encuestadores el acceso al área donde se aplicaría la encuesta.

b. Reducir al mínimo la carga impuesta a los encuestadores y principalmente a los destinatarios de las encuestas. 
c. Aportar al investigador, usuario de los datos, con tasas de respuesta más elevadas y datos de mejor calidad.

Para satisfacer estos criterios, se tomaron las siguientes decisiones:

1. Una vez realizada la selección de los encuestadores se estimó que, entre los abuelos de los estudiantes existirían AM que utilizaban las TIC y podían dar un criterio sobre su uso; y también habría AM que no las utilizaban y podían expresar las razones para ello. Además, se consideró que los AM aceptarían con agrado, responder a las encuestas, y ser parte de una investigación académica en la que sus nietos participaban.

2. Estas muestras sin ser altamente representativas de la población de AM de Quito, podrían brindar respuestas para reflexionar sobre los objetivos de la investigación: el contexto tecnológico de las TIC del AM; el uso de Facebook e Internet; y un conocimiento sobre el nivel de conciencia respecto a privacidad y seguridad en Facebook.

4. Se estipuló un tiempo suficiente para que los encuestadores apliquen las encuestas: 3 semanas; tiempo definido por los encuestadores, como máximo, para estar en contacto con sus abuelos.

5. A cada encuestador voluntario, se le solicitó, siempre que le sea posible, la aplicación de los cuestionarios a sus AM, máximo 4: dos abuelos por parte de padre y dos abuelos por parte de madre.

6. Se hicieron las siguientes recomendaciones a los encuestadores:

a. Comience aclarando al encuestado que se trata de una participación voluntaria, que la información provista se mantendrá en absoluta reserva, ya que se trata de una investigación académica.

b. No intente realizar varias encuestas simultáneamente.

c. Si el encuestador o el encuestado siente cansancio en el momento de iniciar la encuesta, no aplicar la encuesta en ese momento.

d. El encuestador no deberá imponer una respuesta, el encuestado deberá responder una vez que haya entendido perfectamente la pregunta.

e. El encuestador no debe dejar la encuesta para que sea llenada libremente y en solitario por el encuestado; o encargar la realización de la encuesta a alguna persona que no haya recibido la instrucción respectiva para el efecto.

f. La encuesta debe ser llenada con letra legible, de preferencia letra de imprenta.

\subsubsection{Técnicas de Análisis de Datos}

\section{En la investigación documental - Análisis cualitativo asistido por computadora}

Para la segunda etapa de la investigación documental, en la que se cumplió el análisis hermenéutico de los artículos y publicaciones seleccionadas, se puso atención a la orientación encontrada en (Neergaard \& Ulhøi, 2006), que propone, para cada artículo, centrarse en su enfoque de investigación, 
su forma de aplicar la metodología seleccionada, la forma de redactar y estructurar el documento de la investigación, y principalmente los hallazgos clave.

El software Atlas Ti Versión 7.5.7 (https://atlasti.com/), fue el instrumento con que se aplicó el análisis cualitativo asistido por computadora, muy fácil de aprender, posee una interface intuitiva y sencilla de usar, posee otras interesantes características como las señaladas en (Romo et al., 2014):

1. "Herramienta que facilita la organización, manejo e interpretación de grandes cantidades de datos textuales (que pueden ser textos escritos, imágenes, sonidos, mapas y/o videos).

2. Sus creadores resumen las principales fortalezas: visualización, integración, serendipia ${ }^{15}$ y exploración.

3. El proceso de trabajo en ATLAS.ti se puede agrupar en dos niveles: el textual y el conceptual:

a. El nivel textual abarca la preparación y el manejo de los datos, la segmentación de los textos (ya sea texto en sí, pero también imagen, sonidos o video) y la codificación.

b. El nivel conceptual abarca la comparación e interpretación de segmentos ya codificados, así como la elaboración de redes que vinculen conceptos (documentos primarios, citas, códigos, familias, etc.) a un nivel más abstracto y la construcción de teoría fundamentada en los datos.

El proceso de trabajo en ATLAS.ti se ajusta al proceder de un analista cualitativo: pasar de manera continua por los dos niveles descritos, comenzando su trabajo en el nivel textual, luego avanzando al nivel conceptual, para a continuación regresar al nivel textual y posteriormente volver al nivel conceptual; y así de manera continua."

\section{En la Investigación no experimental transversal}

Se utilizaron dos métodos, como se muestra en la Fig. 17:

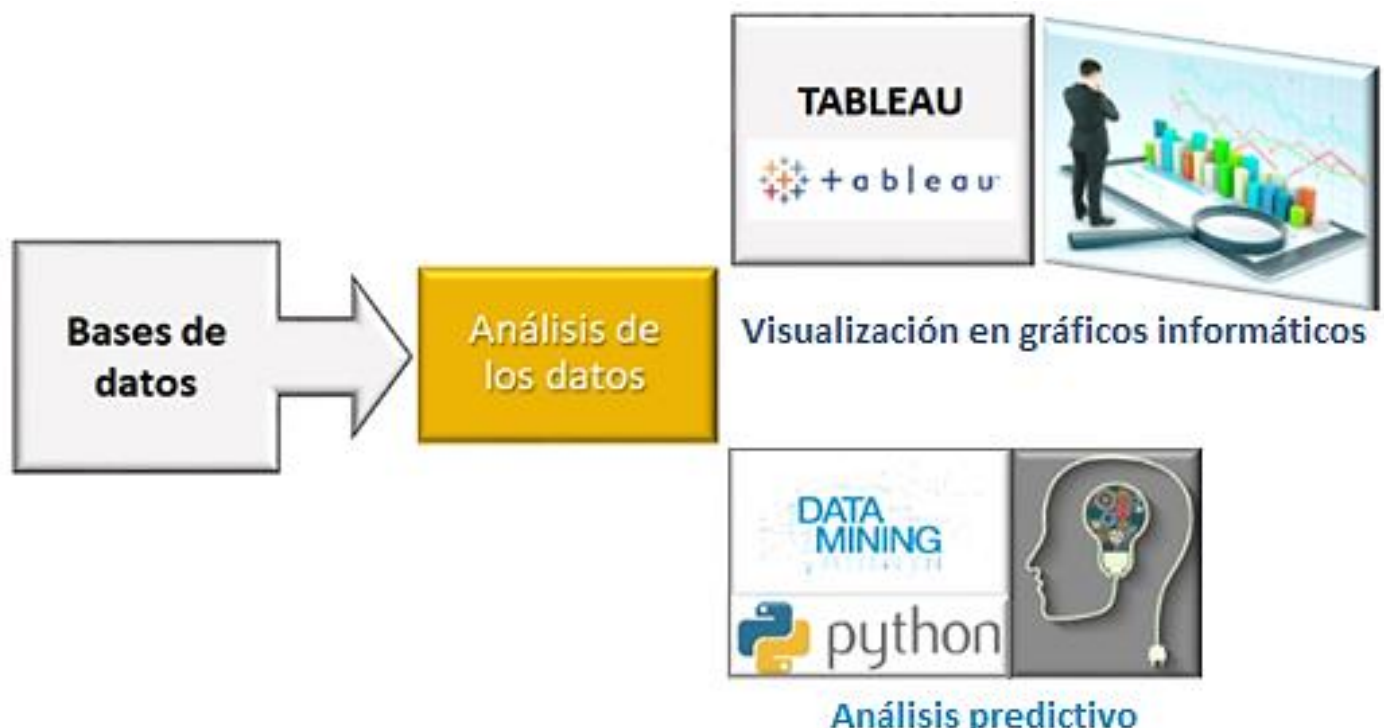

Fig. 17 Métodos de análisis de los datos recopilados con las entrevistas estructuradas

\footnotetext{
${ }^{15}$ Serendipia: Hallazgo valioso que se produce de manera accidental o casual. Fuente: Diccionario de la lengua española
} 
- Visualización en gráficos informáticos

Los datos recopilados con las encuestas estructuradas, fueron registrados en bases de datos desarrolladas en Microsoft SQL Server y en planillas de cálculo en Excel.

El análisis de los datos recopilados, se apoyó en la combinación de tecnologías de base de datos y gráficos informáticos mediante el software Tableau versión académica (https://www.tableau.com/academic).

- Análisis predictivo

Además, para la obtención de conocimiento a partir de los datos de la encuesta que apoyó la estimación del nivel real de conciencia sobre privacidad y seguridad de los usuarios de Facebook, también se tomó como referencia, el algoritmo de minería de datos para clasificación basada en atributos presentado en (Zacharski, 2015), que utiliza el enfoque del vecino más cercano basado en la distancia Manhattan, con miras a desarrollar predicciones de la etiqueta del nivel de conciencia real específico sobre privacidad y seguridad que le correspondería al (los) usuario(s) de Facebook investigado(s), a través de valores estimados de los factores determinantes de ese nivel de conciencia real de personas usuarias de Facebook, valores establecidos con un proceso manual desarrollado a través de reglas aplicadas sobre los datos de la encuesta; los que conformarían, a futuro, el conjunto de entrenamiento contemplado en el algoritmo de minería de datos referido.

Por lo anteriormente señalado, se siguió el proceso del ciclo de vida convencional de minería de datos señalado en (Khan et al., 2012), Fig. 18, para el desarrollo de la investigación No. 4 que se describe en el Capítulo 5.

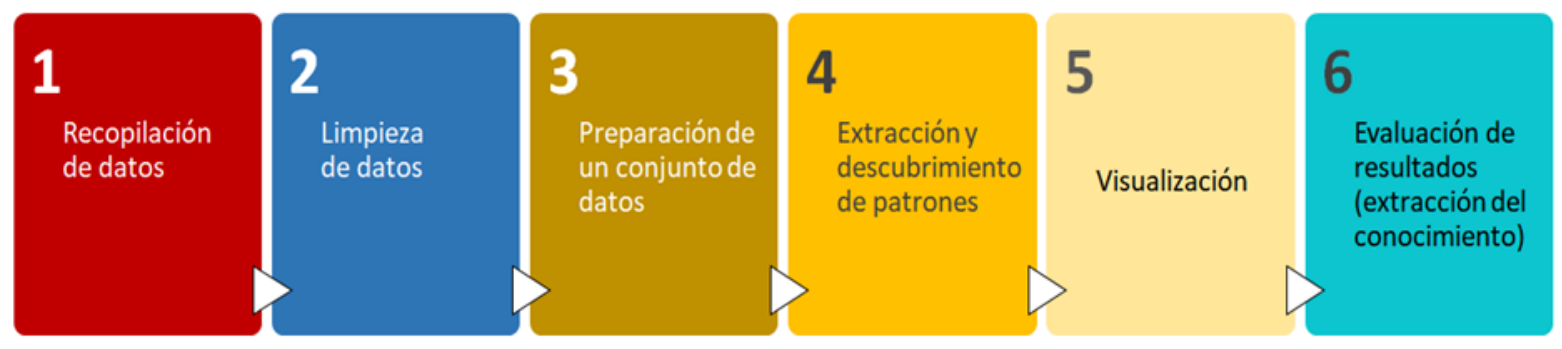

Fig. 18 Ciclo de vida convencional de minería de datos - Fuente: (Khan et al., 2012)

\subsection{Conclusiones}

Este capítulo muestra la necesidad de integrar la investigación cualitativa con la investigación cuantitativa con miras a alcanzar un amplio entendimiento de la red social Facebook como entorno seguro de comunicación para inclusión familiar - social del usuario AM, en la perspectiva del mejoramiento de la calidad de vida, particularmente de la dimensión relaciones interpersonales.

Se demostró también, que es correcta la selección de la Teoría Fundamentada como metodología de investigación, en consideración a la compatibilidad que existe entre las particularidades del estudio desarrollado en esta tesis, con las características de los estudios donde los expertos recomiendan la aplicación de esta metodología.

Se ha considerado al método de codificación de la Teoría Fundamentada, junto con la Hermenéutica y el software Atlas Ti Versión 7.5.7, como los medios apropiados para estructurar los marcos 
conceptuales de las investigaciones, a partir de los documentos difundidos por Internet, seleccionados con perspectiva heurística.

Por otra parte, para el caso de la investigación no experimental transversal, se escogieron dos mecanismos de apoyo al análisis de datos: la visualización en gráficos informáticos, y el análisis predictivo sustentado en el algoritmo de minería de datos para clasificación basada en atributos.

Es importante resaltar el hecho de haber considerado en el desarrollo de los instrumentos de investigación de campo y en su aplicación, los aspectos bioéticos recomendados por la UNESCO en el caso de investigaciones con seres humanos, más aún cuando esos seres humanos se encuentran en una etapa de la vida de alta sensibilidad emocional.

Se ha explicitado que la integración de la investigación cualitativa con la investigación cuantitativa ocurre al transitar a través de los marcos conceptuales, la investigación no experimental transversal, y la explicación final de los hallazgos de las investigaciones. Este recorrido se lo inicia con el análisis cualitativo asistido por computadora de los documentos seleccionados con heurística, continua con la visualización en gráficos informáticos y análisis predictivo de los datos recopilados con las encuestas, y concluye con la publicación de las explicaciones de los hallazgos de las investigaciones.

Las estrategias utilizadas para aplicar las encuestas, no solamente permitieron extraer datos del AM entrevistado; sino que permitieron aportarle al AM entrevistado la posibilidad de que tengan un acercamiento a la red social Facebook y las TIC a través de personas de su confianza, pudiendo alcanzar una sensibilización hacia el uso de la tecnología en el caso de no estar utilizándola, o de ampliar los horizontes de uso para los que ya son usuarios, sobre aspectos posiblemente desconocidos como son los principios de privacidad, las configuraciones de privacidad y seguridad, y más. 


\section{CAPÍTULO 4-ESTADO DEL ARTE: EL AM FRENTE A LA RED SOCIAL FACEBOOK}

\subsection{Introducción}

Este capítulo expone los resultados de la revisión sistemática de literatura que se cumplió, para desvelar los efectos que la red social Facebook pudo haber tenido sobre el bienestar de los usuarios AM.

El procedimiento utilizado para la revisión sistemática de literatura para establecer el estado del arte, enfocó tres fases principales, acorde a lo planteado en (Bong et al., 2018):

1) Planeación de la revisión

En esta fase, las necesidades de la revisión de la literatura se concretaron en las siguientes preguntas de investigación:

a) ¿Cuáles son las perspectivas generales desde las cuales se puede comprender la relación existente entre el AM y las TIC?

b) ¿Qué modelo es válido para aproximarse a la comprensión del AM frente a la red social Facebook?

c) ¿Cuáles son los ámbitos en los que el modelo de aproximación organiza los diferentes aspectos de la realidad del AM frente a la red social Facebook?

d) ¿Cuál es el mejor ámbito en el que se puede desarrollar una nueva investigación relacionada con el AM y la red social Facebook?

2) Ejecución de la revisión

La estructuración de las respuestas a las preguntas de investigación, que definieron el estado del arte, se realizó con:

a) La definición de los términos de búsqueda principales: TIC y los AM, AM y Facebook, Facebook y la calidad de vida del AM, beneficios del uso de Facebook para el AM, actitudes del AM hacia la tecnología, modelos de aceptación, adopción o apropiación de tecnología por parte de las personas mayores.

b) La selección heurística de publicaciones, bajo los siguientes criterios de inclusión y exclusión para:

1. Los AM constituyen el grupo objetivo en los documentos a seleccionar.

2. Los documentos deben enfocarse en las TIC, redes sociales, Facebook, y modelos que puedan describir la aceptación, adopción o apropiación de tecnología por parte de las personas adultas mayores.

3. Se excluyen los documentos publicados en fechas anteriores al 2010, a excepción de aquellos que conceptualicen principios de uso de la tecnología por los AM o que caractericen al AM. 
4. Solo se incluirán documentos que pertenezcan a publicaciones disponibles en Internet con ISSN, ISBN o DOI, que pertenezcan a organizaciones nacionales e internacionales tales como Centro Latinoamericano y Caribeño de Demografía (CELADE), Organización Mundial de la Salud (OMS), o tesis de universidades, o en actas de eventos científicos.

5. Se excluyen los documentos no publicados en idioma inglés o idioma español.

c) El análisis cualitativo de las publicaciones seleccionadas, fundamentado en la hermenéutica y el método de codificación de la Teoría Fundamentada, para catalogar los elementos experienciales del AM con las TIC y Facebook.

3) Anuncio de resultados

El establecimiento del estado del arte se inició con el siguiente marco conceptual:

a) La calidad de vida de las personas se compone de un conjunto de bienestares tales como el bienestar físico, el bienestar material, el bienestar social, el bienestar psicológico y otros.

b) La concepción actual del bienestar del AM, extraída con el análisis cualitativo de (Rodríguez-Piñero \& Huenchuan, 2011), (Bong et al., 2018), (Organización Mundial de la Salud, 2002), (del Valle Gómez \& Coll i Planas, 2011), especifica:

1. El bienestar del AM actualmente se fundamenta en el desarrollo de los conceptos de envejecimiento activo, de esperanza de vida saludable o libre de discapacidad, de autonomía, y de independencia.

2. Un alto nivel de bienestar en el AM, le permite alcanzar una vida plena, saludable, satisfactoria; y con los cuidados requeridos.

3. Para alcanzar un alto nivel de bienestar, los AM deben disfrutar de inclusión familiar y social, entendida como participación con dignidad en la vida de sus propias familias y de su comunidad.

4. El bienestar social, representado por la inclusión familiar y social y evidenciado por el nivel de calidad de las relaciones interpersonales, en los AM contribuye particularmente, a desarrollar sentimientos de pertenencia y aporta hacia un estado de buena salud y felicidad.

c) "El envejecimiento activo como proceso de optimización de las oportunidades de salud, participación y seguridad con el fin de mejorar la calidad de vida de las personas que envejecen, constituye hoy un marco para fundamentar la necesidad de que las personas mayores adopten las tecnologías digitales en su vida cotidiana, tomando en cuenta las ventajas que ofrece para comunicarse y estar en contacto con el mundo, manteniendo seguridad y autonomía." (Casamayou \& Morales González, 2018)

d) La tecnología se ha desarrollado para propender a la mejora de las condiciones de vida de las personas.

e) Los servicios ofrecidos por la red social Facebook han transformado la forma de comunicarse e interactuar de los usuarios.

f) La tecnología es una herramienta necesaria dentro del proceso de envejecimiento en el domicilio, y deber ser accesible, de fácil uso, con servicios que aporten valor al usuario, 
que atiendan necesidades reales de las personas mayores, y a bajo coste. (Innobasque, 2012)

g) El núcleo de la tesis es el mejoramiento de la calidad de vida del AM mediante el uso de la tecnología de Facebook. Se determinó con fundamento en el impacto que las características de Facebook ha tenido en la forma de comunicarse de las personas; en la importancia para los AM de las redes de la familia, amigos y conocidos, que le mantienen su identidad social, y le proporcionan apoyo emocional, material, información y servicios (Concha et al., 2000); en la comprensión de que todas las disminuciones en la interacción social en la vejez se explican mejor por poca salud o discapacidad, y la satisfacción que alcanza el AM con la actividad social y sentirse incluido socialmente (Oddone, 2013).

h) La influencia social, especialmente la opinión de los hijos y nietos, o las peticiones de la familia cercana, o el hecho de disponer de una cuenta en la red social creada por algún miembro de su familia, afectan el comportamiento del AM hacia el uso, aceptación y apropiación de la tecnología de Facebook, a tal punto que están dispuestos a dedicar tiempo para aprender las funciones de Facebook para estar acorde al grupo familiar. (Renaud \& Van Biljon, 2008), (Colombo et al., 2015), (Jung \& Sundar, 2016).

i) Varias investigaciones señalan algunos de los efectos negativos y las consecuencias de convertirse en AM, por ejemplo, en (Renaud \& Van Biljon, 2008) y (Meymo \& Nyström, 2017) se afirma que al entrar en esta etapa de la vida, la persona reduce su participación social con la consiguiente reducción del acceso a la información y la sensación de soledad que siente.

j) El bienestar social es la dimensión de la calidad de vida del AM que puede ser mejorada con el uso de la red social Facebook.

Con la revisión inicial de la literatura, se identificaron, organizaron y catalogaron las relaciones que se han dado entre los AM y las TIC, en cuatro perspectivas:

1) brecha digital;

2) relaciones sociales mediante interacción virtual;

3) actividades lúdicas, relacionadas con el uso de las tecnologías digitales para el mejoramiento de las capacidades funcionales de los AM, a través de juegos digitales interactivos; $y$,

4) e-salud, que se refiere al mejoramiento de la atención y seguimiento de la salud del AM.

Las dos últimas perspectivas salen del ámbito de los objetivos de la tesis, por lo que no son desarrolladas en el presente documento; en tanto que las dos primeras perspectivas se alinean perfectamente con el desarrollo de los objetivos de investigación, como se observa en las siguientes secciones.

\subsection{Modelo de aproximación a la realidad del AM frente a la red social Facebook}

Para reflejar con fidelidad, la realidad documentada del encuentro entre el AM y la red social Facebook, se consideró necesario identificar un modelo que oriente la forma lógica de enfocar las diferentes perspectivas de la realidad que se quiere entender. 
La revisión de la literatura evidenció la existencia de varios modelos que se han venido aplicando para entender la aceptación, la adopción o la apropiación de tecnología por parte de las personas, como son: TAM, TAM2, TAM3, UTAUT, LUM; señalados en la sección 2.4.3.1.

Si bien se podría pensar que todos los principales modelos antes señalados, podrían aplicarse para aproximarse a la comprensión de la relación del AM y la tecnología de red social Facebook, existe la salvedad de que esos modelos fueron desarrollados para comprender los procesos de aceptación de tecnología por las personas que pertenecen a entornos empresariales, característica que ya no se corresponde con la realidad del AM.

Las particularidades que definen a la mayoría de AM en general, pero especialmente en el Ecuador, son: persona retirada de las actividades productivas debido a su jubilación, y por lo tanto ha dejado de pertenecer a un entorno empresarial; persona que actúa en procura de alcanzar los mayores beneficios y satisfacciones individuales, sin eliminar o perder de su horizonte de interés, el valor de las relaciones significativas con la familia y amigos cercanos.

Por lo tanto, el modelo requerido debía apuntar al AM como un individuo independiente de cualquier contexto de negocio, que no tiene que utilizar la tecnología por la obligatoriedad impuesta por otras personas que pretenden satisfacer intereses corporativos o institucionales, sino que lo hace por su propia voluntad en pro de alcanzar beneficios personales.

\subsubsection{Alternativas de modelos de aproximación a la realidad del AM frente a la red social Facebook}

Existen las siguientes alternativas de modelos que se adaptan mejor a las particularidades señaladas del AM:

1. El modelo UTAUT-2 (TEORÍA UNIFICADA DE ACEPTACIÓN Y USO DE TECNOLOGÍA DE LA INFORMACIÓN-2), adapta los constructos y definiciones de UTAUT (desarrollados para aplicarse en contextos organizacionales) al contexto de aceptación y uso de la tecnología del consumidor. La descripción completa de este modelo dada por sus autores consta en (Venkatesh, 2012).

2. El modelo STAM, cuyo origen está en el modelo TAM, enfoca la adopción y aceptación de tecnologías por el AM. En (Renaud \& Van Biljon, 2008), los autores detallan los significados de cada una de las dimensiones que posee el modelo STAM.

3. El modelo teorizado de proceso evolutivo hacia la apropiación de tecnología propuesto por el tesista en el Capítulo 2 de este documento, sección 2.4.3, que tiene la ventaja de incorporar algunas de las perspectivas de UTAUT-2, STAM y otros modelos de uso y aceptación de tecnología, para representar el camino que debe recorrer una persona adulta mayor ya sensibilizada hacia la necesidad de usar una tecnología.

4. El modelo de sensibilización del AM hacia el uso y apropiación de la tecnología, mencionado en la parte final de la sección 2.4.2.3, titulada la brecha digital y la apropiación de las TIC. Este modelo debería considerarse la etapa previa al desarrollo del proceso propiamente dicho de apropiación de tecnología.

\subsubsection{Selección del modelo de aproximación}

Los tres primeros modelos, parten del supuesto que hay una motivación clara del potencial usuario para aproximarse a la tecnología, es decir, el usuario conoce como la tecnología lo puede ayudar a 
alcanzar sus objetivos. Este supuesto no siempre se cumple en el caso del AM; y más común con la realidad es que el AM se haya visto afectado por la falta de oportunidades de acceso a las TIC y de su uso para actividades que le podían beneficiar.

Hay publicaciones como (Majcen et al., 2011), (Teng \& Joo, 2017), (Meymo \& Nyström, 2017), (Casamayou \& Morales González, 2018) y (K. Quinn, 2018), que hacen referencia a la brecha digital en los AM con relación a la tecnología de redes sociales, y mencionan las siguientes causas generales: condiciones de alfabetización en el uso de computadoras; o por sus creencias de no tener capacidad, a su edad, para enfrentarse a nuevos conocimientos; o, por carencia de habilidades técnicas debida a la falta de contacto previo con dispositivos tecnológicos; o, por la necesidad de ayuda de confianza para solventar inquietudes sobre la tecnología o las acciones a seguir para conseguir un objetivo específico; o, porque se desaniman ante su proceso de aprendizaje lento.

A sabiendas que la brecha digital es una realidad para muchos AM, se decidió utilizar el modelo de sensibilización del AM hacia el uso y apropiación de la tecnología, representado en la Fig. 19, basado en la propuesta de (Gómez Navarro et al., 2018) descrita en la sección 2.4.2.3 de este documento; como medio de aproximación al entendimiento de la realidad documentada del AM frente a Facebook.

Con esta selección se organizaron los hallazgos de la revisión sistemática de literatura, y se estructuraron argumentos con los cuales se sensibilizaría a los AM hacia la superación de los distintos niveles de brecha digital en los que estén inmersos, a través de influencia familiar y social, y normas subjetivas.

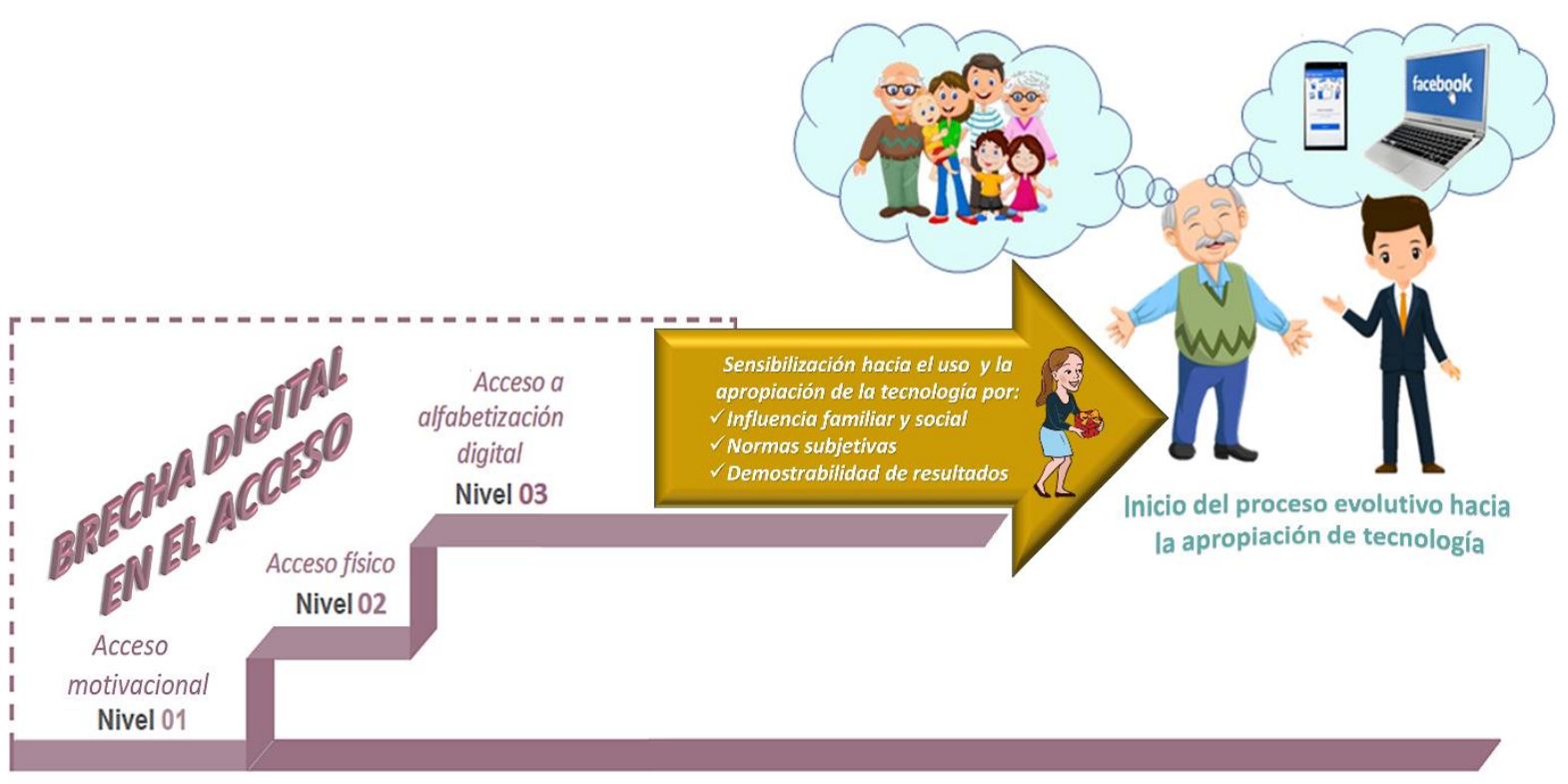

Fig. 19 Modelo de sensibilización del AM hacia el uso y apropiación de la tecnología

Este modelo se sustenta en la hipótesis que la superación de la brecha digital en el acceso motivacional impulsa, al potencial usuario AM, a continuar recorriendo el camino de reducción de los restantes niveles de la brecha digital.

Para la superación del primer nivel de brecha digital, es necesario que el potencial usuario AM de la red social Facebook, establezca expectativas, identifique oportunidades y conozca experiencias sobre potenciales beneficios, que en conjunto le generen una motivación personal significativa. 
Si bien es necesaria la superación del primer nivel de brecha digital en el acceso, no es suficiente para que el AM llegue a su primer contacto real con la tecnología de Facebook. También es necesario que el potencial usuario AM del servicio tecnológico, comprenda los aspectos técnicos para superar la brecha digital en el acceso físico.

Finalmente, debe conocer las oportunidades para sobrepasar la brecha digital en el acceso a alfabetización digital, como medios para disponer de conocimientos, habilidades y destrezas para manejar la tecnología una vez que cuente con la motivación y el acceso físico.

Cabe mencionar que el orden planteado dentro del modelo de sensibilización del AM hacia el uso y apropiación de la tecnología, es lógico para un potencial usuario que parte disponiendo de los tres niveles de brecha digital de acceso. Sin embargo, es necesario expresar que no siempre ese puede ser el punto de partida del potencial usuario, existen otras seis posibilidades adicionales, que se visualizan en la tabla de verdad siguiente:

Tabla 6. Combinaciones posibles de niveles de brecha digital en el acceso de un potencial usuario AM de tecnología

\begin{tabular}{|c|c|c|c|c|}
\hline $\begin{array}{l}\text { El potencial } \\
\text { usuario AM de } \\
\text { tecnología está } \\
\text { comprometido } \\
\text { por la brecha } \\
\text { digital en el } \\
\text { acceso } \\
\text { motivacional }\end{array}$ & $\begin{array}{l}\text { El potencial } \\
\text { usuario AM de } \\
\text { tecnología está } \\
\text { comprometido } \\
\text { por la brecha } \\
\text { digital en el } \\
\text { acceso físico }\end{array}$ & $\begin{array}{l}\text { El potencial } \\
\text { usuario AM de } \\
\text { tecnología está } \\
\text { comprometido } \\
\text { por la brecha } \\
\text { digital en el } \\
\text { acceso a } \\
\text { alfabetización } \\
\text { digital }\end{array}$ & $\begin{array}{c}\text { Niveles de brecha digital en el } \\
\text { acceso del potencial usuario AM } \\
\text { de tecnología }\end{array}$ & $\begin{array}{c}\text { Niveles de } \\
\text { esfuerzo } \\
\text { estimados } \\
\text { para } \\
\text { superar la } \\
\text { brecha } \\
\text { digital en el } \\
\text { acceso } \\
0 \text { - ninguno } \\
6 \text { - máximo }\end{array}$ \\
\hline 1 & 1 & 1 & $\begin{array}{c}\text { Potencial usuario con los tres } \\
\text { niveles de brecha digital en el } \\
\text { acceso }\end{array}$ & 6 \\
\hline 1 & 1 & 0 & $\begin{array}{c}\text { Potencial usuario con dos niveles } \\
\text { de brecha digital en el acceso: } \\
\text { motivacional y físico }\end{array}$ & 3 \\
\hline 1 & 0 & 1 & $\begin{array}{c}\text { Potencial usuario con dos niveles } \\
\text { de brecha digital en el acceso: } \\
\text { motivacional y a alfabetización } \\
\text { digital }\end{array}$ & 4 \\
\hline 1 & 0 & 0 & $\begin{array}{c}\text { Potencial usuario con nivel de } \\
\text { brecha digital en el acceso } \\
\text { motivacional }\end{array}$ & 1 \\
\hline 0 & 1 & 1 & $\begin{array}{l}\text { Potencial usuario con dos niveles } \\
\text { de brecha digital en el acceso: } \\
\text { físico y a alfabetización digital }\end{array}$ & 5 \\
\hline 0 & 1 & 0 & $\begin{array}{l}\text { Potencial usuario con nivel de } \\
\text { brecha digital en el acceso físico }\end{array}$ & 2 \\
\hline 0 & 0 & 1 & $\begin{array}{l}\text { Potencial usuario con nivel de } \\
\text { brecha digital en el acceso a } \\
\text { alfabetización digital }\end{array}$ & 3 \\
\hline 0 & 0 & 0 & $\begin{array}{l}\text { Potencial usuario NO tiene niveles } \\
\text { de brecha digital en el acceso }\end{array}$ & 0 \\
\hline
\end{tabular}

1: El potencial usuario AM de tecnología está comprometido por la brecha digital en el acceso

0 : El potencial usuario AM de tecnología está libre de la brecha digital en el acceso 
El análisis de las posibles combinaciones presentes en la Tabla 6 demuestra que el potencial usuario AM puede presentar distintas condiciones respecto a la brecha digital en el acceso.

Para cada una de esas condiciones, el tesista ha estimado un nivel de esfuerzo, con el ánimo de visualizar con facilidad las condiciones que resultan ser más desventajosas para el AM. Esta estimación del nivel de esfuerzo, siguió la siguiente prelación en cuanto a gravedad de la desventaja, para las tres brechas digitales en el acceso: 1) brecha digital en el acceso a alfabetización digital (nivel de esfuerzo $3)$, 2) brecha digital en el acceso físico (nivel de esfuerzo 2), y 3) brecha digital en el acceso motivacional (nivel de esfuerzo 1).

La brecha digital en el acceso a alfabetización digital se considera de mayor nivel de esfuerzo para el AM, porque para que el AM alcance un manejo autónomo y efectivo de la tecnología, en el presente caso de la red social Facebook, requiere de un dominio del manejo del dispositivo de acceso, también de la interface de usuario de Facebook para lograr una satisfactoria interacción virtual, y de los principios y configuraciones para mantener a salvo su privacidad y seguridad. Es posible que el nivel de esfuerzo pueda ser aminorado con ayuda de alguna persona de confianza, sin embargo, esa ayuda no siempre estará presente cuando la necesite el AM.

A la brecha digital en el acceso físico se le ha estimado un nivel de esfuerzo 2, debido a que conlleva la necesidad de contar con infraestructura tecnológica, que puede afectar la seguridad económica del AM, con relación a los pagos mensuales del contrato de acceso a Internet con la suficiente velocidad de los datos para una experiencia satisfactoria; y al precio del dispositivo de acceso (PC, laptop, teléfono inteligente), que ciertamente debe ser considerado una sola vez. Sin embargo, el esfuerzo del AM en este ámbito de la brecha digital, puede ser aliviano con ayuda de sus familiares cercanos, en una proporción mayor a la que el AM experimentaría en el ámbito analizado en el párrafo anterior.

La brecha digital en el acceso motivacional recibió un nivel de esfuerzo 1, en consideración a que tiene que ver con la decisión del AM de aceptar los argumentos de sus familiares y amigos, sobre los posibles beneficios que el uso de Facebook puede acarrearle a su calidad de vida, y de que es una alternativa tecnológica viable para facilitar sus propias circunstancias de vida.

Con las consideraciones anteriores, la condición de mayor adversidad es tener los tres niveles de brecha digital en el acceso (combinación 111 - color rojo), es la que mayor esfuerzo exigiría del AM para superar la brecha digital - nivel de esfuerzo = $6(1 \times 1+1 \times 2+1 \times 3)$; en tanto que la mejor condición es no contar con niveles de brecha digital en el acceso (combinación 000 - color verde), nivel de esfuerzo $=0$.

Entre esas dos condiciones extremas, se considera que la condición de brecha digital en el acceso, susceptible de ser superada con mayor facilidad en el AM es la correspondiente a la combinación 100 - nivel de esfuerzo $=1(1 \times 1+0 \times 2+0 \times 3)$, es decir, aquella en la que cuenta con acceso físico a la tecnología, y con acceso a alfabetización digital (dispone de ayuda de confianza, tuvo la oportunidad de adquirir conocimientos para el manejo de tecnología, tiene opciones de recibir capacitación para iniciarse en el manejo de la tecnología); por lo tanto, le hace falta únicamente tener una motivación que le impulse al uso de la tecnología.

Otra condición menos, favorable que la anterior, pero que también pudiera ser susceptible de ser superada con algo más de esfuerzo es aquella combinación $010-$ nivel de esfuerzo $=2$, la cual demuestra que hay motivación, hay acceso a alfabetización digital, y solo le falta el acceso físico, que 
se puede superar con el apoyo económico de familiares cercanos, en el caso que el AM no pueda cubrir los costos involucrados.

La combinación que le sigue a la anterior es la 001 - nivel de esfuerzo = 3, que evidencia que el AM tendría motivación, acceso físico, pero dificultad en el acceso a alfabetización digital, la cual puede resultar insuperable si no se cuenta con ayuda de confianza o si el AM tiene un bajo nivel de estudios.

El resto de combinaciones, donde se tienen dos niveles de brecha digital en el acceso, requieren de un mayor esfuerzo para ser superadas, y por consiguiente pueden generar la renuncia al uso de la tecnología.

\subsubsection{Modelo integral de apropiación de tecnología por el AM (MIAT-AM)}

Luego del análisis de las alternativas de los modelos de aproximación a la realidad del AM frente a la red social Facebook, se ha concluido que se pueden sistematizar, en un solo modelo, las dos propuestas planteadas en esta tesis con perspectiva de apropiación de tecnología: el modelo de sensibilización del AM hacia el uso y apropiación de tecnología, y el proceso evolutivo hacia la apropiación de tecnología, en la forma que se muestra en la Fig. 20. La sistematización referida, generó, lo que en este documento se ha llamado, modelo integral de apropiación de tecnología por el AM (MIAT-AM). De esta forma se ha logrado articular la transición completa que experimentaría el AM, desde alguno de los niveles de brecha digital, hasta el uso persistente y creativo de la tecnología para satisfacer sus intereses, en procura de una mejor calidad de vida (apropiación de la tecnología). 


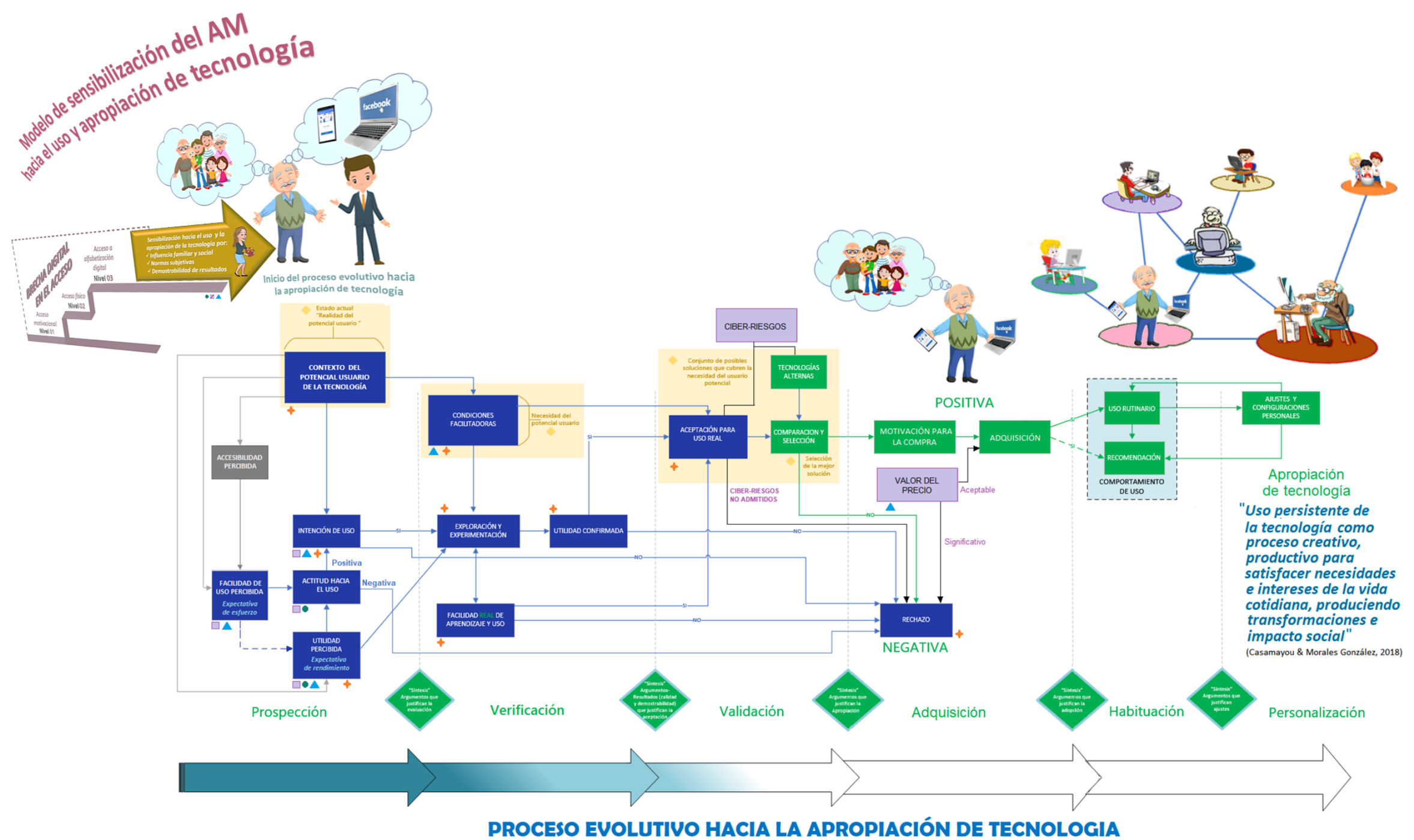

Fig. 20 Modelo integral de apropiación de tecnología del AM (MIAT-AM) 


\subsection{El AM frente a la red social Facebook}

Como se señaló antes, para la comprensión de la situación del AM frente a Facebook, los hallazgos de la revisión sistemática de literatura fueron organizados utilizando el modelo de sensibilización del AM hacia el uso y apropiación de la tecnología; en los términos que se presentan a continuación:

\subsection{1. Ámbitos de sensibilización del AM para la reducción de la brecha digital en el acceso motivacional}

El punto de partida para orientar la reducción de la brecha digital por el acceso motivacional es encontrar en estudios científicos, los beneficios que la tecnología de la red social Facebook haya traído a la calidad de vida del AM. Se considera que estos beneficios puestos en conocimiento del AM y compatibilizados con sus condiciones particulares de vida, podrían sensibilizar al AM para superar sus creencias, sus barreras mentales, y las limitaciones propias de la edad, para conducirlo hacia el uso y apropiación de la tecnología de Facebook.

De la revisión sistemática de literatura, se presenta en la Tabla 7 una síntesis de las razones que pueden darse a conocer al AM para motivarlo a probar, usar y apropiarse de las TIC en general, y en particular de Facebook.

Tabla 7. Síntesis de los ámbitos de sensibilización del AM respecto de los beneficios de las TIC y en particular de Facebook

\begin{tabular}{|c|c|c|}
\hline Ámbitos de sensibilización & Descripción del factor de sensibilización & Fuente \\
\hline \multirow{2}{*}{ General } & $\begin{array}{l}\text { Las redes sociales, Facebook en particular, son para el } \\
\text { AM, los medios sustitutos más importantes, } \\
\text { disponibles a través de Internet, para mantenerse } \\
\text { activo y continuar con su desempeño acostumbrado y } \\
\text { sus roles. }\end{array}$ & \multirow{2}{*}{$\begin{array}{l}\text { (Oddone, 2013) - } \\
\text { (Casamayou \& } \\
\text { Morales González, } \\
\text { 2018) - (Agudo } \\
\text { Prado \& Fombona } \\
\text { Cadavieco, 2013) - } \\
\text { (Choi \& Dinitto, } \\
\text { 2013) - (Meymo \& } \\
\text { Nyström, 2017) - } \\
\text { (Aldana González } \\
\text { et al., 2012) }\end{array}$} \\
\hline & $\begin{array}{l}\text { Los AM deben comprender que necesitan tomar la } \\
\text { decisión de usar esos medios tecnológicos sustitutos, } \\
\text { porque son instrumentos para envejecer bien, } \\
\text { entretener, educar, y socializar, benefician la salud } \\
\text { física y mental, apoyan su inclusión social, y les ayuda } \\
\text { a no quedar marginados de lo que sucede en su } \\
\text { comunidad. }\end{array}$ & \\
\hline \multirow{6}{*}{ Aspecto sociológico del AM } & Facilita la participación social. & \multirow{6}{*}{$\begin{array}{l}\text { (Mahmud et al., } \\
\text { 2016) - (Boyd et al., } \\
\text { 2018) - (Teng \& } \\
\text { Joo, 2017) - } \\
\text { (Sinclair \& Grieve, } \\
\text { 2017) - (Seabrook } \\
\text { et al., 2016) - (Haris } \\
\text { et al., 2014) } \\
\text { (Wallbridge, 2009) } \\
\text { - (Casamayou \& } \\
\text { Morales González, } \\
\text { 2018) - (Barbosa } \\
\text { Neves et al., 2019) - } \\
\text { (Ramos et al., } \\
\text { 2018) - (Finn \& Ph, }\end{array}$} \\
\hline & $\begin{array}{l}\text { Mejora la conexión social y el apoyo social - provee } \\
\text { capital social. Facebook puede ser una buena fuente de } \\
\text { apoyo, frente a problemas de salud. }\end{array}$ & \\
\hline & Favorece la comunicación intergeneracional. & \\
\hline & Reduce el aislamiento social. & \\
\hline & Amplía la red de contactos con personas del pasado. & \\
\hline & $\begin{array}{l}\text { Permite superar las distancias geográficas entre el AM } \\
\text { y sus familiares cercanos y amigos. }\end{array}$ & \\
\hline
\end{tabular}




\begin{tabular}{|c|c|c|}
\hline & Refuerza las relaciones fuera de línea. & \multirow{3}{*}{$\begin{array}{l}\text { 2010) - (Jung \& } \\
\text { Sundar, 2016) - } \\
\text { (Lappa, 2018) - } \\
\text { (Casamayou \& } \\
\text { Morales González, } \\
2018)\end{array}$} \\
\hline & Apoya la inclusión social. & \\
\hline & $\begin{array}{l}\text { Mantiene los vínculos con la comunidad, y la red social } \\
\text { menos personal. }\end{array}$ & \\
\hline \multirow[b]{2}{*}{ Proceso cognitivo del AM } & $\begin{array}{l}\text { Evita el desgaste cognitivo a través de estímulos, } \\
\text { aprendizajes e interacciones sociales frecuentes. }\end{array}$ & \multirow[b]{2}{*}{$\begin{array}{l}\text { (Agudo Prado \& } \\
\text { Fombona } \\
\text { Cadavieco, 2013) - } \\
\text { (Casamayou \& } \\
\text { Morales González, } \\
\text { 2018) - (Finn \& Ph, } \\
\text { 2010) - (Seabrook } \\
\text { et al., 2016) - (Vilte } \\
\text { et al., 2013) }\end{array}$} \\
\hline & $\begin{array}{l}\text { El uso de las TIC presentan los siguientes beneficios en } \\
\text { el aspecto cognitivo de las personas mayores: } \\
\text { a. Favorece la concentración y la atención. } \\
\text { b. Desarrolla un aprendizaje ininterrumpido. } \\
\text { c. Estimula los procesos cognitivos (entrena la } \\
\text { memoria, mejora la atención, desarrolla la } \\
\text { inteligencia emocional y la creatividad). } \\
\text { d. Mejora las capacidades comunicativas. }\end{array}$ & \\
\hline \multirow{5}{*}{$\begin{array}{l}\text { Bienestar físico y bienestar } \\
\text { psicológico }\end{array}$} & Mantenimiento de la psicomotricidad fina. & \multirow{5}{*}{$\begin{array}{l}\text { (Agudo Prado \& } \\
\text { Fombona } \\
\text { Cadavieco, 2013) - } \\
\text { (Haris et al., 2014) - } \\
\text { (Mahmud et al., } \\
\text { 2016) - (Chopik, } \\
\text { 2016) - } \\
\text { (Sinclair \& Grieve, } \\
\text { 2017) - } \\
\text { (Casamayou \& } \\
\text { Morales González, } \\
\text { 2018) - (Nef et al., } \\
\text { 2013) - (Seabrook } \\
\text { et al., 2016) - } \\
\text { (Ramos et al., } \\
\text { 2018) - (D. Quinn et } \\
\text { al., 2016) }\end{array}$} \\
\hline & $\begin{array}{l}\text { Favorece el autoestima, la autoconfianza, la identidad } \\
\text { social. }\end{array}$ & \\
\hline & $\begin{array}{l}\text { La salud física y psicológica de los AM se ve mejorada } \\
\text { con la reducción de la sensación subjetiva de soledad y } \\
\text { aislamiento social, hacia lo cual puede contribuir } \\
\text { Facebook. }\end{array}$ & \\
\hline & $\begin{array}{l}\text { El uso de Facebook, a los AM les significa una mejor } \\
\text { autopercepción de la salud, mantenimiento de } \\
\text { habilidades funcionales (valerse por sí mismo), mayor } \\
\text { bienestar subjetivo, por lo tanto, menos síntomas } \\
\text { depresivos, mayor estabilidad emocional, menos riesgo } \\
\text { de contraer enfermedades mentales, menor desgaste } \\
\text { cognitivo, reducción del estrés, niveles más altos de } \\
\text { satisfacción con la vida y autoestima. }\end{array}$ & \\
\hline & $\begin{array}{l}\text { Apoya la adaptación hedónica y la perspectiva } \\
\text { hedónica. }\end{array}$ & \\
\hline \multirow{3}{*}{ Entretenimiento y ocio } & $\begin{array}{l}\text { Facebook hace entretenida la vida diaria del AM, le } \\
\text { permite invertir el tiempo que dispone debido a } \\
\text { problemas médicos, su retiro y la reducción de parte de } \\
\text { su familia; en actividad social, entretenimiento y } \\
\text { hobbies. }\end{array}$ & \multirow{3}{*}{$\begin{array}{l}\text { (Haris et al., 2014) - } \\
\text { (Casamayou \& } \\
\text { Morales González, } \\
\text { 2018) - (Jung \& } \\
\text { Sundar, 2016) - } \\
\text { (Finn \& Ph, 2010) - } \\
\text { (Teng \& Joo, 2017) } \\
\text { (Ramos et al., } \\
\text { 2018) }\end{array}$} \\
\hline & $\begin{array}{l}\text { Vigilancia social: revisar fotos, notas, enlaces y diversos } \\
\text { estados de las personas sin dejar comentarios. }\end{array}$ & \\
\hline & $\begin{array}{l}\text { Facebook es un medio de diversión y de autoexpresión, } \\
\text { que estimula la creatividad del AM. }\end{array}$ & \\
\hline \multirow{2}{*}{ Acceso a información } & $\begin{array}{l}\text { Facebook es un medio de fácil acceso a información } \\
\text { diversa relacionada con la vida saludable en la vejez, } \\
\text { familia y finanzas. }\end{array}$ & \multirow{2}{*}{$\begin{array}{l}\text { (Haris et al., 2014) - } \\
\text { (Teng \& Joo, 2017) } \\
\text { - (Casamayou \& } \\
\text { Morales González, } \\
\text { 2018) - (Ramos et } \\
\text { al., 2018) }\end{array}$} \\
\hline & $\begin{array}{l}\text { Las redes sociales les brindan apoyo informativo en } \\
\text { términos de consejos, sugerencias e información. }\end{array}$ & \\
\hline
\end{tabular}




\subsubsection{Alternativas para la reducción de la brecha digital en el acceso físico}

La brecha digital en el acceso físico del AM tiene que ver con dos aspectos claramente diferenciados, el uno que involucra exclusivamente al potencial usuario AM y corresponde a la disponibilidad de la infraestructura necesaria para ingresar al servicio de Internet. $Y$, el segundo aspecto, que sale del control del AM, y que se relaciona con las características del diseño de la interface de usuario en los dispositivos computacionales y en la plataforma de Internet que provee el servicio, temas que se analizan en la siguiente sección.

Para el primer aspecto, el potencial usuario AM debe disponer de la capacidad económica, o en su defecto del apoyo de sus familiares, para disponer de la infraestructura necesaria para el acceso a Internet: por un lado, el contrato con el proveedor del servicio de Internet (ISP por sus siglas en inglés); $y$, por otro lado, la adquisición de los dispositivos computacionales de uso personal para aprovechar del servicio tecnológico, sea PC, laptop, o teléfono inteligente.

Vale señalar, que en (Colombo et al., 2015), (Finn \& Ph, 2010), (Choi \& Dinitto, 2013), (Sippl et al., 2017), y (Abdullah et al., 2011), se señala a la pobreza y los ingresos bajos como factores que impiden cubrir los costos asociados con la conexión a Internet o la disponibilidad de un dispositivo de acceso funcional. Por lo tanto, el contexto económico es determinante en la existencia o no del nivel de brecha digital en el acceso físico.

El peso de este factor importante que afecta el uso de la tecnología por parte del AM, y lo aleja de una alternativa para mejorar su calidad de vida, bien podría ser alivianado, a través de políticas públicas y leyes dirigidas a beneficiar a este grupo poblacional, orientadas a contar con un acceso más económico a Internet y a los dispositivos de computación.

\section{Alternativas para la reducción de la brecha digital por el acceso físico, relacionadas con la mejora de la usabilidad de las interfaces de usuario a ser utilizadas por el AM}

Para iniciar, es de destacar la coincidencia en las observaciones realizadas en (Diaz \& Harari, 2014b), (Diaz \& Harari, 2015), (Diaz \& Harari, 2014a), (Vilte et al., 2013), (Curiel et al., 2014), (Bong et al., 2018), (Casamayou \& Morales González, 2018), con referencia a la falta de consideración de las características propias de los AM, tanto en el diseño de los dispositivos como de las interfaces de usuario de los equipos computacionales de acceso a los servicios de Internet: PC's, laptops, teléfonos inteligentes; como en las interfaces de acceso a los servicios de las plataformas de redes sociales.

Las características del AM que se deben tomar en cuenta, son las limitaciones físicas y cognitivas debido al envejecimiento, como las señaladas en (Casamayou \& Morales González, 2018), (Jung \& Sundar, 2016), (Choi \& Dinitto, 2013) (Majcen et al., 2011), (Leist et al., 2011), (Finn \& Ph, 2010), y (Renaud \& Van Biljon, 2008): deficiencias sensoriales (discapacidad auditiva, problemas de visión), reducción de movilidad, disminución inevitable de la destreza manual y el control motor fino, problemas de discapacidad, y dolor; dificultad en el uso de terminología especializada, problemas de memorización de procedimientos para cumplir una actividad, facilidad para distraerse.

Ante tal inobservancia, los diseñadores corren el riesgo de crear barreras en todo el contexto tecnológico: diseño de tecnología; usabilidad de equipo y/o servicio; y, capacitación y educación formal, afectando especialmente al AM por la dificultad para aprender y usar la tecnología, que en última instancia lo termina alejando con una sensación de miedo e incapacidad, con lamentables consecuencias en su nivel de aislamiento social y familiar. 


\section{Alternativa No. 1 relacionada con el proceso de desarrollo de tecnología}

De (Bong et al., 2018), (Diaz \& Harari, 2014b),(Diaz \& Harari, 2014a) (Diaz \& Harari, 2015), (Vilte et al., 2013), (Leist et al., 2011) se extrae esta primera alternativa, que apunta a mejorar las características operativas y funcionales de las interfaces de usuario de los dispositivos y servicios tecnológicos, mediante la incorporación de miembros del grupo etario AM en dos etapas primordiales del proceso general de desarrollo de tecnología:

1. La etapa de definición de especificaciones del nuevo producto o servicio tecnológico,

2. La etapa de evaluación de usabilidad del nuevo producto o servicio.

\section{Alternativa No. 2 relacionada con el diseño de la interfaz humano-computadora ( $\mathrm{HCl}$ por sus siglas} en inglés)

Conocer las barreras de usabilidad ayudará en el diseño de nuevas interfaces de usuario y en la mejora de las existentes. En (Finn \& Ph, 2010), (De Oleo Moreta \& Rodríguez Baena, 2012), (Vilte et al., 2013), y (Boyd et al., 2018), se han expuesto algunas barreras de usabilidad que se sintetizan en: diseño de interfaz deficiente; interfaz percibida como inconsistente y confusa, que no resulta sencilla para el manejo y la comprensión por parte de los AM; interfaz sobrecargada de contenido y elementos que provoca confusión en la interacción con la aplicación, interfaz con excesiva publicidad que desconcierta.

(Boll et al., 2017) comenta: "con relación a diseño de tecnología/equipo, en términos de $\mathrm{HCl}$, ajustes especificos de la interface de usuario (UI por sus siglas en inglés), no extraordinarios, harían que las redes sociales podrían ser fácilmente utilizables y más atractivas para los AM."

\section{Alternativa No. 3 relacionada con los intereses del AM que influirían el diseño de los servicios tecnológicos}

Las observaciones que se deben tomar en cuenta en el diseño de los servicios tecnológicos de comunicación e interacción basadas en TIC, a ser utilizadas por AM, se han compilado de (Finn \& Ph, 2010), (Leist et al., 2011), (Choi \& Dinitto, 2013),(Diaz \& Harari, 2014b), (Jung \& Sundar, 2016), (Meymo \& Nyström, 2017) y (Boll et al., 2017), (Bong et al., 2018) en los siguientes términos:

1. Para los AM. mantener relaciones cercanas existentes es más importante que crear nuevas relaciones.

2. Las relaciones de los AM con sus familiares cercanos no son necesariamente recíprocas y simétricas.

3. La asimetría en las relaciones del AM es aceptable con los familiares, pero no con los amigos.

4. Las tecnologías deben generar en el AM un sentido autonomía.

5. Es importante la privacidad y seguridad de los datos del AM.

6. Los AM prefieren interfaces de usuario intuitivas, de fácil uso, con opciones simples y fácilmente comprensibles, que reduzcan el esfuerzo cognitivo de ellos.

7. Al AM le interesa estar informado del acontecer diario a través de noticias o grupos de interés común.

8. Al AM le gusta tener experiencias positivas, recibiendo o proveyendo reacciones positivas a las publicaciones.

9. El AM desea recibir recomendaciones por el sistema tecnológico.

10. La modalidad de prestación de servicio que atrae a los usuarios $A M$, es la que le provee mayor presencia social; y que además se centra en la publicación de elementos visuales 
(fotos, vídeos), con posibilidad de comentar las fotos de otros usuarios y recibir comentarios sobre las suyas.

11. A los AM les gustaría que se agreguen para las interacciones con las tecnologías, rasgos más naturales como la interacción mediante el habla.

\subsection{3. Ámbitos de sensibilización del AM para la reducción de la brecha digital en el acceso a la alfabetización digital}

Respecto a acciones que se han tomado para reducir la brecha digital en el acceso a alfabetización digital del AM, se puede afirmar que existen evidencias suficientes de los esfuerzos, vinculados con la educación y capacitación, que se han realizado para reducir la brecha digital, y proveerle al AM de habilidades digitales para el manejo de Internet, principalmente de las redes sociales, en particular de Facebook.

En Ecuador, se pueden citar varios ejemplos como muestras del esfuerzo realizado en este sentido. En (Cordova Jorge \& Pacheco Fernando, 2013) se hace mención al proyecto de extensión universitaria denominado "Las redes sociales en la tercera edad", desarrollado por la Universidad Estatal de Milagro, ubicada en la provincia del Guayas, con el cual se propició que el AM use la red social Facebook entre otras herramientas web interactivas, como medio de distracción y de comunicación con familiares y amigos.

En (Játiva Espinoza \& Jaramillo Vásconez, 2013), Anexo 2, se presenta un detalle de los competidores relevantes existentes en la ciudad de Quito, en el año 2013 en que se realizó el estudio, del sector de los servicios de capacitación en tecnología para $A M$, habiéndose encontrado que es un sector heterogéneo compuesto por organizaciones con diferentes características, como: instituciones educativas de gran experiencia en el sector de la educación como la ESPE y el Centro de Estudios del Comercio de la Cámara de Comercio de Quito; fundaciones e instituciones públicas como el CEAM (Centro de Experiencia del AM Patronato Municipal San José) y la Red Sesenta y PiQuito del Municipio de Quito; y, empresas privadas o personas naturales.

De las participaciones de los AM en cursos de capacitación enfocados en la inclusión digital, se han extraído importantes experiencias, así, según (Meymo \& Nyström, 2017) y (Aldana González et al., 2012), se ha observado gran interés y entusiasmo de los AM por mejorar sus conocimientos técnicos. Según (Casamayou \& Morales González, 2018), hay diferentes factores que influyen positiva o negativamente en el aprendizaje de las personas adultas mayores, como son: el nivel de estudios, la edad, actitudes propias de la persona como optimismo, curiosidad, motivación y miedo, el nivel de sus funciones cognitivas (atención, memoria, razonamiento), las expectativas de uso, y la disponibilidad de la tecnología de acceso al servicio deseado.

De las experiencias antes citadas, y de otros hallazgos interesantes sobre AM participantes en eventos de capacitación relacionados con los servicios de comunicación e interacción que ofrecen las TIC, se han desprendido las propuestas de sensibilización hacia la alfabetización digital del AM presentes en la Tabla 8. Si bien los criterios en que se sustentan, fueron citados hace más o menos 10 años, se consideran que siguen siendo vigentes. 
Tabla 8. Síntesis de las propuestas de sensibilización del AM hacia la alfabetización digital

\begin{tabular}{|c|c|c|}
\hline $\begin{array}{l}\text { Propuestas de } \\
\text { sensibilización }\end{array}$ & Descripción del factor de sensibilización & Fuente \\
\hline $\begin{array}{l}\text { Para crear en el AM } \\
\text { predisposición hacia el } \\
\text { aprendizaje. }\end{array}$ & $\begin{array}{l}\text { - Compatibilizar la situación propia del AM con los } \\
\text { distintos beneficios potenciales del uso de } \\
\text { Facebook, que estarían al alcance del AM con el } \\
\text { esfuerzo de aprendizaje. } \\
\text { Recordarle al AM su disponibilidad de capacidades } \\
\text { intelectuales suficientes para emprender un nuevo } \\
\text { aprendizaje, caracterizarlos como personas activas, } \\
\text { dispuestas a aprender acerca de las TIC y con gran } \\
\text { capacidad para desarrollar sus procesos cognitivos, } \\
\text { y que es un mito de que el AM no puede aprender } \\
\text { algo nuevo y que son personas en declive. }\end{array}$ & $\begin{array}{l}\text { (Lehtinen et al., } \\
\text { 2011) - (Aldana } \\
\text { González et al., } \\
2012 \text { ) }\end{array}$ \\
\hline $\begin{array}{l}\text { Para superar la tecnofobia } \\
\text { en el AM. }\end{array}$ & $\begin{array}{l}\text { - Enseñarles a los AM a controlar sus indicios de } \\
\text { ansiedad con perseverancia, confianza y tolerancia } \\
\text { a la frustración. } \\
\text { Desarrollar el proceso de aprendizaje con la } \\
\text { provisión de las funciones fáciles de utilizar } \\
\text { mediante ejemplos prácticos relacionados con los } \\
\text { intereses particulares de los AM. }\end{array}$ & $\begin{array}{l}\text { (Abdullah et al., } \\
\text { 2011) - (Aldana } \\
\text { González et al., } \\
2012 \text { ) }\end{array}$ \\
\hline $\begin{array}{l}\text { Para mantener la } \\
\text { motivación hacia el } \\
\text { aprendizaje, rodear al AM } \\
\text { de un ambiente de } \\
\text { entusiasmo, confianza, } \\
\text { acompañamiento y } \\
\text { compatibilidad. }\end{array}$ & 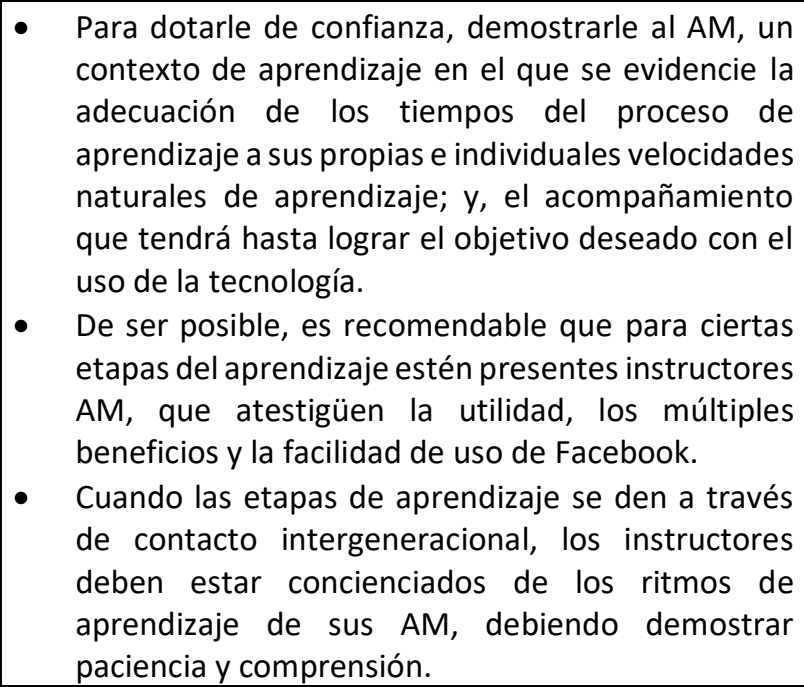 & $\begin{array}{l}\text { (Aldana González } \\
\text { et al., 2012) } \\
\text { (Renaud \& Van } \\
\text { Biljon, 2008) }\end{array}$ \\
\hline
\end{tabular}

Por otra parte, cabe señalar que la brecha digital debido al nivel de alfabetización digital que demuestran los AM, finalmente desaparecerá debido a la exposición casi universal de la población, dentro de su etapa de vida productiva, al uso de la computadora y la tecnología de Internet, el uso cada vez mayor de los teléfonos inteligentes y sus novedosas aplicaciones. En esa perspectiva, en (PROSIC, 2010) se señala: “... en los próximos años muchos de quienes superen los 65 años serán personas que por razones de trabajo o motivadas por las ventajas que ofrecen las TIC estarán habituadas al uso de éstas. Esta lógica es la que permite afirmar que el incremento será gradual pero sostenido con cada generación, por lo cual la brecha digital debido a esta circunstancia se cerrará con el tiempo." Esta tendencia, se ve evidenciada en (INEC, 2018), donde se muestra una condición decreciente de los niveles de analfabetismo digital conforme los años avanzan, como se observa en la Fig. 21. 


\section{Analfabetismo digital: Nacional}

En 2018 , el $10,7 \%$ de las personas de 15 a 49 años son analfabetas digitales, 10,7 puntos menos que en 2012.

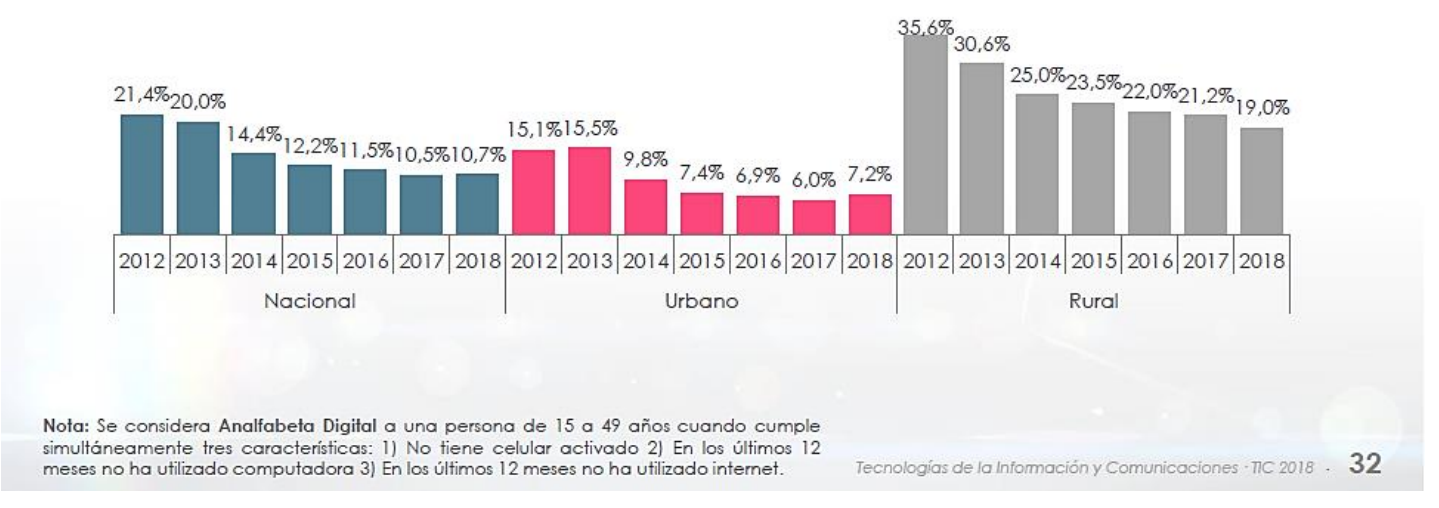

Fig. 21 Tendencia decreciente de los niveles de analfabetismo digital en Ecuador - Fuente (INEC, 2018)

\subsubsection{Precauciones a tener en cuenta para evitar efectos adversos con el uso de Facebook}

Si se ha logrado cerrar la brecha digital en los tres niveles de acceso, y el AM inicia con el uso de la tecnología, para el caso del presente estudio, de la red social Facebook, se deben poner atención a otros aspectos también importantes para mantener cerrada la brecha digital en el acceso motivacional. Estos aspectos, que no deben ser descuidados, se indican a continuación:

1. El AM quiere contar con apoyo constante de confianza y capacitación a su medida cuando el sistema está en uso. (Leist et al., 2011)

2. El AM debe mantenerse alejado de las interacciones virtuales superficiales, breves y ligeras con personas poco o nada significativas para él, ya que podrían resultar peligrosas para su privacidad, seguridad y bienestar emocional. (Laing \& Future Foundation, 2015)

3. Sintetizando a (Mahmud et al., 2016), el AM requiere los siguientes compromisos de los miembros de su familia:

a. De que van a ser receptivos de sus interacciones virtuales y van a ser tolerantes con él. Los esfuerzos realizados por los usuarios AM de Facebook, para compartir la información con los miembros de la familia, cuando parecen no ser apreciados por falta de respuesta, han provocado que dejen de compartir.

b. Cuando el AM percibe la falta de apoyo social familiar en términos de compromiso de tiempo y esfuerzo, tienden a rechazar la red familiar.

c. No incomodar su estado de ánimo creando una sensación de control al ser contacto en la red social o juzgando sus participaciones en la red.

d. No hacer publicaciones inapropiadas.

e. No permitir que conflictos entre miembros de la familia se extiendan a Facebook, y afecten la forma de participación en la red social a tal punto que generen estrés. 
4. Dejar de lado la influencia social negativa relacionada a las personas adultas mayores y la tecnología, porque pueden conformar barreras mentales que impidan darle a la tecnología todo el sentido posible en su vida. (Casamayou \& Morales González, 2018)

5. El AM debe ser muy consciente para detectar si el uso frecuente de Internet y de la red social Facebook le está causando una reducción del tiempo para relaciones sociales reales con sus familiares y amigos, y le está impidiendo otras actividades necesarias para su salud física, como la actividad física al aire libre, que terminen con la decisión de limitar el uso de la red social. (Nef et al., 2013) (Lappa, 2018)

6. Es importante que el $\mathrm{AM}$ y sus contactos tengan muy claro que el uso de la red social Facebook ayuda a conservar el contacto social y familiar, complementa y amplia las interacciones reales; y que, bajo ningún concepto, se puede creer que una interacción virtual sea capaz de sustituir la riqueza emocional y calidez de una interacción social real cara a cara.

\subsection{Conclusiones}

1) La sensibilización del AM para la reducción de la brecha digital en el acceso motivacional es un aspecto muy importante si se toma en cuenta que, sin una gran motivación, el AM no estará dispuesto esforzarse para superar las deficiencias que tiene para el uso inicial de la tecnología. En este ámbito se revisaron los numerosos beneficios que AM han recibido del uso de Facebook, con el afán de que posteriormente sean expuestos a otros $\mathrm{AM}$ y se conviertan en un complemento a su motivación particular.

Resumiendo, los potenciales beneficios del uso de Facebook para los AM son:

1. Es una opción válida para que la población que envejece enfrente sentimientos de aislamiento social. Facebook contribuye a la inclusión familiar y social del AM, permitiendo comunicación intergeneracional; favoreciendo la conservación, e inclusive la ampliación de la red social del AM; siendo un complemento para las redes sociales fuera de línea.

2. Posibilita la participación del $\mathrm{AM}$ en la comunidad a la que pertenece y en la sociedad en general

3. La tecnología de Facebook le provee al AM de facilidades para una interacción virtual ubicua.

4. Estimula las funciones cognitivas, reduciendo la posibilidad de que el AM experimente un estado de deterioro cognitivo.

5. Aporta al bienestar físico y psicológico del AM, beneficia la autoestima, la autoconfianza, fortalece su identidad, le permite al AM mantener conciencia de su pertenencia a una familia.

6. Contribuye con eficacia al entretenimiento y el ocio del AM.

7. Permite un fácil acceso a la información.

Sin embargo, de los beneficios anotados, existen publicaciones que demuestran que existe preocupación, en algunos AM, para que se ponga atención a su privacidad y seguridad de datos en el entorno del servicio de Facebook.

Del análisis expuesto sobre la red social Facebook y el AM, se concluye que Facebook es una tecnología potencialmente necesaria para el AM que envejece en el domicilio. Facebook es una alternativa tecnológica que satisface algunas de las necesidades reales de bienestar social del AM y puede mejorar su calidad de vida. Tiene características que le aportan valor al AM como presencia social, ubicuidad, comunicación multimedia, comunicación sincrónica y asincrónica. 
2) Se concluyó que los aspectos a tomarse en cuenta para la reducción de la brecha digital en el acceso físico se corresponden con tres contextos del AM: el contexto económico, el contexto físico, y el contexto tecnológico.

El primero es importante porque si el AM no tiene la independencia económica o la ayuda de sus familiares y/o amigos cercanos, no podrá cubrir los mínimos requerimientos técnicos para acceder al servicio de Facebook.

El segundo, se refirió a las limitaciones propias del AM debido a su edad que le podrían limitar y hasta impedir el uso de la red social; por lo que estas características se recomiendan que sean tomadas en cuenta en el desarrollo de la tecnología y sus interfaces, para no crear barreras de usabilidad.

$\mathrm{Y}$, en el contexto tecnológico, enfocado desde dos perspectivas: la tecnología para acceder al servicio; $y$, el servicio propiamente dicho. Se plantearon tres opciones que apuntan a reducir las barreras de usabilidad: 1) relacionada con el proceso de desarrollo de tecnología; 2) concerniente con el diseño de la interfaz humano-computadora; 3 ) ligada con los intereses del AM que influirían el diseño de los servicios tecnológicos

3) Los ámbitos de sensibilización del AM para la reducción de la brecha digital en el acceso a la alfabetización digital tienen que ver con varios factores que pueden influir positiva o negativamente en el aprendizaje de la tecnología por parte de las personas adultas mayores: 1) la actitud de los AM frente a eventos de capacitación, que se determinó que normalmente es positiva; $y 2$ ) el enfoque con que se acoja al AM para presentar y desarrollar un evento de capacitación.

Se reconocieron tres propuestas que ayudarían a sensibilizar al AM hacia la alfabetización digital, que deben ser puestas en práctica por quienes pretenden desarrollar actividades de inclusión digital de los AM: 1) realizar una estimulación previa para crear la predisposición positiva del AM hacia el aprendizaje, dándoles a conocer los potenciales beneficios de la tecnología que se pretende aprender a manejar, y evidenciando las capacidades intelectuales que disponen; 2 ) explicar cómo se va a sortear la tecnofobia; y 3) presentar el ambiente de entusiasmo, confianza, acompañamiento y compatibilidad que experimentará el AM durante el proceso de aprendizaje.

4) Se deben tener precauciones para evitar efectos adversos con el uso de Facebook, es decir, si se ha logrado superar cualquier nivel de brecha digital que el AM haya presentado, y se logró que el AM decida involucrarse con el uso inicial o pruebas de la tecnología, es necesario tomar precauciones para evitar un retroceso en la motivación o peor aún, una deserción del proceso de apropiación de tecnología.

Se anotaron como aspectos relevantes a considerarse: la necesidad de apoyo en el uso de la tecnología, para alcanzar los objetivos del AM; los compromisos que los miembros de la red social del AM deben cumplir.

5) Poniendo atención a la preocupación en algunos AM por que se ponga la suficiente atención a su privacidad y seguridad de datos en el entorno de Facebook, se identificó como ámbito trascendente en el que se puede desarrollar una nueva investigación, las causas que favorecen la exposición de los usuarios AM de la red social, a los ciber-riesgos propios del entorno de Facebook, tomando en cuenta que:

1. Conociéndolas, se las puede catalogar y así determinar los responsables de su minimización. 
2. Para aquellas causas que se cataloguen específicamente como dependientes de los usuarios de Facebook, identificar la mayor cantidad de factores determinantes de ellas.

3. El usuario AM de Facebook necesita percibir el entorno de la red social Facebook como seguro, para que sus interacciones las realice con tranquilidad, satisfacción y alcance la apropiación social de Facebook como alternativa para alcanzar una mejor calidad de vida. 


\section{CAPÍTULO 5 - RESULTADOS DE LAS INVESTIGACIONES}

\subsection{Introducción}

En este capítulo se presentan los resultados de las investigaciones parciales realizadas en el contexto de la tesis doctoral, no en orden cronológico, sino más bien en orden lógico; que derivaron en publicaciones en congresos internacionales relacionados al área.

La descripción de cada una de las investigaciones incluye: 1) un título; 2) una ficha descriptiva diseñada para resumir las características relevantes de cada investigación; 3) los resultados alcanzados con la investigación; 4) discusión; 5) conclusiones; y 6) una tabla con el detalle de las publicaciones derivadas. El Anexo A contiene las publicaciones completas a las que se hacen referencia en este capítulo.

\subsection{Investigación No. 1: razones por las que los AM deberían tener una actitud positiva hacia Facebook}

Esta investigación fue motivada por: 1) la importancia que tienen en la sociedad actual, las diversas alternativas de comunicación e interacción social que las TIC han puesto al alcance de las personas; 2) la influencia que Facebook alcanzó a nivel mundial, en las formas de comunicarse de las personas de diferentes edades; 3 ) la relevancia que tiene el mejoramiento de la calidad de vida de la población $A M$, que se lo analiza desde distintos enfoques, y que en esta investigación se lo hizo desde la perspectiva del uso de Facebook; 4) las reacciones positivas observadas en AM del entorno cercano del tesista, durante y después de la interacción virtual a través de Facebook; y, 5) la brecha digital que ha afectado a muchos adultos mayores, alejándolos de la opción de usar las TIC para mejorar su nivel de calidad de vida.

\subsubsection{Caracterización de la investigación No. 1}

\subsubsection{Propósito}

Tomando en cuenta las 5 motivaciones anteriormente indicadas, se consideró necesario realizar una investigación con el propósito de encontrar argumentos para influir en la actitud del AM, y motivarle a la interacción social a través de Facebook, en pro de alcanzar un mayor nivel de calidad de vida.

La investigación apuntó a estructurar un instrumento dirigido al AM, constituido por un conjunto de motivaciones y una base conceptual que fundamente cada una de ellas. El instrumento así concebido, tuvo el propósito de canalizar, de forma resumida, los hallazgos descritos en el estado del arte sobre el AM frente a Facebook; $y$, aportar a la reducción de la brecha digital en el acceso motivacional.

Se consideró que el instrumento debía servir para difundir al AM, los diferentes beneficios potenciales de la utilización de Internet en general, y de Facebook en particular, Fig. 22, principalmente, aquellos relacionados con el fortalecimiento de las conexiones familiares y sociales del AM, por la consecución de relaciones interpersonales significativas (frecuentes, duraderas, de confianza, con compromiso, con respeto, con aceptación, satisfactorias y recíprocas); sin dejar de señalar otros beneficios relacionados a otras dimensiones de la calidad de vida de los AM. Se decidió que este instrumento fuese un decálogo. 


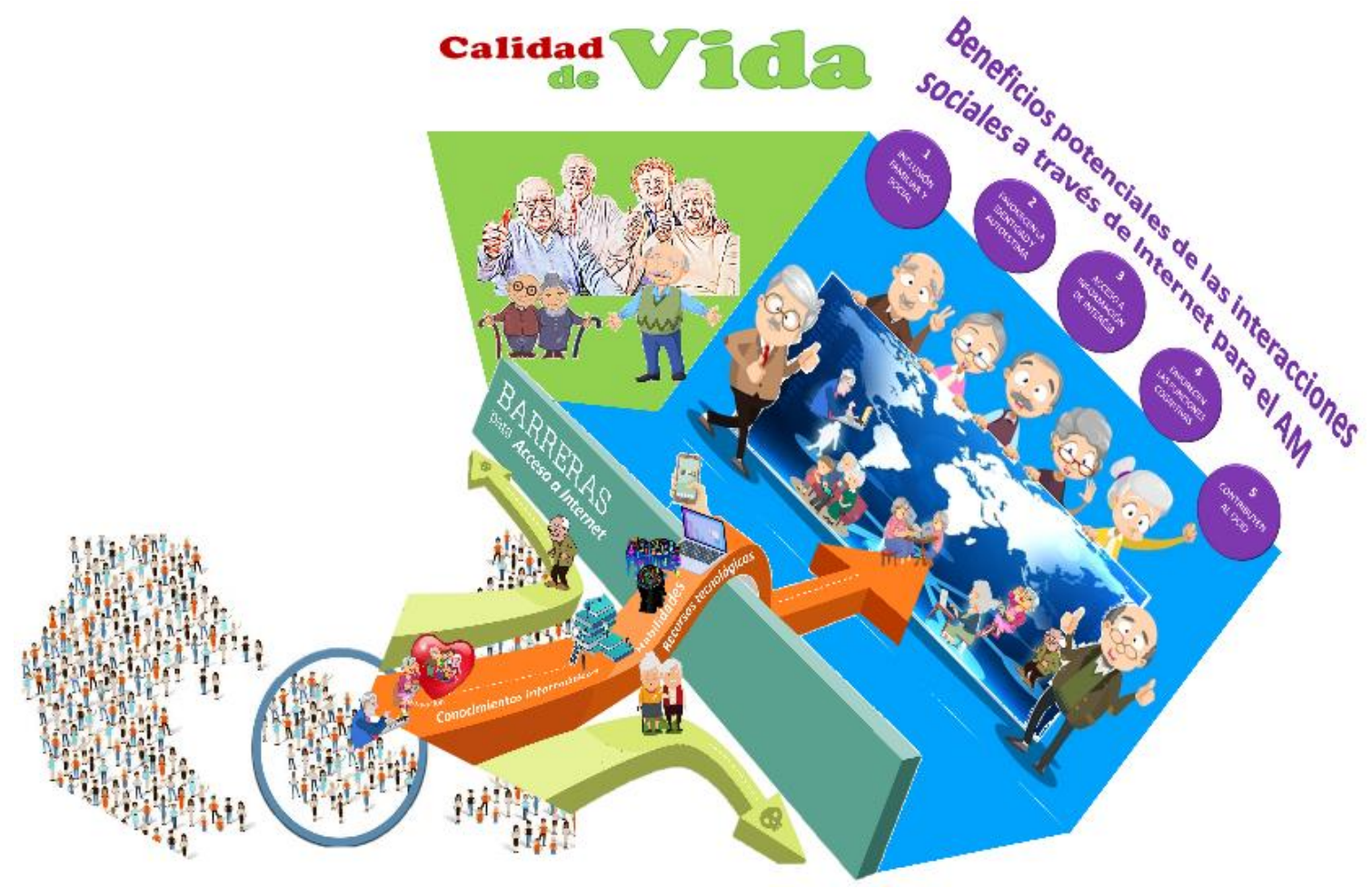

Fig. 22. Razones por las que los AM deberían tener una actitud positiva hacia Facebook

\subsubsection{Ficha descriptiva de la investigación No. 1}

En la Tabla 9 se muestran características relevantes de la investigación No. 1.

Tabla 9. Ficha descriptiva de la investigación No. 1

\section{Ficha descriptiva de la investigación No. 1}

\begin{tabular}{|l|l|}
\hline Características descriptivas & \multicolumn{1}{c|}{ Texto descriptivo } \\
\hline Nombre: & $\begin{array}{l}\text { Razones por las que los AM deberían tener una actitud positiva hacia } \\
\text { Facebook }\end{array}$ \\
\hline Año: & $2016-2017$ \\
\hline Área de Investigación: & Computación social \\
\hline Tipo de investigación: & Cualitativa \\
\hline Enfoque Metodológico: & $\begin{array}{l}\text { Mixto: } \\
\text { 1) Investigación cualitativa con Teoría Fundamentada: método de } \\
\text { codificación y generación de conceptos teóricos. } \\
\text { 2) Investigación no experimental transversal. }\end{array}$ \\
\hline $\begin{array}{l}\text { Técnicas de investigación } \\
\text { utilizadas }\end{array}$ & $\begin{array}{l}\text { Investigación documental. } \\
\text { Investigación en campo. }\end{array}$ \\
\hline $\begin{array}{l}\text { Métodos de recolección de } \\
\text { datos }\end{array}$ & $\begin{array}{l}\text { Investigación documental: heurística - hermenéutica } \\
\text { Investigación en campo: } \\
\text { Observación cualitativa directa de AM del entorno de influencia del } \\
\text { tesista: registro de observaciones en las guías de observación } \\
\text { cualitativa. } \\
\text { Investigación no experimental transversal para esta investigación No.1: } \\
\text { entrevistas estructuradas basadas en un cuestionario concerniente a } \\
\text { las relaciones interpersonales de los AM. }\end{array}$ \\
\hline
\end{tabular}


Análisis de datos:
1) Investigación documental: análisis cualitativo de datos asistido por computadora, a través del software Atlas Ti Versión 7.5.7.

2) Observación directa: reflexión continua de las vivencias registradas.

3) Entrevistas estructuradas: análisis de datos cuantitativos registrados en bases de datos empleando el software Tableau.

\subsubsection{Objetivo}

Hacer explícitas las bases conceptuales que sustentarían cada uno de los mensajes de un decálogo, con los que se pretendería moldear una actitud positiva del AM hacia Facebook, para que alcance los beneficios que le acreditan a la red social, para la calidad de vida de los AM.

\subsubsection{Preguntas de Investigación principales}

¿Cuáles son los mensajes para un decálogo que motive al AM a utilizar la interacción social a través de Facebook como medio para establecer relaciones interpersonales satisfactorias?

¿Cuáles son las bases conceptuales de los mensajes que conformarían el decálogo citado?

\subsubsection{Contexto de la investigación}

1) Investigación documental: publicaciones de diversas características y naturaleza, difundidas a través de Internet por fuentes confiables como son UIT, CEPAL, memorias de congresos y artículos en revistas indexadas; enfocadas en: teorías relativas a la vejez; la calidad de vida del AM, en particular, la dimensión bienestar social; los componentes que determinan la calidad de las relaciones interpersonales del AM.

2) Investigación en campo - observación directa: entorno inmediato del tesista, conformado por AM con las siguientes edades: 1-94 años, 1-82 años, 1-74 años, 1-71 años, 1-70 años, 1-66 años, 3-65 años, 1-62años, 10-58 a 61 años. El nivel socio-económico de los AM es medio. El nivel académico es variado, desde los AM de más edad que normalmente tienen un nivel académico menor, hasta los AM de menos edad que presentan un nivel académico hasta de tercer nivel universitario.

3) Investigación no experimental transversal No. 1: muestra intencional de AM pertenecientes al entorno de influencia del investigador, conformada por 128 AM, 59 hombres y 69 mujeres, Fig. 23.

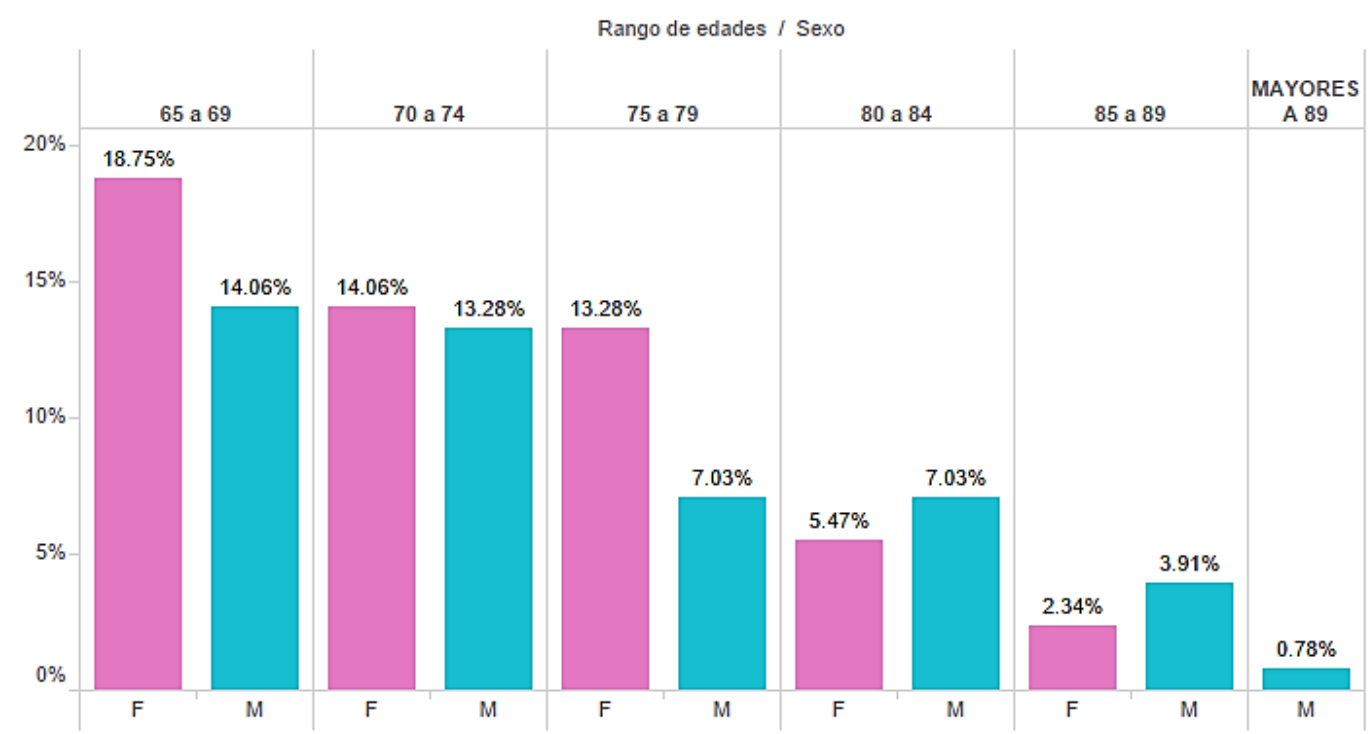

Fig. 23 Configuración de la muestra validada de AM por rangos de edad y sexo. 


\subsubsection{Resultados de la investigación}

\subsubsection{De la observación directa:}

1) El $100 \%$ de los AM de edad avanzada (>75 años) observados, exteriorizan desinterés por el uso de Facebook y medios semejantes, prefiriendo los medios tradicionales, en especial el contacto cara a cara. En este $100 \%$ de AM, no se ha incluido un caso especial para la realidad del Ecuador, de una adulta mayor con 82 años, que vivió en el extranjero durante una etapa importante de su vida, que maneja con comodidad las funciones básicas de la red social Facebook, para mantenerse en contacto con sus amistades de otros países.

Cuando estos AM de edad avanzada observan alguna aplicación basada en las TIC, Facebook u otras aplicaciones de videoconferencia, lo hacen por intermedio de la ayuda de confianza que le proveen algunos de sus familiares cercanos.

Los comentarios que se escucharon de los AM, y con los que se percibió temor en el uso de la tecnología fueron: ¿qué pasa si hago algo mal y mando el mensaje a otro lado?, ¿y si hago alguna mala acción y se daña el equipo? Esos temores les obliga a esperar por ayuda de confianza, y son evidencias de los efectos de la brecha digital.

2) Los adultos mayores observados, que si utilizan la red social Facebook, lo hacen motivados por la conexión social con los miembros de la familia, especialmente con aquellos que se encuentran lejos. Ellos manifiestan satisfacción y emoción con las interacciones sociales virtuales.

\subsubsection{De la investigación no experimental transversal:}

De los datos obtenidos con la encuesta aplicada a la muestra de AM se obtuvieron los siguientes resultados:

1) Para la interpretación correcta de la Fig. 24, cabe aclarar, que el número de $\mathrm{AM}$ en cada uno de los rangos de análisis no fue el mismo, Fig. 23. El número de AM entrevistados era menor conforme la edad aumentaba, reflejando la realidad de este segmento poblacional; $y$ es por esta razón que se hizo un análisis respecto al total (100\%) dentro de cada rango.

La Fig. 24 muestra que:

1. En la muestra tomada, los $A M$ de más de 84 años avanzada no emplean las redes sociales para sus interacciones sociales. Este resultado confirma el primer hallazgo extraído de la observación directa. Esta actitud puede deberse principalmente a factores biológicos propios de la edad, que degradan, en mayor o menor proporción, habilidades motrices, visuales, auditivas y cognitivas; $y$, que generan en el $A M$, miedo y desconfianza en su capacidad de aprender y/o manejar la tecnología.

2. Observando los tres rangos inferiores de edad, se desprende que conforme se incrementa la edad, se nota una tendencia a un menor uso de las redes sociales, lo contrario ocurre con el correo electrónico; esto es lógico considerando el tiempo de vida que tienen esos servicios tecnológicos, y la tendencia de las personas a usar servicios que le aporten mayor presencia social.

Los datos para el rango de edad de 80 a 84 años, muestran un comportamiento diferente a lo señalado en el párrafo anterior, probablemente porque los AM de esas edades utilizan la tecnología con ayuda de sus familiares de confianza y eso les facilita la conexión por medios más modernos. 
3. Las videoconferencias, a través de un servicio parcialmente gratuito como Skype, por tener mayor tiempo de vida que las redes sociales, muestran mayor familiarización con los AM de los diferentes rangos.

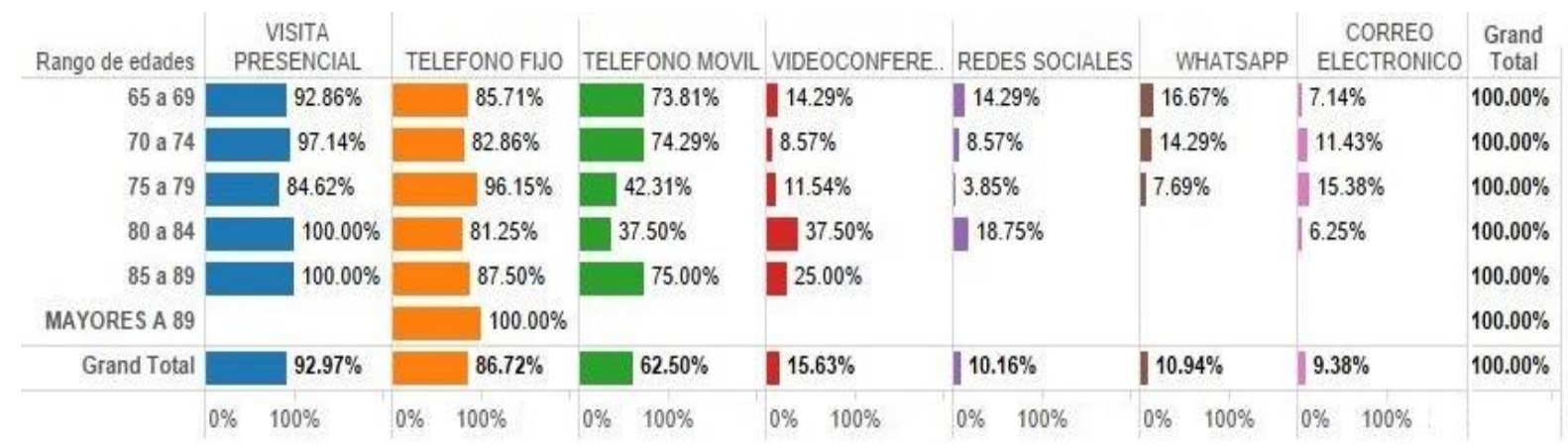

Fig. 24 Medios de comunicación que los AM emplean en sus interacciones sociales.

2) Dado que se pretende motivar a los AM hacia una actitud positiva que los conduzca a utilizar los servicios basados en Internet, es necesario desvelar las razones del desinterés manifestado en la entrevista estructurada, con respecto a aprender a utilizar los servicios de Internet.

En la Fig. 25, para las alternativas de calidad de relaciones interpersonales: excelentes, muy buenas y buenas, que no tienen interés por aprender a utilizar Internet, se pueden señalar dos causas que justifican esa actitud: la primera, los AM están conformes con el nivel de calidad de las relaciones interpersonales que dicen tener, aún sin utilizar los servicios de comunicación basados en Internet. La segunda, los AM ya son usuarios de Internet, se han beneficiado de sus servicios, y tienen el suficiente dominio del manejo de la plataforma tecnológica como para manifestarse desinteresados en aprender.

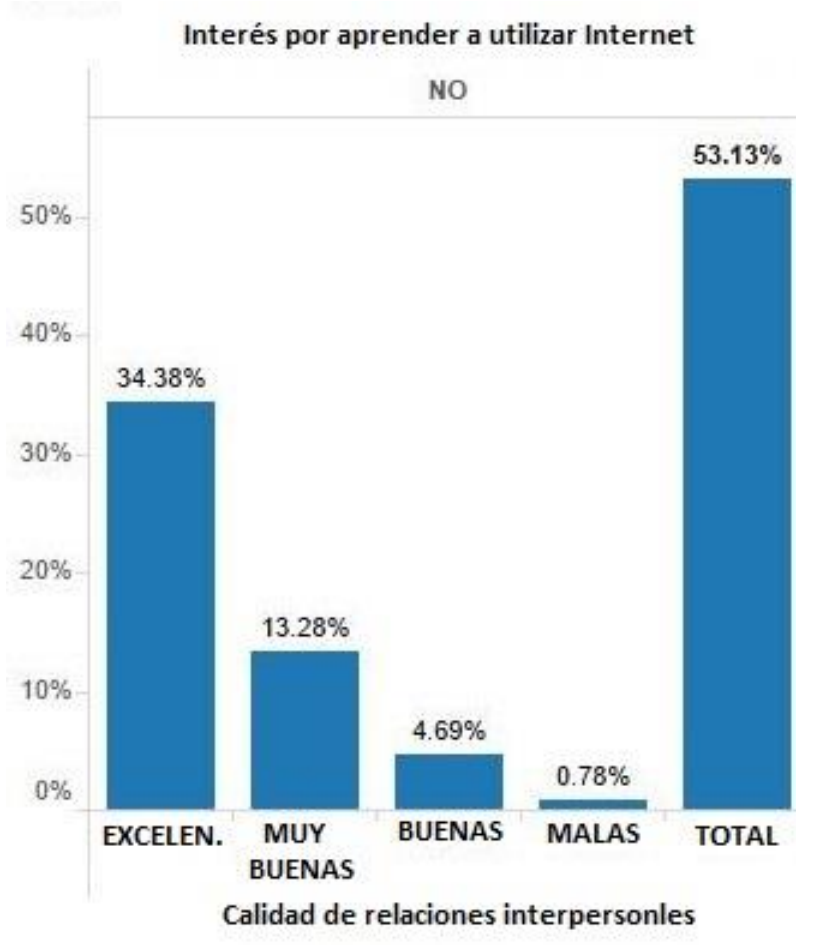

Fig. 25 Calidad de relaciones interpersonales declaradas frente a desinterés de los AM por aprender los servicios por Internet 
3) Respecto a aquellos AM que habiendo reconocido tener mala calidad de relaciones interpersonales y que manifiestan no tener interés en el uso o aprendizaje de servicios ofrecidos por Internet, se puede conjeturar, que se debe a barreras mentales que se han creado respecto a la tecnología: miedo a la tecnología; creer que a su edad es posible que no tengan aptitudes para aprender, e inclusive podría estar influyendo el nivel de formación académica en general que poseen. Es decir, son los afectados por la brecha digital.

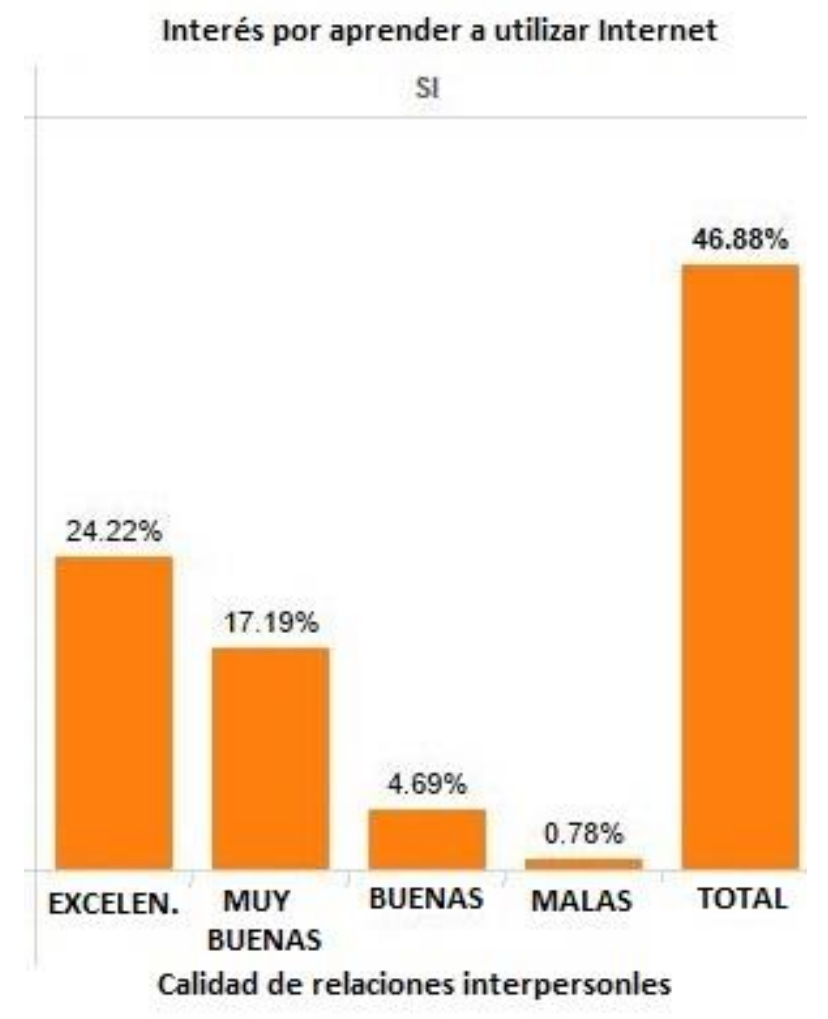

Fig. 26 Calidad de relaciones interpersonales declaradas frente a Interés de los AM por aprender los servicios por Internet

4) De la Fig. 26 se puede afirmar, en general, que prácticamente la mitad de los AM entrevistados manifestaron su deseo de mejorar o aprender destrezas en el manejo de servicios de Internet, como lo es Facebook; es muy posible que quieran ganar autonomía y disminuir la dependencia de la ayuda de confianza que reciben, lo que les permitiría aprovechar Facebook y los demás servicios por Internet, en horarios más amplios y sin tener que sentirse indirectamente supervisados por las personas que ejercen la ayuda de confianza.

5) De la Fig. 27(a), se desprende que todos los AM emplean los sistemas tradicionales de comunicación: cara a cara, y comunicación de voz a través de los servicios de telefonía fijos y móviles; independientemente del nivel de estudios académicos.

En contraposición a lo anterior, la Fig. 27(b) reflejó que el uso de los diferentes servicios de interacción virtual es dependiente directamente del nivel de estudios académicos de los AM: a mayor nivel de estudios mayor empleo de Skype, Facebook, WhatsApp, y correo electrónico; realidad que también podría estar reflejando, en la misma proporción, las condiciones socioeconómicas de los AM; y también podría ser una razón más para el desinterés de los AM por utilizar o aprender las TIC para interacción social. 
Entre los AM que no tienen algún nivel de estudios, Skype y Facebook son utilizados, por la presencia social que brindan, pero deben estar requiriendo de asistencia de familiares cercanos, y además deben poseer una motivación.

6) Por otra parte, la Fig. 27(b), también evidencia que Facebook es la plataforma de interacción virtual más utilizada entre los AM entrevistados.

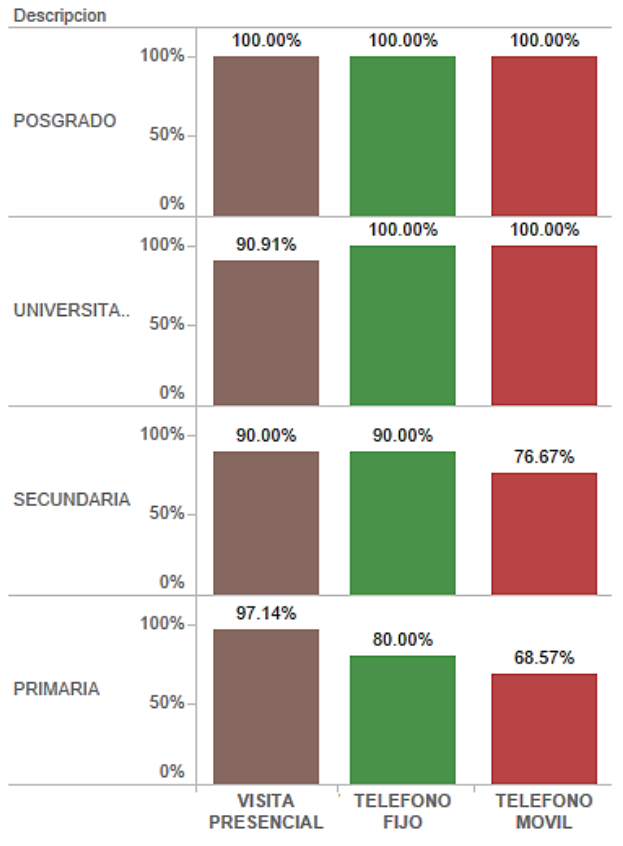

(a)

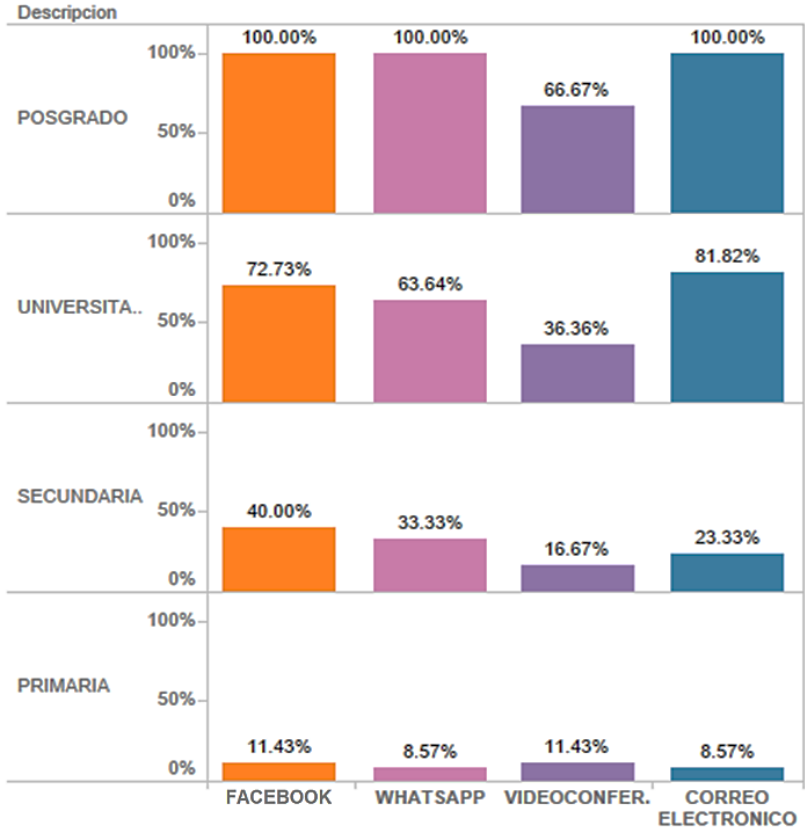

(b)

Fig. 27 Nivel de Estudios de los AM frente a medios de comunicación utilizados: (a) tradicionales, (b) virtuales.

\subsubsection{De la investigación documental:}

Dos fueron los resultados que sintetizaron la investigación documental.

1) Un ideograma en el que se puntualizaban los beneficios potenciales del uso de Facebook para la calidad de vida del AM, Fig. 28, el mismo que fue sustentado por las publicaciones de estudios científicos realizados en diferentes zonas del planeta, que se exponen en la Tabla 10.

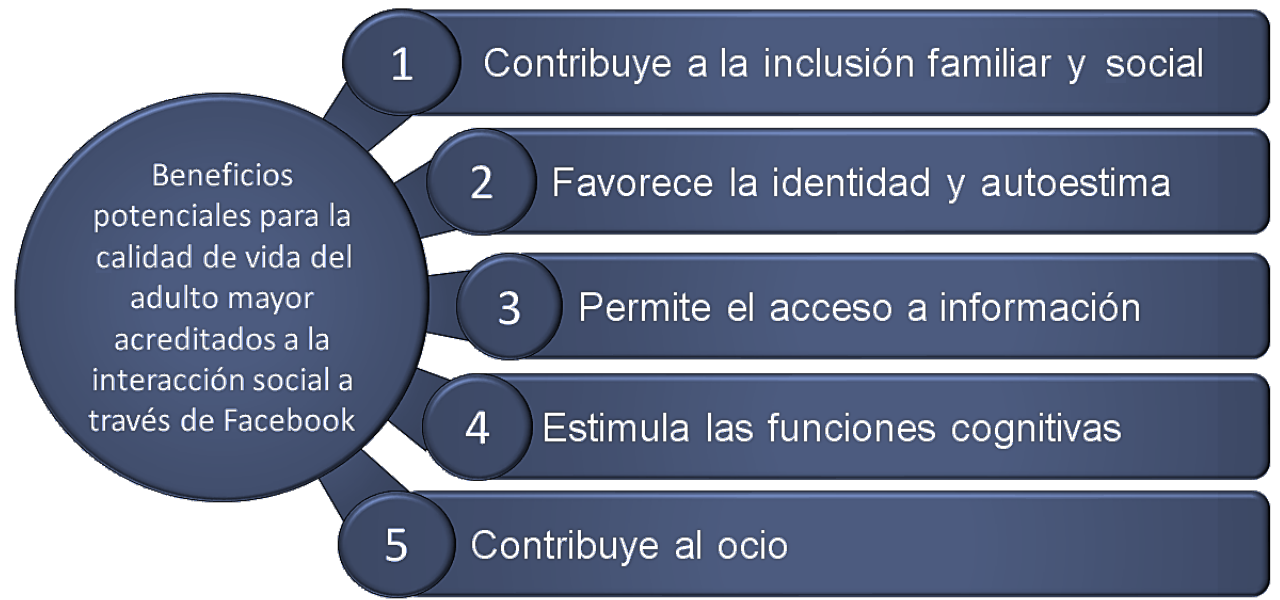

Fig. 28 Beneficios potenciales de las interacciones sociales a través de Internet para el AM que vive en su casa 
Tabla 10. Publicaciones que sustentan los diferentes beneficios potenciales de las interacciones sociales a través de Facebook para el AM

\begin{tabular}{|c|c|c|c|c|c|}
\hline \multirow[t]{2}{*}{ Referencias } & \multicolumn{5}{|c|}{$\begin{array}{l}\text { Beneficios potenciales } \\
\text { sustentados }\end{array}$} \\
\hline & 1 & 2 & 3 & 4 & 5 \\
\hline (Age UK, 2011) & SI & $\mathrm{SI}$ & $\mathrm{SI}$ & & SI \\
\hline (Ala-mutka et al., 2009) & SI & $\mathrm{SI}$ & SI & & \\
\hline (Aldana González et al., 2012) & & SI & & SI & \\
\hline (Haris et al., 2014) & SI & & & & \\
\hline $\begin{array}{l}\text { (Hartnett, Elizabeth; Minocha, Shailey; Palmer, Jane; Petre, } \\
\text { Marian; Evans, Shirley; Middup, Christopher Paul; Dunn, Kathryn; } \\
\text { Murphy, Brendan; Heap, Tania and Roberts, 2013) }\end{array}$ & SI & $\mathrm{SI}$ & $\mathrm{SI}$ & & \\
\hline (Hendry et al., 2015) & $\mathrm{SI}$ & $\mathrm{SI}$ & $\mathrm{SI}$ & & \\
\hline (Hope et al., 2014) & $\mathrm{SI}$ & $\mathrm{SI}$ & & & $\mathrm{SI}$ \\
\hline (Myhre et al., 2016) & & & & $\mathrm{SI}$ & \\
\hline (Moser et al., 2011) & $\mathrm{SI}$ & & & & $\mathrm{SI}$ \\
\hline (Agudo Prado \& Fombona Cadavieco, 2013) & $\mathrm{SI}$ & $\mathrm{SI}$ & $\mathrm{SI}$ & $\mathrm{SI}$ & $\mathrm{SI}$ \\
\hline (D. Quinn et al., 2016) & $\mathrm{SI}$ & & & & \\
\hline (Vilte et al., 2013) & $\mathrm{SI}$ & & $\mathrm{SI}$ & $\mathrm{SI}$ & $\mathrm{SI}$ \\
\hline (F. Zhang \& Kaufman, 2015) & $\mathrm{SI}$ & $\mathrm{SI}$ & $\mathrm{SI}$ & $\mathrm{SI}$ & $\mathrm{SI}$ \\
\hline
\end{tabular}

2) El segundo resultado fue el Decálogo para una actitud positiva del AM hacia Facebook, junto con las bases conceptuales de cada uno de los mensajes, como se muestra en la Tabla 11:

Tabla 11. Decálogo y sus bases conceptuales

\begin{tabular}{|c|l|l|}
\hline Ordinal & \multicolumn{1}{|c|}{ Mensajes del Decálogo } & \multicolumn{1}{c|}{ Bases conceptuales } \\
\hline 1 & $\begin{array}{l}\text { Soy capaz de mantenerme } \\
\text { activo como en otras etapas } \\
\text { de mi vida. }\end{array}$ & $\begin{array}{l}\text { Las teorías orientadas a la vejez enfocadas en (Aranibar, } \\
\text { 2001): de la Modernidad con su Visión dinámica, de la } \\
\text { Modernidad con la Perspectiva de Ciclo de vida, y de la } \\
\text { Actividad. }\end{array}$ \\
\hline \multirow{5}{*}{$\begin{array}{l}\text { Soy el artífice de mi calidad de } \\
\text { vida }\end{array}$} & $\begin{array}{l}\text { "La Calidad de Vida no es algo que una persona puede tener } \\
\text { o no, sino que es necesario considerarla como algo en una } \\
\text { escala; una persona puede tener baja o alta calidad de vida. } \\
\text { La calidad de vida se puede evaluar e incrementar." (Esteban } \\
\text { et al., 2012) } \\
\text { "Cualquier estímulo puede modificar la construcción } \\
\text { individual de su calidad de vida." (Zahava \& Bowling, 2004) }\end{array}$ \\
\hline \multirow{3}{*}{$\begin{array}{l}\text { La actividad social es } \\
\text { beneficiosa y produce } \\
\text { satisfacción en mi vida. }\end{array}$} & $\begin{array}{l}\text { "La actividad social es beneficiosa en sí misma y tiene como } \\
\text { resultado una mayor satisfacción en la vida; la interacción } \\
\text { social es importante en el desarrollo del concepto de símismo } \\
\text { en la vejez; todas las disminuciones en la interacción social en } \\
\text { la vejez se explican mejor por poca salud o discapacidad." } \\
\text { (Oddone, 2013) }\end{array}$ \\
\hline
\end{tabular}




\begin{tabular}{|c|c|c|}
\hline 4 & $\begin{array}{l}\text { Las conexiones con mis seres } \\
\text { queridos son importantes en } \\
\text { mi vida. }\end{array}$ & $\begin{array}{l}\text { "Las redes de la familia, amigos y conocidos, no solo } \\
\text { favorecen a que los mayores mantengan su identidad social, } \\
\text { sino que proporcionan apoyo emocional, material, } \\
\text { información y servicios." (Concha et al., 2000) } \\
\text { En este mismo ámbito, cabe perfectamente el concepto de } \\
\text { inclusión familiar y social, que para este estudio fue } \\
\text { concebido, a través de una adaptación del texto de (Simplican } \\
\text { et al., 2015), como: aceptación social de las personas } \\
\text { ancianas dentro de su entorno familiar y su comunidad } \\
\text { (componente subjetivo), para lograr interacción social, } \\
\text { relaciones y redes sociales (componentes objetivos). }\end{array}$ \\
\hline 5 & $\begin{array}{l}\text { Con Facebook puedo evitar el } \\
\text { aislamiento social y la soledad } \\
\text { que afectarían mis } \\
\text { bienestares: emocional, físico } \\
\text { y social. }\end{array}$ & $\begin{array}{l}\text { Las definiciones de aislamiento social, y soledad que se } \\
\text { encuentran en (Elder \& Retrum, 2012): } \\
\text { Aislamiento social "es el distanciamiento de un individuo, } \\
\text { psicológica o físicamente, o ambos, de su red de relaciones } \\
\text { deseadas o necesarias con otras personas. El aislamiento } \\
\text { social es la experiencia de la disminución de la conexión social } \\
\text { de una persona, que se mide por la calidad, el tipo, la } \\
\text { frecuencia y la satisfacción emocional de los lazos sociales"; } \\
\text { Soledad "es la ausencia de conexiones sociales significativas } \\
\text { que son una necesidad inherente que todos los seres humanos } \\
\text { tienen." }\end{array}$ \\
\hline 6 & $\begin{array}{l}\text { Facebook es una alternativa } \\
\text { válida para mantenerme } \\
\text { activo socialmente con mis } \\
\text { seres queridos que viven } \\
\text { lejos. }\end{array}$ & $\begin{array}{l}\text { "Si el retiro o las limitaciones de la edad hacen imposible la } \\
\text { participación propiamente dicha [en la actividad social], la } \\
\text { gente encontrará sustitutos para los roles o actividades } \\
\text { anteriores a los que hayan tenido que renunciar." (Oddone, } \\
2013 \text { ) }\end{array}$ \\
\hline 7 & $\begin{array}{l}\text { Facebook me permite } \\
\text { mantener relaciones } \\
\text { interpersonales con diferente } \\
\text { intensidad e importancia. }\end{array}$ & $\begin{array}{l}\text { Según (Grossetti, 2009) se define una relación interpersonal } \\
\text { como: "Un conocimiento y un compromiso recíproco } \\
\text { cimentados en las interacciones que dan lugar a formas } \\
\text { específicas de confianza." } \\
\text { La intensidad del compromiso recíproco existente en una } \\
\text { relación interpersonal, en este estudio es referida como la } \\
\text { fuerza de la relación o fuerza del vínculo, respecto a la cual } \\
\text { hay afirmaciones importantes como las siguientes: } \\
\text { a) "La fuerza de la relación es una propiedad cuantificable } \\
\text { que caracteriza el enlace entre dos nodos [en una red } \\
\text { social]." (Petroczi et al., 2007) } \\
\text { b) "La fuerza de un vínculo positivo y simétrico es una } \\
\text { combinación (probablemente lineal) de la cantidad de } \\
\text { tiempo, la intensidad emocional, la intimidad (confianza } \\
\text { mutua) y los servicios recíprocos que caracterizan al } \\
\text { vínculo" Un vínculo dado puede ser fuerte, débil o } \\
\text { ausente (relación o conexión sin significado sustancial - } \\
\text { insignificante)." (Granovetter, 1973) } \\
\text { Los factores que determinan la fuerza de una relación } \\
\text { interpersonal se clasifican en indicadores y predictores } \\
\text { (Marsden \& Campbell, 1984). }\end{array}$ \\
\hline
\end{tabular}




\begin{tabular}{|c|c|c|}
\hline 8 & $\begin{array}{l}\text { Puedo aprender a utilizar } \\
\text { Facebook. }\end{array}$ & $\begin{array}{l}\text { "La capacidad de aprendizaje se conserva en el } \\
\text { envejecimiento normal hasta más allá de los ochenta años; } \\
\text { uno de los aprendizajes que se puede desarrollar con la } \\
\text { estimulación de los procesos cognitivos es el uso y manejo de } \\
\text { las TIC. Los AM en eventos de capacitación demuestran una } \\
\text { actitud de disposición y entusiasmo ante el uso de la } \\
\text { computadora e Internet." (Aldana González et al., 2012) } \\
\text { "No está demostrado que las personas mayores sean } \\
\text { incapaces de realizar actividades intelectuales. Los estudios } \\
\text { del National Institute of Aging de los Estados Unidos sobre el } \\
\text { cerebro de las personas mayores demuestran que éste es tan } \\
\text { activo y eficiente como el de una persona joven. La vejez } \\
\text { mantiene una elevada capacidad para el aprendizaje, } \\
\text { favorecida por la riqueza y la sabiduría de la experiencia." } \\
\text { (Agudo Prado \& Fombona Cadavieco, 2013) }\end{array}$ \\
\hline 9 & $\begin{array}{l}\text { Facebook tiene } \\
\text { funcionalidades que } \\
\text { integralmente aprovechadas } \\
\text { me proporcionarán } \\
\text { interacciones sociales } \\
\text { virtuales muy satisfactorias. }\end{array}$ & $\begin{array}{l}\text { El aprovechamiento integral de las funcionalidades que } \\
\text { ofrece Facebook para interacción social se refiere a la } \\
\text { explotación de la totalidad de características que la } \\
\text { plataforma de red social pone al servicio del usuario de } \\
\text { Facebook, para ayudarle a establecer relaciones } \\
\text { interpersonales satisfactorias: presencia social, ubicuidad, } \\
\text { usabilidad, emisiones unicast, multicast o broadcast, } \\
\text { servicios de comunicación multimedia, y modos de } \\
\text { comunicación síncrona/asíncrona. }\end{array}$ \\
\hline 10 & $\begin{array}{l}\text { Tengo posibilidad de } \\
\text { encontrar otras formas de } \\
\text { utilización de Facebook e } \\
\text { Internet que también me } \\
\text { generarán satisfacción. }\end{array}$ & $\begin{array}{l}\text { El AM descubrirá que, a través de Facebook, a más de estar } \\
\text { activo socialmente con sus seres queridos que viven lejos y } \\
\text { mantener las amistades actuales (Inclusión familiar y social), } \\
\text { se le hacen realidad, paulatinamente, todos los otros } \\
\text { beneficios señalados en la Fig. } 28 \text {. }\end{array}$ \\
\hline
\end{tabular}

\subsubsection{Discusión}

La investigación no experimental transversal demostró que Facebook es el servicio de interacción social basado en Internet que más utilizan los AM entrevistados; la investigación documental mostró la existencia de valiosos beneficios potenciales que Facebook puede tener para la calidad de vida del AM, la observación directa expuso el efecto positivo en el estado de ánimo del AM cuando establece comunicación con sus seres queridos, especialmente con aquellos que se encuentran geográficamente distantes, sin importar que lo esté haciendo de forma virtual, porque le comparten vivencias fotográficas o en vídeo; todo estos resultados justifican la búsqueda de maneras de propiciar en el AM una actitud positiva hacia el uso de Facebook; la vía para intentar alcanzar ese objetivo en la investigación No. 1, fue el decálogo presentado en la Tabla 11, cuyos mensajes estuvieron fundamentados en bases conceptuales extraídas de investigaciones formales.

Con el decálogo propuesto se espera que el AM tenga un punto de partida amplio para superar creencias y barreras mentales que aparecen en su mente como consecuencia de sentir disminuidas algunas de sus facultades físicas, funcionales y mentales, que le han generado temor, aislamiento 
social, soledad, angustia, y más sentimientos y emociones que afectarían negativamente su calidad de vida, e inclusive podrían terminar perturbando su salud física y mental.

Las características funcionales de Facebook, pueden acercarle al AM a las personas importantes para él, sin importar el lugar en el que se encuentren, sin generar o generarse los inconvenientes de trasladarse de un lugar a otro, con la riqueza de poder comunicarse con elementos multimedia, en cualquier momento que lo juzgue oportuno, y durante el tiempo que lo sienta conveniente, percibiendo cercanía y presencia social de los interlocutores, favoreciendo sus oportunidades de involucrarse en las actividades de su familia y amigos.

También Facebook tiene otros beneficios que van más allá de las relaciones interpersonales y que el decálogo desea hacer conocer al AM, por ejemplo, la posibilidad de aprovechar su tiempo libre o de descanso para revisar información de su interés, ver series y películas que son transmitidas por la plataforma de Facebook, e inclusive podría ser artífice de publicaciones y difusiones multimedia, que le aportarían autosatisfacción, incrementando su autoestima.

Nótese que la redacción del decálogo se lo ha hecho en primera persona del singular, de tal forma que el AM que lo lea perciba que sale de su ser interior hacia su mente, fortaleciendo su espíritu y deseos de alcanzar nuevos logros que beneficien su vida, valorando las relaciones con los demás, en especial con la familia cercana, que se ha visto que es la principal motivación de las personas que se encuentran en esa etapa de la vida.

\subsubsection{Conclusiones}

Se tiene certeza, por los hallazgos en las publicaciones científicas analizadas, que la dinámica de uso de los servicios de comunicación basados en TIC por parte del AM, beneficia cualitativamente su calidad de vida, ya que estimula sus funciones cognitivas, beneficia sus habilidades motrices, sus relaciones sociales, modifican su enfoque del tiempo y el ocio; inclusive les brindan la oportunidad de mantener participación ciudadana activa.

Facebook es una alternativa válida para que un AM, que posee autonomía, suficiente salud, y que viva en su casa, se mantenga activo socialmente y goce de inclusión familiar y social.

Sin embargo, sería deseable que la plataforma Facebook mejore ciertos aspectos de usabilidad, debido a que presenta, desde el punto de vista de los AM, algunos inconvenientes como los señalados en (Diaz \& Harari, 2014b), (Vilte et al., 2013) y (Gomes et al., 2014), a más de una cantidad agobiante de publicidad o información sin relevancia para el AM.

El decálogo propuesto se constituye en un compendio de investigaciones previas enfocadas en teorías de la vejez, conceptos y atributos relacionados al AM, que fueron entrelazadas y estructuradas a través de este estudio, de manera lógica para sensibilizar al AM hacia el cambio de actitud frente a la interacción social a través de Facebook. 


\subsubsection{Publicaciones derivadas de la investigación}

La Tabla 12 presenta el detalle de las dos publicaciones derivadas de la investigación No. 1.

Tabla 12. Detalle de las publicaciones derivadas de la investigación No.1

Detalle de las publicaciones derivadas de la investigación No.1

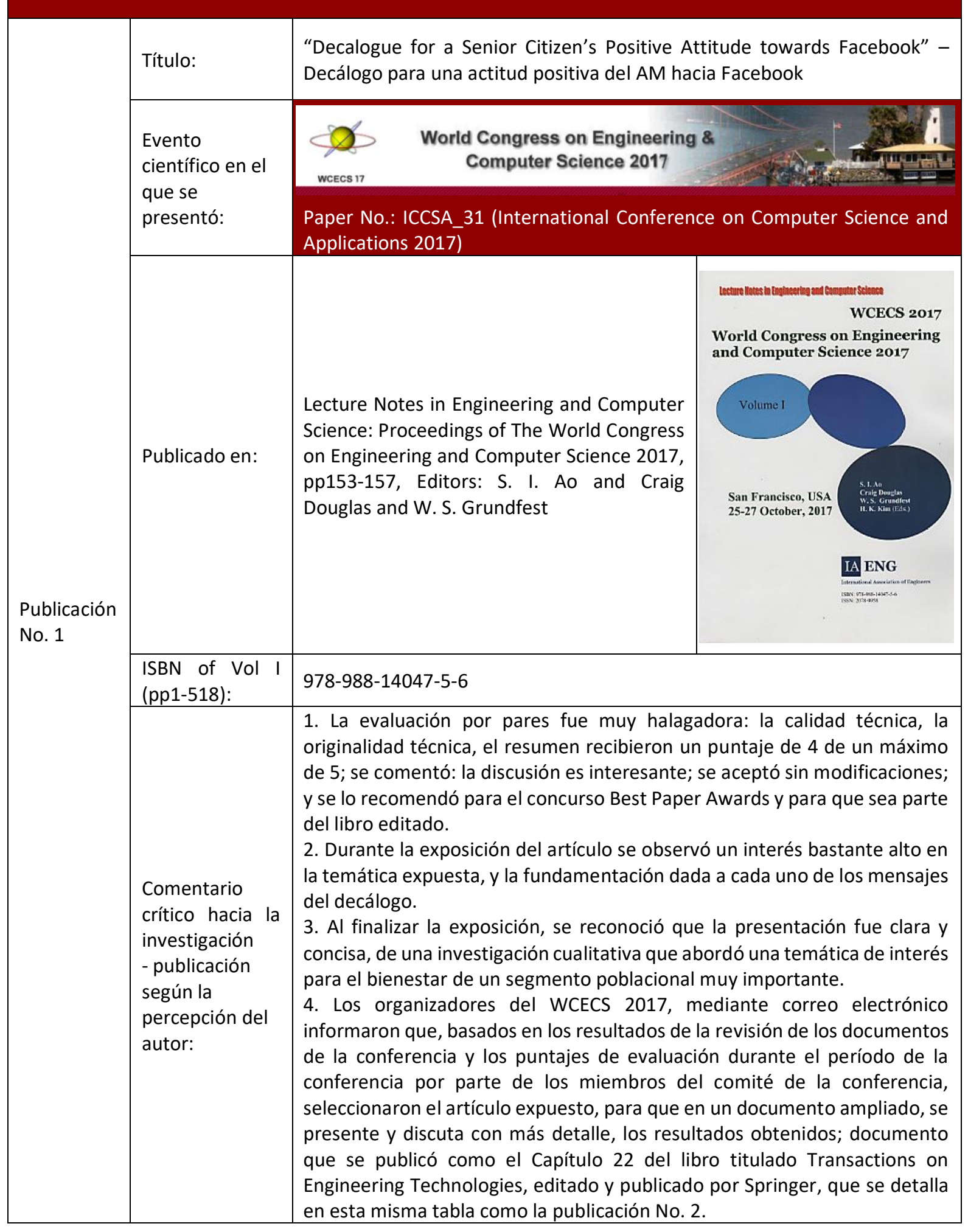




\begin{tabular}{|c|c|c|c|}
\hline & & \multicolumn{2}{|c|}{$\begin{array}{l}\text { 5. Se recibió como sugerencia de uno de los asistentes a la exposición, la } \\
\text { aplicación de data mining como opción para el análisis de los resultados de } \\
\text { las encuestas estructuradas. }\end{array}$} \\
\hline \multirow{8}{*}{$\begin{array}{l}\text { Publicación } \\
\text { No. } 2\end{array}$} & Título: & \multicolumn{2}{|c|}{$\begin{array}{l}\text { "Why Should a Senior Citizen be a Facebook User? Reasons for A Senior } \\
\text { Citizen's Positive Attitude Towards Facebook" }\end{array}$} \\
\hline & & & $\begin{array}{l}\text { Sio-long Ao A Haeng Kon Kim } \\
\text { Matyar A.Amourzegar Editiors }\end{array}$ \\
\hline & Publicado en: & $\begin{array}{l}\text { Capítulo } 22 \text { del libro "Transactions on } \\
\text { Engineering Technologies", editado y } \\
\text { publicado por Springer }\end{array}$ & $\begin{array}{l}\text { Transactions } \\
\text { on Engineering } \\
\text { Technologies } \\
\text { World Congress on Engineering and } \\
\text { Computer Science } 2017\end{array}$ \\
\hline & & & Q Springer \\
\hline & ISBN: & \multicolumn{2}{|l|}{$978-981-13-2190-0$} \\
\hline & ISBN: & \multicolumn{2}{|l|}{ 978-981-13-2191-7 (eBook) } \\
\hline & $\mathrm{DOI}$ & \multicolumn{2}{|l|}{$10.1007 / 978-981-13-2191-7$} \\
\hline & $\begin{array}{l}\text { Library of } \\
\text { Congress } \\
\text { Control } \\
\text { Number: }\end{array}$ & \multicolumn{2}{|l|}{2018943704} \\
\hline
\end{tabular}

\subsection{Investigación No. 2: identificación del contexto tecnológico de las TIC del} AM

La investigación fue motivada por los siguientes sucesos trascendentes:

1. La población AM, a nivel mundial, está en continuo crecimiento.

2. El aislamiento familiar y social en el que podrían caer los AM a raíz de su jubilación, disminuyendo su interacción social y perdiendo sus vínculos sociales, aspectos que afectan negativamente las relaciones interpersonales del AM y otras dimensiones de su calidad de vida.

3. El importante momento tecnológico que vive el mundo debido a las TIC, caracterizado especialmente por las nuevas oportunidades de comunicación e interacción social que las redes sociales ofrecen a sus usuarios, con características de ubicuidad (sin limitaciones de tiempo, horario y ubicación), presencia social, comunicación síncrona y asíncrona, difusiones unicast, multicast y broadcast y servicios de comunicación multimedia.

4. La existencia de teorías del envejecimiento que tienen un enfoque positivo y optimista de la vejez, como son la teoría de la actividad, la teoría de la modernidad con su visión dinámica y con su 
perspectiva de ciclo de vida; que sostienen que el $A M$ es capaz de mantenerse activo como en otras etapas de su vida. Estas teorías dan soporte a la hipótesis que el AM puede alcanzar mayores niveles de calidad de vida mediante el uso de la tecnología de redes sociales.

5. El interés de apoyar el desarrollo de los conceptos de envejecimiento activo y las dimensiones de la calidad de vida del AM, desde el uso de la red social Facebook como entorno seguro de comunicación para inclusión familiar y social de las personas adultas mayores.

\subsubsection{Caracterización de la investigación No. 2}

\subsubsection{Propósito}

La investigación tuvo como propósito conocer el contexto tecnológico de las TIC del AM que tiene la particularidad de vivir en su casa, ubicada en una zona urbana, y que pertenece al entorno de influencia del tesista. Esto significa, clarificar la disponibilidad que tiene el AM, de recursos tecnológicos, conocimientos informáticos y habilidades, para una eventual participación en la red social Facebook, en pro de alcanzar potenciales beneficios difundidos en investigaciones científicas realizadas alrededor del mundo, Fig. 29.

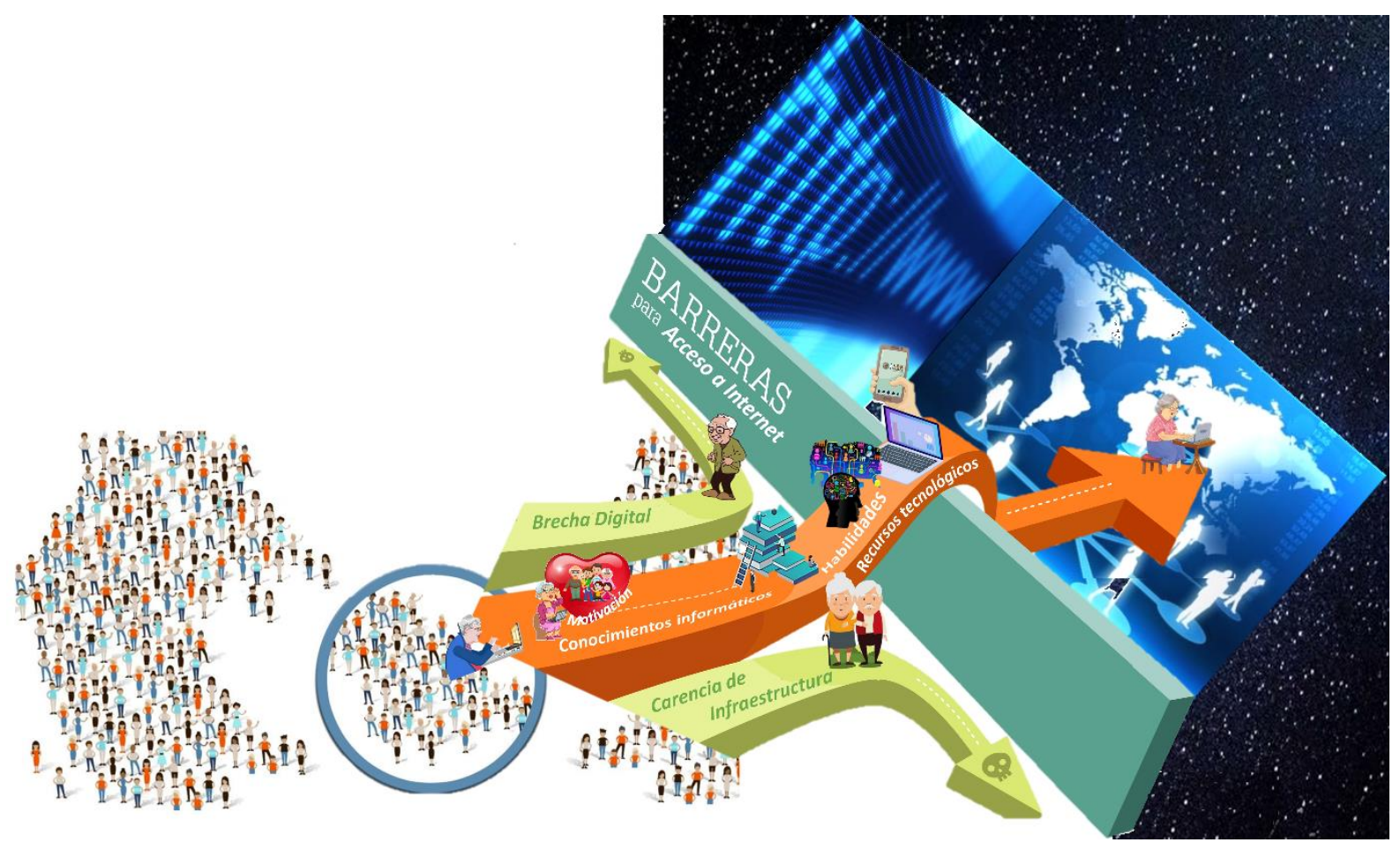

Fig. 29 Contexto tecnológico de las TIC: recursos tecnológicos, conocimientos informáticos y habilidades disponibles.

\subsubsection{Ficha descriptiva de la investigación No. 2}

En la Tabla 13 se exhiben características importantes de la investigación No. 2.

Tabla 13. Ficha descriptiva de la investigación No. 2

\begin{tabular}{|l|l|}
\hline \multicolumn{2}{|c|}{ Ficha descriptiva de la investigación No. 2} \\
\hline Características descriptivas & \multicolumn{1}{|c|}{ Texto descriptivo } \\
\hline Nombre: & $\begin{array}{l}\text { Identificación del contexto tecnológico de las TIC del AM: recursos } \\
\text { tecnológicos, conocimientos informáticos y habilidades disponibles. }\end{array}$ \\
\hline Año: & 2016 \\
\hline
\end{tabular}




\begin{tabular}{|c|c|}
\hline Área de Investigación & Computación social. \\
\hline Tipo de investigación & Cualitativa. \\
\hline Enfoque Metodológico & Investigación no experimental transversal. \\
\hline $\begin{array}{l}\text { Técnicas de investigación } \\
\text { utilizadas }\end{array}$ & Investigación en campo. \\
\hline $\begin{array}{l}\text { Métodos de recolección de } \\
\text { datos }\end{array}$ & $\begin{array}{l}\text { - Observación cualitativa directa: realizada con la ayuda de todos los } \\
\text { sentidos del observador, con la finalidad de captar detalles de eventos, } \\
\text { sucesos complementarios de situaciones particulares, e interacciones } \\
\text { del objeto de estudio, en procura de una comprensión holística del } \\
\text { contexto tecnológico de las TIC del AM. } \\
\text { - Investigación no experimental transversal para esta investigación No.2: } \\
\text { entrevistas estandarizadas basadas en dos cuestionarios; el primero } \\
\text { concerniente a las relaciones interpersonales de los AM, aplicado a la } \\
\text { muestra No. } 1 \text { de AM; y, el segundo cuestionario, encaminado a } \\
\text { determinar cómo los AM utilizan Internet y Facebook, o las razones que } \\
\text { los desalentaron en su uso, aplicado a la muestra No. } 2 \text { de AM. } \\
\text { Los cuestionarios contenían los siguientes tipos de preguntas: } \\
\text { a) Generales: para registrar 1) datos sociodemográficos del AM; y, 2) el } \\
\text { interés por aprender los servicios de comunicación basados en TIC. } \\
\text { b) De antecedentes: para conocer datos respecto a: } 1 \text { ) uso o no de } \\
\text { Internet; 2) disponibilidad económica para cubrir los costos del acceso a } \\
\text { Internet establecidos por el proveedor de servicios de internet; 3) } \\
\text { disponibilidad de un dispositivo de acceso a Internet (computador de } \\
\text { escritorio, laptop, teléfono inteligente, o Tablet) para su uso personal. } \\
\text { c) De conocimiento: para identificar } 1 \text { ) el nivel de conocimientos } \\
\text { informáticos; y, 2) los medios de comunicación que efectivamente } \\
\text { utilizan para establecer conexiones con sus contactos activos. } \\
\text { d) De sentimientos: para auscultar 1) la percepción sobre el costo que } \\
\text { tiene el acceso a Internet; y, 2) la percepción sobre la seguridad en } \\
\text { Internet. }\end{array}$ \\
\hline Análisis de datos: & $\begin{array}{l}\text { 1) De la observación directa: reflexión sobre las vivencias registradas. } \\
\text { 2) De las entrevistas estructuradas: análisis de datos cuantitativos } \\
\text { presentes en bases de datos empleando el software Tableau. }\end{array}$ \\
\hline
\end{tabular}

\subsubsection{Objetivo}

Comprender la potencialidad del contexto de las TIC del AM ecuatoriano que vive en su casa, para el aprovechamiento de la oportunidad digital de interacción social a través de Internet.

\subsubsection{Pregunta de Investigación}

¿El contexto tecnológico del AM ecuatoriano que vive en su casa, lo potencializa para el aprovechamiento de la interacción social a través de Internet?

\subsubsection{Contexto de la investigación}

1) Para la observación cualitativa directa: $8 \mathrm{AM}$ del entorno de influencia del investigador, familiares y amigos.

2) Para la investigación no experimental transversal No. 2: dos muestras intencionales de AM pertenecientes al entorno de influencia del investigador. La muestra No. 1 conformada por $128 \mathrm{AM}$, 59 hombres y 69 mujeres. La muestra No. 2 de AM constituida de 33 personas constituida por 10 hombres y 23 mujeres. En ambas muestras, los AM tenían diferentes niveles de estudio y vivían en sus hogares ubicados en zonas urbanas. Las configuraciones de las muestras se presentan en la Fig. 30. 
Estas muestras sin ser altamente representativas de la población de $A M$, brindaron opiniones que permitieron reflexionar sobre el contexto tecnológico de las TIC del AM.

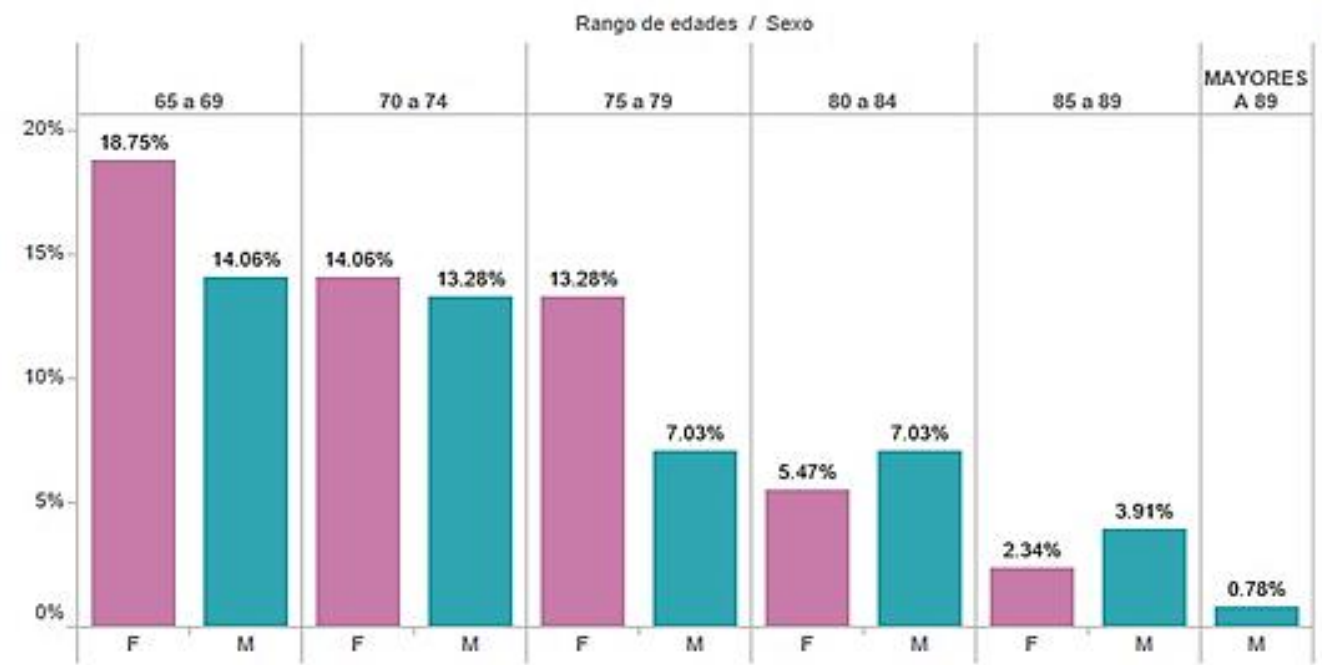

(a)

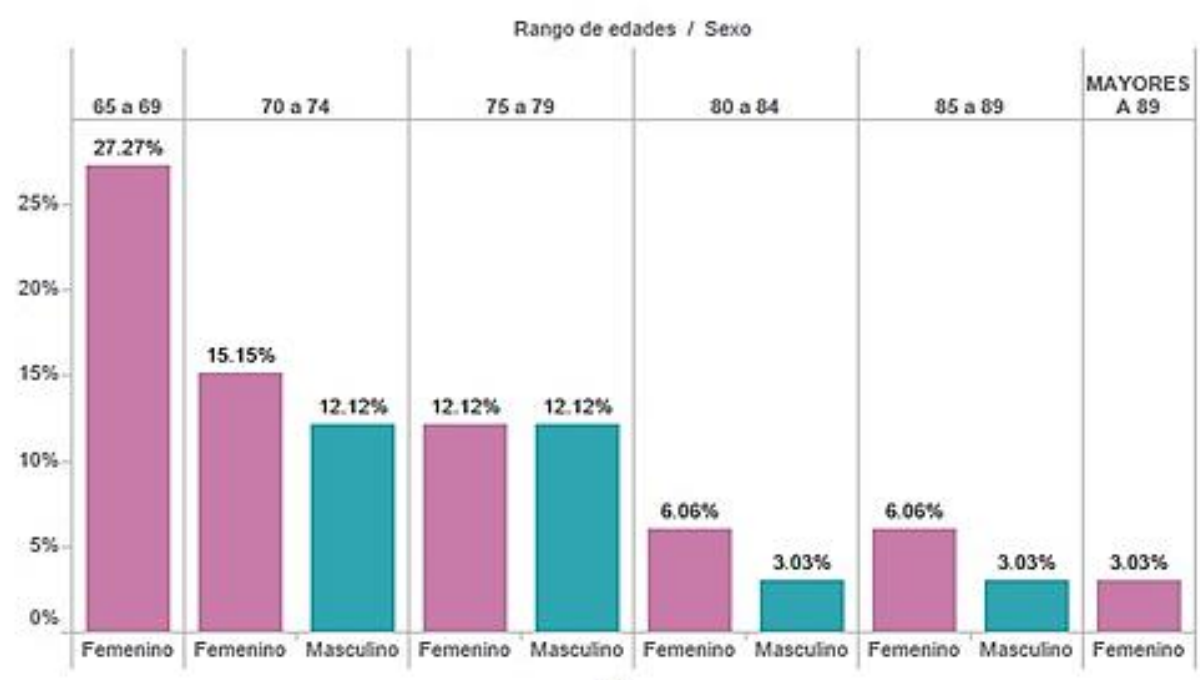

(b)

Fig. 30 Configuraciones de las muestras válidas de AM por rangos de edad y sexo: (a) muestra 1, (b) muestra 2

El acceso al contexto de investigación no experimental transversal señalado, se lo realizó a través de estudiantes de la Universidad Central del Ecuador y de la Universidad de las Fuerzas Armadas, que debieron entrevistar a los AM relacionados con ellos, sus abuelos. Los jóvenes encuestadores voluntarios, fueron capacitados en los términos técnicos utilizados en los cuestionarios, y en la forma de llenar las encuestas.

\subsubsection{Resultados de la investigación}

\subsubsection{De la observación directa:}

Se reconocieron ciertas particularidades en los AM observados, usuarios de Facebook, con respecto a cada uno de los componentes del contexto tecnológico de las TIC, que fueron organizadas por rangos de edad, como se describen a continuación:

1. AM con edad entre 65 y 70 años (cantidad: 5 AM): 
a) Recursos tecnológicos: utilizan mayoritariamente teléfonos inteligentes, y con menos frecuencia computadores personales (PC-escritorio o Laptops), para acceder a la red social Facebook.

b) Conocimientos informáticos: muchos de ellos demuestran tener suficientes conocimientos informáticos para mantener una actividad autónoma con los recursos tecnológicos que usan, esto se debe a su reciente experiencia laboral con dispositivos tecnológicos.

c) Habilidades disponibles: demuestran comodidad y facilidad en el manejo de las aplicaciones de software que están ejecutándose en los dispositivos con los que acceden a la red social, habiendo observado que participan activamente y de forma creativa en Facebook.

d) Algunos, envían animaciones con fotografías de sus contactos, ediciones de las fotografías de sus familiares y amigos, lo que les hace sentir alegres, diferentes, cómodos y seguros frente a la tecnología; disfrutan de recibir reacciones "Me gusta", así como comentarios alentadores para seguir con esas iniciativas.

Otros prefieren compartir actividades cotidianas de sus negocios, para promocionar la variedad de sus productos, captar comentarios y reacciones, mostrar el entorno con sus clientes.

Otros más, utilizan la red social en actividades de ocio, por ejemplo, aprender a cocinar, a mantener jardines, a realizar manualidades, bricolaje.

Otros prefieren utilizar Facebook para actividades de entretenimiento, como ver vídeos de distinta índole: documentales educativos, películas, vídeos en tiempo real, reportajes y noticias.

2. AM con edad entre 71 a 75 años (2 AM):

a) Recursos tecnológicos: normalmente teléfonos inteligentes.

b) Conocimientos informáticos: suficientes, para manejar y aprovechar, sin inconvenientes, los equipos que disponen.

c) Habilidades disponibles: se les nota más inseguros en utilizar nuevas aplicaciones y utilizan con suficiente dominio aquellas con las que alcanzaron familiarización completa, como por ejemplo Facebook. Sin embargo, se ha observado que por su edad van sintiendo las limitaciones físicas, con un nivel más acentuado, principalmente de reducción de la visión, y en uno de los casos, cierto temblor en sus manos, lo que les reduce las posibilidades de un manejo más confortable de la tecnología.

3. AM con edad mayor a 75 años (1 AM):

d) Recursos tecnológicos: los más ancianos, salvo pocas excepciones, no utilizan servicios tecnológicos y en consecuencia la tecnología circundante les permite mantener formas tradicionales de interacción personal.

e) Conocimientos informáticos: muy reducidos, para comprender las nuevas aplicaciones y servicios de la tecnología que les rodea. 
f) Habilidades disponibles: se trata de usuarios, en su mayoría pasivos, es decir requieren de la ayuda de personas de confianza para lograr los objetivos que buscan con la red social; y por lo tanto están supeditados a la disponibilidad de esa ayuda que no está frecuentemente a disposición.

\subsubsection{De la investigación no experimental transversal:}

Resultados obtenidos de la muestra No. 1

1) Medios de interacción social utilizados por los AM.

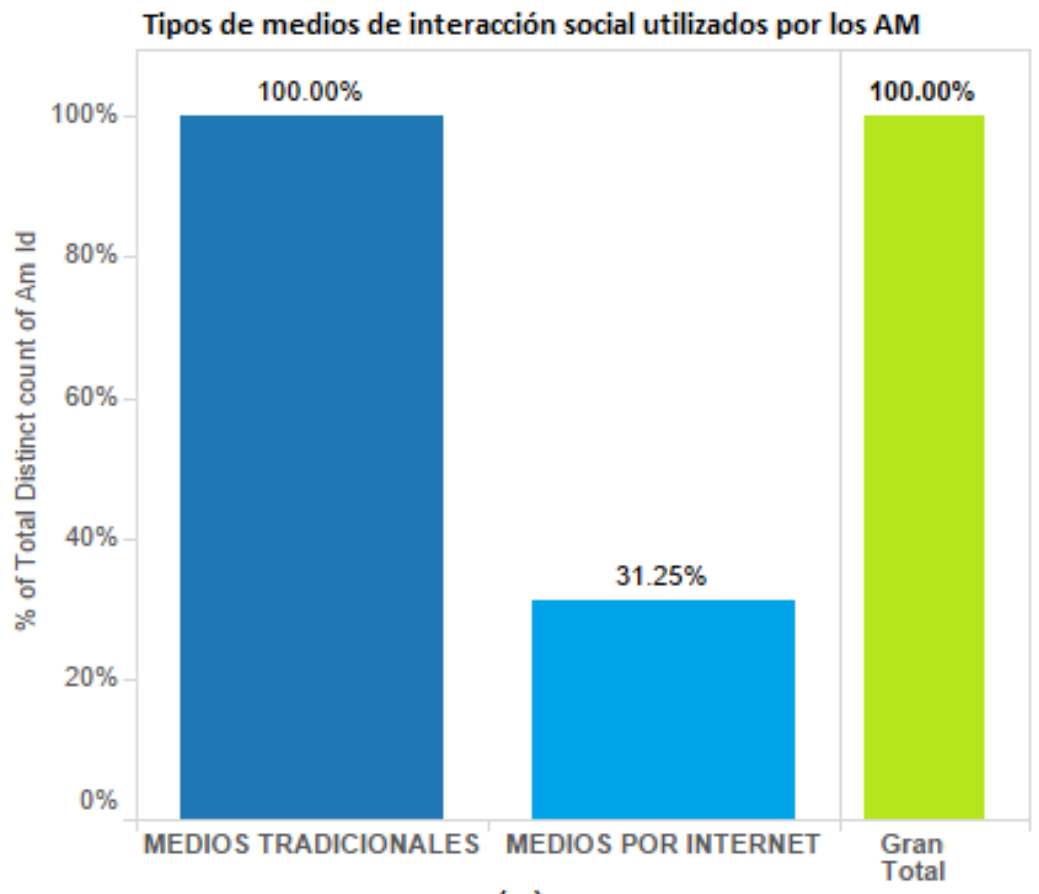

(a)

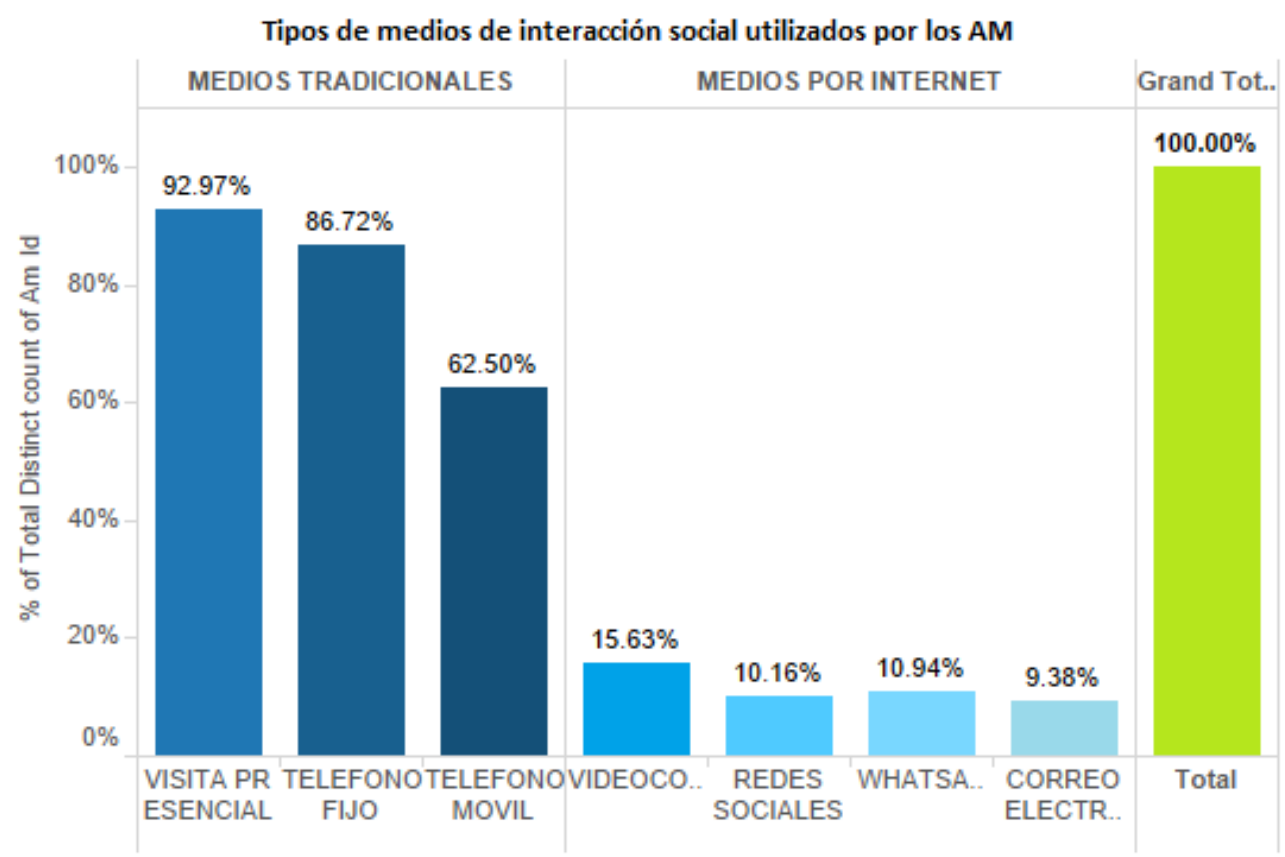

(b)

Fig. 31. Medios de interacción social utilizados por los AM:(a) consolidados, (b) detallados. 
Los AM prefieren utilizar los servicios de comunicación tradicionales antes que los servicios de comunicación basados en TIC, sin importar su edad, su sexo, y su nivel estudios académicos.

La Fig. 31 muestra que el $100 \%$ de AM entrevistados utilizan la visita presencial para mantenerse socialmente activos con familiares y amigos. Es importante tomar en cuenta el hecho que, la visita presencial es de mayor impacto emocional que una visita o relación a distancia; sentirle al contacto, esto es: verle, escucharle, percibir sus emociones y tenerle físicamente presente, resulta afectivamente más relevante en una relación interpersonal que sólo escucharle.

Dado el alto porcentaje de AM que emplean los medios tecnológicos tradicionales: telefonía fija y telefonía móvil, en sus conexiones interpersonales, se puede suponer que lo hacen mayoritariamente con los mismos contactos con los cuales se comunican presencialmente, y lo realizan para complementar la imposibilidad física de tener contacto directo diario; entonces, estos medios tradicionales les aporta en la calidad de la relación interpersonal, porque les brinda frecuencia en la comunicación, apoyo social, autoestima al sentir que sus familiares y amigos que viven cerca están pendientes de ellos.

Con relación a los medios de comunicación e interacción por Internet, la Fig. 31 demuestra que una tercera parte de los AM los utilizan, notándose que la videoconferencia es la más utilizada. Tomando en cuenta el contexto en el que se acostumbra utilizar esta tecnología, se puede afirmar que la usan los AM para mantenerse en contacto con familiares que se encuentran geográficamente distantes, procurando mantener una conexión tecnológica que le brinde la sensación de la visita presencial; es decir con un alto grado de presencia social.

Manteniendo como referencia el significado de presencia social, se observa que la tecnología que le sigue en preferencia de uso a las videoconferencias son las redes sociales, principalmente Facebook; situación que resulta lógica, al considerar que por la red social se pueden compartir diversos tipos de recursos que tienen un peso emocional alto como son: fotografías, mensajes con audio y vídeos, mensajes de texto, reacciones, y otras formas creativas de mensajes como los vídeos en vivo.

Nótese también que el sistema de mensajería instantánea WhastApp tiene un porcentaje de uso semejante al de la red social Facebook, justamente por los beneficios de la inmediatez con que llegan todos los mensajes. Respecto al correo electrónico, al parecer la tendencia es cada vez a ser menos utilizado.

Estas cuatro tecnologías se complementan para permitir al AM y sus contactos geográficamente distantes, mantener con vida la relación interpersonal y en función de su uso se generará un cierto nivel, que podría resultar aceptable, de calidad de la relación interpersonal.

2) Correlación entre la calidad de las relaciones interpersonales percibidas por los AM y los tipos de medios de interacción social utilizados. 


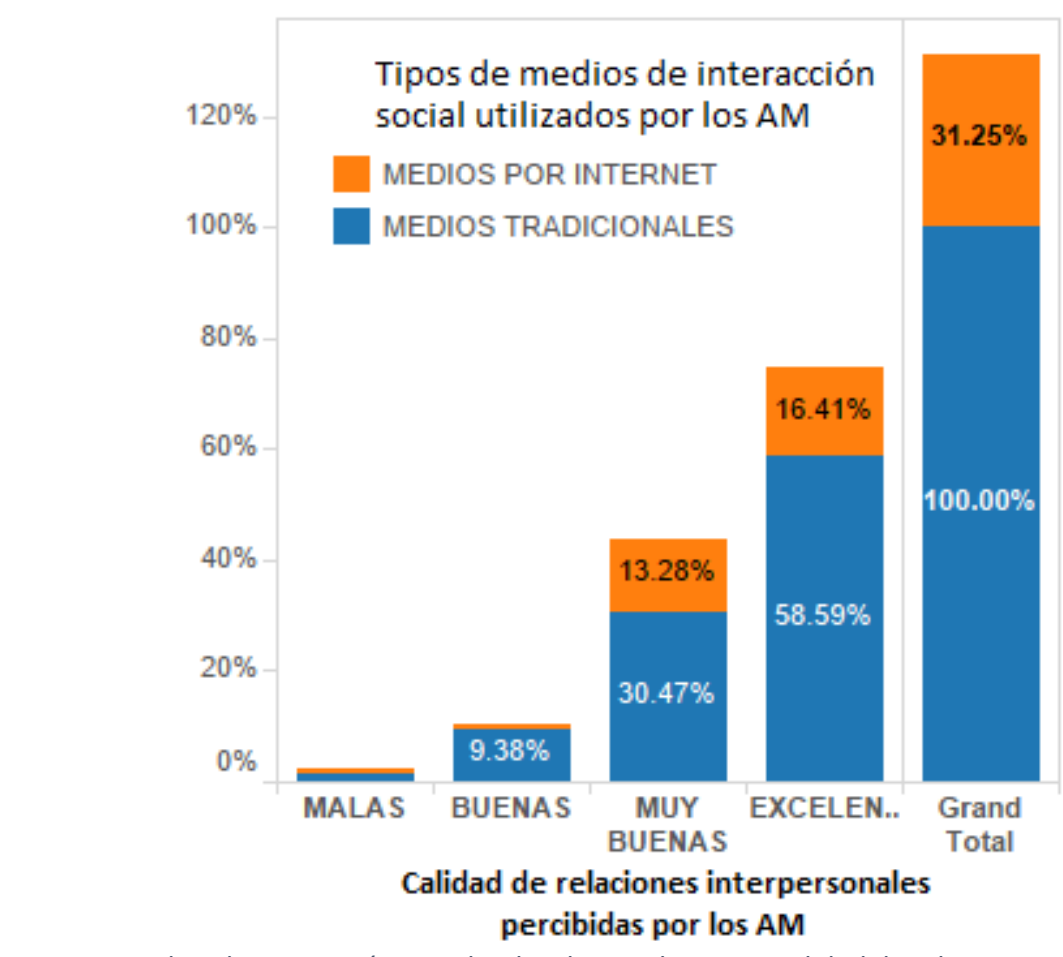

Fig. 32. Medios de interacción social utilizados por los AM y calidad de relaciones interpersonales

De la observación de la Fig. 32, se desprende que la calidad de las relaciones interpersonales percibida por los AM entrevistados tiene tendencia a ser considerada excelente, es decir, se entendería que están satisfechos con la calidad de sus relaciones interpersonales en cuanto al número de contactos, la frecuencia de sus conexiones, la duración de las interacciones, la variedad de temas que enfocan y la ayuda social que reciben.

De los AM que dicen tener una calidad excelente de relaciones interpersonales, el $16.41 \%$ afirmó que utiliza los medios de comunicación por Internet, lo que daría a entender que a través de la tecnología alcanzaron ese nivel, lo que significaría que posiblemente estos AM tengan contactos geográficamente distantes y por eso utilizaron la tecnología, a diferencia de los demás. Análisis similar se puede hacer en los otros niveles de calidad de relaciones interpersonales.

Ampliando el análisis, se puede conjeturar que la calidad de las relaciones interpersonales siempre será incrementada a través de la tecnología, ya que el no uso de la tecnología en circunstancias que ameritan, podría a los AM hacerles perder oportunidades de conexión con personas importantes para ellos que se encuentren geográficamente distantes. Eso si, como en toda regla, pueden existir excepciones, en las cuales los AM pueden sentirse afectados negativamente en sus relaciones interpersonales, por ejemplo, ante una falta de comunicación tecnológica, que hubiera estado programada y que no se realizó, con la consecuente preocupación y ansiedad, y a lo mejor posterior malestar, si las circunstancias que pudieron afectar la conexión, al AM le hacen sentir una sensación de ubicarse en segundo plano de importancia en la vida de su contacto. Hay que tomar en cuenta que, con el envejecimiento, la sensibilidad emocional en el AM se incrementa.

De ahí que se debe tomar en cuenta el compromiso que conlleva ser contacto de un AM a través de tecnología, en el sentido de mantener la frecuencia de las conexiones, el cumplir con las conexiones 
que se hayan convenido, la duración de las conexiones; es decir cumplir a cabalidad la responsabilidad emocional con el AM sobre la relación interpersonal que se establece.

3) Disponibilidad de acceso a Internet y medios comunicación utilizados por el AM.

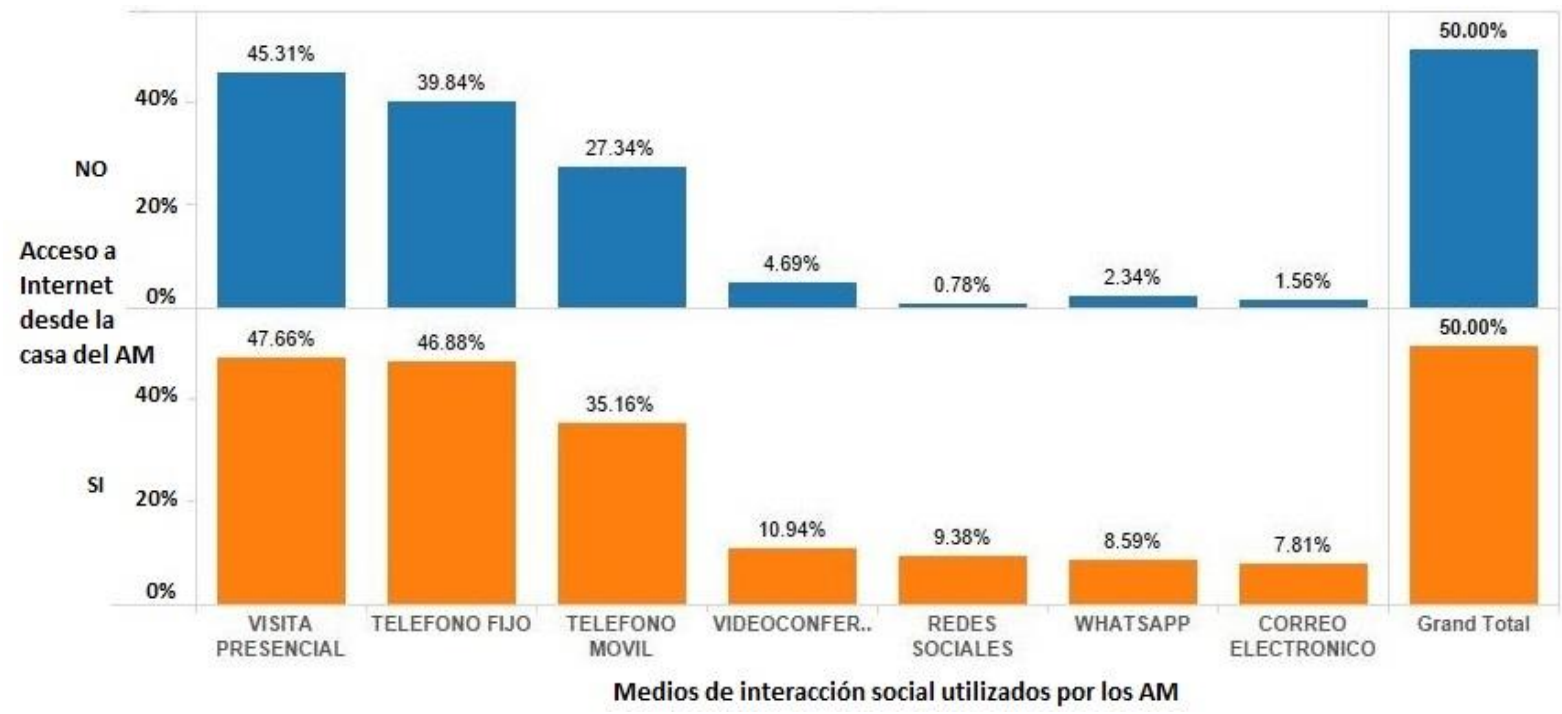

Fig. 33. Disponibilidad de acceso a Internet desde la casa y medios de interacción social utilizados por los AM

De la Fig. 33 se desprende que la no disponibilidad de acceso a Internet desde la casa no le imposibilita al AM usar los medios de comunicación por Internet.

Además, de los AM que tienen acceso a Internet, un porcentaje reducido lo aprovecha para uso propio; eso significa que las personas que viven con él son las personas que aprovechan la conexión, por ejemplo, nietos de edad escolar (primaria o secundaria) e inclusive de educación superior.

4) Correlación entre la edad y el interés de los AM por aprender los servicios de interacción social por Internet.

La Fig. 34 muestra una tendencia inversamente proporcional del interés por aprender a utilizar los servicios de interacción social por Internet con relación a la edad. El mayor interés por aprender el manejo de los servicios de comunicación por Internet es de los AM jóvenes; los mayores de 80 años en su mayoría no tienen interés.

\section{Interés de los AM por aprender los servicios de interacción social por Internet}

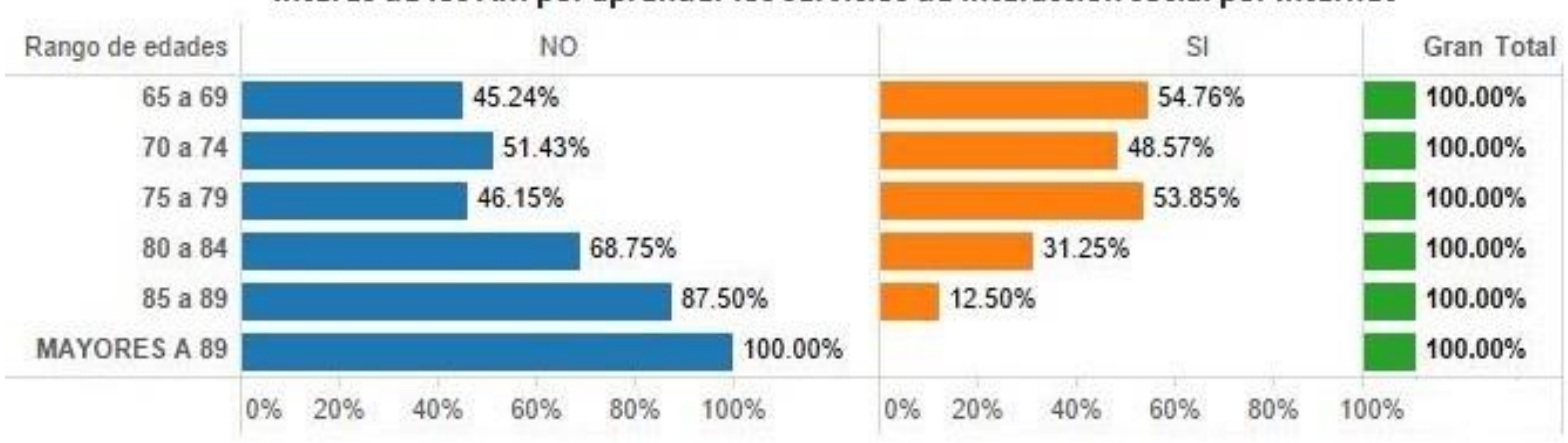

Fig. 34. Interés de los AM por aprender los servicios de interacción social por Internet por rangos de edad 
Los AM con interés en aprender a aprovechar las TIC, entienden que estas tecnologías los ayudaría a ampliar las posibilidades de contacto con sus personas importantes que residen lejos de su ciudad de residencia: hijos, nietos o buenos amigos, o ya se han comunicado a través de ellas, pero no de forma autónoma sino con ayuda de familiares cercanos, y desean tener libertad para aprovechar las características de ubicuidad que les ofrece, por ejemplo, Facebook.

Respecto al grupo de AM que no tienen interés en aprender los servicios de comunicación por Internet, una parte ya tienen el dominio necesario para obtener los beneficios que les ofrecen los medios de comunicación a través de TIC, por lo tanto, no necesitan aprender a usarlos. Los miembros restantes del grupo, simplemente no están interesados por aprender, posiblemente debido a que no sienten necesidad bajo el argumento que consideran que sus relaciones interpersonales, son lo suficientemente buenas con las modalidades de comunicación que manejan; o, creen que les resultaría muy difícil aprender algo nuevo en esta etapa final de su vida.

5) Interés de los AM por aprender los servicios de interacción social por Internet frente a disponibilidad de acceso a Internet desde la casa.

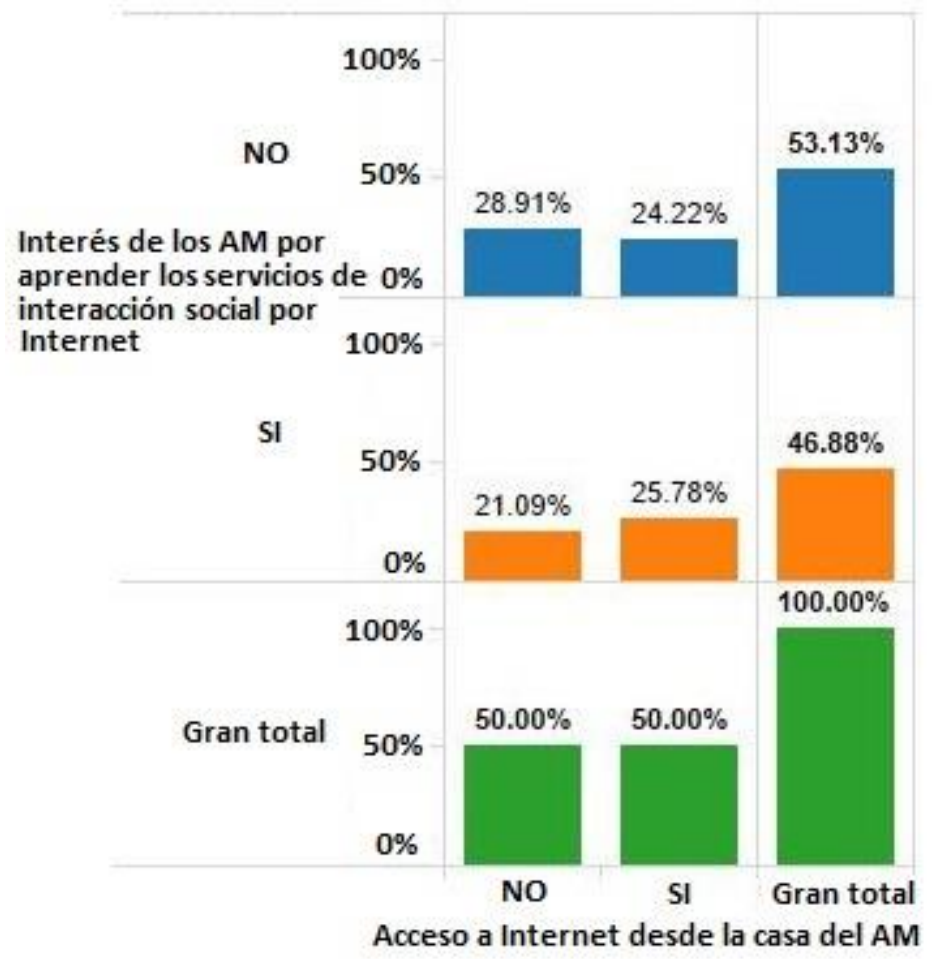

Fig. 35. Interés de los AM por aprender los servicios de interacción social por Internet frente a disponibilidad de acceso a Internet.

La Fig. 35 permite afirmar que prácticamente la mitad de los AM estarían potencialmente en capacidad de usar los servicios de comunicación basados en TIC porque disponen de acceso a Internet desde su hogar. Hay AM que, no teniendo acceso a Internet, si les interesa aprender a utilizar Internet. Hay AM que tienen acceso a Internet y no les interesa aprender, seguramente porque ellos ya utilizan las TIC; o, el acceso a Internet no es por sus necesidades sino por las de familiares que viven con ellos, y requieren Internet por razones particulares. 
Hay AM que tienen acceso a Internet y les interesa aprender el uso de Internet, puede ser por dos razones: ya los usan, pero con ayuda de alguna persona de confianza; o quieren aprovechar lo que disponen por necesidades de sus familiares.

Resultados obtenidos de la muestra No. 2

1) Motivaciones que tuvieron los AM para acceder a Internet.

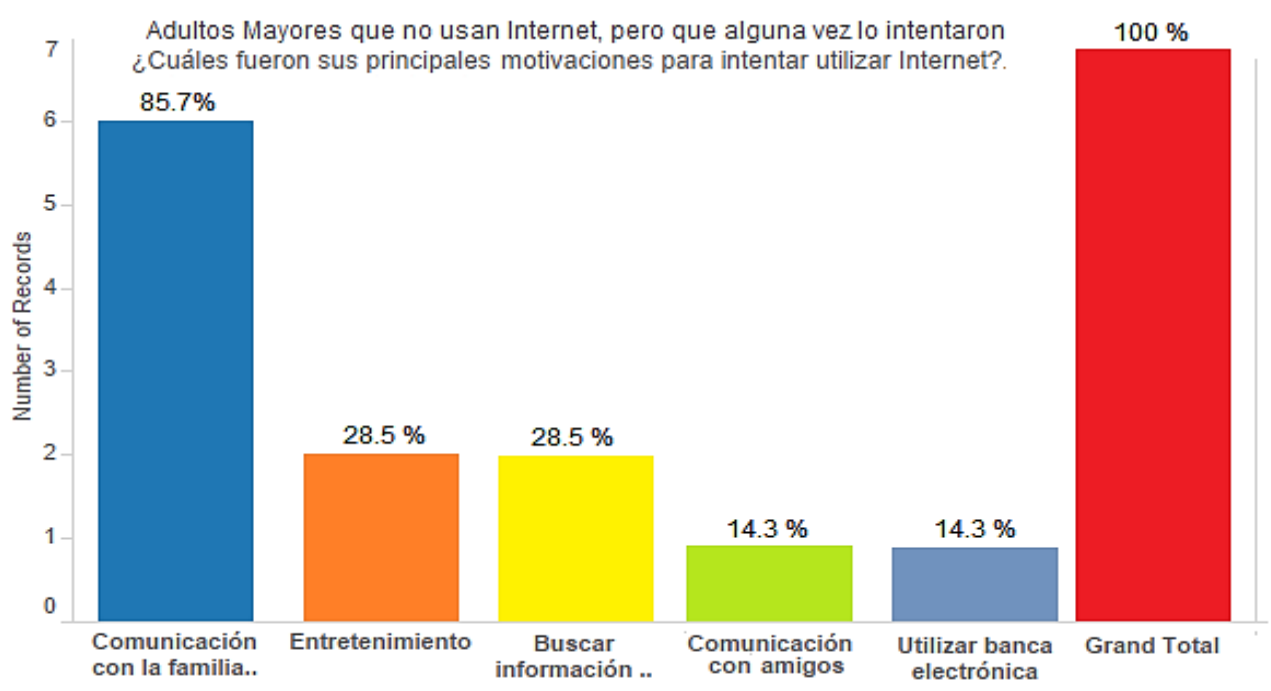

Fig. 36. Principales motivaciones de los AM que alguna vez intentaron utilizar Internet

En la Fig. 36 se observa que el principal factor motivador que conduce al AM a utilizar los medios de comunicación basados en Internet, o intentar hacerlo, es mantener conexión con los miembros de la familia nuclear que se encuentran lejos; este resultado coincide con estudios realizados con adultos en otros países del mundo.

2) Percepción del AM respecto al valor de acceso a Internet.

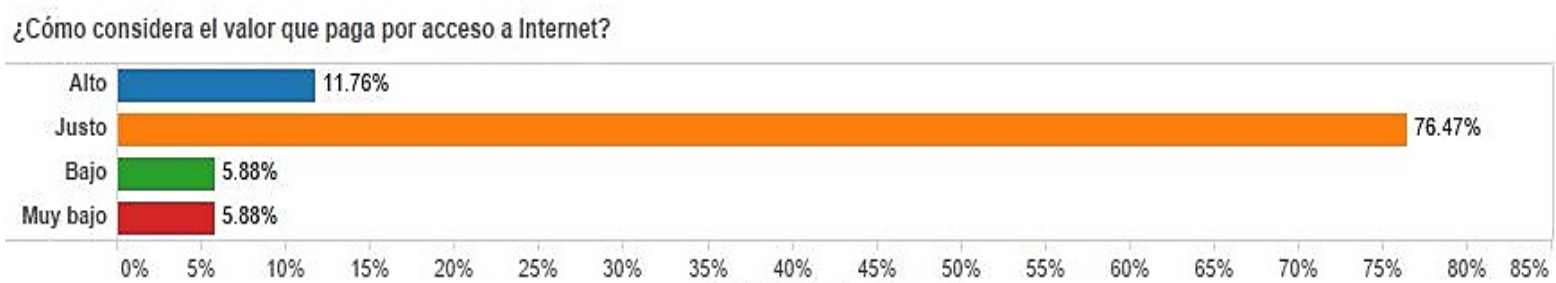

Fig. 37 Percepción del AM respecto al valor de acceso a Internet

Del análisis de la Fig. 37, se extrae que un alto porcentaje de AM no tienen inconvenientes con el pago del acceso a Internet, lo consideran justo, es decir, la factura emitida por el ISP no es considerada de impacto alto en la economía de la mayoría de AM de la muestra.

3) Disponibilidad de un equipo en casa para uso personal del AM, tipos de recursos tecnológicos utilizados y frecuencia de acceso a servicios de Internet de los AM. 
El AM con acceso a Internet desde su casa

¿dispone de un computador o de un dispositivo similar en su casa para uso personal?

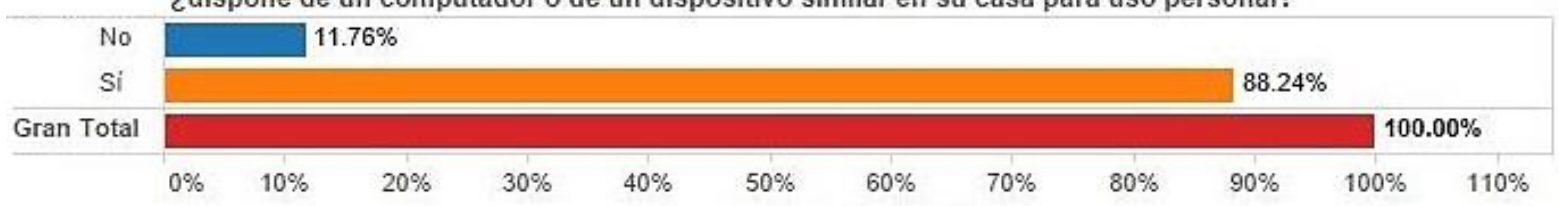

Fig. 38 Disponibilidad del recurso tecnológico para uso personal del AM.

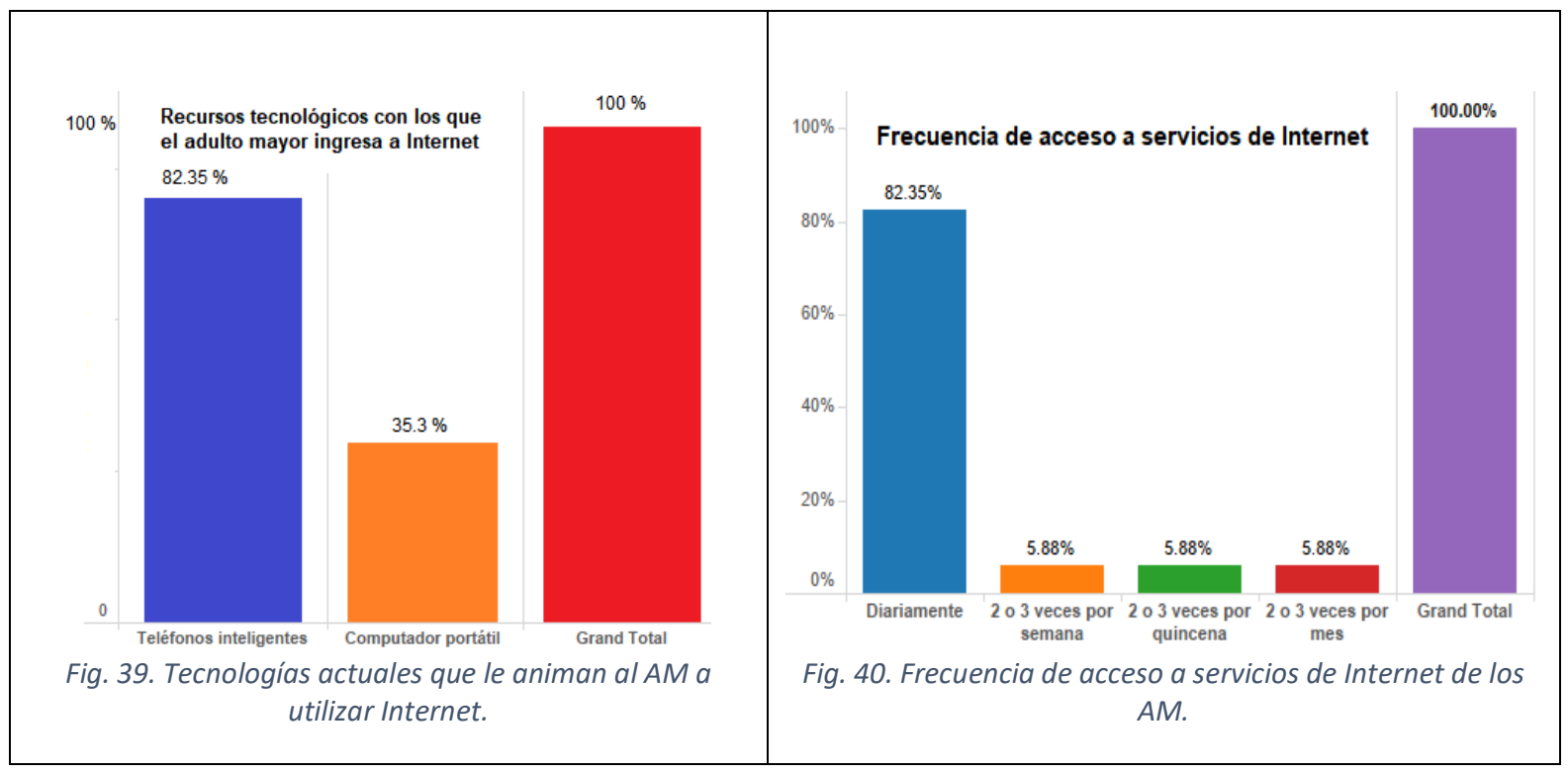

La Fig. 38 muestra que la gran mayoría de AM que tienen acceso a Internet desde su casa, disponen de un equipo de uso personal para acceder a los servicios.

Del análisis integrado de las Fig. 39 y Fig. 40, se desprende que los AM que utilizan servicios de Internet, acceden mayoritariamente con frecuencia diaria a través de las tecnologías con las que están más familiarizados y les suministran facilidad de uso como son los teléfonos inteligentes. Las otras frecuencias de acceso tienen que ver, posiblemente, con el acceso que tienen los AM con ayuda de alguna persona de confianza.

4) Factores que desalientan al AM a utilizar los servicios de Internet.

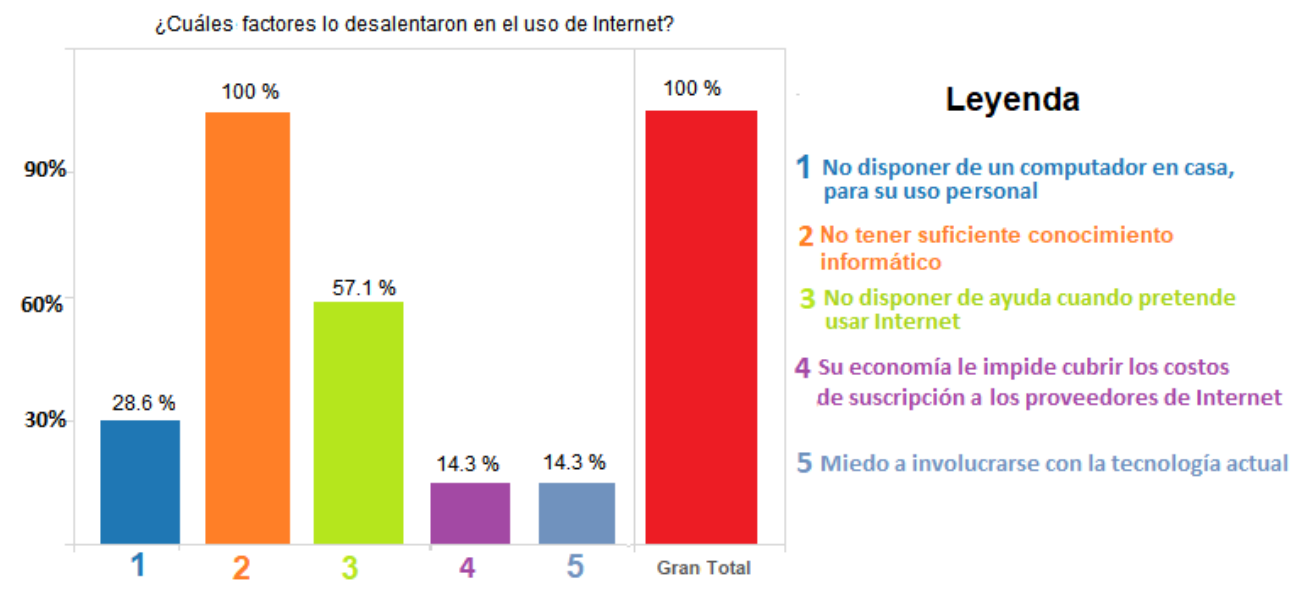

Fig. 41. Factores que desalientan al AM a utilizar Internet 
Respecto a las razones que le desalientan al AM al uso de Internet, Fig. 41, la principal causa es el no tener suficiente conocimiento informático, es decir, la brecha digital. Sin embargo, es importante tomar en cuenta que esta situación es superable con motivación propia del AM, más motivación inducida mediante la puesta en conocimiento de beneficios potenciales que estaría perdiendo a causa de la no utilización de la tecnología, y de la potencialidad intelectual que mantiene a su edad para adquirir nuevos conocimientos.

El segundo factor se complementa con el primero, ya que la motivación con la que podría superar la brecha digital, requiere de soporte de confianza, que le ayude en los momentos oportunos para que alcance el objetivo que pretenda, antes de que le llegue frustración, ansiedad y se produzca la pérdida de la motivación.

Los dos primeros factores tienen que ver también con el quinto factor, miedo a involucrarse con la tecnología, y se lo puede superar de igual manera que el primero.

El tercer factor en importancia, no disponer de un computador en su casa, es superable, ya que no requiere de una gran inversión por no ser necesario un computador de última generación ni de altas prestaciones; y se relaciona con el cuarto factor, la condición económica del AM. Estos aspectos podrían ser superados a través del desarrollo de una política estatal orientada para los AM, que permita la adquisición de computadores a precios muy rebajados, por su condición de grupo etario en condiciones de riesgo, que establezca ciertos requerimientos mínimos que le permitan al usuario acceder a servicios como las redes sociales, entretenimiento, acceso a información, banca electrónica.

5) Competencias digitales de los AM.

En general, de la Fig. 42, es posible afirmar que existe un alto porcentaje de AM que no poseen competencias digitales. Todos los AM con edades mayores a 80 años manifiestan no disponer de competencias digitales; en tanto que los AM jóvenes expresan que si las poseen hasta con nivel medio, aunque se puede asegurar que más de la mitad de ellos no tiene conocimientos informáticos.

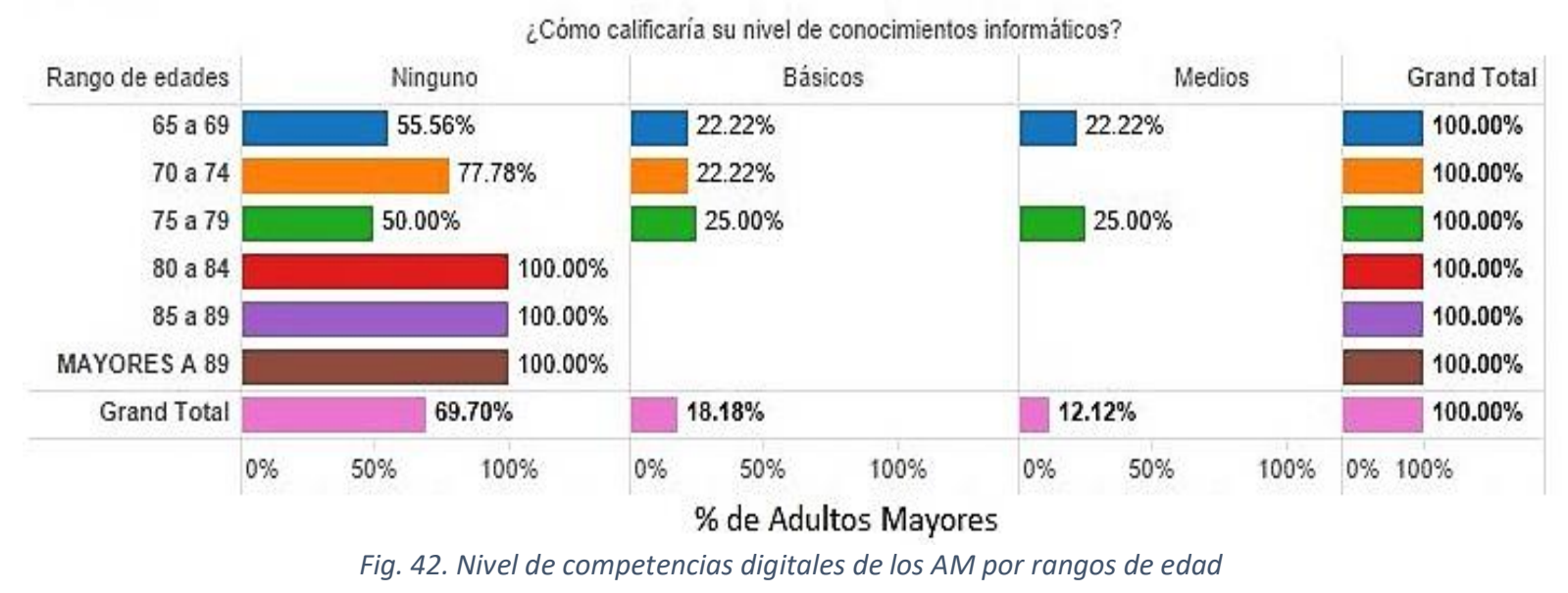

\subsubsection{Discusión}

El contexto tecnológico de las TIC del AM, conformado por: los recursos tecnológicos; las habilidades para manejar la infraestructura tecnológica, los servicios y aplicaciones; $y$, los conocimientos informáticos; se ve influenciado por el contexto económico del AM, el cual determina indirectamente las características de algunos de los componentes del contexto tecnológico, como son: velocidad de 
conexión a Internet, tipo de dispositivo que se utiliza para el acceso, posibilidad de superar la brecha digital mediante capacitación especializada.

Además, se debe tener claro que el contexto tecnológico del AM representa la capacidad de la persona para ingresar al inmenso mundo de Internet y sus servicios; pero, los beneficios que se extraigan, si bien son dependientes de la calidad del contexto tecnológico disponible, no son determinantes de la cantidad y calidad de beneficios que obtenga el AM para su calidad de vida, pues esos parámetros tienen que ver con aspectos objetivos y subjetivos que sienta o perciba el AM cuando utiliza las TIC; $y$ también, de la respuesta que reciba de sus interlocutores con las interacciones virtuales.

\subsubsection{Conclusión}

Cuando el AM, que vive en su casa ubicada en zona urbana, tiene una buena motivación, como establecer contacto con sus familiares que viven lejos, entonces crea un contexto tecnológico de las TIC que lo potencializa para el aprovechamiento de la oportunidad digital de interacción a través de Internet, con: 1) la obtención de recursos tecnológicos como son: acceso a Internet y tecnología para uso personal; 2) una buena actitud frente a las TIC, concretada en una buena predisposición para superar barreras mentales y/o limitaciones funcionales, y así adquirir suficientes conocimientos informáticos, o buscar y aceptar ayuda de personas de confianza para suplir sus deficiencias.

\subsubsection{Publicación derivada de la investigación}

El detalle de la publicación se presenta en la Tabla 14.

Tabla 14. Publicación derivada de la investigación No.2

\begin{tabular}{|c|c|c|c|}
\hline \multicolumn{4}{|c|}{ Detalle de la publicación derivada de la investigación No.2 } \\
\hline \multirow{5}{*}{ Publicación No. 1} & Título: & $\begin{array}{l}\text { "Comprensión de la potencialidad } \\
\text { ecuatoriano que vive en su casa } \\
\text { interacción social a través de Interne }\end{array}$ & $\begin{array}{l}\text { el contexto tecnológico del AM } \\
\text { para el aprovechamiento de la } \\
\text { " }\end{array}$ \\
\hline & $\begin{array}{l}\text { Evento científico en el que } \\
\text { se presentó: }\end{array}$ & 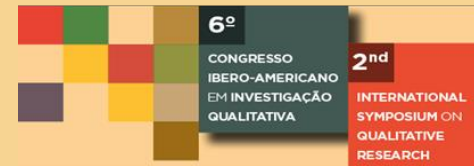 & $\begin{array}{l}\begin{array}{l}12,13 \text { e } 14 \\
\text { de lelutho } \\
2017\end{array} \\
\text { Salamanca Espanha }\end{array}$ \\
\hline & & \multicolumn{2}{|c|}{ 60 Congreso Iberoamericano en Investigación Cualitativa (CIAIQ17) } \\
\hline & Publicado en: & $\begin{array}{l}\text { Atas CIAIQ2017 - Investigação } \\
\text { Qualitativa em Engenharia e } \\
\text { Tecnologia - Actas CIAIQ2017 } \\
\text { Investigación Cualitativa en } \\
\text { Ingeniería y Tecnología - } \\
\text { Volume } 4\end{array}$ & 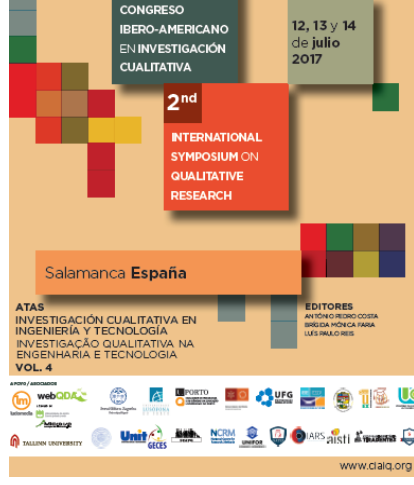 \\
\hline & ISBN - Volume 4: & 978-972-8914-78-3 & \\
\hline
\end{tabular}




\subsection{Investigación No. 3: factores determinantes de la exposición del usuario AM a los ciber-riesgos del entorno de la red social Facebook}

La red social Facebook ha propiciado un cambio sin precedentes en la forma de comunicarse e interactuar de las personas; sin embargo, su uso no está exento de ciber-riesgos para los usuarios, entre ellos se pueden citar malware, phishing, spam, bots, y más, Fig. 43, por lo que es necesario orientar una forma más segura de participación en ese entorno, debiendo esa orientación partir del conocimiento y el entendimiento de las causas de los ciber-riesgos que envuelven al usuario de Facebook.

El entorno de Facebook está conformado por: 1) la plataforma tecnológica que soporta los diferentes servicios que ofrece para interacción virtual, 2) los usuarios con sus características propias de comportamiento psicosocial y de cultura, y 3) la responsabilidad legal de todos los involucrados en el acceso al servicio debido al manejo de información personal y sensible de los usuarios.

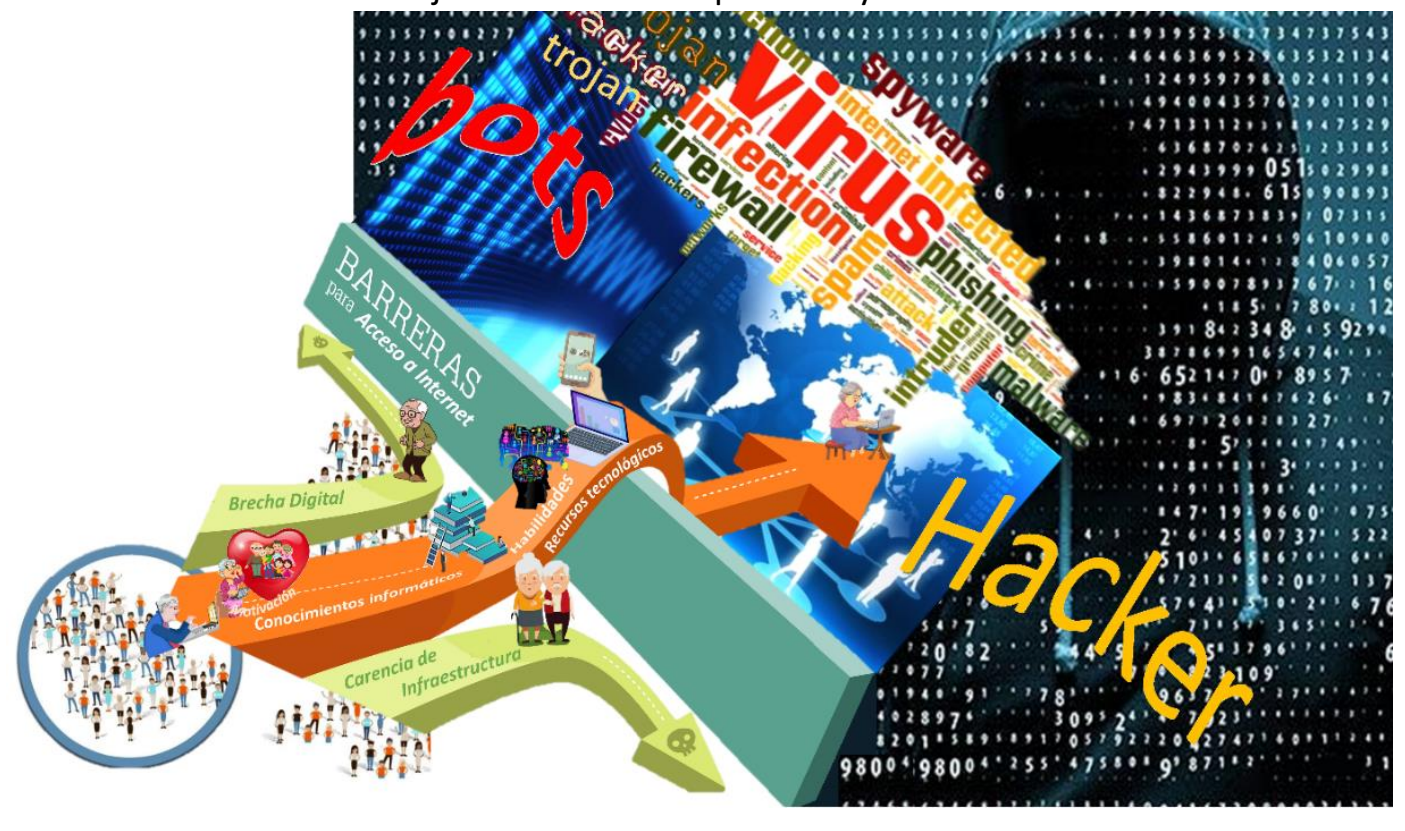

Fig. 43 Ciber-riesgos en el entorno de Facebook

Esta investigación permitió desarrollar la fundamentación teórica que sustentó la investigación No. 4, y así, de forma integrada, derivaron en una publicación, cuyos detalles serán presentados más adelante.

\subsubsection{Caracterización de la investigación No. 3 \\ 5.4.1.1. Propósito}

Para lograr que los usuarios de Facebook participen con tranquilidad y obtengan satisfacción de las interacciones virtuales que realicen a través de la red social Facebook, es importante que tengan conocimiento de los aspectos positivos y negativos del entorno ofrecido para esa interactividad social virtual. Habiendo enfocado ya los beneficios de la red social, que se consideran reales y evidenciados formalmente por estudios científicos, ahora se considera el momento oportuno para enfocar la otra cara de la moneda de Facebook, la de los ciber-riesgos, pero yendo más allá de la simple definición, conceptualización y del posible impacto en el caso de que una amenaza sea concretada; y más bien dando importancia a las causas que originan la exposición a esos ciber-riesgos, porque es allí donde se puede encontrar la opción para minimizar al máximo el riesgo y su impacto. La investigación se 
propuso visualizar y analizar las causas de los ciber-riesgos desde distintas perspectivas: comportamientos psicosociales de los usuarios y cultura de seguridad; aspectos jurídicos; $y$, aspectos tecnológicos, propios de la plataforma que soporta el servicio.

\subsubsection{Ficha descriptiva de la investigación No. 3}

En la Tabla 15 se presentan particularidades significativas de la investigación No. 3.

Tabla 15. Ficha descriptiva de la investigación No. 3

\begin{tabular}{|l|l|}
\hline \multicolumn{2}{|c|}{ Ficha técnica descriptiva de la investigación No. 3 } \\
\hline Características descriptivas & \multicolumn{1}{c|}{ Texto descriptivo } \\
\hline Nombre: & $\begin{array}{l}\text { Factores determinantes de la exposición del usuario AM a los ciber-riesgos } \\
\text { del entorno de la red social Facebook }\end{array}$ \\
\hline Año: & 2018 - 2019 \\
\hline Área de Investigación: & Computación social \\
\hline Tipo de investigación: & Cualitativa \\
\hline Enfoque Metodológico & $\begin{array}{l}\text { Investigación cualitativa con Teoría Fundamentada: Método de codificación } \\
\text { y generación de conceptos teóricos. }\end{array}$ \\
\hline $\begin{array}{l}\text { Técnicas de investigación } \\
\text { utilizadas }\end{array}$ & Investigación documental \\
\hline $\begin{array}{l}\text { Métodos de recolección de } \\
\text { datos }\end{array}$ & Heurística y Hermenéutica \\
\hline Análisis de datos: & $\begin{array}{l}\text { De la Investigación documental: Análisis cualitativo de datos asistido por } \\
\text { computadora, a través del software Atlas Ti Versión 7.5.7. }\end{array}$ \\
\hline
\end{tabular}

\subsubsection{Objetivo}

Exponer de forma organizada y con amplio espectro, la faceta poco conocida de Facebook, concerniente a las causas que ocasionan los ciber-riesgos para los usuarios del entorno de la red social, mediante una catalogación en categorías o disciplinas científicas involucradas, conceptos en cada categoría, códigos para cada concepto; $y$, factores causantes de los riesgos dentro de cada código.

\subsubsection{Hipótesis}

Si se quiere generar un entorno seguro en Facebook, no es suficiente conocer el significado de cada uno de los ciber-riesgos, ni siquiera las consecuencias negativas que éstos pueden generar en los usuarios, sino que es necesario la identificación y conceptualización de cada una de las causas que los originan. Ese conocimiento permitirá establecer acciones de mejoramiento necesarias en el respectivo ámbito, principalmente, en aquellas causas que se deban estrictamente al usuario de Facebook, porque es posible remediarlas con esfuerzos personales y capacitación, para construir un comportamiento seguro que genere la percepción de tener bajo control los ciber-riesgos en el entorno de Facebook, y alcanzar satisfacción integral con las interacciones virtuales, en pro de mejorar la calidad de vida.

\subsubsection{Pregunta de Investigación}

Para organizar los resultados del análisis hermenéutico de las publicaciones indexadas, se planteó la pregunta: ¿cuáles disciplinas científicas enmarcan las distintas causas de los ciber-riesgos de seguridad y privacidad con los que coexisten las personas cuando utilizan la red social Facebook? 


\subsubsection{Contexto de la investigación}

Investigación documental: publicaciones de diversas características y naturaleza, difundidas a través de Internet por fuentes confiables y artículos en revistas indexadas o actas de congresos; relacionadas con las causas de los tres tipos de ciber-riesgos definidos para el entorno de la red social Facebook, a saber: 1) contra la información; 2) contra el ser humano; y, 3) contra la infraestructura.

\subsubsection{Resultados de la investigación}

Los resultados del estudio corresponden a la estructuración de un enfoque interdisciplinario de las causas de los ciber-riesgos en el entorno de Facebook, presentado como lo establece la Teoría Fundamentada: en categorías, conceptos y códigos; habiéndose integrado con la Hermenéutica para con la interpretación de las publicaciones, establecer las disciplinas científicas o categorías involucradas, los nombres de los conceptos para cada disciplina, las designaciones de los códigos en cada concepto; $y$, asignar a cada código, los distintos factores causantes de los riesgos, como se detalla a continuación con los ideogramas creados con la asistencia del software para análisis de datos cualitativos Atlas Ti:

\section{Enfoque interdisciplinario:}

La investigación documental permitió organizar las causas de los ciber-riesgos en tres categorías con ámbitos claramente diferenciados, cada una correspondiente a una disciplina científica, Fig. 44.

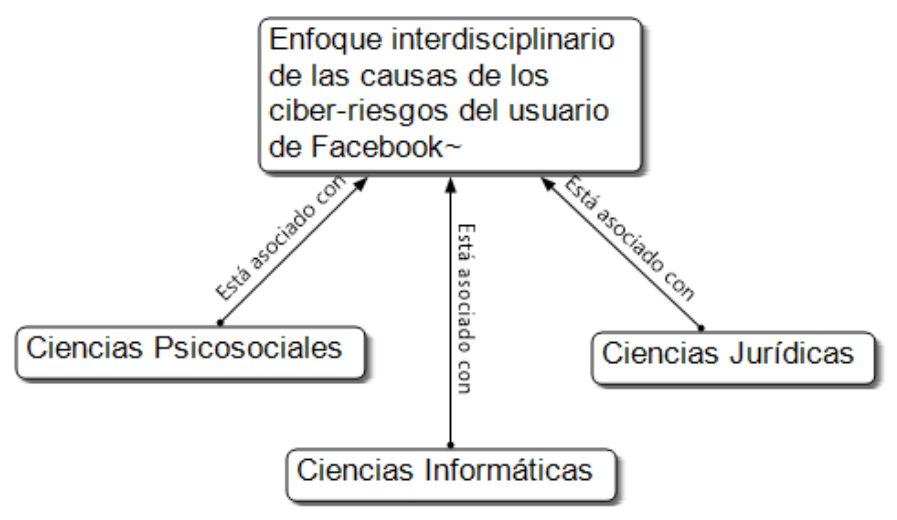

Fig. 44. Disciplinas científicas que conforman el enfoque interdisciplinario de las causas de los ciber-riesgos del entorno de Facebook.

\section{Disciplina científica: ciencias psicosociales}

En la categoría ciencias psicosociales, se identificó un concepto determinado por tres códigos que tienen que ver con la forma de actuar del usuario de Facebook en el entorno de la red social, Fig. 45.

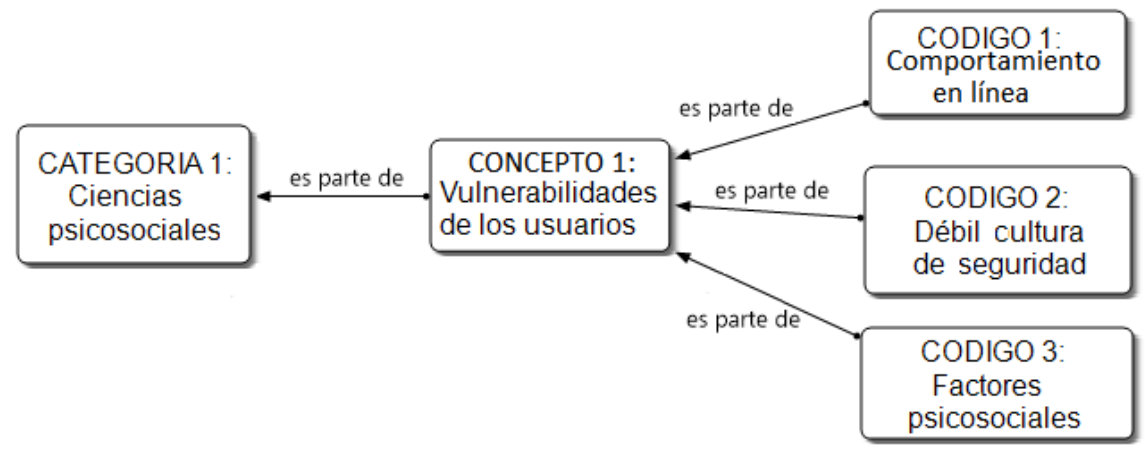

Fig. 45. Composición de la disciplina ciencias psicosociales 
Se encontraron tres factores correspondientes al comportamiento en línea, que le hacen vulnerable al usuario de Facebook, Fig. 46.

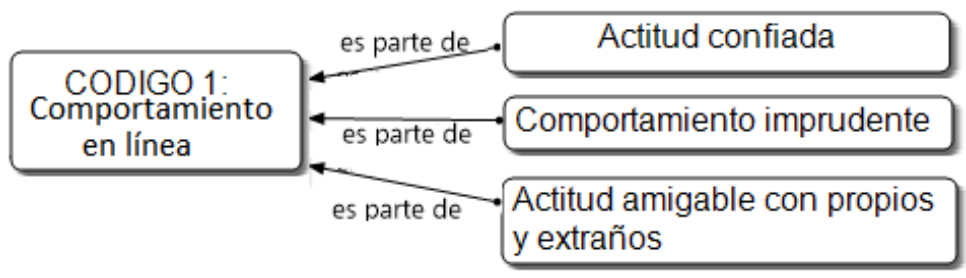

Fig. 46. Factores que conforman el código 1: comportamiento en línea

La débil cultura de privacidad y seguridad se estructuró a través de siete factores que involucraron conocimientos, ideas y costumbres cuando se registran y durante su participación en la red social, Fig.

47.

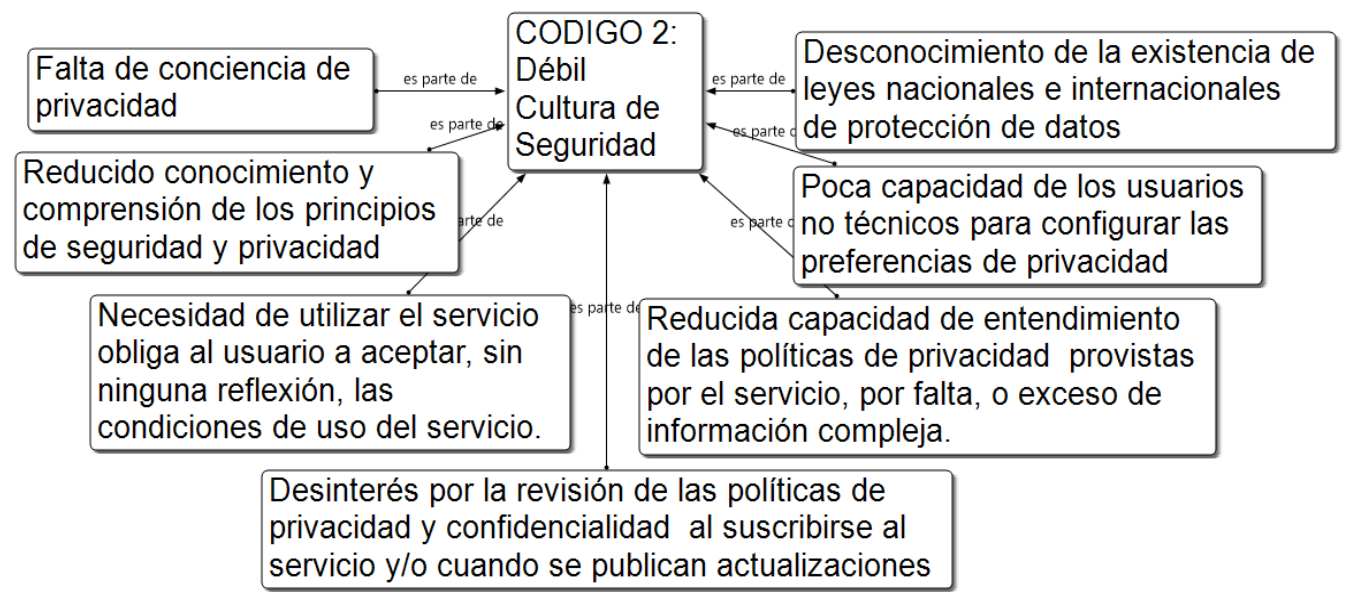

Fig. 47. Factores que conforman el código 2: débil cultura de seguridad

Los factores psicosociales que tienen que ver con sus intereses sociales como estar a la moda, estar en contacto con famosos, o tener reconocimiento por sus posesiones materiales, Fig. 48.

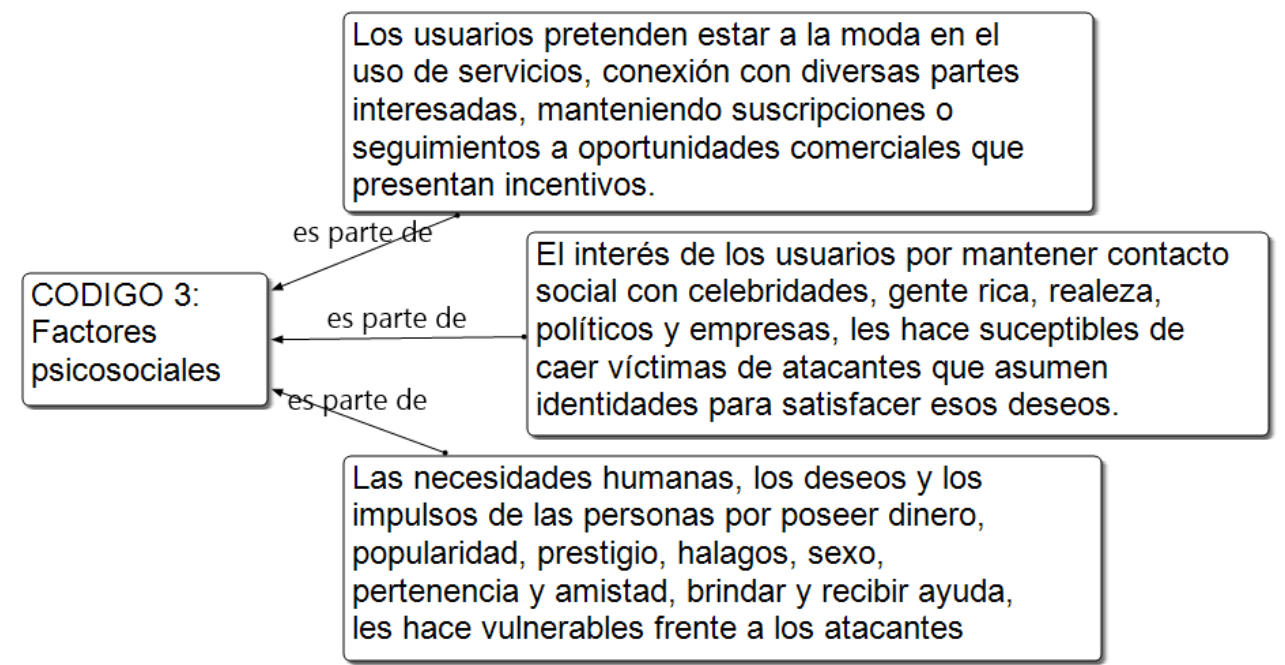

Fig. 48. Factores que conforman el código 3: factores psicosociales 


\section{Disciplina científica: ciencias informáticas}

Esta categoría, que tiene que ver con la plataforma tecnológica con la que se ofrece el servicio y también con que se accede a él, se estructuró con 4 conceptos, Fig. 49.

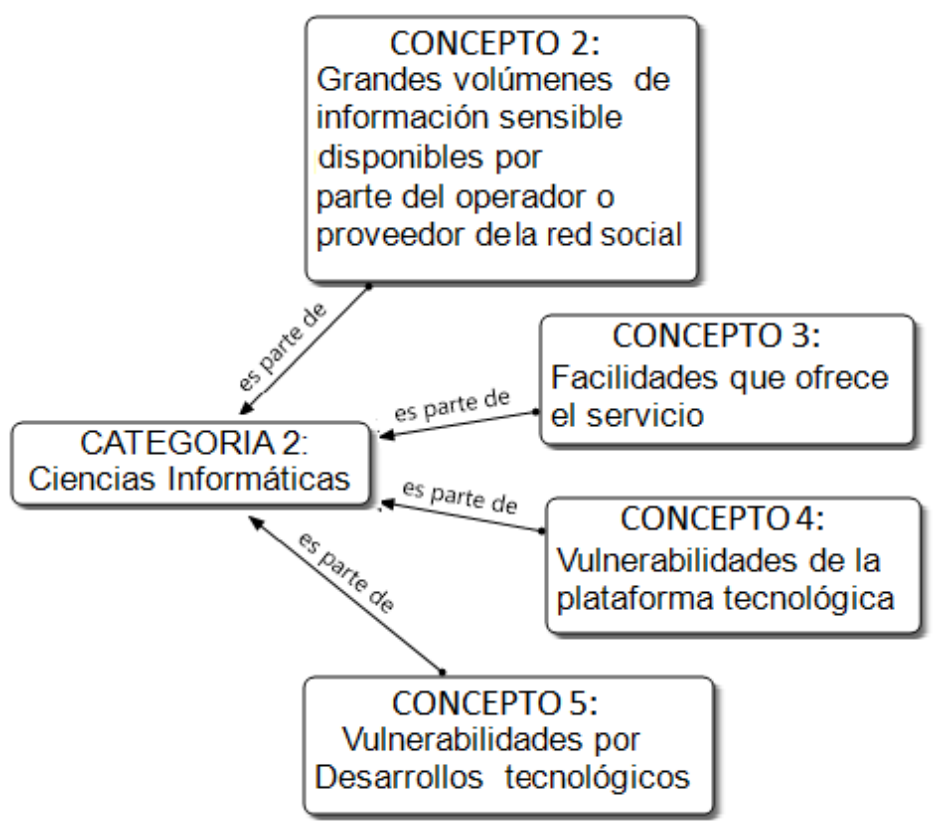

Fig. 49. Composición de la disciplina ciencias informáticas

EL concepto 2, fue constituido por 4 códigos que muestran las razones de los grandes volúmenes de información sensible de los usuarios, que almacena la plataforma tecnológica que ofrece el servicio, Fig. 50.

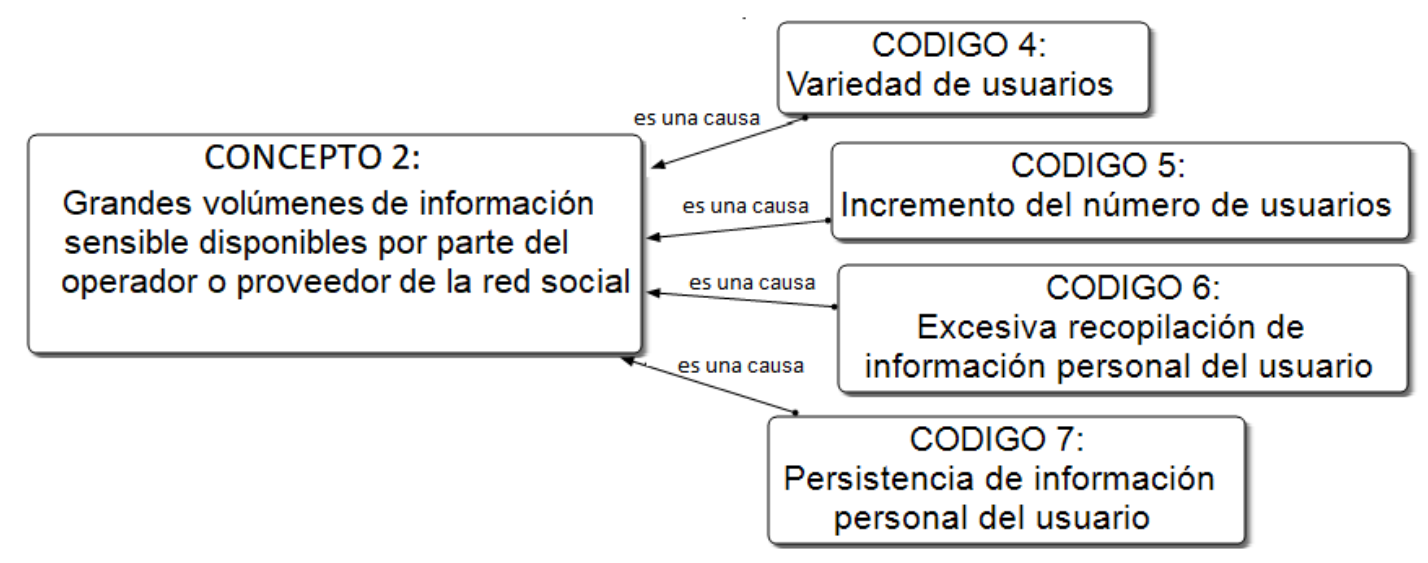

Fig. 50. Códigos del concepto 2: grandes volúmenes de información sensible disponibles por el operador o proveedor de la red social

Las fuentes de la variedad de usuarios (código 4) y el incremento del número de usuarios (código 5),, son tres, y están representadas en la Fig. 51 


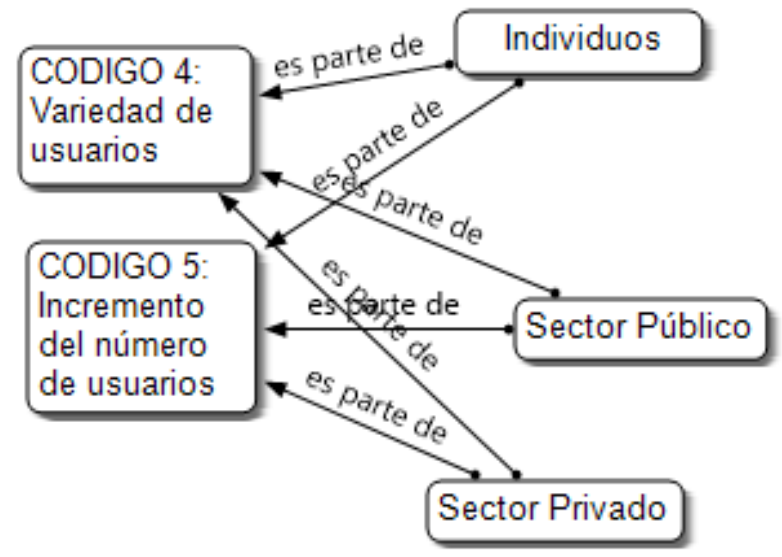

Fig. 51. Factores del código 4: variedad de usuarios; y, del código 5: incremento del número de usuarios

La excesiva recopilación de información personal del usuario de Facebook no solo se debe a la información que conscientemente entrega el usuario de la red social, sino a otros factores externos a él, como se observa en la Fig. 52. En esta misma figura, se evidencia que la información almacenada en los sistemas de almacenamiento del proveedor de la red social, es muy posible que quede fuera del alcance de los usuarios por diversas razones.



Fig. 52. Factores del código 6: excesiva recopilación de información personal; y, del código 7: persistencia de información personal del usuario. 
La forma como fue concebido el servicio de la red social Facebook ofrece facilidades para los atacantes. Estas facilidades que ofrece el servicio (concepto 3) quedaron descritas a través de 2 códigos y sus respectivos factores, como se expone en la Fig. 53.

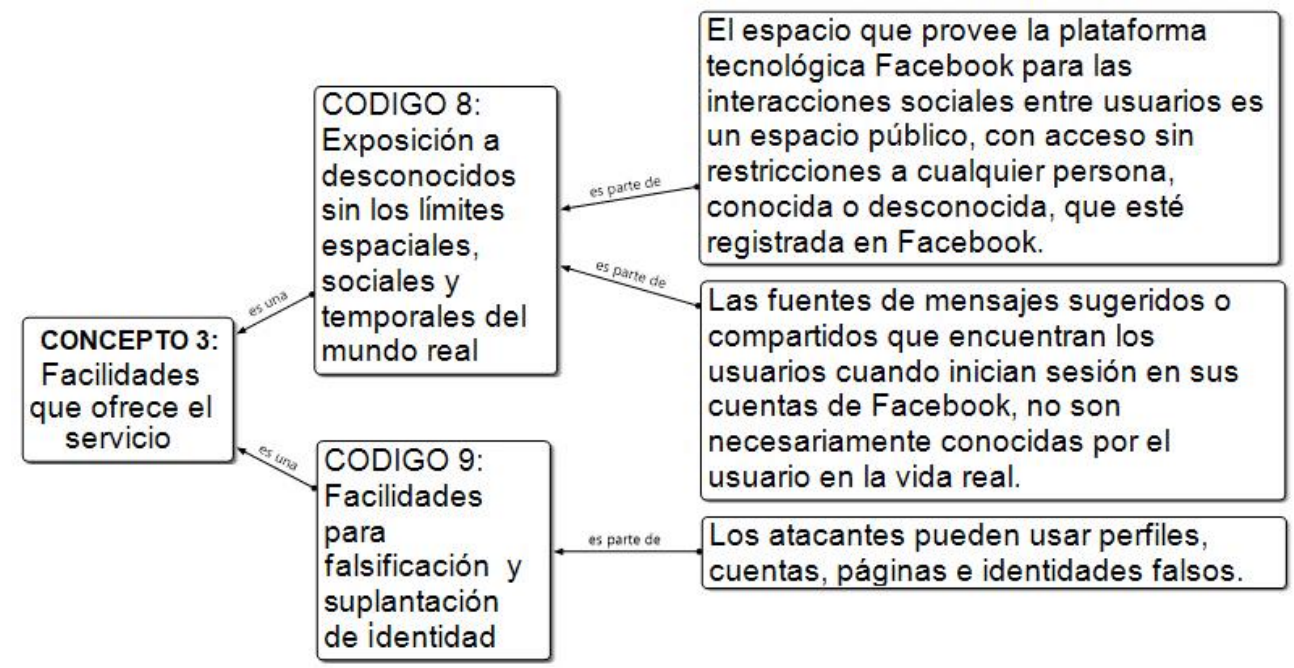

Fig. 53. Códigos del Concepto 3 y factores del código 8: exposición a desconocidos; y, del código 9: facilidades para falsificación y suplantación de identidad

las vulnerabilidades de la plataforma tecnológica, concepto 4 en las causas pertenecientes a las ciencias informáticas, se ha descrito por dos códigos, como se presenta en la Fig. 54

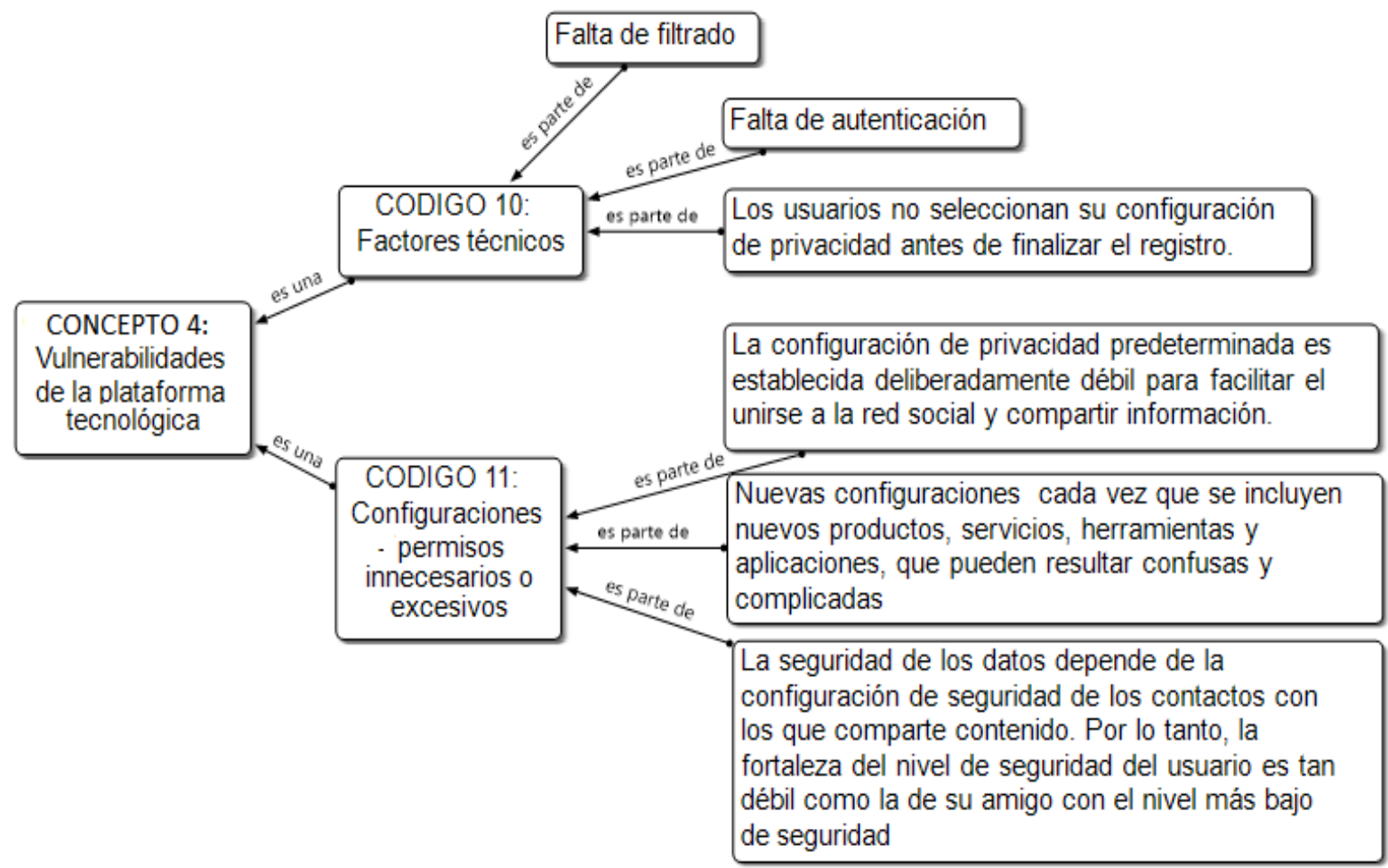

Fig. 54. Códigos del concepto 4 y factores del código 10: factores técnicos; y, del código 11: configuraciones - permisos innecesarios o excesivos 
Los desarrollos tecnológicos que siempre ofrecen mejores prestaciones a costos menores, si bien benefician a los usuarios de la tecnología, son también causas de ciber-riesgos, como se describe en la Fig. 55.



Fig. 55. Códigos de la categoría 5 y factores del código 12: la plataforma abierta a aplicaciones de terceros; del código 13: acceso por variedad de dispositivos; y, del código 14: mejoras tecnológicas

\section{Disciplina científica: ciencias jurídicas}

Las causas de los ciber-riesgos asociadas con la legislación nacional e internacional y el contenido de los términos de uso y las políticas de datos, se muestran en la Fig. 56.

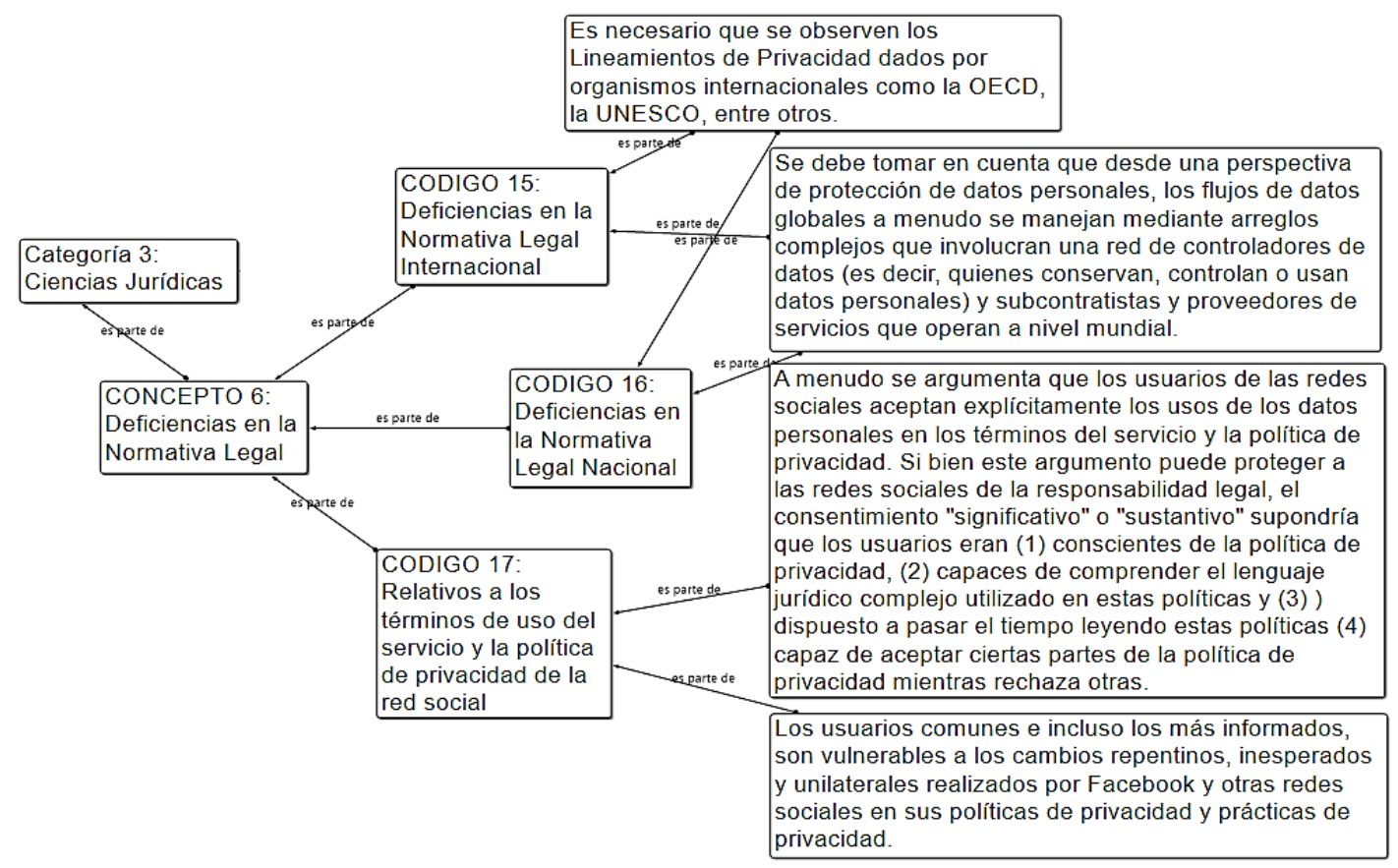

Fig. 56. Códigos del concepto 6 y factores del código 15: normativa legal Internacional; del código 16: normativa legal Nacional; y, del código 17: relativos a los términos de uso del servicio y la política de privacidad de la red social. 


\subsubsection{Discusión}

En la Tabla 16 constan las causas que le hacen al usuario de Facebook propenso a ser víctima de los ciber-riesgos, organizadas en conceptos y categorías de acuerdo a los lineamientos de la Teoría Fundamentada.

Tabla 16. Organización de las causas de los ciber-riesgos en el entorno de Facebook, en conceptos y categorías

\begin{tabular}{lll}
\hline $\begin{array}{l}\text { Números de } \\
\text { identificación }\end{array}$ & $\begin{array}{l}\text { Nombres de identificación de los conceptos que } \\
\text { agrupan las causas de los ciber-riesgos en Facebook }\end{array}$ & $\begin{array}{l}\text { Nombres de } \\
\text { identificación de las } \\
\text { categorías (disciplinas } \\
\text { científicas) }\end{array}$ \\
\hline 1 & $\begin{array}{l}\text { Vulnerabilidades atribuibles a los usuarios: a) Nivel de } \\
\text { cultura de seguridad y privacidad; } y \text { b) Nivel de riesgo } \\
\text { por comportamientos psicosociales. }\end{array}$ & Ciencias Psicosociales. \\
\hline 3 & $\begin{array}{l}\text { Almacenamiento de grandes volúmenes de } \\
\text { información. }\end{array}$ & Ciencias Informáticas. \\
\hline 5 & Facilidades que ofrece el servicio. & \\
\hline 6 & Vulnerabilidades de la plataforma tecnológica. & \\
\hline
\end{tabular}

La Tabla 17 sintetiza las publicaciones que dieron soporte al compendio de la Tabla 16.

Tabla 17. Publicaciones seleccionadas que soportan los conceptos en que se organizaron las causas de los ciber-riesgos en el entorno de Facebook.

\begin{tabular}{|c|c|c|c|c|c|c|}
\hline \multirow[t]{2}{*}{ Referencia a la publicación } & \multicolumn{6}{|c|}{$\begin{array}{c}\text { Número de identificación de los conceptos que agrupan las } \\
\text { causas de los ciber-riesgos en Facebook }\end{array}$} \\
\hline & 1 & 2 & 3 & 4 & 5 & 6 \\
\hline (UNESCO, 2012) & & SI & & SI & SI & \\
\hline (Algarni et al., 2014) & $\mathrm{SI}$ & $\mathrm{SI}$ & $\mathrm{SI}$ & $\mathrm{SI}$ & & \\
\hline (Netter et al., 2013) & SI & SI & SI & SI & & SI \\
\hline (Cornejo \& Tapia, 2011) & & $\mathrm{SI}$ & $\mathrm{SI}$ & & & \\
\hline (Lara et al., 2014) & & & & & & $\mathrm{SI}$ \\
\hline (OECD, 1980) & & $\mathrm{SI}$ & & $\mathrm{SI}$ & $\mathrm{SI}$ & SI \\
\hline (OECD, 2011) & & $\mathrm{SI}$ & & $\mathrm{SI}$ & $\mathrm{SI}$ & \\
\hline (Wong, 2014) & $\mathrm{SI}$ & $\mathrm{SI}$ & & $\mathrm{SI}$ & $\mathrm{SI}$ & \\
\hline (C. Zhang et al., 2010) & & & & & SI & \\
\hline (Zhan \& Fang, 2011) & $\mathrm{SI}$ & $\mathrm{SI}$ & $\mathrm{SI}$ & $\mathrm{SI}$ & & \\
\hline
\end{tabular}

\subsubsection{Modelo Conceptual de las Causas de los Ciber-riesgos en el Entorno de Facebook}

Las causas de los ciber-riesgos en el entorno de Facebook fueron organizadas en un modelo conceptual, que resultó mejor estructurado con un enfoque interdisciplinario desde las ciencias: Psicosociales, Jurídicas, e Informáticas, como se muestra en la Fig. 57. 


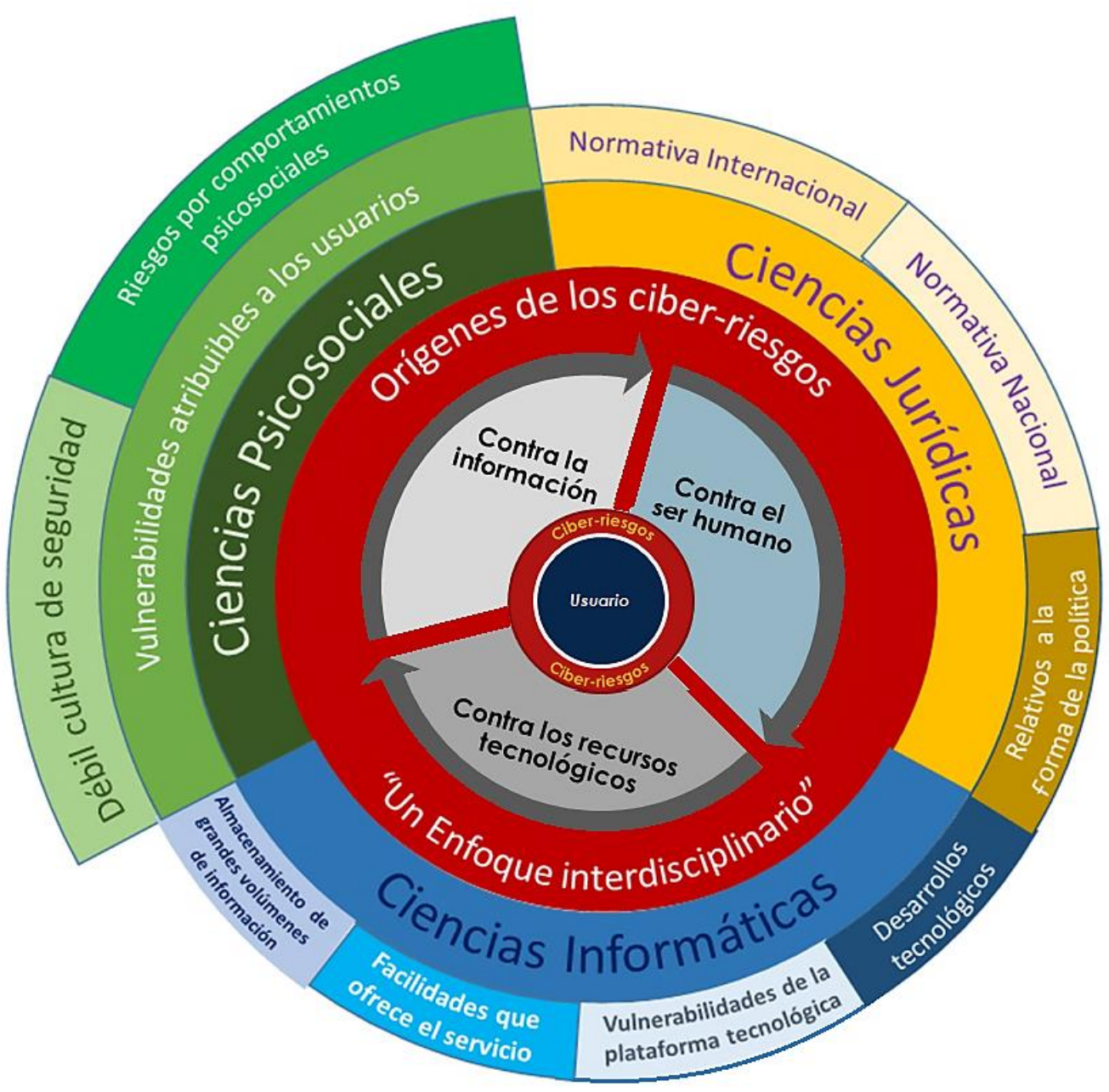

Fig. 57. Modelo conceptual, con enfoque interdisciplinario, de las causas de los ciber-riesgos en el entorno de Facebook

Este modelo debe entenderse desde el círculo concéntrico más interno, que representa al usuario de la red social Facebook. A partir de allí, los siguientes círculos concéntricos significan:

1. Que el usuario de Facebook está rodeado de ciber-riesgos.

2. Que esos ciber-riesgos pueden ser contra:
a. La información,
b. el ser humano, y
c. la infraestructura.

3. Que los orígenes de los ciber-riesgos deben ser entendidos desde disciplinas científicas diferentes.

4. Que esas áreas científicas son:
a. Las ciencias psicosociales
b. Las ciencias informáticas, y
c. Las ciencias informáticas.

5. Que, en cada una de esas ciencias, se han conceptualizado los diversos orígenes de los ciber riesgos. $Y$,

6. Que, cada causa se descompone en diversos factores.

Para ejemplificar los factores, por necesidades de este estudio, se muestran aquellos correspondientes a las vulnerabilidades atribuibles a los usuarios, que en las siguientes secciones se describen con detalle. 


\subsubsection{Factores determinantes del grado de conciencia sobre privacidad y seguridad en Facebook}

Las vulnerabilidades atribuibles a los usuarios de Facebook, presentes en el modelo conceptual de la Fig. 57, se consideraron en este estudio como los factores determinantes del grado de conciencia sobre privacidad y seguridad en la red social; y, están definidos por las características significativas y los atributos presentes en la Tabla 18.

Tabla 18. Factores determinantes del grado de conciencia sobre privacidad y seguridad, características significativas y grupos de atributos.

\begin{tabular}{lll}
\hline $\begin{array}{l}\text { Factores } \\
\text { determinantes del } \\
\text { grado de }\end{array}$ & Características & \\
$\begin{array}{l}\text { conciencia sobre } \\
\text { privacidad y }\end{array}$ & significativas & \\
seguridad & &
\end{tabular}

1. ¿Reconoce lo que es una violación de su Privacidad en línea?

A. Nivel de

2. ¿ildentifica correctamente los términos que se refieren a ciber-riesgos conocimientos sobre principios de seguridad $y$ privacidad. a los que está expuesto un usuario de Facebook?

3. ¿Conoce estrategias para preservar la seguridad de los datos del computador?

4. ¿Conoce estrategias para preservar la privacidad en Facebook?

5. ¿Entiende el principio de confidencialidad?

6. ¿Comprende el significado de privacidad en línea?

1. ¿ildentifica correctamente los temas fundamentales enfocados en la

B. Nivel de política de Privacidad de Facebook?

comprensión de

la política de privacidad y datos de

Facebook y sus actualizaciones.

2. ¿Conoce las aplicaciones o personas que pueden llegar a obtener sus datos personales registrados en su perfil de Facebook?

3. ¿Revisa las actualizaciones que Facebook hace a su política de Datos?

4. ¿Sabe interpretar la política de privacidad de Facebook?

5. ¿Conoce las acciones para control de información personal, que Facebook le ha otorgado como usuario?

6. ¿Sabe que la información personal que Facebook recopila de los usuarios es compartida con alguien?

Nivel de cultura de seguridad y privacidad
1. ¿Crea Grupos de usuarios?

2. ¿Conoce el efecto que tiene el seleccionar "Todos" en la configuración de privacidad de Facebook?

C. Nivel de experticia en las configuraciones de privacidad disponibles en la red social.

3. ¿Sabe cuál es la opción de configuración que un usuario debería utilizar para restringir: quienes pueden enviarle solicitudes de amistad; $y$, quienes pueden ver su lista de amigos?

4. ¿Sabe cuál es la opción de configuración que un usuario debería utilizar para restringir en Facebook: la invitación de alguien para asistir a un evento, las invitaciones a una app que le haya enviado alguien, mensajes y vídeo-llamadas de alguien, así como ponerse en contacto mediante la app de Messenger?

1. ¿Tiene conocimiento de donde Facebook guarda los datos personales que registró al abrir la cuenta de usuario?

D. Nivel de conocimiento elemental sobre aspectos jurídicos en el contexto operativo de la red social
2. ¿Sabe a ciencia cierta que, en los lugares donde cree que Facebook guarda sus datos personales, SI existen leyes vigentes de protección de datos que lo protegen, de alguna forma, ante una violación de seguridad y/o privacidad por ser usuario de Facebook?

3. ¿Conoce con certeza, si en su País de residencia, hay leyes vigentes de protección de datos que lo protegen, de alguna forma, ante una violación de seguridad y/o privacidad por ser usuario de Facebook?

4. ¿Conoce cómo actuar correctamente si fuera víctima de algún daño por utilizar Facebook? 


\begin{tabular}{|c|c|c|c|c|}
\hline \multirow{12}{*}{$\begin{array}{l}\text { Nivel de riesgo } \\
\text { generado por } \\
\text { comportamientos } \\
\text { psicosociales }\end{array}$} & A. & $\begin{array}{l}\text { No saber } \\
\text { reconocer a un } \\
\text { usuario } \\
\text { confiable }\end{array}$ & 1. & $\begin{array}{l}\text { ¿Entiende lo que es hacer un análisis exhaustivo para determinar si } \\
\text { una persona es confiable? }\end{array}$ \\
\hline & B. & $\begin{array}{l}\text { No saber actuar } \\
\text { ante solicitudes } \\
\text { de amistad de } \\
\text { conocidos y/o } \\
\text { desconocidos }\end{array}$ & 2. & $\begin{array}{l}\text { ¿Conoce la forma correcta de actuar cuando un } \\
\text { conocido/desconocido le envía una solicitud de amistad? }\end{array}$ \\
\hline & C. & $\begin{array}{l}\text { Enviar } \\
\text { información } \\
\text { confidencial }\end{array}$ & 3. & ¿Utiliza la red social para enviar información confidencial? \\
\hline & D. & $\begin{array}{l}\text { Aceptar } \\
\text { ofrecimientos } \\
\text { de extraños }\end{array}$ & 4. & $\begin{array}{l}\text { ¿Sabe actuar correctamente ante ofrecimientos y comunicaciones de } \\
\text { un usuario extraño de Facebook? }\end{array}$ \\
\hline & E. & $\begin{array}{l}\text { Hacer } \\
\text { transacciones } \\
\text { con tarjeta de } \\
\text { crédito }\end{array}$ & 5. & $\begin{array}{l}\text { ¿Ha realizado alguna transacción a través de Facebook que haya } \\
\text { requerido el número de su tarjeta de crédito? }\end{array}$ \\
\hline & F. & $\begin{array}{l}\text { Difundir la } \\
\text { actividad actual }\end{array}$ & 6. & ¿Hace publicaciones en Facebook de sus actividades actuales? \\
\hline & G. & $\begin{array}{l}\text { Sentir atracción } \\
\text { por mantener } \\
\text { contacto con } \\
\text { famosos }\end{array}$ & 7. & ¿Siente atracción por ser contacto de personas famosas? \\
\hline & $\mathrm{H}$. & $\begin{array}{l}\text { Gustar de hacer } \\
\text { publicaciones } \\
\text { relacionadas con } \\
\text { su vida personal }\end{array}$ & 8. & ¿Gusta hacer publicaciones relacionadas con su vida personal? \\
\hline & I. & $\begin{array}{l}\text { Recibir apoyo } \\
\text { emocional }\end{array}$ & 9. & $\begin{array}{l}\text { ¿Ha recibido apoyo emocional de usuarios de Facebook, conocidos y } \\
\text { desconocidos por usted, frente a algún inconveniente o calamidad que } \\
\text { ha sufrido? }\end{array}$ \\
\hline & J. & $\begin{array}{l}\text { Brindar apoyo } \\
\text { emocional }\end{array}$ & 10. & $\begin{array}{l}\text { ¿Ha utilizado Facebook para brindar apoyo emocional a usuarios de la } \\
\text { red social, conocidos y desconocidos por usted, frente a algún } \\
\text { inconveniente o calamidad que decían tener? }\end{array}$ \\
\hline & K. & $\begin{array}{l}\text { No clasificar a } \\
\text { sus contactos en } \\
\text { grupos afines }\end{array}$ & 11. & ¿Clasifica a sus contactos en grupos afines? \\
\hline & L. & $\begin{array}{l}\text { Que Facebook le } \\
\text { aleje de sus } \\
\text { contactos cara a } \\
\text { cara }\end{array}$ & 12. & $\begin{array}{l}\text { ¿Ha reducido sus relaciones personales cara a cara con las personas } \\
\text { que convive a diario debido al uso de Facebook? }\end{array}$ \\
\hline
\end{tabular}

\subsubsection{Conclusiones}

La aplicación iterativa de los lineamientos dados por la Teoría Fundamentada y la hermenéutica, permitieron estructurar una sólida fundamentación, conformada por: 1) el modelo conceptual, con enfoque interdisciplinario, de las causas de los ciber-riesgos en el entorno de Facebook; y, 2) los factores determinantes del nivel real de conciencia del usuario de Facebook respecto a privacidad y seguridad en la red social; instrumentos valiosos que servirían para estructurar la propuesta de proceso de estimación del nivel real de conciencia de los usuarios de Facebook respecto a seguridad y privacidad en la red social, y la interpretación de los resultados que se alcancen cuando el proceso sea aplicado. 
Varias son las causas que le hacen al usuario de Facebook propenso a ser víctima de los ciber-riesgos, algunas de ellas son atribuibles al comportamiento propio del usuario, en tanto que otras le corresponden a la plataforma tecnológica y a la concepción misma del servicio ofrecido por la red social, y que permanecerán latentes para ser explotadas por ciber-delincuentes que pretenderán beneficiarse ilegalmente con sus acciones, y sobre las que debería asumir, de alguna manera, responsabilidades el proveedor del servicio.

Con respecto a las causas atribuibles al usuario, es imperativo tener conciencia de ellas, y tomar correctivos como los que se sugieren a continuación:

1. Asigne tiempo para analizar y comprender las políticas de privacidad que maneja Facebook. Nunca deje de revisar y entender las actualizaciones.

2. Identifique claramente hacia quien publica su información, formando grupos de contactos.

3. No acepte ninguna clase de propuesta de personas que son desconocidas para usted en la vida real.

4. Ante una solicitud de amistad, verifique efectivamente si la persona que le solicita es real, para lo cual: revise el perfil de la página de Facebook del solicitante; examine los contactos que dispone para tratar de identificar a algún contacto en común o el círculo de amigos que posee, observe las publicaciones que ha realizado para conocer sus intereses y actitudes.

5. Configure su interface de usuario de Facebook, para que solamente lo que usted desee que esté abierto al público tenga esa característica.

6. Tome en cuenta que cuando le solicitan aceptar un nuevo servicio o aplicación, es muy posible que, al aceptarlos, esté concediendo su autorización para la captación de su información personal por parte de terceros.

7. Comparta con sus contactos estos consejos, ya que su privacidad también depende de las configuraciones y actuaciones de sus contactos.

8. Revise si en la legislación de su país existen leyes de protección de datos e identifique la forma de actuar ante una violación a su seguridad y/o su privacidad.

Es necesario que se entienda que una persona puede perder el control de sus datos cuando los operadores de la red social generan copias de seguridad de la información almacenada en sus plataformas; y de esta forma, la información, no necesariamente actualizada, tiene el potencial de ser almacenada por períodos indefinidos, situación que se ahonda si se considera que el costo de almacenamiento y descarga a disco se reduce constantemente, y por lo tanto las copias de seguridad pueden ser realizadas con mayor frecuencia. La principal amenaza para los usuarios, asociada con estas copias de seguridad, aparecería cuando se restituya a la plataforma, la información de los usuarios, a partir de copias de seguridad que no están totalmente actualizadas; $y$, al realizar búsquedas podrían aparecer informaciones (datos, fotos, vídeos) que la persona haya considerado que ya no existían. 


\subsection{Investigación No. 4: estimación del nivel real de conciencia de los usuarios de Facebook respecto a privacidad y seguridad en la red social}

Con fundamentación en los resultados de la investigación documental No.3: 1) el modelo conceptual de las causas de los ciber-riesgos en el entorno de Facebook, formulado con enfoque interdisciplinario desde las ciencias: Psicosociales, Jurídicas, e Informáticas, presentado en la Fig. 57; y, 2) los diferentes atributos que conforman las características significativas que sistematizan los factores: a) nivel de riesgo generado por los comportamientos psicosociales en Facebook; y, b) nivel de cultura de seguridad y privacidad del usuario, detallados en la Tabla 18; con los cuales se teorizó la estimación del grado de conciencia sobre privacidad y seguridad de un usuario de Facebook; se consideró necesario demostrar la validez de la teorización referida.

\subsubsection{Caracterización de la investigación No. 4}

\subsubsection{Propósito}

Demostrar la validez de los factores teorizados en la investigación No. 3, para la estimación del grado de conciencia sobre privacidad y seguridad de un usuario de Facebook.

Para la demostración se requiere establecer un proceso que operativice el método de aplicación práctica de los factores determinantes del nivel de conciencia sobre privacidad y seguridad a los usuarios de Facebook; el mismo que debe ser validado.

\subsubsection{Ficha descriptiva de la investigación No. 4}

En la Tabla 19 se presentan características significativas de la investigación No. 4.

Tabla 19. Ficha descriptiva de la investigación No. 4

\begin{tabular}{|c|c|}
\hline & Ficha técnica descriptiva de la investigación No. 4 \\
\hline $\begin{array}{l}\text { Características } \\
\text { descriptivas }\end{array}$ & Texto descriptivo \\
\hline Nombre: & $\begin{array}{l}\text { Estimación del nivel real de conciencia de los usuarios de Facebook respecto a privacidad } \\
\text { y seguridad en la red social }\end{array}$ \\
\hline Año: & $2018-2019-2020$ \\
\hline $\begin{array}{l}\text { Área de } \\
\text { Investigación: }\end{array}$ & Computación social \\
\hline $\begin{array}{l}\text { Tipo de } \\
\text { investigación: }\end{array}$ & Cualitativa \\
\hline $\begin{array}{l}\text { Enfoque } \\
\text { Metodológico: }\end{array}$ & Investigación no experimental transversal. \\
\hline $\begin{array}{l}\text { Técnicas de } \\
\text { investigación } \\
\text { utilizadas: }\end{array}$ & Investigación en campo. \\
\hline $\begin{array}{l}\text { Métodos de } \\
\text { recolección de } \\
\text { datos: }\end{array}$ & Entrevistas estructuradas \\
\hline Análisis de datos: & $\begin{array}{l}\text { - Almacenamiento de los datos de las entrevistas estructuradas en una planilla de cálculo } \\
\text { en Microsoft Excel. } \\
\text { - Preparación del conjunto de datos. } \\
\text { - Comparación del nivel real de conciencia sobre privacidad y seguridad de los usuarios } \\
\text { de Facebook con el nivel de conciencia hipotético que asume que posee el usuario de } \\
\text { Facebook. }\end{array}$ \\
\hline
\end{tabular}


- Análisis de datos cuantitativos presentes en una planilla de cálculo en Microsoft Excel, empleando el software Tableau.

\subsubsection{Objetivo}

Estructurar un proceso para la estimación del nivel real de conciencia de los usuarios de Facebook respecto a privacidad y seguridad en la red social, y validar tanto el proceso como el método de determinación del nivel de conciencia.

\subsubsection{Hipótesis}

La estimación del nivel real de conciencia de usuarios de Facebook respecto a privacidad y seguridad en la red social puede seguir un proceso basado en los comportamientos psicosociales y la cultura de privacidad y seguridad que las personas manifiestan en sus interacciones virtuales en Facebook.

\subsubsection{Preguntas de Investigación}

1. ¿El nivel real de conciencia de los usuarios de Facebook respecto a privacidad y seguridad en la red social puede determinarse a través de los comportamientos psicosociales y la cultura de privacidad y seguridad que las personas manifiestan en sus interacciones virtuales en Facebook?

2. ¿Es posible estructurar un proceso para estimar el nivel real de conciencia de los usuarios de Facebook respecto a privacidad y seguridad en la red social que se fundamente en los comportamientos psicosociales y en la cultura de privacidad y seguridad que las personas manifiestan en sus interacciones virtuales en Facebook?

\subsubsection{Contexto de la investigación}

Investigación no experimental transversal: el contexto de investigación para instrumentar la propuesta de proceso, y hacer una primera aproximación hacia su validación mediante la verificación de la fidelidad con que refleja la realidad, estuvo constituido por una muestra no representativa del universo de usuarios de Facebook, compuesta por 226 miembros del entorno de influencia del investigador, hombres y mujeres ecuatorianos con distintos niveles de formación académica, pertenecientes a los grupos etarios: AM (edad: mayor a 64 años), adultos (edad: entre 41 y 64 años), adultos jóvenes (edad: en el rango de 18 a 40 años) y niños/adolescentes (edad: menor a 18 años), como se muestra en la Fig. 58.

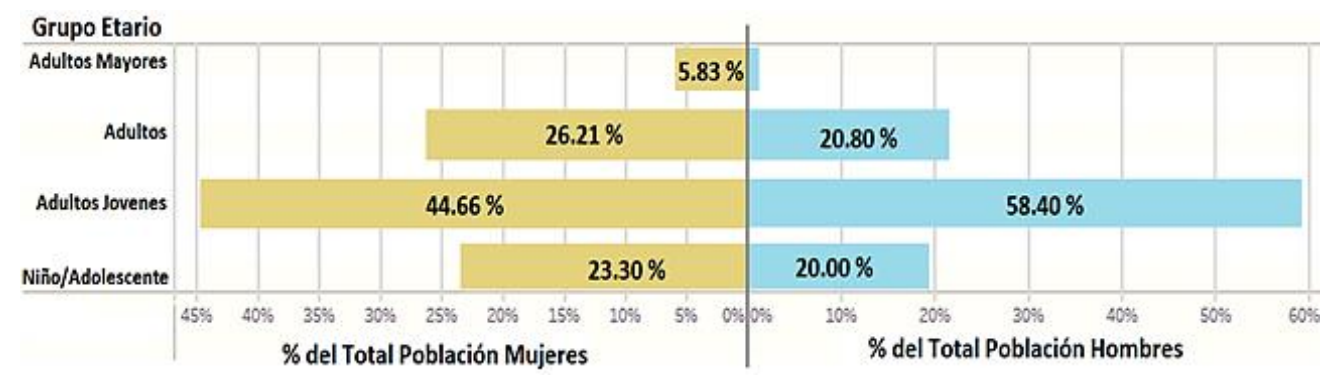

Fig. 58 Pirámide de población por grupo etario de usuarios de Facebook entrevistados

\subsubsection{Resultados de la investigación}

Para obtener los resultados en esta investigación, se tomó como referencia el ciclo de vida convencional de minería de datos, Fig. 59, según lo señalado en (Khan et al., 2012). 


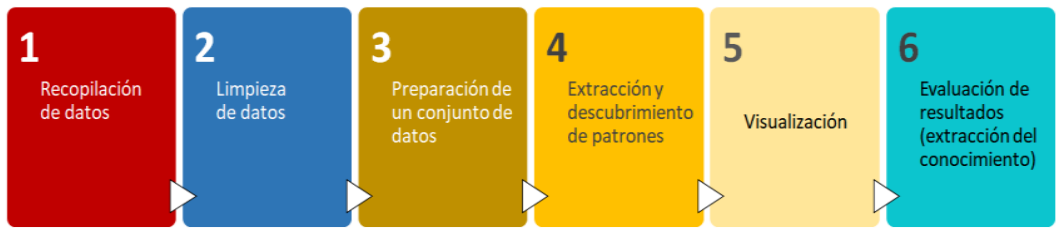

Fig. 59 Ciclo de vida convencional de minería de datos - Fuente: (Khan et al., 2012)

\subsubsection{Entrevista estructurada definitiva para la recopilación de datos limpios}

Las etapas 1 y 2 presentes en la Fig. 59, se integraron en un solo proceso al que se lo llamó recolección de datos limpios, Fig. 60. Este proceso se fundamentó en el criterio de que es posible una recolección de datos limpios a partir de una encuesta estructurada, si se garantiza que el cuestionario está organizado para enfocar el objetivo del estudio, y sus preguntas están claramente redactadas.

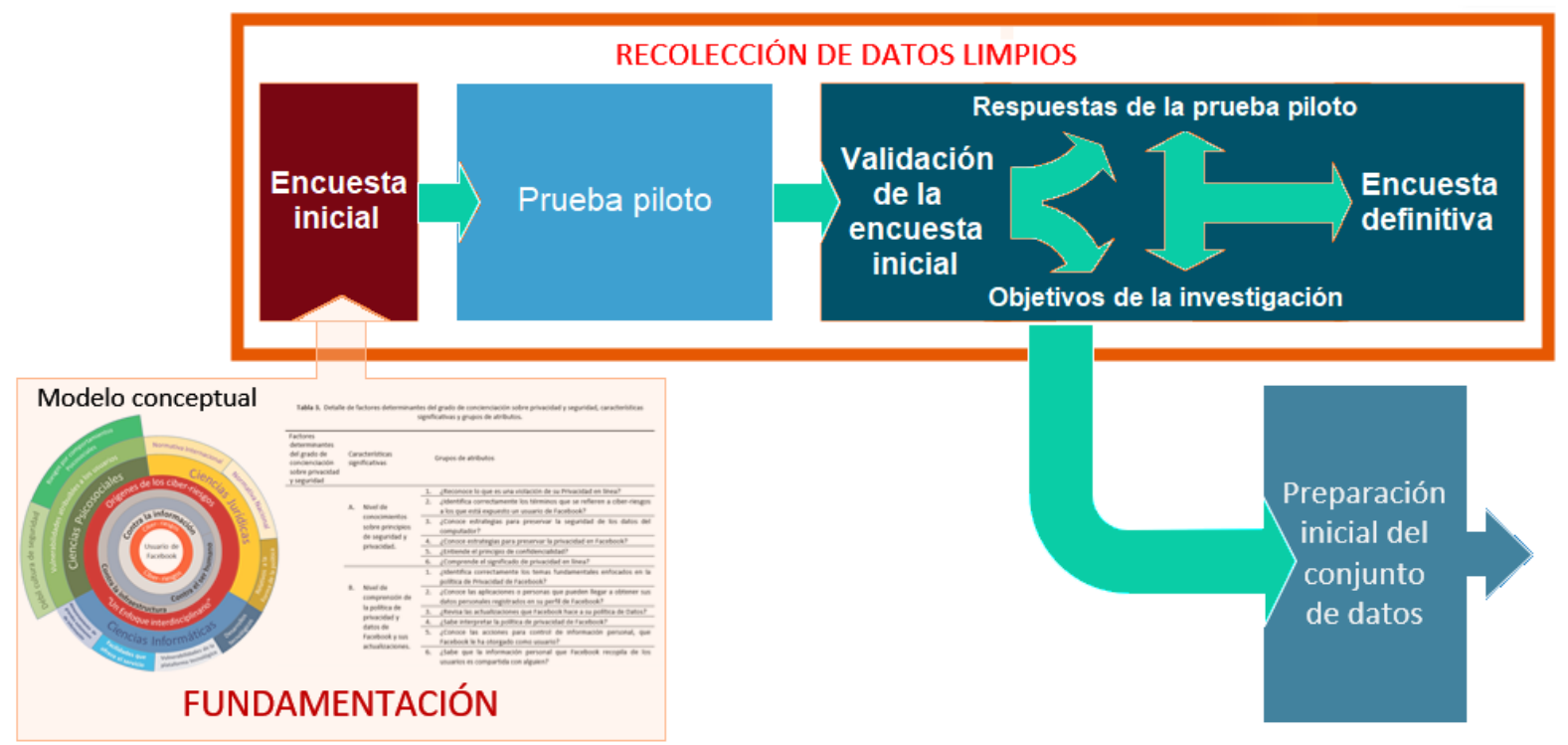

Fig. 60. Preparación proactiva de la recopilación de datos limpios

El proceso indicado, permitió la conformación de la entrevista estructurada definitiva, de la cual parte el proceso propuesto para estimar el nivel real de conciencia de los usuarios de Facebook respecto a privacidad y seguridad. La descripción de este proceso se presenta a continuación:

1. Entrevista estructurada inicial: Se elaboró con apoyo de Google Forms, constituida de 52 preguntas; enfocada a recoger datos relacionados con diferentes aspectos del entrevistado AM: sociodemográficos, de uso de Facebook, de actitudes en la interactividad virtual, de configuraciones de privacidad/seguridad, de conocimiento de los fundamentos de privacidad/seguridad, de comprensión de la política de datos de Facebook, de aspectos legales elementales aplicables en el entorno de Facebook.

2. Validación de la encuesta inicial: la entrevista estructurada inicial se sometió a validación por parte de un grupo de prueba de 30 personas (PRUEBA PILOTO).

Se realizó la validación de las secciones y de las preguntas de la encuesta inicial, contrastando las respuestas obtenidas del grupo de prueba con el objetivo de la investigación, lo que condujo a:

- el incremento de dos preguntas: a) ¿cuáles fueron las motivaciones que le condujeron a ser usuario de Facebook?, b) de la lista siguiente, seleccione las razones que justifican su necesidad de varias cuentas activas de usuario de Facebook. 
- Un mejoramiento de la redacción de las preguntas.

- Un reordenamiento de las preguntas para estructurar con facilidad las características significativas descritas en la Tabla 18.

Con esos cambios, se definió la entrevista estructurada definitiva para la recolección de datos limpios; y también, varios acuerdos relacionados a la forma en que se aplicaría e interpretaría la encuesta.

3. Los acuerdos relacionados con la entrevista estructurada definitiva fueron:

A) Para enfocar completamente las vulnerabilidades de los usuarios de Facebook, según la visión del modelo conceptual de la Fig. 57 y los factores señalados en la Tabla 18, la entrevista estructurada final estaría conformada por las secciones indicadas en la Tabla 20.

Tabla 20. Secciones de la entrevista estructurada

\begin{tabular}{clc}
\hline Ordinal & Nombres de las secciones & $\begin{array}{c}\text { Número } \\
\text { de } \\
\text { preguntas }\end{array}$ \\
\hline 1 & Datos socio-demográficos del encuestado & 9 \\
\hline 2 & Uso de Facebook & 9 \\
\hline 3 & $\begin{array}{l}\text { Conocimiento de las configuraciones de } \\
\text { privacidad en Facebook }\end{array}$ & 5 \\
\hline 4 & $\begin{array}{l}\text { Conocimiento de los principios de } \\
\text { seguridad y privacidad en Facebook }\end{array}$ & 5 \\
\hline 5 & $\begin{array}{l}\text { Comprensión de la política de privacidad y } \\
\text { la política de datos de Facebook }\end{array}$ & \\
\hline & $\begin{array}{l}\text { Conocimientos elementales de aspectos } \\
\text { jurídicos relacionados al contexto } \\
\text { operativo; y, de seguridad y privacidad en } \\
\text { Facebook }\end{array}$ & 5 \\
\hline 7 & Comportamientos psicosociales \\
\hline
\end{tabular}

B) Una sola pregunta en la sección de datos socio-demográficos, era suficiente para determinar el nivel hipotético de conciencia sobre privacidad de los usuarios de Facebook: "¿Cómo calificaría su nivel de conocimientos sobre seguridad y privacidad en la red social Facebook?", las opciones de respuesta fueron: Avanzados, Medios, Básicos y Ninguno; nivel hipotético que apoyaría posteriormente la validación de la propuesta.

C) Las preguntas de la sección 2, uso de Facebook, permitirían conocer los intereses iniciales del entrevistado por los que se hizo usuario de Facebook.

D) Las preguntas de las secciones 3 a la 7 servirían para determinar el nivel real de conciencia sobre privacidad y seguridad de los usuarios de la red social, de conformidad a las características significativas señaladas en la Tabla 18. 
E) Condicionar al entrevistado a responder todas las preguntas. $\mathrm{Y}$,

F) El enlace de acceso a la entrevista estructurada definitiva se distribuiría a los encuestadores mediante correo electrónico, para su aplicación a la muestra seleccionada. Las respuestas de la encuesta se registran en tiempo real en Google Drive, una vez que el encuestador finaliza la aplicación, pulsando el botón de envío. Los datos entonces, quedan listos y disponibles para su análisis correspondiente.

\subsubsection{Reglas para la preparación del conjunto de datos}

La etapa 3 de la Fig. 59, preparación del conjunto de datos, se cumplió paralelamente a la obtención de la encuesta definitiva. Se la concibió como un subproceso de la preparación proactiva de la recopilación de datos limpios de la Fig. 60, al que se lo llamó preparación inicial del conjunto de datos.

En este subproceso se establecieron las reglas para la preparación e interpretación del conjunto de datos extraídos de la muestra a través de la encuesta definitiva. En forma general se determinó que, algunas de las preguntas proveerían datos que luego deberían ser integrados con otros para definir un atributo importante, y así hasta obtener los 32 atributos descritos en la Tabla 18. Con los 32 atributos se conforman las características significativas que estructuran los dos factores determinantes: nivel de riesgo por comportamientos psicosociales y nivel de cultura de seguridad y privacidad; con los que, finalmente, se hace la estimación del nivel real de conciencia sobre privacidad y seguridad del usuario de Facebook. Sintetizando:

1. cada atributo tendría un valor cuantificado según la respuesta a una o varias preguntas vinculadas de la entrevista estructurada definitiva;

2. cada usuario de Facebook entrevistado sería representado por un conjunto de atributos, que según la Tabla 18, son en total 32 atributos, por lo tanto, cada persona entrevistada se simbolizaría por una lista de números contenida en un vector de atributos, que representaría un punto en un espacio multidimensional de 32 dimensiones;

3. los 32 atributos, siguiendo el detalle de la Tabla 18, se organizan para conformar 4 características significativas cuantificadas para describir el nivel cuantificado de la cultura de seguridad y privacidad del usuario de la red social; y 12 características significativas cuantificadas para representar el nivel cuantificado de riesgo por comportamientos psicosociales del usuario de Facebook; y

4. con los valores de los dos factores determinantes del nivel de conciencia, se estima el nivel real de conciencia sobre seguridad y privacidad en Facebook del usuario de Facebook, que finalmente es catalogado en 4 opciones cualitativas: avanzado, medio, básico o ninguno.

Las reglas que se establecieron para asignar valores a los atributos y características de la Tabla 18 son:

REGLAS PARA EL FACTOR DETERMINANTE: NIVEL DE CULTURA DE SEGURIDAD Y PRIVACIDAD DEL USUARIO DE FACEBOOK

No. 1 - Cuantificación de los atributos de la característica significativa "nivel de conocimientos sobre principios de seguridad y privacidad": se calculan según las opciones de respuestas que el entrevistado escogió para responder a las preguntas de la encuesta definitiva, según se detallan en las tablas: Tabla 21, Tabla 22 y Tabla 23. 
Tabla 21. Estimación del valor del atributo No. 1 de la característica significativa "nivel de conocimientos sobre principios de seguridad y privacidad".

\begin{tabular}{|c|c|c|c|c|c|c|c|c|c|c|}
\hline $\begin{array}{l}\text { Factores determinantes del } \\
\text { grado de conciencia sobre } \\
\text { privacidad y seguridad }\end{array}$ & \begin{tabular}{|c|} 
Características \\
significativas
\end{tabular} & $\begin{array}{c}\text { Grupos de atributos, Tabla 18, que } \\
\text { orientaron a la definición de las } \\
\text { preguntas de la entrevista } \\
\text { estructurada definitiva }\end{array}$ & \multirow[t]{2}{*}{$\begin{array}{c}\text { Valor } \\
\text { cuantificado }\end{array}$} & \multirow{2}{*}{$\begin{array}{c}\text { Criterio de cuantificación } \\
\text { basado en respuesta a } \\
\text { atributo }\end{array}$} & \multirow{2}{*}{$\begin{array}{c}\text { Preguntas de la entrevista } \\
\text { estructurada definitiva } \\
\text { consideradas para generar el } \\
\text { atributo }\end{array}$} & \multicolumn{5}{|c|}{ Opciones de respuestas } \\
\hline \multirow{17}{*}{$\begin{array}{l}\text { Nivel de cultura de } \\
\text { seguridad y privacidad }\end{array}$} & \multirow{17}{*}{\begin{tabular}{|l|} 
A. Nivel de \\
conocimientos \\
sobre principios \\
de seguridad y \\
privacidad.
\end{tabular}} & \multirow{17}{*}{$\begin{array}{l}\text { 1. ¿Reconoce lo que es una } \\
\text { violación de su Privacidad en } \\
\text { línea? }\end{array}$} & & & & $\begin{array}{l}\text { Que los datos } \\
\text { personales se } \\
\text { mantengan fuera } \\
\text { del alcance de } \\
\text { personas NO } \\
\text { autorizadas }\end{array}$ & \begin{tabular}{|l} 
Que mi \\
información \\
personal esté \\
disponible fuera \\
del contexto en \\
el que fue \\
registrado
\end{tabular} & \begin{tabular}{|l|} 
Que no tenga \\
control sobre mi \\
información \\
personal \\
mantenida en la \\
plataforma de \\
red social
\end{tabular} & $\begin{array}{l}\text { Que se haya } \\
\text { dado la pérdida } \\
\text { o acceso no } \\
\text { autorizado o } \\
\text { divulgación de } \\
\text { datos } \\
\text { personales }\end{array}$ & $\begin{array}{l}\text { ESTIMACIÓN DE VALOR } \\
\text { (CUANTIFICACIÓN): }\end{array}$ \\
\hline & & & 0,8 & \multirow{16}{*}{ Tabla de verdad } & \multirow{16}{*}{$\begin{array}{c}\text { ¿Cuáles opciones considera } \\
\text { usted que constituyen una } \\
\text { violación de su Privacidad } \\
\text { en línea? } \\
\text { El entrevistado siempre está } \\
\text { obligado a seleccionar alguna } \\
\text { de las posibles respuestas }\end{array}$} & 1 & 1 & 1 & 1 & 0,8 \\
\hline & & & 0,5 & & & 1 & 1 & 1 & 0 & 0,5 \\
\hline & & & 0,5 & & & 1 & 1 & 0 & 1 & 0,5 \\
\hline & & & 0,25 & & & 1 & 1 & 0 & 0 & 0,25 \\
\hline & & & 0,5 & & & 1 & 0 & 1 & 1 & 0,5 \\
\hline & & & 0,25 & & & 1 & 0 & 1 & 0 & 0,25 \\
\hline & & & 0,25 & & & 1 & 0 & 0 & 1 & 0,25 \\
\hline & & & 0 & & & 1 & 0 & 0 & 0 & 0 \\
\hline & & & 1 & & & 0 & 1 & 1 & 1 & 1 \\
\hline & & & 0,66 & & & 0 & 1 & 1 & 0 & 0,66 \\
\hline & & & 0,66 & & & 0 & 1 & 0 & 1 & 0,66 \\
\hline & & & 0,33 & & & 0 & 1 & 0 & 0 & 0,33 \\
\hline & & & 0,66 & & & 0 & 0 & 1 & 1 & 0,66 \\
\hline & & & 0,33 & & & 0 & 0 & 1 & 0 & 0,33 \\
\hline & & & 0,33 & & & 0 & 0 & 0 & 1 & 0,33 \\
\hline & & & $\mathrm{x}$ & & & 0 & 0 & 0 & 0 & $\mathrm{x}$ \\
\hline
\end{tabular}


Para la comprensión de la tabla de verdad que se incluye en la Tabla 21, es importante señalar el significado que tienen los valores lógicos: 0 significa que el entrevistado no señaló esa opción como parte de su respuesta a la pregunta de la entrevista estructurada definitiva. El valor 1 se utiliza para simbolizar que la opción de respuesta correspondiente si fue marcada por el entrevistado como respuesta a la pregunta.

En cuanto a la estimación de valores para cada combinación, se utilizó un rango discreto de posibles valores que está entre 0 y 1 , en el cual, 0 significa que la respuesta escogida por el entrevistado es totalmente errónea y corresponde a la opción marcada en la tabla de verdad con color rojo.

El valor de cuantificación igual a 1 significa que el entrevistado dio una respuesta totalmente correcta al señalar todas las opciones en color azul.

Si el entrevistado escoge algunas de las opciones de color azul, entonces el valor que se le asigna es la media aritmética de las opciones escogidas; siempre y cuando no haya señalado la opción en color rojo.

En el caso de haber señalado la opción en color rojo conjuntamente con algunas de las opciones de color azul, entonces se le penalizó con un valor menor a la media aritmética de las opciones en azul, siendo que la penalización fue mayor si el número de respuestas seleccionadas era mayor, tomando en cuenta que se interpretó como un menor discernimiento entre las respuestas propuestas en la encuesta, y un mayor desconocimiento resulta evidenciado al seleccionar todas las opciones, rojas y azules. El hecho de seleccionar la opción de color rojo en combinación con alguna(s) de las opciones de color azul, demuestra un desconocimiento mayor que si escoge solamente alguna(s) de las de color azul.

Por otra parte, para las siguientes tablas, cuando se utiliza como fórmula de cálculo la media aritmética de las opciones de color azul señaladas por el entrevistado, significa que, si el usuario de Facebook escogió todas las opciones correctas, entonces cada una de ellas será asignada con un valor numérico de 1 , que al sumarse y dividirse para el número de opciones correctas se tendrá un valor máximo de 1 para el atributo correspondiente. En este caso, obviamente, el rango discreto de posibles valores del atributo va de 0 hasta 1 , en pasos de uno dividido para el máximo número de respuestas correctas. Adicionalmente es importante señalar que, la aplicación de la media aritmética a las respuestas correctas, significa que criterio aplicado por el tesista fue que todas las respuestas correctas tienen la misma ponderación, es decir, todas las respuestas correctas en color azul, tienen el mismo grado de importancia en la determinación del valor cuantificado del atributo correspondiente.

Con los criterios aplicados en las distintas reglas para la cuantificación del atributo, los valores obtenidos tienen siempre valores positivos, en el rango entre 0 y 1 inclusive. 
Tabla 22. Estimación del valor de los atributos No. 2 No. 3 y No. 4 de la característica significativa "nivel de conocimientos sobre principios de seguridad y privacidad".

Las opciones en color azul asignan al entrevistado un valor de 1 en esa opción

Las opciones en color rojo asignan al entrevistado un valor de 0 en esa opción

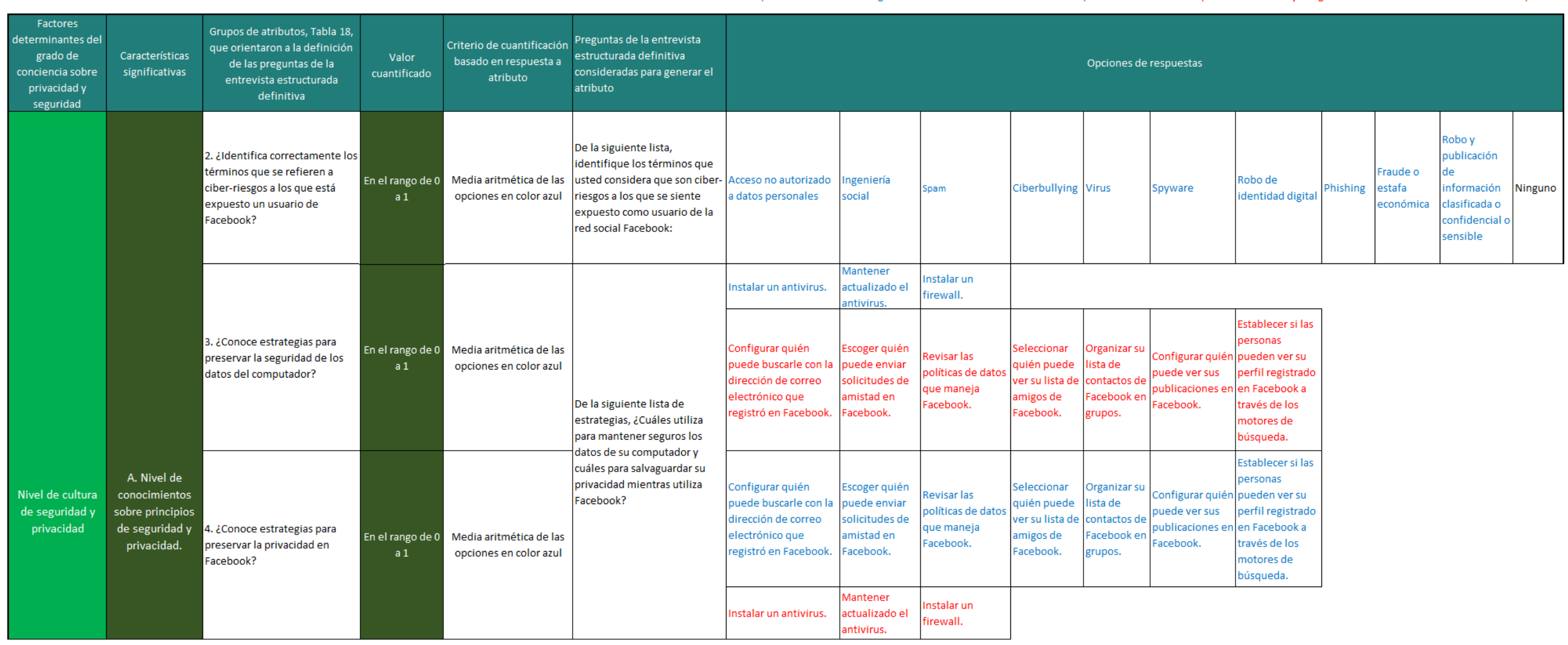


Tabla 23. Estimación del valor de los atributos No. 5 y No. 6 de la característica significativa "nivel de conocimientos sobre principios de seguridad y privacidad".

\begin{tabular}{|c|c|c|c|c|c|c|c|c|c|}
\hline $\begin{array}{l}\text { Factores } \\
\text { determinantes del } \\
\text { grado de } \\
\text { conciencia sobre } \\
\text { privacidad y } \\
\text { seguridad }\end{array}$ & $\begin{array}{c}\text { Características } \\
\text { significativas }\end{array}$ & $\begin{array}{c}\text { Grupos de atributos, Tabla 18, } \\
\text { que orientaron a la definición } \\
\text { de las preguntas de la } \\
\text { entrevista estructurada } \\
\text { definitiva }\end{array}$ & $\begin{array}{c}\text { Valor } \\
\text { cuantificado }\end{array}$ & $\begin{array}{c}\text { Criterio de cuantificación } \\
\text { basado en respuesta a } \\
\text { atributo }\end{array}$ & $\begin{array}{l}\text { Preguntas de la entrevista } \\
\text { estructurada definitiva } \\
\text { consideradas para generar el } \\
\text { atributo }\end{array}$ & & Opciones de $\mathrm{r}$ & espuestas & \\
\hline \multirow{2}{*}{$\begin{array}{l}\text { Nivel de cultura } \\
\text { de seguridad y } \\
\text { privacidad }\end{array}$} & \multirow{2}{*}{$\begin{array}{c}\text { A. Nivel de } \\
\text { conocimientos } \\
\text { sobre principios } \\
\text { de seguridad y } \\
\text { privacidad. }\end{array}$} & $\begin{array}{l}\text { 5. ¿Entiende el principio de } \\
\text { confidencialidad? }\end{array}$ & 1 & No & $\begin{array}{l}\text { La posibilidad que usted tiene, } \\
\text { en Facebook, de organizar su } \\
\text { lista de usuarios en grupos y } \\
\text { escoger cual de ellos va a ver } \\
\text { sus publicaciones, se } \\
\text { corresponde con ¿cuál de los } \\
\text { siguientes principios de } \\
\text { seguridad? }\end{array}$ & Confidencialidad & Integridad & & \\
\hline & & $\begin{array}{l}\text { 6. ¿Comprende el significado } \\
\text { de privacidad en línea? }\end{array}$ & $\begin{array}{c}\text { En el rango de } 0 \\
\text { a } 1\end{array}$ & $\begin{array}{l}\text { Media aritmética de las } \\
\text { opciones en color azul }\end{array}$ & $\begin{array}{l}\text { Cuando una red social señala } \\
\text { que usted dispone de } \\
\text { Privacidad en línea, el } \\
\text { significado que usted le } \\
\text { atribuye a esa afirmación es } \\
\text { que: }\end{array}$ & $\begin{array}{l}\text { Tiene capacidad para } \\
\text { borrar y modificar } \\
\text { (actualizar, corregir) } \\
\text { todos los datos } \\
\text { personales que usted } \\
\text { ha registrado en la red } \\
\text { social }\end{array}$ & $\begin{array}{l}\text { Decide el } \\
\text { destino de sus } \\
\text { datos } \\
\text { personales } \\
\text { registrados en } \\
\text { la red social }\end{array}$ & $\begin{array}{l}\text { Determina } \\
\text { cuándo y en qué } \\
\text { medida su } \\
\text { información } \\
\text { personal } \\
\text { almacenada se } \\
\text { comunica a otros }\end{array}$ & $\begin{array}{l}\text { Tiene el } \\
\text { reconocimien } \\
\text { to jurídico del } \\
\text { derecho de } \\
\text { control de sus } \\
\text { datos } \\
\text { personales }\end{array}$ \\
\hline
\end{tabular}

Las opciones en color rojo asignan al entrevistado un valor de 0 en esa opción 
La Tabla 24 explica el procedimiento para catalogar la característica significativa "nivel de conocimientos sobre principios de seguridad y privacidad" de un usuario de Facebook entrevistado, para manejar una escala conceptual en cuatro niveles cualitativos: avanzado, medio, bajo y ninguno. La catalogación se aplica a un valor numérico que representa el nivel cuantificado de conocimientos sobre principios de seguridad y privacidad, generado con la media aritmética de los valores cuantificados de los seis atributos que definen a la característica significativa señalada, que se obtuvieron según lo descrito en las tres tablas inmediatamente anteriores, pertenecientes a la regla No. 1.

Similar procedimiento se aplica para calcular y catalogar las demás características significativas del factor determinante "nivel de cultura de seguridad y privacidad".

Tabla 24. Cálculo del valor de la característica significativa "nivel de conocimientos sobre principios de seguridad y privacidad".

\begin{tabular}{|c|c|c|c|c|}
\hline $\begin{array}{l}\text { Factor determinante del } \\
\text { grado de conciencia sobre } \\
\text { privacidad y seguridad }\end{array}$ & $\begin{array}{l}\text { Característica } \\
\text { significativa }\end{array}$ & Tipo & & Método de cálculo \\
\hline \multirow{6}{*}{$\begin{array}{l}\text { Nivel de cultura de } \\
\text { seguridad y privacidad }\end{array}$} & \multirow{6}{*}{$\begin{array}{c}\text { A. Nivel de } \\
\text { conocimientos } \\
\text { sobre principios de } \\
\text { seguridad y } \\
\text { privacidad }\end{array}$} & CUANTIFICADO & \multicolumn{2}{|c|}{$\begin{array}{c}\text { "MEDIA ARITMÉTICA" } \\
\text { de los valores cuantificados } \\
\text { de los atributos Nos. } 1 \text { al } 6\end{array}$} \\
\hline & & \multirow{5}{*}{ CUALITATIVO } & \multicolumn{2}{|c|}{$\begin{array}{l}\text { "RANGO EN QUE SE ENCUENTRA EL VALOR DEL } \\
\text { NIVEL CUANTIFICADO" }\end{array}$} \\
\hline & & & Avanzado & $\begin{array}{l}\text { el nivel cuantificado tiene un } \\
\text { valor entre } 0,76 \text { a } 1\end{array}$ \\
\hline & & & Medio & $\begin{array}{l}\text { el nivel cuantificado tiene un } \\
\text { valor entre } 0,51 \text { a } 0,75\end{array}$ \\
\hline & & & Bajo & $\begin{array}{l}\text { el nivel cuantificado tiene un } \\
\text { valor entre } 0,26 \text { a } 0,5) \text {, }\end{array}$ \\
\hline & & & Ninguno & $\begin{array}{l}\text { el nivel cuantificado tiene un } \\
\text { valor entre } 0 \text { a } 0,25\end{array}$ \\
\hline
\end{tabular}


No. 2 - Cuantificación de los atributos de la característica significativa "nivel de comprensión de la política de privacidad y datos de Facebook y sus actualizaciones": se calculan según las opciones de respuestas que el entrevistado escogió para responder a las preguntas de la encuesta definitiva, según se detallan en las tablas: Tabla 25, y Tabla 26.

Tabla 25. Estimación del valor de los atributos No. 1, No. 2 y No.3 de la característica significativa "nivel de comprensión de la política de privacidad y datos de Facebook y sus actualizaciones".

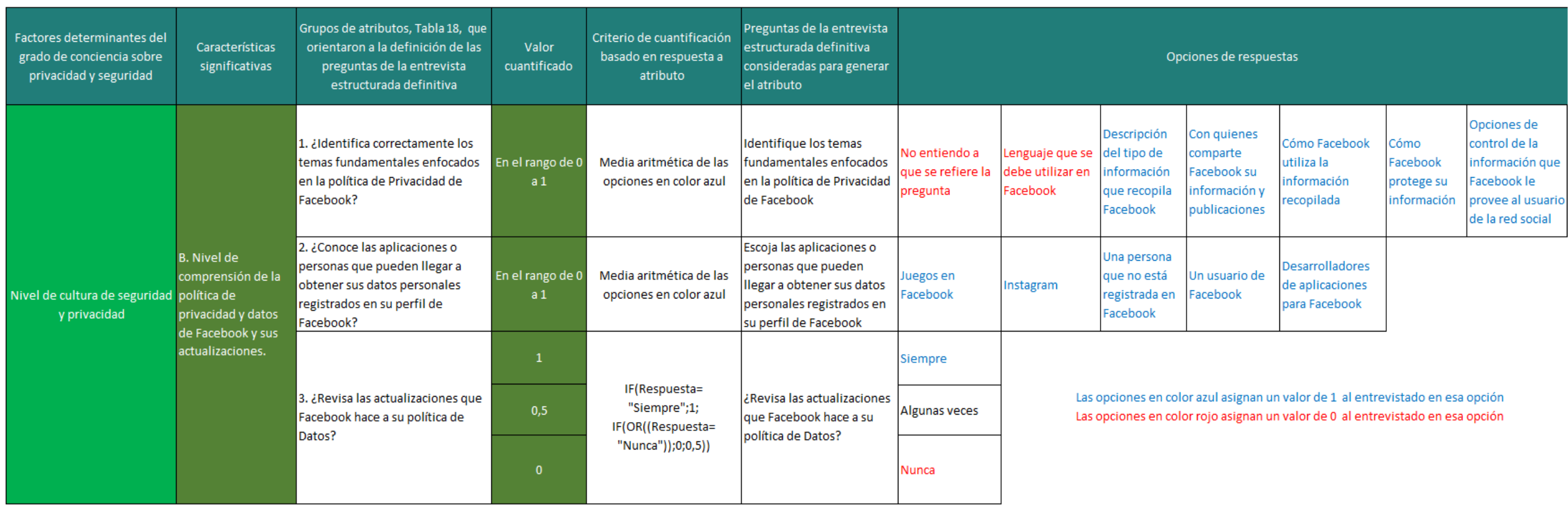


Tabla 26. Estimación del valor de los atributos No. 4, No.5 y No. 6 de la característica significativa "nivel de comprensión de la política de privacidad y datos de Facebook y sus actualizaciones".

\begin{tabular}{|c|c|c|c|c|c|c|c|c|}
\hline $\begin{array}{l}\text { Factores determinantes del } \\
\text { grado de conciencia sobre } \\
\text { privacidad y seguridad }\end{array}$ & $\begin{array}{l}\text { Características } \\
\text { significativas }\end{array}$ & $\begin{array}{c}\text { Grupos de atributos, Tabla 18, que } \\
\text { orientaron a la definición de las } \\
\text { preguntas de la entrevista } \\
\text { estructurada definitiva }\end{array}$ & $\begin{array}{c}\text { Valor } \\
\text { cuantificado }\end{array}$ & $\begin{array}{l}\text { Criterio de } \\
\text { cuantificación basado } \\
\text { en respuesta a } \\
\text { atributo }\end{array}$ & $\begin{array}{l}\text { Preguntas de la entrevista } \\
\text { estructurada definitiva } \\
\text { consideradas para generar el } \\
\text { atributo }\end{array}$ & \multicolumn{3}{|c|}{ Opciones de respuestas } \\
\hline \multirow{11}{*}{$\begin{array}{l}\text { Nivel de cultura de } \\
\text { seguridad y privacidad }\end{array}$} & \multirow{11}{*}{$\begin{array}{l}\text { B. Nivel de } \\
\text { comprensión de la } \\
\text { política de } \\
\text { privacidad y datos } \\
\text { de Facebook y sus } \\
\text { actualizaciones. }\end{array}$} & \multirow{6}{*}{$\begin{array}{l}\text { 4. ¿Sabe interpretar la política de } \\
\text { privacidad de Facebook? }\end{array}$} & 1 & NO & \multirow{2}{*}{$\begin{array}{l}\text { ¿Cree usted que Facebook } \\
\text { recopiló su información } \\
\text { personal solamente para } \\
\text { facilitar que los demás } \\
\text { usuarios lo identifiquen en la } \\
\text { red social? }\end{array}$} & No & & \\
\hline & & & 0 & SI & & SI & NOSÉ & \\
\hline & & & 1 & SI & \multirow{2}{*}{$\begin{array}{l}\text { Facebook comparte sus datos } \\
\text { personales publicados en la } \\
\text { red social, con empresas y } \\
\text { personas desconocidas para } \\
\text { usted ¿Autorizó usted esa } \\
\text { acción? }\end{array}$} & SI & & \\
\hline & & & 0 & No & & No & & \\
\hline & & & 1 & SI & \multirow{2}{*}{$\begin{array}{l}\text { Seleccione las opciones que } \\
\text { reflejen su sentir con relación } \\
\text { a la revisión de la política de } \\
\text { privacidad y/o la política de } \\
\text { datos de Facebook }\end{array}$} & $\begin{array}{l}\text { La revisé totalmente } \\
\text { pero tiene términos } \\
\text { legales y técnicos que } \\
\text { no los entendí } \\
\end{array}$ & $\begin{array}{l}\text { La revisé totalmente y } \\
\text { considero que es muy } \\
\text { clara y fácil de entender }\end{array}$ & \\
\hline & & & 0 & NO & & $\begin{array}{l}\text { No la revisé porque es } \\
\text { muy extensa para } \\
\text { revisarla y entenderla } \\
\text { completamente }\end{array}$ & \begin{tabular}{|l|} 
No la revisé porque \\
estoy obligado a \\
aceptarla tal como está \\
publicada para utilizar \\
los servicios de \\
Facebook
\end{tabular} & $\begin{array}{l}\text { No la revisé porque } \\
\text { no estoy obligado a } \\
\text { hacerlo para } \\
\text { registrarme como } \\
\text { usuario de Facebook }\end{array}$ \\
\hline & & \multirow{3}{*}{$\begin{array}{l}\text { 5. ¿Conoce las acciones para } \\
\text { control de información personal, } \\
\text { que Facebook le ha otorgado como } \\
\text { usuario? }\end{array}$} & 1 & \begin{tabular}{|l|} 
Selecciona las dos \\
opciones de color azul
\end{tabular} & \multirow{3}{*}{$\begin{array}{l}\text { ¿Cuáles de las siguientes } \\
\text { acciones para control de su } \\
\text { información personal, } \\
\text { considera que Facebook le ha } \\
\text { otorgado como usuario? }\end{array}$} & Capacidad para & Capacidad para & \\
\hline & & & 0,5 & $\begin{array}{l}\text { Seleciona una de las } \\
\text { opciones de color azul }\end{array}$ & & $\begin{array}{l}\text { lactualizar la } \\
\text { información (R2) }\end{array}$ & $\begin{array}{l}\text { rectificar la información } \\
\text { (R3) }\end{array}$ & \\
\hline & & & 0 & $\begin{array}{l}\text { Seleciona la opción } \\
\text { de color rojo }\end{array}$ & & \begin{tabular}{|l|} 
Capacidad para borrar \\
definitivamente toda su \\
información de la \\
plataforma tecnológica \\
de Facebook (R1) \\
\end{tabular} & & \\
\hline & & \multirow{2}{*}{$\begin{array}{l}\text { 6. ¿Sabe que la información } \\
\text { personal que Facebook recopila de } \\
\text { los usuarios es compartida con } \\
\text { alguien? }\end{array}$} & 1 & SI & \multirow{2}{*}{\begin{tabular}{|l|} 
¿Cree usted que la \\
información personal que \\
Facebook recopila de los \\
usuarios es compartida con \\
alguien?
\end{tabular}} & \multicolumn{3}{|c|}{$\begin{array}{l}\text { Las opciones en color azul asignan un valor de } 1 \\
\text { al entrevistado en esa opción }\end{array}$} \\
\hline & & & 0 & No & & \multicolumn{3}{|c|}{$\begin{array}{l}\text { Las opciones en color rojo asignan un valor de } 0 \\
\text { al entrevistado en esa opción }\end{array}$} \\
\hline
\end{tabular}


La Tabla 27 explica el procedimiento de cálculo y catalogación del nivel de comprensión de la política de privacidad y datos de Facebook y sus actualizaciones.

Tabla 27. Cálculo y catalogación de la característica significativa "nivel de comprensión de la política de privacidad y datos de Facebook y sus actualizaciones"

\begin{tabular}{|c|c|c|c|c|}
\hline $\begin{array}{l}\text { Factor determinante del } \\
\text { grado de conciencia sobre } \\
\text { privacidad y seguridad }\end{array}$ & $\begin{array}{l}\text { Característica } \\
\text { significativa }\end{array}$ & Tipo & & Método de cálculo \\
\hline \multirow{6}{*}{$\begin{array}{l}\text { Nivel de cultura de } \\
\text { seguridad y privacidad }\end{array}$} & \multirow{6}{*}{$\begin{array}{l}\text { B. Nivel de } \\
\text { comprensión de } \\
\text { la política de } \\
\text { privacidad y datos } \\
\text { de Facebook y sus } \\
\text { actualizaciones. }\end{array}$} & CUANTIFICADO & \multicolumn{2}{|c|}{$\begin{array}{c}\text { "MEDIA ARITMÉTICA" } \\
\text { de los valores cuantificados } \\
\text { de los atributos Nos. } 1 \text { al } 6\end{array}$} \\
\hline & & \multirow{5}{*}{ CUALITATIVO } & \multicolumn{2}{|c|}{$\begin{array}{l}\text { "RANGO EN QUE SE ENCUENTRA EL VALOR DEL } \\
\text { NIVEL CUANTIFICADO" }\end{array}$} \\
\hline & & & Avanzado & $\begin{array}{l}\text { el nivel cuantificado tiene un } \\
\text { valor entre } 0,76 \text { a } 1\end{array}$ \\
\hline & & & Medio & $\begin{array}{l}\text { el nivel cuantificado tiene un } \\
\text { valor entre } 0,51 \text { a } 0,75\end{array}$ \\
\hline & & & Bajo & $\begin{array}{l}\text { el nivel cuantificado tiene un } \\
\text { valor entre } 0,26 \text { a } 0,5) \text {, }\end{array}$ \\
\hline & & & Ninguno & $\begin{array}{l}\text { el nivel cuantificado tiene un } \\
\text { valor entre } 0 \text { a } 0,25\end{array}$ \\
\hline
\end{tabular}


No. 3 - Cuantificación de los atributos de la característica significativa "nivel de experticia en las configuraciones de privacidad disponibles en la red social": se calculan según las opciones de respuestas que el entrevistado escogió para responder a las preguntas de la encuesta definitiva, según se detallan en la Tabla 28.

Tabla 28. Estimación del valor de los atributos del No. 1 al No.4 de la característica significativa "nivel de experticia en las configuraciones de privacidad disponibles en la red social".

\begin{tabular}{|c|c|c|c|c|c|c|c|c|}
\hline $\begin{array}{l}\text { Factores determinantes del grado de } \\
\text { conciencia sobre privacidad y seguridad }\end{array}$ & $\begin{array}{l}\text { Caracteristicas } \\
\text { significativas }\end{array}$ & $\begin{array}{c}\text { Grupos de atributos, Tabla 18, que } \\
\text { orientaron a la definición de las } \\
\begin{array}{c}\text { preguntas de la entrevista } \\
\text { estructurada definitiva }\end{array}\end{array}$ & $\begin{array}{c}\text { Valor } \\
\text { cuantificado }\end{array}$ & $\begin{array}{c}\text { Criterio de } \\
\text { cuantificación basado } \\
\text { en respuesta a atributo }\end{array}$ & $\begin{array}{l}\text { Preguntas de la entrevista } \\
\text { estructurada definitiva } \\
\text { consideradas para generar el } \\
\text { atributo }\end{array}$ & \multicolumn{3}{|c|}{ Opciones de respuestas } \\
\hline \multirow{8}{*}{$\begin{array}{l}\text { Nivel de cultura de seguridad y } \\
\text { privacidad }\end{array}$} & \multirow{8}{*}{$\begin{array}{l}\text { C. Nivel de experticia } \\
\text { en las configuraciones } \\
\text { de privacidad } \\
\text { disponibles en la red } \\
\text { social. }\end{array}$} & \multirow{2}{*}{ 1. ¿Crea Grupos de usuarios? } & 1 & sI & \multirow{2}{*}{$\begin{array}{l}\text { Indique con que frecuencia } \\
\text { utiliza cada una de las } \\
\text { siguientes opciones ofrecidas } \\
\text { por Facebook: [Configuración } \\
\text { de privacidad/seguridad] }\end{array}$} & Poca frecuencia & Mucha frecuencia & \\
\hline & & & 0 & No & & No utilizo & & \\
\hline & & $\begin{array}{l}\text { 2. ¿Conoce el efecto que tiene el } \\
\text { seleccionar "Todos" en la }\end{array}$ & 1 & sI & $\begin{array}{l}\text { ¿Qué efecto tiene el } \\
\text { seleccionar “Todos" en la }\end{array}$ & $\begin{array}{l}\text { Que concedo a todos los } \\
\text { usuarios de Internet - } \\
\text { registrados o no en } \\
\text { Facebook - la posibilidad } \\
\text { de visualizar mi perfil } \\
\text { personal. }\end{array}$ & & \\
\hline & & $\begin{array}{l}\text { configuración de privacidad de } \\
\text { Facebook? }\end{array}$ & 0 & No & $\begin{array}{l}\text { configuración de privacidad de } \\
\text { Facebook? }\end{array}$ & $\begin{array}{l}\text { Que autorizo a todas las } \\
\text { personas registradas en } \\
\text { Facebook a visualizar mi } \\
\text { perfil personal cuando lo } \\
\text { deseen. }\end{array}$ & $\begin{array}{l}\text { Que permito a todos } \\
\text { mis contactos de } \\
\text { Facebook capacidad } \\
\text { para visualizar mi perfil } \\
\text { personal. } \\
\end{array}$ & $\begin{array}{l}\text { No entiendo la } \\
\text { pregunta - no se } \\
\text { cómo responder }\end{array}$ \\
\hline & & $\begin{array}{l}\text { 3. ¿Sabe cuál es la opción de } \\
\text { configuración que un usuario debería } \\
\text { utilizar para restringir: quienes }\end{array}$ & 1 & sI & $\begin{array}{l}\text { ¿Cuál es la opción de } \\
\text { configuración que un usuario } \\
\text { debería utilizar para restringir: }\end{array}$ & Privacidad & & \\
\hline & & $\begin{array}{l}\text { pueden enviarle solicitudes de } \\
\text { amistad; } y \text {, quienes pueden ver su } \\
\text { lista de amigos? }\end{array}$ & 0 & No & $\begin{array}{l}\text { solicitudes de amistad - 2) } \\
\text { Quienes pueden ver su lista de } \\
\text { amigos }\end{array}$ & $\begin{array}{l}\text { Seguridad e inicio de } \\
\text { sesión }\end{array}$ & $\begin{array}{l}\text { Desconozco la } \\
\text { respuesta }\end{array}$ & Bloqueos \\
\hline & & $\begin{array}{l}\text { 4. ¿Sabe cuál es la opción de } \\
\text { configuración que un usuario debería } \\
\text { utilizar para restringir en Facebook: } \\
\text { la invitación de alguien para asistir a } \\
\text { un evento, las invitaciones a una app }\end{array}$ & 1 & sI & \begin{tabular}{|l|} 
¿Cuál es la opción de \\
configuración que un usuario \\
debería utilizar para restringir \\
en Facebook: la invitación de \\
alguien para asistir a un evento;
\end{tabular} & Bloqueos & & \\
\hline & & $\begin{array}{l}\text { que le haya enviado alguien, } \\
\text { mensajes y vídeo-llamadas de } \\
\text { alguien, así como ponerse en } \\
\text { contacto mediante la app de } \\
\text { Messenger? }\end{array}$ & 0 & NO & $\begin{array}{l}\text { le haya enviado alguien; } \\
\text { mensajes y videollamadas de } \\
\text { alguien asi como ponerse en } \\
\text { contacto mediante la app de } \\
\text { Messenger? }\end{array}$ & Privacidad & $\begin{array}{l}\text { Desconozco la } \\
\text { respuesta }\end{array}$ & Bloqueos \\
\hline
\end{tabular}


El procedimiento de cálculo y catalogación del nivel cuantificado de experticia en las configuraciones de privacidad disponibles en la red social se expone en la Tabla 29.

Tabla 29. Cálculo del valor de la característica significativa "nivel de experticia en las configuraciones de privacidad disponibles en la red social"

\begin{tabular}{|c|c|c|c|c|}
\hline $\begin{array}{l}\text { Factor determinante del } \\
\text { grado de conciencia sobre } \\
\text { privacidad y seguridad }\end{array}$ & $\begin{array}{l}\text { Característica } \\
\text { significativa }\end{array}$ & Tipo & & Método de cálculo \\
\hline \multirow{6}{*}{$\begin{array}{l}\text { Nivel de cultura de } \\
\text { seguridad y privacidad }\end{array}$} & \multirow{6}{*}{$\begin{array}{l}\text { C. Nivel de experticia } \\
\text { en las } \\
\text { configuraciones } \\
\text { de privacidad }\end{array}$} & CUANTIFICADO & \multicolumn{2}{|c|}{$\begin{array}{c}\text { "MEDIA ARITMÉTICA" } \\
\text { de los valores cuantificados } \\
\text { de los atributos Nos. } 1 \text { al } 4\end{array}$} \\
\hline & & \multirow{5}{*}{ CUALITATIVO } & \multicolumn{2}{|c|}{$\begin{array}{l}\text { "RANGO EN QUE SE ENCUENTRA EL VALOR DEL } \\
\text { NIVEL CUANTIFICADO" }\end{array}$} \\
\hline & & & Avanzado & $\begin{array}{l}\text { el nivel cuantificado tiene un } \\
\text { valor entre } 0,76 \text { a } 1\end{array}$ \\
\hline & & & Medio & $\begin{array}{l}\text { el nivel cuantificado tiene un } \\
\text { valor entre } 0,51 \text { a } 0,75\end{array}$ \\
\hline & & & Bajo & $\begin{array}{l}\text { el nivel cuantificado tiene un } \\
\text { valor entre } 0,26 \text { a } 0,5 \text { ), }\end{array}$ \\
\hline & & & Ninguno & $\begin{array}{l}\text { el nivel cuantificado tiene un } \\
\text { valor entre } 0 \text { a } 0,25\end{array}$ \\
\hline
\end{tabular}


No. 4 - Cuantificación de los atributos de la característica significativa "nivel de conocimiento elemental sobre aspectos jurídicos en el contexto operativo de la red social": se calculan según las opciones de respuestas que el entrevistado escogió para responder a las preguntas de la encuesta definitiva, según se detallan en la Tabla 30.

Tabla 30. Estimación del valor de los atributos del No. 1 al No.4 de la característica significativa "nivel de conocimiento elemental sobre aspectos jurídicos en el contexto operativo de la red social".

\begin{tabular}{|c|c|c|c|c|c|c|c|c|c|c|c|c|}
\hline $\begin{array}{c}\begin{array}{c}\text { Factores determinantes } \\
\text { del grado de conciencia } \\
\text { sobre privacidad y } \\
\text { seguridad }\end{array} \\
\end{array}$ & $\begin{array}{l}\text { Características } \\
\text { significativas }\end{array}$ & $\begin{array}{c}\text { Grupos de atributos, Tabla 18, que } \\
\text { orientaron a la definición de las } \\
\text { preguntas de la entrevista } \\
\text { estructurada definitiva }\end{array}$ & $\begin{array}{c}\text { Valor } \\
\text { cuantificado }\end{array}$ & \begin{tabular}{|c}
$\begin{array}{c}\text { Criterio de cuantificación } \\
\text { basado en respuesta a } \\
\text { atributo }\end{array}$ \\
\end{tabular} & $\begin{array}{l}\text { Preguntas de la entrevista } \\
\text { estructurada definitiva } \\
\text { consideradas para generar el } \\
\text { atributo } \\
\end{array}$ & \multicolumn{7}{|c|}{ Opciones de respuestas } \\
\hline \multirow{8}{*}{$\begin{array}{l}\text { Nivel de cultura de } \\
\text { seguridad y } \\
\text { privacidad }\end{array}$} & \multirow{8}{*}{$\begin{array}{l}\text { D. Nivel de } \\
\text { conocimiento } \\
\text { elemental sobre } \\
\text { aspectos jurídicos } \\
\text { en el contexto } \\
\text { operativo de la } \\
\text { red social }\end{array}$} & \multirow[b]{2}{*}{$\begin{array}{l}\text { 1. ¿Tiene conocimiento de donde } \\
\text { Facebook guarda los datos personales } \\
\text { que registró al abrir la cuenta de } \\
\text { usuario? }\end{array}$} & 1 & $\begin{array}{c}\text { Sl: Aplica } 3 \text { o más de las } 6 \\
\text { opciones de respuesta en } \\
\text { color azul }\end{array}$ & \multirow{2}{*}{$\begin{array}{l}\text { Indique en qué regiones del } \\
\text { mundo, usted cree que } \\
\text { Facebook guarda los datos } \\
\text { personales que usted } \\
\text { registró al abrir su cuenta de } \\
\text { usuario }\end{array}$} & & \multirow[b]{2}{*}{$\begin{array}{l}\text { Estados Unidos } \\
\text { de América }\end{array}$} & \multirow[b]{2}{*}{ Latinoamérica } & \multirow[b]{2}{*}{ Europa } & \multirow[b]{2}{*}{ Asia } & \multirow[b]{2}{*}{ África } & \multirow[b]{2}{*}{ Oceania } \\
\hline & & & 0 & \begin{tabular}{|c|} 
NO: Escoge la primera \\
opción de respuesta en \\
color rojo o aplica menos \\
de 3 de las otras 6 \\
opciones de respuesta \\
en color azul
\end{tabular} & & No sé & & & & & & \\
\hline & & \multirow{2}{*}{$\begin{array}{l}\text { 2. ¿Sabe a ciencia cierta que, en los } \\
\text { lugares donde cree que Facebook } \\
\text { guarda sus datos personales, SI } \\
\text { existen leyes vigentes de protección } \\
\text { de datos que lo protegen, de alguna } \\
\text { forma, ante una violación de } \\
\text { seguridad y/o privacidad por ser } \\
\text { usuario de Facebook? }\end{array}$} & 1 & $\mathrm{SI}$ & \multirow{2}{*}{\begin{tabular}{|l|} 
¿En los lugares donde usted \\
cree que Facebook guarda \\
sus datos personales, existen \\
leyes vigentes de protección \\
de datos que lo protejan a \\
usted, de alguna forma, ante \\
una violación de seguridad \\
y/o privacidad por ser \\
usuario de Facebook?
\end{tabular}} & Si existen & & & & & & \\
\hline & & & 0 & No & & Desconozco & No existen & & & & & \\
\hline & & \multirow{2}{*}{$\begin{array}{l}\text { 3. ¿Conoce con certeza, si en su Pais } \\
\text { de residencia, hay leyes vigentes de } \\
\text { protección de datos que lo protegen, } \\
\text { de alguna forma, ante una violación } \\
\text { de seguridad y/o privacidad por ser } \\
\text { usuario de Facebook? }\end{array}$} & 1 & sI & \multirow{2}{*}{\begin{tabular}{|l|} 
¿Conoce si existen en su Pais \\
de residencia, leyes vigentes \\
de protección de datos que \\
lo protejan a usted, de \\
alguna forma, ante una \\
violación de seguridad y/o \\
privacidad por ser usuario de \\
Facebook?
\end{tabular}} & Si existen & No existen & & & & & \\
\hline & & & 0 & No & & Desconozco & & & & & & \\
\hline & & \multirow{2}{*}{$\begin{array}{l}\text { 4. ¿Conoce cómo actuar } \\
\text { correctamente si fuera víctima de } \\
\text { algún daño por utilizar Facebook? }\end{array}$} & 1 & SI & \multirow{2}{*}{$\begin{array}{l}\text { ¿Si fuera víctima de algún } \\
\text { daño por utilizar Facebook, } \\
\text { cuales acciones tomaría para } \\
\text { protegerse? }\end{array}$} & $\begin{array}{l}\text { Bloquear al } \\
\text { contacto que } \\
\text { causó el daño }\end{array}$ & $\begin{array}{l}\text { Denunciar a } \\
\text { Facebook el } \\
\text { acontecimiento }\end{array}$ & \begin{tabular}{|l|} 
Buscar \\
asesoramiento \\
legal especializado
\end{tabular} & & & & \\
\hline & & & 0 & No & & $\begin{array}{l}\text { Eliminar mi cuenta } \\
\text { y dejar de usar } \\
\text { Facebook }\end{array}$ & \begin{tabular}{|l} 
Eliminar mi \\
cuenta actual y \\
crear una nueva
\end{tabular} & \begin{tabular}{|l} 
Denunciar el \\
hecho al \\
proveedor de \\
Internet \\
\end{tabular} & \begin{tabular}{|l} 
Denunciar a las \\
autoridades \\
competentes
\end{tabular} & Ninguna acción & & \\
\hline
\end{tabular}


Tabla 31. Cálculo del valor de la característica significativa "nivel de conocimiento elemental sobre aspectos jurídicos en el contexto operativo de la red social"

\begin{tabular}{|c|c|c|c|c|}
\hline $\begin{array}{l}\text { Factor determinante del } \\
\text { grado de conciencia sobre } \\
\text { privacidad y seguridad }\end{array}$ & $\begin{array}{l}\text { Característica } \\
\text { significativa }\end{array}$ & Tipo & \multicolumn{2}{|r|}{ Método de cálculo } \\
\hline \multirow{6}{*}{$\begin{array}{l}\text { Nivel de cultura de } \\
\text { seguridad y privacidad }\end{array}$} & \multirow{6}{*}{$\begin{array}{l}\text { D. Nivel de } \\
\text { conocimiento } \\
\text { elemental sobre } \\
\text { aspectos jurídicos } \\
\text { en el contexto } \\
\text { operativo de la } \\
\text { red social }\end{array}$} & CUANTIFICADO & \multicolumn{2}{|c|}{$\begin{array}{c}\text { "MEDIA ARITMÉTICA" } \\
\text { de los valores cuantificados } \\
\text { de los atributos Nos. } 1 \text { al } 4\end{array}$} \\
\hline & & \multirow{5}{*}{ CUALITATIVO } & \multicolumn{2}{|c|}{$\begin{array}{c}\text { "RANGO EN QUE SE ENCUENTRA EL VALOR DEL } \\
\text { NIVEL CUANTIFICADO" }\end{array}$} \\
\hline & & & Avanzado & $\begin{array}{l}\text { el nivel cuantificado tiene un } \\
\text { valor entre } 0,76 \text { a } 1\end{array}$ \\
\hline & & & Medio & $\begin{array}{l}\text { el nivel cuantificado tiene un } \\
\text { valor entre } 0,51 \text { a } 0,75\end{array}$ \\
\hline & & & Bajo & $\begin{array}{l}\text { el nivel cuantificado tiene un } \\
\text { valor entre } 0,26 \text { a } 0,5)\end{array}$ \\
\hline & & & Ninguno & $\begin{array}{l}\text { el nivel cuantificado tiene un } \\
\text { valor entre } 0 \text { a } 0,25\end{array}$ \\
\hline
\end{tabular}


No. 5 - Método de estimación del nivel de cultura de seguridad y privacidad: Con la media aritmética de los 4 valores correspondientes a las características significativas del nivel de cultura de seguridad y privacidad del usuario de Facebook, se determina un valor para ese factor determinante, como se describe en la Tabla 32.

Tabla 32. Método de estimación del nivel de cultura de seguridad y privacidad

\begin{tabular}{|c|c|c|c|c|}
\hline $\begin{array}{l}\text { Factor determinante } \\
\text { del grado de } \\
\text { conciencia sobre } \\
\text { privacidad y seguridad }\end{array}$ & Tipo & $\begin{array}{l}\text { Característica significativa } \\
\text { cuantificada }\end{array}$ & & Método de cálculo \\
\hline \multirow{9}{*}{$\begin{array}{l}\text { Nivel de cultura de } \\
\text { seguridad y privacidad }\end{array}$} & \multirow{4}{*}{ CUANTIFICADO } & $\begin{array}{l}\text { Nivel cuantificado de conocimientos sobre } \\
\text { principios de seguridad y privacidad. }\end{array}$ & VALOR 1 & \multirow{4}{*}{$\begin{array}{l}\text { "MEDIA ARITMÉTICA" } \\
\text { VALOR } 5=(\text { VALOR } 1+ \\
\text { VALOR } 2+\text { VALOR } 3+ \\
\text { VALOR } 4) / 4\end{array}$} \\
\hline & & $\begin{array}{l}\text { Nivel cuantificado de comprensión de la } \\
\text { política de privacidad y datos de facebook } \\
\text { y sus actualizaciones. }\end{array}$ & VALOR 2 & \\
\hline & & $\begin{array}{l}\text { Nivel cuantificado de experticia en las } \\
\text { configuraciones de privacidad disponibles } \\
\text { en la red social. }\end{array}$ & VALOR 3 & \\
\hline & & $\begin{array}{l}\text { Nivel cuantificado de conocimiento } \\
\text { elemental sobre aspectos jurídicos en el } \\
\text { contexto operativo de la red social. }\end{array}$ & VALOR 4 & \\
\hline & \multirow{5}{*}{ CUALITATIVO } & & \multicolumn{2}{|c|}{$\begin{array}{c}\text { "RANGO EN QUE SE ENCUENTRA EL VALOR } \\
\text { DEL NIVEL CUANTIFICADO" }\end{array}$} \\
\hline & & & Avanzado & $\begin{array}{l}\text { el nivel cuantificado tiene un } \\
\text { valor entre } 0,76 \text { a } 1\end{array}$ \\
\hline & & & Medio & $\begin{array}{l}\text { el nivel cuantificado tiene un } \\
\text { valor entre } 0,51 \text { a } 0,75\end{array}$ \\
\hline & & & Bajo & $\begin{array}{l}\text { el nivel cuantificado tiene un } \\
\text { valor entre } 0,26 \text { a } 0,5) \text {, }\end{array}$ \\
\hline & & & Ninguno & $\begin{array}{l}\text { el nivel cuantificado tiene un } \\
\text { valor entre } 0 \text { a } 0,25\end{array}$ \\
\hline
\end{tabular}




\section{REGLAS PARA EL FACTOR DETERMINANTE: NIVEL DE RIESGO POR COMPORTAMIENTOS PSICOSOCIALES}

No. 6 - Cuantificación de los atributos y de las características significativas del factor determinante "nivel de riesgo por comportamientos psicosociales": se calculan según las opciones de respuestas que el entrevistado escogió para responder a las preguntas de la encuesta definitiva, según se detallan en la Tabla 33, Tabla 34, Tabla 35, Tabla 36 y Tabla 37.

Tabla 33. Estimación del valor del atributo No. 1.

\begin{tabular}{|c|c|c|c|c|c|}
\hline $\begin{array}{l}\text { Factores determinantes } \\
\text { del grado de conciencia } \\
\text { sobre privacidad y } \\
\text { seguridad }\end{array}$ & $\begin{array}{l}\text { Características } \\
\text { significativas }\end{array}$ & $\begin{array}{c}\text { Grupos de atributos, Tabla 18, } \\
\text { que orientaron a la definición } \\
\text { de las preguntas de la } \\
\text { entrevista estructurada } \\
\text { definitiva }\end{array}$ & $\begin{array}{c}\text { Valor } \\
\text { cuantificado }\end{array}$ & $\begin{array}{c}\text { Criterio de cuantificación } \\
\text { basado en respuesta a } \\
\text { atributo }\end{array}$ & $\begin{array}{l}\text { Preguntas de la entrevista } \\
\text { estructurada definitiva } \\
\text { consideradas para generar el } \\
\text { atributo }\end{array}$ \\
\hline \multirow[b]{2}{*}{$\begin{array}{l}\text { Nivel de riesgo generado } \\
\text { por comportamientos } \\
\text { psicosociales }\end{array}$} & \multirow[b]{2}{*}{$\begin{array}{l}\text { A. No saber } \\
\text { reconocer a un } \\
\text { usuario confiable }\end{array}$} & \multirow[b]{2}{*}{\begin{tabular}{|l|} 
1. ¿Entiende lo que es hacer \\
un análisis exhaustivo para \\
determinar si una persona es \\
confiable?
\end{tabular}} & 1 & $\begin{array}{c}\text { SI: Aplica } 4 \text { o más de las } 8 \\
\text { opciones de respuesta en } \\
\text { color azul }\end{array}$ & \multirow{2}{*}{$\begin{array}{l}\text { ¿Cuáles de las siguientes } \\
\text { opciones, utiliza cuando } \\
\text { recibe una solicitud de } \\
\text { amistad, para analizar } \\
\text { exhaustivamente un perfil en } \\
\text { Facebook y determinar si el } \\
\text { solicitante es o no confiable? }\end{array}$} \\
\hline & & & 0 & $\begin{array}{l}\text { NO: Escoge la primera } \\
\text { opción de respuesta en } \\
\text { color rojo o aplica menos } \\
\text { de } 4 \text { de las otras } 8 \\
\text { opciones de respuesta } \\
\text { en color azul }\end{array}$ & \\
\hline
\end{tabular}

Preguntas de la entrevista

estructurada definitiva

consideradas para generar el

atributo

¿Cuáles de las siguientes opciones, utiliza cuando recibe una solicitud de amistad, para analizar

exhaustivamente un perfil en Nunca investigo el perfil

Facebook y determinar si el

solicitante es o no confiable?

en Facebook de quien me

solicita amistad a través

de la red social
Opciones de respuestas

\begin{tabular}{|c|c|c|c|c|c|c|c|}
\hline $\begin{array}{l}\text { Verifico la actividad } \\
\text { de la cuenta del } \\
\text { solicitante para } \\
\text { determinar si es poca } \\
\text { o nula y la forma de } \\
\text { actuar en la red social } \\
\qquad(\mathrm{SI}=1 ; \mathrm{NO}=0)\end{array}$ & $\begin{array}{l}\text { Observo si } \\
\text { alguno de mis } \\
\text { contactos es } \\
\text { también un } \\
\text { contacto de } \\
\text { quien envía la } \\
\text { solicitud } \\
(\mathrm{SI}=1 ; \mathrm{NO}=0)\end{array}$ & $\begin{array}{c}\text { Pongo atención } \\
\text { en los contactos } \\
\text { de la cuenta para } \\
\text { determinar si } \\
\text { pueden ser } \\
\text { reales o no } \\
(\mathrm{SI}=1 ; \mathrm{NO}=0)\end{array}$ & \begin{tabular}{|c|} 
Analizo las \\
fechas de \\
nacimiento para \\
determinar si son \\
irreales o poco \\
creibles \\
$(\mathrm{SI}=1 ; \mathrm{NO}=0)$
\end{tabular} & $\begin{array}{c}\text { Observo si en sus } \\
\text { publicaciones } \\
\text { existen fotos que } \\
\text { pretendan ser } \\
\text { atractivas para el } \\
\text { sexo opuesto } \\
(\mathrm{SI}=1 ; \mathrm{NO}=0)\end{array}$ & $\begin{array}{c}\text { Reviso si } \\
\text { pretenden } \\
\text { mostrarse con } \\
\text { celebridades o } \\
\text { personas famosas } \\
(\mathrm{SI}=1 ; \mathrm{NO}=0)\end{array}$ & $\begin{array}{c}\text { Analizo los } \\
\text { números } \\
\text { telefónicos } \\
\text { disponibles en la } \\
\text { información del } \\
\text { perfil } \\
(\mathrm{SI}=1 ; \mathrm{NO}=0)\end{array}$ & $\begin{array}{c}\text { Analizo las fotos } \\
\text { que se } \\
\text { encuentran en su } \\
\text { muro para tratar } \\
\text { identificarlo y } \\
\text { determinar su } \\
\text { tipo de actividad } \\
(\mathrm{SI}=1 ; \mathrm{NO}=0)\end{array}$ \\
\hline
\end{tabular}


Tabla 34. Estimación del valor del atributo No. 2.

\begin{tabular}{|c|c|c|c|c|c|c|c|}
\hline $\begin{array}{c}\text { Factores determinantes } \\
\text { del grado de conciencia } \\
\text { sobre privacidad y } \\
\text { seguridad }\end{array}$ & $\begin{array}{l}\text { Características } \\
\text { significativas }\end{array}$ & $\begin{array}{c}\text { Grupos de atributos, Tabla 18, } \\
\text { que orientaron a la definición } \\
\text { de las preguntas de la } \\
\text { entrevista estructurada } \\
\text { definitiva }\end{array}$ & $\begin{array}{c}\text { Valor } \\
\text { cuantificado }\end{array}$ & $\begin{array}{c}\text { Criterio de cuantificación } \\
\text { basado en respuesta a } \\
\text { atributo }\end{array}$ & $\begin{array}{l}\text { Preguntas de la entrevista } \\
\text { estructurada definitiva } \\
\text { consideradas para generar el } \\
\text { atributo }\end{array}$ & \multicolumn{2}{|c|}{ Opciones de respuestas } \\
\hline \multirow{6}{*}{$\begin{array}{l}\text { Nivel de riesgo generado } \\
\text { por comportamientos } \\
\text { psicosociales }\end{array}$} & \multirow{6}{*}{$\begin{array}{l}\text { B. No saber actuar } \\
\text { ante solicitudes de } \\
\text { amistad de } \\
\text { conocidos y/o } \\
\text { desconocidos }\end{array}$} & \multirow{6}{*}{$\begin{array}{l}\text { 2. ¿Conoce la forma correcta } \\
\text { de actuar cuando un } \\
\text { conocido/desconocido le } \\
\text { envía una solicitud de } \\
\text { amistad? }\end{array}$} & 1 & SI & \begin{tabular}{|l} 
Seleccione la opción que \\
mejor describa su forma de \\
actuar cuando un conocido le \\
envía una solicitud de amistad.
\end{tabular} & $\begin{array}{l}\text { Observo el perfil de } \\
\text { Facebook de la persona } \\
\text { que hace la solicitud para } \\
\text { verificar que la petición } \\
\text { venga de quien dice ser y } \\
\text { si es verdad acepto el } \\
\text { pedido. }\end{array}$ & $\begin{array}{l}\text { Hago un análisis } \\
\text { exhaustivo de la } \\
\text { persona que hace la } \\
\text { solicitud para verificar } \\
\text { que la petición venga } \\
\text { de quien dice ser y si } \\
\text { es verdad acepto el } \\
\text { pedido. }\end{array}$ \\
\hline & & & 0,5 & $\begin{array}{l}\text { Actúa con sentido de } \\
\text { seguridad }=0,5\end{array}$ & & $\begin{array}{l}\text { No acepto el pedido creo } \\
\text { que es falso y por lo tanto } \\
\text { es riesgoso. }\end{array}$ & \\
\hline & & & 0 & NO & & $\begin{array}{l}\text { Acepto el pedido de } \\
\text { inmediato }\end{array}$ & \\
\hline & & & 1 & $\mathrm{SI}$ & \multirow{3}{*}{$\begin{array}{l}\text { Seleccione la opción que } \\
\text { mejor describa su forma de } \\
\text { actuar cuando un desconocido } \\
\text { le envía una solicitud de } \\
\text { amistad. }\end{array}$} & $\begin{array}{l}\text { No acepto el pedido creo } \\
\text { que es falso y riesgoso }\end{array}$ & \\
\hline & & & 0,5 & $\begin{array}{l}\text { Actua con sentido de } \\
\text { seguridad }=0,5\end{array}$ & & $\begin{array}{l}\text { Hago un análisis } \\
\text { exhaustivo de la persona } \\
\text { que hace la solicitud para } \\
\text { verificar que la petición } \\
\text { venga de quien dice ser y } \\
\text { si es verdad acepto el } \\
\text { pedido } \\
\end{array}$ & \\
\hline & & & 0 & NO & & \begin{tabular}{|l|} 
Observo el perfil de \\
Facebook de la persona \\
que hace la solicitud para \\
verificar que la petición \\
venga de quien dice ser y \\
si es verdad acepto el \\
pedido
\end{tabular} & \\
\hline
\end{tabular}


Tabla 35. Estimación de los valores de los atributos del No. 3 al No. 6.

\begin{tabular}{|c|c|c|c|c|c|c|c|}
\hline $\begin{array}{l}\text { Factores determinantes } \\
\text { del grado de conciencia } \\
\text { sobre privacidad y } \\
\text { seguridad }\end{array}$ & $\begin{array}{l}\text { Caracteristicas } \\
\text { significativas }\end{array}$ & $\begin{array}{c}\text { Grupos de atributos, Tabla 18, } \\
\text { que orientaron a la definición } \\
\text { de las preguntas de la } \\
\text { entrevista estructurada } \\
\text { definitiva }\end{array}$ & $\begin{array}{c}\text { Valor } \\
\text { cuantificado }\end{array}$ & $\begin{array}{c}\text { Criterio de cuantificación } \\
\text { basado en respuesta a } \\
\text { atributo }\end{array}$ & $\begin{array}{l}\text { Preguntas de la entrevista } \\
\text { estructurada definitiva } \\
\text { consideradas para generar el } \\
\text { atributo }\end{array}$ & \multicolumn{2}{|c|}{ Opciones de respuestas } \\
\hline \multirow{7}{*}{$\begin{array}{l}\text { Nivel de riesgo generado } \\
\text { por comportamientos } \\
\text { psicosociales }\end{array}$} & $\begin{array}{l}\text { C. Enviar } \\
\text { información } \\
\text { confidencial }\end{array}$ & $\begin{array}{l}\text { 3. ¿Utiliza la red social para } \\
\text { enviar información } \\
\text { confidencial? }\end{array}$ & 1 & NO & $\begin{array}{l}\text { Si un contacto de Facebook, de } \\
\text { su entera confianza, le solicita } \\
\text { que le envie a través de la red } \\
\text { social Facebook su cédula de } \\
\text { ciudadanía digitalizada.¿Usted } \\
\text { cumple el pedido? }\end{array}$ & & \\
\hline & \multirow[b]{2}{*}{$\begin{array}{l}\text { D. Aceptar } \\
\text { ofrecimientos de } \\
\text { extraños }\end{array}$} & \multirow{2}{*}{$\begin{array}{l}\text { 4. ¿Sabe actuar correctamente } \\
\text { ante ofrecimientos y } \\
\text { comunicaciones de un usuario } \\
\text { extraño de Facebook? }\end{array}$} & 1 & SI & \multirow{2}{*}{\begin{tabular}{|l|} 
Seleccione la opción que \\
mejor describa su forma de \\
actuar cuando un usuario de \\
Facebook le comunica que es \\
ganador de una importante \\
suma de dinero, por lo que le \\
solicita: datos personales, \\
número de cédula de \\
ciudadanía, número de cuenta \\
del banco donde depositar el \\
dinero.
\end{tabular}} & $\begin{array}{l}\text { No acepto el pedido creo } \\
\text { que es falso y riesgoso }\end{array}$ & \\
\hline & & & 0 & NO & & \begin{tabular}{|l|} 
Hago un análisis \\
exhaustivo de la persona \\
que hace la solicitud para \\
verificar que la petición \\
venga de quien dice ser y \\
si es verdad envio los datos \\
solicitados
\end{tabular} & $\begin{array}{l}\text { Observo el perfil de } \\
\text { Facebook de la } \\
\text { persona que hace la } \\
\text { solicitud para verificar } \\
\text { que la petición venga } \\
\text { de quien dice ser y si } \\
\text { es verdad envío los } \\
\text { datos solicitados }\end{array}$ \\
\hline & \multirow{2}{*}{$\begin{array}{l}\text { E. Hacer } \\
\text { transacciones con } \\
\text { tarjeta de crédito }\end{array}$} & \multirow{2}{*}{$\begin{array}{l}\text { 5. ¿Ha realizado alguna } \\
\text { transacción a través de } \\
\text { Facebook que haya requerido } \\
\text { el número de su tarjeta de } \\
\text { crédito? }\end{array}$} & 1 & NO & \multirow{2}{*}{\begin{tabular}{|l|} 
¿Ha realizado alguna \\
transacción a través de \\
Faceboook que haya requerido \\
el número de su tarjeta de \\
crédito?
\end{tabular}} & & \\
\hline & & & 0 & SI & & & \\
\hline & \multirow{2}{*}{$\begin{array}{l}\text { F. Difundir la } \\
\text { actividad actual }\end{array}$} & \multirow{2}{*}{$\begin{array}{l}\text { 6. ¿Hace publicaciones en } \\
\text { Facebook de sus actividades } \\
\text { actuales? }\end{array}$} & 1 & No & \multirow{2}{*}{$\begin{array}{l}\text { ¿Durante un viaje, hace } \\
\text { publicaciones en Facebook de } \\
\text { los sitios en los que se } \\
\text { encuentra en ese momento? }\end{array}$} & & \\
\hline & & & 0 & SI & & & \\
\hline
\end{tabular}


Tabla 36. Estimación de los valores de los atributos No. 7, No. 8 y No. 11

\begin{tabular}{|c|c|c|c|c|c|c|c|c|c|c|c|c|}
\hline $\begin{array}{c}\text { Factores determinantes } \\
\text { del grado de conciencia } \\
\text { sobre privacidad y } \\
\text { seguridad }\end{array}$ & $\begin{array}{l}\text { Características } \\
\text { significativas }\end{array}$ & $\mid \begin{array}{c}\text { Grupos de atributos, Tabla } \\
18, \text { que orientaron a la } \\
\text { definición de las preguntas } \\
\text { de la entrevista estructurada } \\
\text { definitiva }\end{array}$ & $\begin{array}{c}\text { Valor } \\
\text { cuantificado }\end{array}$ & $\begin{array}{c}\text { Criterio de } \\
\text { cuantificación basado } \\
\text { en respuesta a atributo }\end{array}$ & $\begin{array}{l}\text { Preguntas de la entrevista } \\
\text { estructurada definitiva } \\
\text { consideradas para generar el } \\
\text { atributo }\end{array}$ & \multicolumn{7}{|c|}{ Opciones de respuestas } \\
\hline \multirow{8}{*}{$\begin{array}{l}\text { Nivel de riesgo } \\
\text { generado por } \\
\text { comportamientos } \\
\text { psicosociales }\end{array}$} & \multirow{3}{*}{$\begin{array}{l}\text { G. Sentir atracción } \\
\text { por mantener } \\
\text { contacto con } \\
\text { famosos }\end{array}$} & \multirow{3}{*}{$\begin{array}{l}\text { 7. ¿Siente atracción por ser } \\
\text { contacto de personas } \\
\text { famosas? }\end{array}$} & 1 & No & \multirow{3}{*}{$\begin{array}{l}\text { Seleccione la opción que } \\
\text { mejor describa su forma de } \\
\text { actuar cuando una persona } \\
\text { famosa le invita a ser su } \\
\text { contacto o participar en } \\
\text { algún evento. }\end{array}$} & $\begin{array}{l}\text { No acepto el pedido } \\
\text { creo que es falso y } \\
\text { riesgoso }\end{array}$ & & & & & & \\
\hline & & & 0,5 & $\begin{array}{l}\text { Actúa con sentido de } \\
\text { seguridad }=0,5\end{array}$ & & \begin{tabular}{|l|} 
Hago un análisis \\
exhaustivo de la \\
persona que hace la \\
solicitud para verificar \\
que la petición venga \\
de quien dice ser y si es \\
verdad acepto el pedido \\
\end{tabular} & & & & & & \\
\hline & & & 0 & sI & & \begin{tabular}{|l} 
observo el perfil de \\
Facebook de la persona \\
que hace la solicitud \\
para verificar que la \\
petición venga de quien \\
dice ser y si es verdad \\
acepto el pedido
\end{tabular} & $\begin{array}{l}\text { Acepto el } \\
\text { pedido de } \\
\text { inmediato }\end{array}$ & & & & & \\
\hline & \multirow{2}{*}{$\begin{array}{l}\text { H. Gustar de hacer } \\
\text { publicaciones } \\
\text { relacionadas con } \\
\text { su vida personal }\end{array}$} & \multirow{2}{*}{$\begin{array}{l}\text { 8. ¿Gusta hacer } \\
\text { publicaciones relacionadas } \\
\text { con su vida personal? }\end{array}$} & 1 & No & \multirow{5}{*}{$\begin{array}{l}\text { ¿A qué personas elige para } \\
\text { visualizar publicaciones } \\
\text { relacionadas con su vida } \\
\text { personal? }\end{array}$} & \begin{tabular}{|l|} 
Procuro no hacer \\
publicaciones relacionadas \\
con mi vida personal
\end{tabular} & & & & & & \\
\hline & & & 0 & sI & & Al público en general & \begin{tabular}{|l} 
Familiares \\
cercanos
\end{tabular} & $\begin{array}{l}\text { Parientes en } \\
\text { general }\end{array}$ & Amigos & $\begin{array}{l}\text { Conocidos - } \\
\text { vecinos }\end{array}$ & \begin{tabular}{|l|} 
Excompañeros \\
de trabajo
\end{tabular} & \\
\hline & \multirow{3}{*}{$\begin{array}{l}\text { K. No clasificar a } \\
\text { sus contactos en } \\
\text { grupos afines }\end{array}$} & \multirow{3}{*}{$\begin{array}{l}\text { 11. ¿Clasifica a sus contactos } \\
\text { en grupos afines? }\end{array}$} & 1 & $\begin{array}{c}\text { SI (seleccionó todas las } \\
\text { opciones en azul) }\end{array}$ & & & & & & & & \multirow[b]{2}{*}{$\begin{array}{l}\text { Conocidos - } \\
\text { vecinos }\end{array}$} \\
\hline & & & 0,5 & $\begin{array}{c}\text { Entiende que debe } \\
\text { diferenciar grupos de } \\
\text { personas (selecionó } \\
\text { algunas en azul, pero no } \\
\text { todas y con alguna } \\
\text { opción en rojo) }\end{array}$ & & \multirow[t]{2}{*}{$\begin{array}{l}\text { No se escoger quien puede } \\
\text { visualizar mi publicación }\end{array}$} & \multirow[t]{2}{*}{$\begin{array}{l}\text { Al público } \\
\text { en general }\end{array}$} & $\begin{array}{l}\text { Familiares } \\
\text { cercanos }\end{array}$ & \begin{tabular}{|l} 
Parientes \\
en \\
general
\end{tabular} & Amigos & $\begin{array}{l}\text { Excompañeros } \\
\text { de trabajo }\end{array}$ & \\
\hline & & & 0 & $\begin{array}{c}\text { NO ( si solamente } \\
\text { escogió alguna de las } \\
\text { opciones en rojo) }\end{array}$ & & & & & & & & \\
\hline
\end{tabular}




\begin{tabular}{|c|c|c|c|c|c|c|}
\hline $\begin{array}{l}\text { Factores determinantes } \\
\text { del grado de conciencia } \\
\text { sobre privacidad y } \\
\text { seguridad }\end{array}$ & $\begin{array}{l}\text { Características } \\
\text { significativas }\end{array}$ & $\begin{array}{c}\text { Grupos de atributos, Tabla 18, } \\
\text { que orientaron a la definición } \\
\text { de las preguntas de la } \\
\text { entrevista estructurada } \\
\text { definitiva }\end{array}$ & $\begin{array}{c}\text { Valor } \\
\text { cuantificado }\end{array}$ & $\begin{array}{c}\text { Criterio de cuantificación } \\
\text { basado en respuesta a } \\
\text { atributo }\end{array}$ & $\begin{array}{l}\text { Preguntas de la entrevista } \\
\text { estructurada definitiva } \\
\text { consideradas para generar el } \\
\text { atributo }\end{array}$ & Opciones de respuestas \\
\hline \multirow{9}{*}{$\begin{array}{l}\text { Nivel de riesgo generado } \\
\text { por comportamientos } \\
\text { psicosociales }\end{array}$} & \multirow{3}{*}{$\begin{array}{l}\text { I. Recibir apoyo } \\
\text { emocional }\end{array}$} & \multirow{3}{*}{$\begin{array}{l}\text { 9. ¿Ha recibido apoyo } \\
\text { emocional de usuarios de } \\
\text { Facebook, conocidos y } \\
\text { desconocidos por usted, } \\
\text { frente a algún inconveniente } \\
\text { o calamidad que ha sufrido? }\end{array}$} & 1 & Nunca & \multirow{3}{*}{$\begin{array}{l}\text { ¿Ha recibido a través de } \\
\text { Facebook apoyo emocional de } \\
\text { usuarios de la red social, } \\
\text { conocidos y desconocidos por } \\
\text { usted, frente a algún } \\
\text { inconveniente o calamidad } \\
\text { que ha sufrido? }\end{array}$} & Nunca \\
\hline & & & 0,5 & Pocas veces & & Pocas veces \\
\hline & & & 0 & Frecuentemente & & Frecuentemente \\
\hline & \multirow{3}{*}{$\begin{array}{l}\text { J. Brindar apoyo } \\
\text { emocional }\end{array}$} & \multirow{3}{*}{$\begin{array}{l}\text { 10. ¿Ha utilizado Facebook } \\
\text { para brindar apoyo emocional } \\
\text { a usuarios de la red social, } \\
\text { conocidos y desconocidos por } \\
\text { usted, frente a algún }\end{array}$} & 1 & Nunca & \multirow{3}{*}{$\begin{array}{l}\text { ¿Ha utilizado Facebook para } \\
\text { brindar apoyo emocional a } \\
\text { usuarios de la red social, } \\
\text { conocidos y desconocidos por } \\
\text { usted, frente a algún }\end{array}$} & Nunca \\
\hline & & & 0,5 & Pocas veces & & Pocas veces \\
\hline & & & 0 & Frecuentemente & & Frecuentemente \\
\hline & \multirow{3}{*}{$\begin{array}{l}\text { L. Que Facebook le } \\
\text { aleje de sus } \\
\text { contactos cara a } \\
\text { cara }\end{array}$} & \multirow{3}{*}{\begin{tabular}{|l|} 
12. ¿Ha reducido sus \\
relaciones personales cara a \\
cara con las personas que \\
convive a diario debido al uso \\
de Facebook?
\end{tabular}} & 1 & No & \multirow{3}{*}{$\begin{array}{l}\text { ¿Ha reducido sus relaciones } \\
\text { personales cara a cara con las } \\
\text { personas que convive a diario } \\
\text { debido al uso de Facebook? }\end{array}$} & No \\
\hline & & & 0,5 & Tal vez & & Tal vez \\
\hline & & & 0 & Sí & & Sí \\
\hline
\end{tabular}


No. 5 - Método de estimación del nivel de riesgo por comportamientos psicosociales: Con la media aritmética de los 12 valores correspondientes a las características significativas del nivel de riesgo por comportamientos psicosociales del usuario de Facebook, se determina un valor para ese factor determinante, como se describe en la Tabla 38.

Tabla 38. Método de estimación del nivel de riesgo por comportamientos psicosociales

\begin{tabular}{|c|c|c|c|c|}
\hline \begin{tabular}{|} 
Factor determinante \\
del grado de \\
conciencia sobre \\
privacidad y seguridad
\end{tabular} & Tіро & $\begin{array}{l}\text { Característica significativa } \\
\text { cuantificada }\end{array}$ & & Método de cálculo \\
\hline \multirow{7}{*}{$\begin{array}{l}\text { Nivel de riesgo } \\
\text { generado por } \\
\text { comportamientos } \\
\text { psicosociales }\end{array}$} & CUANTIFICADO & $\begin{array}{l}\text { Son doce las características significativas } \\
\text { que definen el factor determinante }\end{array}$ & $\begin{array}{l}\text { VALOR } 1 \text { al } \\
\text { VALOR } 12\end{array}$ & $\begin{array}{c}\text { "MEDIA ARITMÉTICA" } \\
\text { VALOR } 13=(\text { VALOR } 1+ \\
\text { VALOR } 2+\text { VALOR } 3+\ldots \\
\text { VALOR 12) } / 12\end{array}$ \\
\hline & \multirow{6}{*}{ CUALITATIVO } & & \multicolumn{2}{|c|}{$\begin{array}{c}\text { "RANGO EN QUE SE ENCUENTRA EL VALOR } \\
\text { DEL NIVEL CUANTIFICADO" }\end{array}$} \\
\hline & & & Bajo & $\begin{array}{l}\text { el nivel cuantificado tiene un } \\
\text { valor entre } 0,81 \text { a } 1\end{array}$ \\
\hline & & & Moderado & $\begin{array}{l}\text { el nivel cuantificado tiene un } \\
\text { valor entre } 0,61 \text { a } 0,80 \text { ), }\end{array}$ \\
\hline & & & Considerable & $\begin{array}{l}\text { el nivel cuantificado tiene un } \\
\text { valor entre } 0,41 \text { a } 0,60 \text { ), }\end{array}$ \\
\hline & & & Alto & $\begin{array}{l}\text { el nivel cuantificado tiene un } \\
\text { valor entre } 0,21 \text { a } 0,40\end{array}$ \\
\hline & & & Máximo & $\begin{array}{l}\text { el nivel cuantificado tiene un } \\
\text { valor entre } 0 \text { a } 0,20\end{array}$ \\
\hline
\end{tabular}




\section{REGLA PARA EL MÉTODO DE ESTIMACIÓN DEL NIVEL REAL DE CONCIENCIA SOBRE PRIVACIDAD Y SEGURIDAD}

No. 7: Con la media aritmética de los niveles cuantitativos estimados para los dos factores determinantes, se obtiene el valor estimado del nivel real de conciencia sobre privacidad y seguridad del usuario de Facebook, mediante la media aritmética, como se describe en la Tabla 39. El nivel cualitativo que se obtiene para el nivel real de conciencia, es el que se utiliza para comparar con el nivel hipotético de conciencia que dice tener el usuario de Facebook entrevistado, comparación que permite generar interesantes conclusiones, que se muestra en las siguientes secciones.

Tabla 39. Método de estimación del nivel real de conciencia sobre privacidad y seguridad de un usuario de Facebook.

\begin{tabular}{|c|c|c|c|c|}
\hline \multirow{8}{*}{$\begin{array}{l}\text { NIVEL REAL DE } \\
\text { CONCIENCIA SOBRE } \\
\text { PRIVACIDADY } \\
\text { SEGURIDAD }\end{array}$} & Tіро & $\begin{array}{l}\text { Factor determinante del grado de } \\
\text { conciencia sobre privacidad y }\end{array}$ & \multicolumn{2}{|r|}{ Método de cálculo } \\
\hline & \multirow{2}{*}{ CUANTIFICADO } & $\begin{array}{l}\text { Nivel de cultura de seguridad y } \\
\text { privacidad }\end{array}$ & VALOR 5 & \multirow{2}{*}{$\begin{array}{l}\text { "MEDIA ARITMÉTICA" } \\
\text { VALOR } 14=(\text { VALOR } 5+ \\
\text { VALOR } 13) / 2\end{array}$} \\
\hline & & $\begin{array}{l}\text { Nivel de riesgo generado por } \\
\text { comportamientos psicosociales }\end{array}$ & VALOR 13 & \\
\hline & \multirow{5}{*}{ CUALITATIVO } & & \multicolumn{2}{|c|}{$\begin{array}{l}\text { "RANGO EN QUE SE ENCUENTRA EL VALOR } \\
\text { DEL NIVEL CUANTIFICADO" }\end{array}$} \\
\hline & & & Avanzado & $\begin{array}{l}\text { el nivel cuantificado tiene un } \\
\text { valor entre } 0,76 \text { a } 1\end{array}$ \\
\hline & & & Medio & $\begin{array}{l}\text { el nivel cuantificado tiene un } \\
\text { valor entre } 0,51 \text { a } 0,75\end{array}$ \\
\hline & & & Bajo & $\begin{array}{l}\text { el nivel cuantificado tiene un } \\
\text { valor entre } 0,26 \text { a } 0,5) \text {, }\end{array}$ \\
\hline & & & Ninguno & $\begin{array}{l}\text { el nivel cuantificado tiene un } \\
\text { valor entre } 0 \text { a } 0,25\end{array}$ \\
\hline
\end{tabular}

La aplicación de estas reglas se puede encontrar en el archivo en formato Excel Archivo 3.xlsx del Anexo D. 
5.5.2.3. Proceso propuesto para la estimación del nivel real de conciencia de usuarios de Facebook respecto a privacidad y seguridad en la red social

El proceso propuesto en esta sección, Fig. 61, cumple con las etapas del ciclo de vida convencional de minería de datos de la Fig. 59, como se describe a continuación:

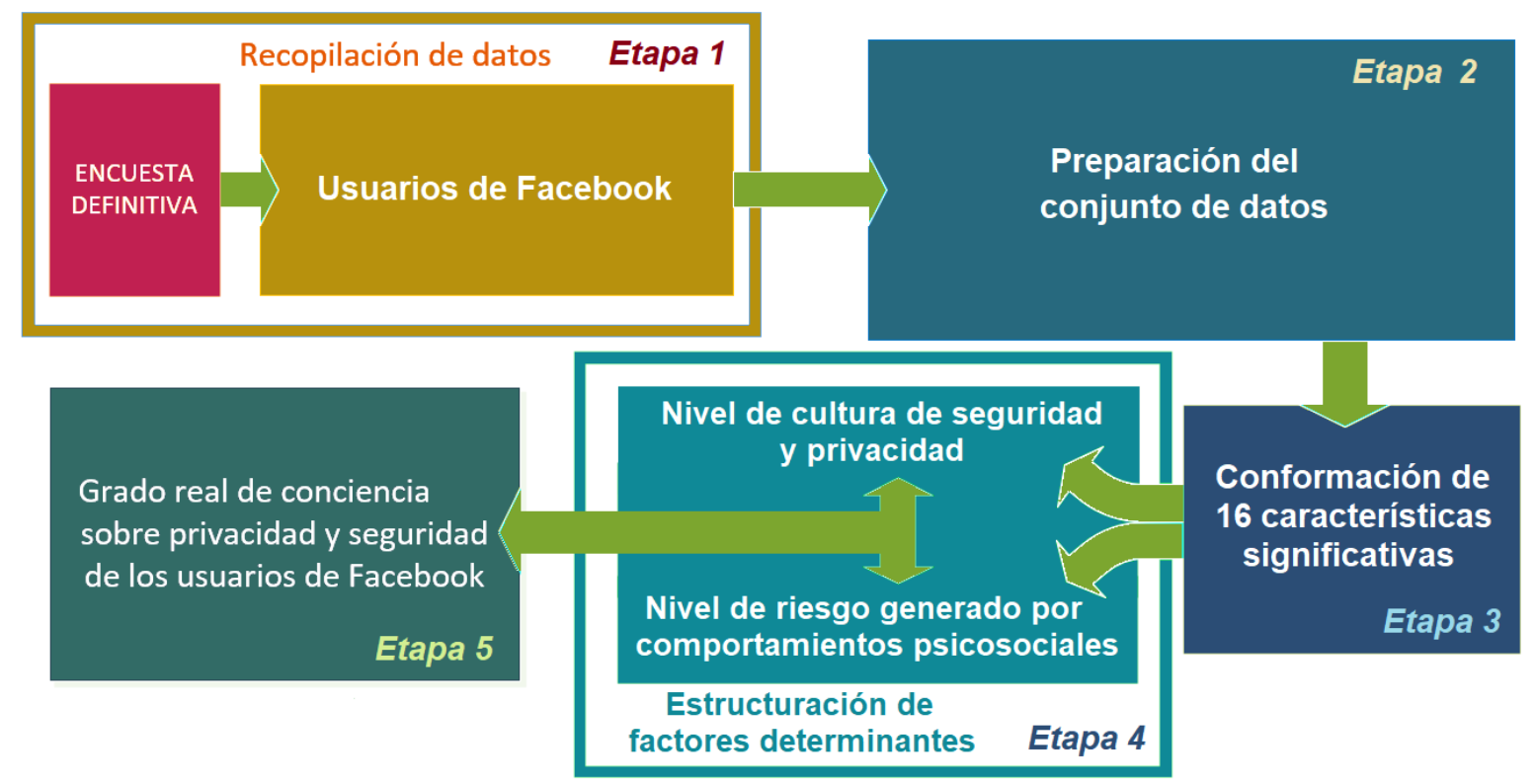

Fig. 61. Proceso propuesto para la estimación del nivel real de conciencia de usuarios de Facebook respecto a privacidad y seguridad en la red social

Tabla 40 Etapas del ciclo de vida convencional de minería de datos frente a etapas del proceso propuesto

\begin{tabular}{|l|l|}
\hline $\begin{array}{l}\text { Etapas del ciclo de vida convencional de } \\
\text { minería de datos }\end{array}$ & $\begin{array}{l}\text { Etapas del proceso propuesto para la estimación del nivel real } \\
\text { de conciencia de usuarios de Facebook respecto a privacidad y } \\
\text { seguridad en la red social }\end{array}$ \\
\hline Etapa 1: recopilación de datos. & $\begin{array}{l}\text { Etapa 1: aplicación de la encuesta definitiva a la muestra de } \\
\text { usuarios de Facebook en estudio. El cuestionario de la encuesta } \\
\text { definitiva es el que garantiza la recolección de datos limpios. }\end{array}$ \\
\hline Etapa 2: limpieza de datos. & $\begin{array}{l}\text { Etapa 2: preparación del conjunto de datos recopilados de la } \\
\text { muestra, mediante la aplicación de las reglas generadas en la } \\
\text { preparación inicial del conjunto de datos, descritas en la } \\
\text { subsección anterior. }\end{array}$ \\
\hline Etapa 3: preparación del conjunto \\
\hline $\begin{array}{l}\text { Etapa 4: extracción y descubrimiento de de } \\
\text { patrones. }\end{array}$ & $\begin{array}{l}\text { Etapas } 3 \text { y 4 del proceso propuesto, con las que se realiza la } \\
\text { conformación de las 16 características significativas; y, la } \\
\text { estructuración de los dos factores determinantes: nivel de cultura } \\
\text { de seguridad y privacidad; y, nivel de riesgo generado por } \\
\text { comportamientos psicosociales. }\end{array}$ \\
\hline Etapa 5: visualización & $\begin{array}{l}\text { Etapa } 5 \text { del proceso propuesto, en la que se estima el nivel real } \\
\text { de conciencia sobre privacidad y seguridad en Facebook de los } \\
\text { usuarios de Facebook. }\end{array}$ \\
\hline extracción de conocimiento. &
\end{tabular}




\section{Descripción del proceso propuesto para la estimación del nivel real de conciencia de usuarios de Facebook respecto a privacidad y seguridad en la red social}

La estructuración de la propuesta se basó en una metodología esencialmente cuantitativa. El proceso propuesto, Fig. 61, inicia con la aplicación de la entrevista estructurada definitiva, a la muestra de usuarios de Facebook en estudio.

En la segunda etapa, cada una de las respuestas obtenidas fueron cuantificadas con un valor asignado según la respuesta; y con las respuestas a preguntas vinculadas se estructuró el espacio multidimensional de 32 atributos.

En la tercera etapa se aplicó la regla: para la conformación y representación numérica de cada una de las 16 características significativas detalladas en la Tabla 18, para cada usuario de Facebook, se calcula la media aritmética de los valores de los atributos que conforman la respectiva característica.

En etapa 4 la regla aplicada fue: el promedio de los valores obtenidos para las características que conforman la cultura de seguridad y privacidad en línea del usuario de Facebook determinarían su nivel de cultura. El nivel de riesgo generado por los comportamientos psicosociales se estima de forma similar.

En la etapa 5, se aplican dos reglas: 1) La media aritmética de los valores de los factores determinantes: cultura de seguridad y privacidad en línea del usuario de Facebook, y nivel de riesgo generado por sus comportamientos psicosociales, determina un valor para el nivel real de conciencia sobre privacidad y seguridad en cada usuario de Facebook. 2) El valor calculado con la regla anterior, se encasilla en uno de los 4 posibles valores cualitativos de nivel real de conciencia sobre privacidad y seguridad en cada usuario de Facebook: Avanzado, Intermedio, Básico, Ninguno, definidos por los siguientes rangos de valores: Avanzado: [0.76,1]; Intermedio: [0.51,0.75]; Básico: [0.26,0.50]; Ninguno: [00.0,0.25].

\subsubsection{Discusión}

\subsubsection{Validación del proceso propuesto}

La validez del proceso propuesto para estimar el nivel real de conciencia sobre privacidad y seguridad de un usuario de Facebook quedó demostrada mediante su aplicación a una muestra amplia de usuarios de Facebook, y observando que provee datos válidos que reflejan con fidelidad la realidad, posicionando el nivel real de conciencia de la persona, en una de las cuatro instancias definidas: avanzada, intermedia, básica, o ninguna.

La validez está sujeta a un único condicionamiento: la entrevista estructurada planteada para esta investigación, debe ser respondida por el usuario de Facebook, de una manera consciente y comprometida.

La aplicación del proceso propuesto a una muestra de usuarios ecuatorianos de Facebook, permitió obtener el resultado de la Fig. 62. Esta figura muestra, que el nivel de conciencia real cualitativo en casi los dos tercios de los AM entrevistados, es el nivel básico; $y$, en el tercio restante, es el nivel medio. Este comportamiento se debe, como se observa en la Fig. 65, más que a un alto nivel de cultura de seguridad, a sus comportamientos psicosociales prudentes propios de su edad. 


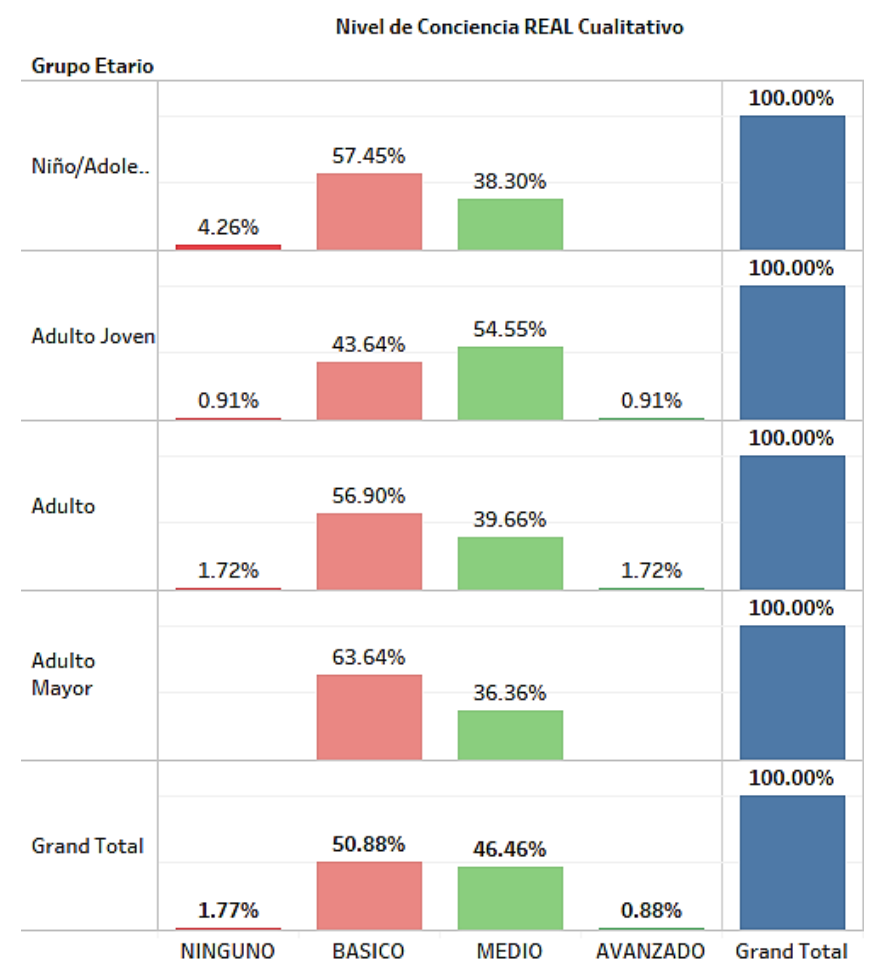

Fig. 62. Resultados obtenidos aplicando el proceso propuesto a la muestra

Obsérvese que solamente en los adultos jóvenes se presenta una proporción mayor a 1 entre el nivel real de conciencia medio y el nivel básico; esto puede ser porque las personas de ese grupo de etario, a más de tener actitudes y comportamientos cautos, posiblemente por razones culturales, saben los riesgos que existen en el entorno de Facebook, y conocen como realizar configuraciones que aseguran su privacidad y seguridad.

\subsubsection{Aportes complementarios del proceso}

Al hacer un análisis minucioso de los resultados intermedios que se van obteniendo en la tercera y cuarta etapas del proceso propuesto, es posible extraer otros aportes que complementan el conocimiento sobre nivel de conciencia sobre privacidad y seguridad, entre los que se pueden citar:

1) Los resultados obtenidos con la entrevista estructurada respecto a la comparación del nivel real de conciencia sobre privacidad y seguridad de un usuario de Facebook con el nivel hipotético de conciencia supuesto por él mismo, se muestra en la Fig. 63.

El nivel hipotético de conciencia se obtuvo de la entrevista estructurada, cuando el entrevistado respondió la pregunta: ¿Cómo calificaría su nivel de conocimientos sobre seguridad y privacidad en la red social Facebook?, la cual tenía como opciones de respuesta: Avanzado, Medio, Básico y Ninguno. 


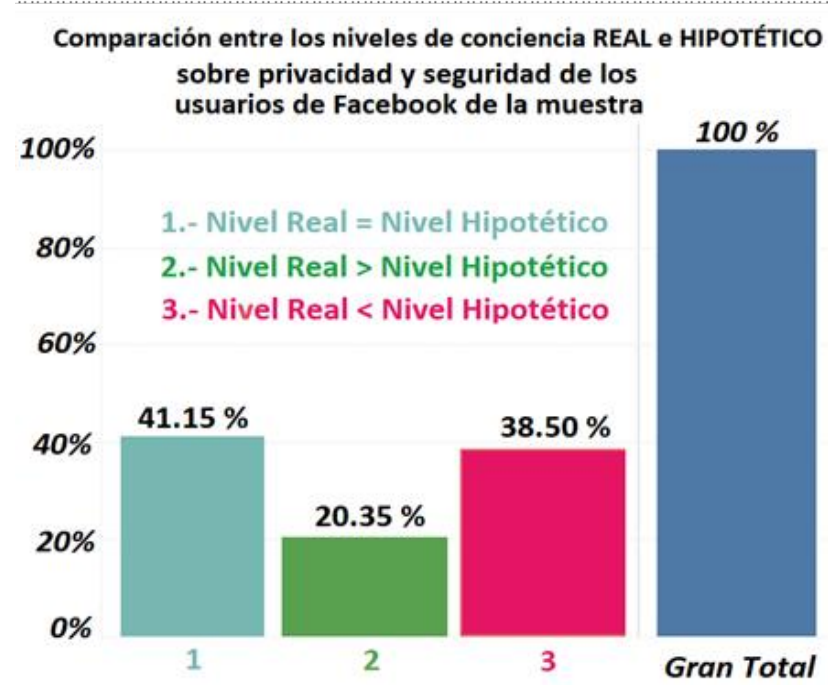

Fig. 63. Resultados obtenidos de la muestra al comparar los niveles de conciencia real e hipotético

Partiendo de los resultados anteriores, se puede afirmar que en la realidad se puede situar a la persona usuaria de Facebook en una de las dos alternativas siguientes, con respecto a su nivel real de conciencia sobre privacidad y seguridad en la red social:

A) Hace una apreciación correcta, nivel de conciencia hipotético = nivel de conciencia real, cualquiera que haya sido el nivel supuesto (avanzado, intermedio, básico, o ninguno);

B) Hace una apreciación incorrecta, con dos posibles opciones:

a) que el usuario se subestime (nivel de conciencia hipotético < nivel de conciencia real),

b) que el usuario se sobrestime (nivel de conciencia hipotético $>$ nivel de conciencia real), con posibles consecuencias negativas sobre la exposición al riesgo.

Este análisis se ha concretado en un ideograma, Fig. 64, que facilita la ubicación del usuario en este contexto y la comprensión de su situación.

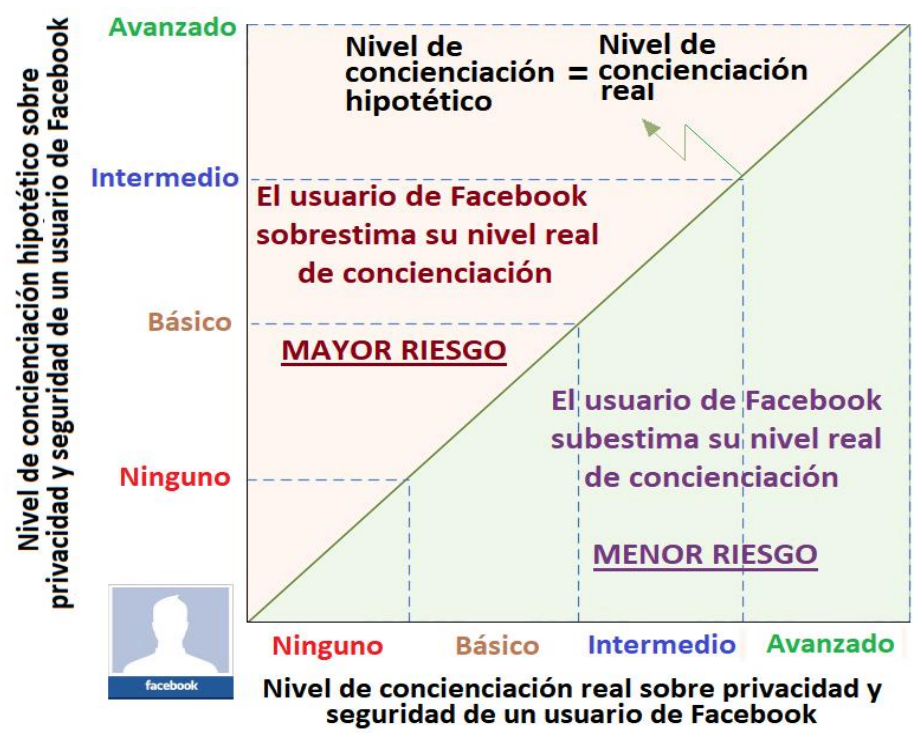

Fig. 64. Posibles ubicaciones para el usuario de Facebook resultantes de la comparación del nivel real de conciencia con su nivel hipotético 
2) Los resultados extraídos de la muestra con relación a nivel de riesgo debido a comportamientos Psicosociales, y nivel de cultura de seguridad se presentan en la Fig. 65(a) y en la Fig. 65(b). Se observa que los comportamientos psicosociales de los usuarios de Facebook no son compatibles con su nivel de cultura de seguridad y privacidad en línea. Mientras, por un lado, la mayoría de miembros de los distintos grupos etarios tienen comportamientos psicosociales medianamente seguros (nivel de riesgo moderado), o seguros (nivel de riesgo bajo); por otro lado, el nivel de cultura de seguridad y privacidad de la mayoría de usuarios es precario: bajo o ninguno.

Este resultado complementario ayudaría a orientar acciones de mejoramiento para cada grupo de usuario particular, para fortalecer sus comportamientos psicosociales y/o su cultura de seguridad.

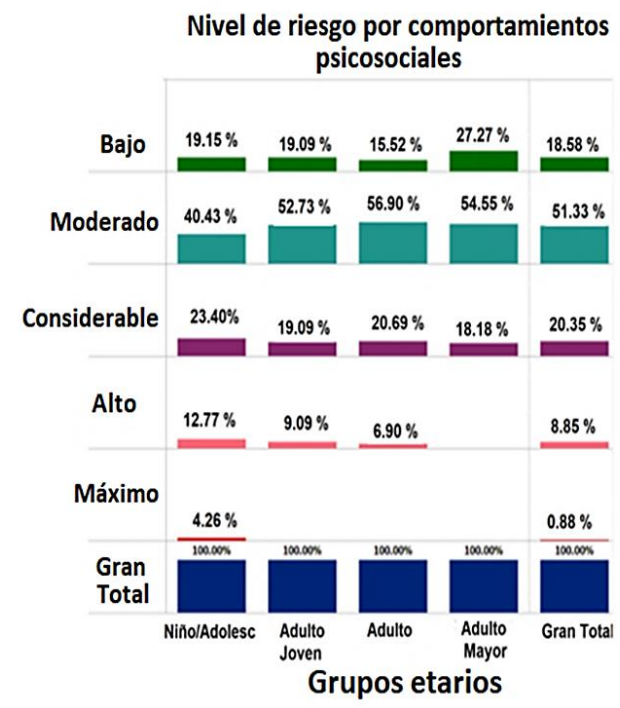

(a)

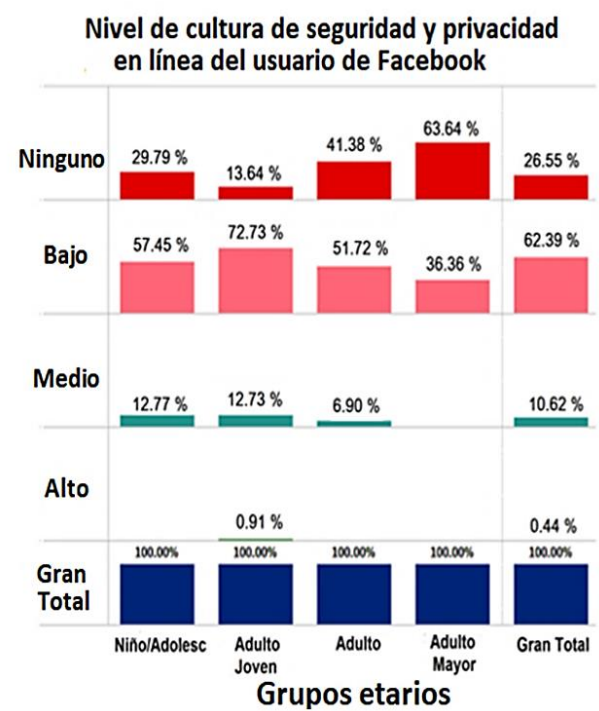

(b)

Fig. 65 (a) Nivel de riesgo debido a comportamientos Psicosociales. (b) Nivel de cultura de seguridad.

A partir de los resultados anteriores, se diseñó el mapa de caracterización de un usuario de Facebook, con relación a los factores determinantes del grado de conciencia sobre privacidad y seguridad, Fig. 66. Al usuario de Facebook se lo posiciona de conformidad con la realidad en que desempeña sus interacciones virtuales a través de la red social; demostrando compatibilidad o incompatibilidad entre la forma natural, personal, y particular de actuar al establecer sus relaciones interpersonales reales y virtuales (comportamientos psicosociales), y su nivel de cultura de seguridad y privacidad en línea.

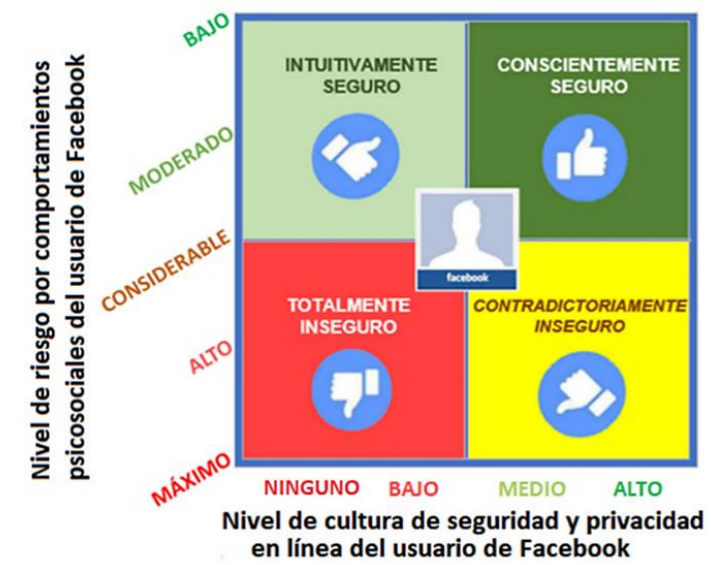

Fig. 66. Mapa de caracterización del Usuario de Facebook. 
3) Se pueden llegar a identificar con precisión los temas específicos en los que el usuario de Facebook debe desarrollar esfuerzos de fortalecimiento, dentro de cada uno de los factores determinantes. En la Tabla 41 se ejemplifican temas específicos para reforzamiento que se han obtenido de los distintos resultados alcanzados con el progreso del proceso propuesto.

Tabla 41. Temas específicos, que según los resultados deberían reforzarse

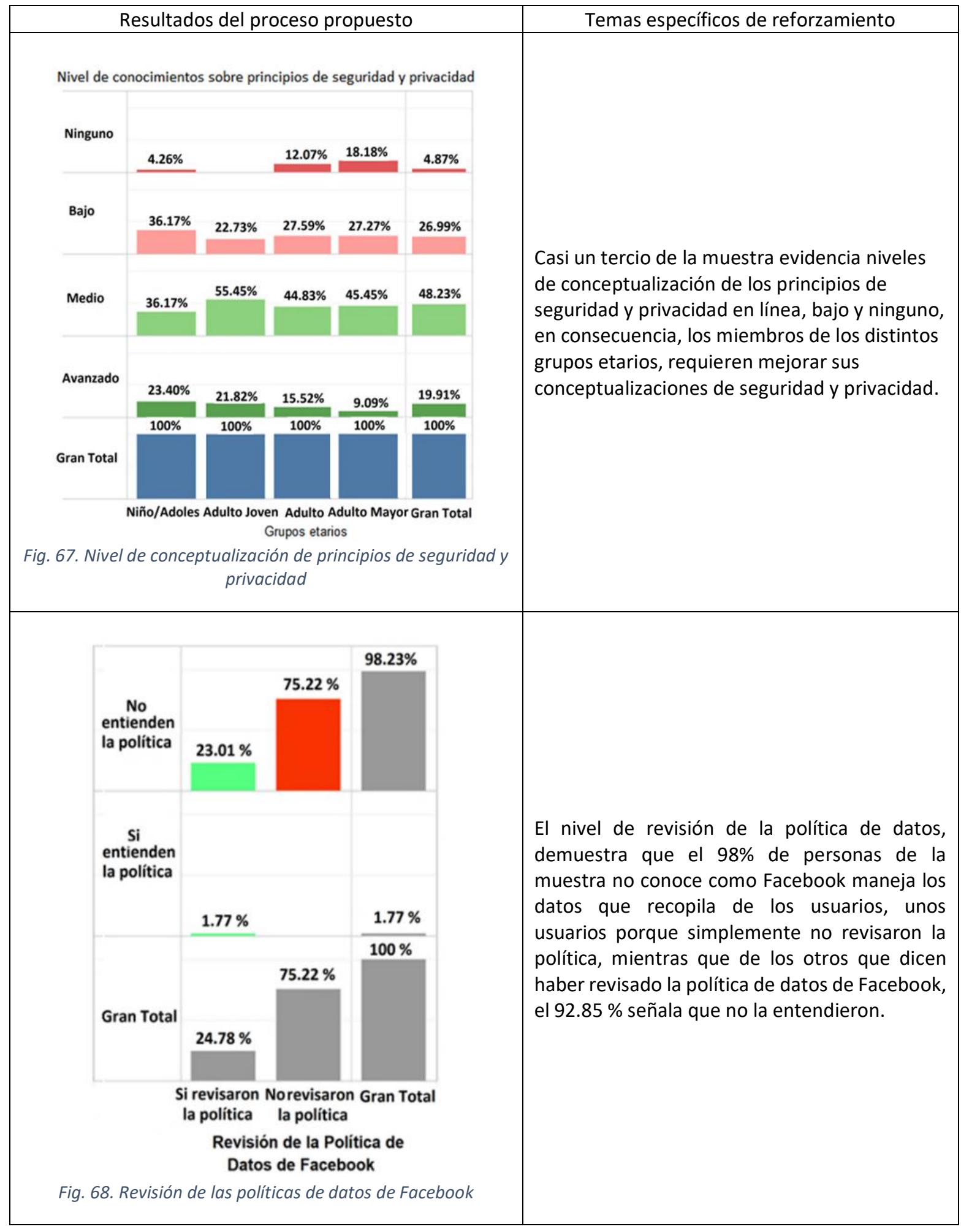




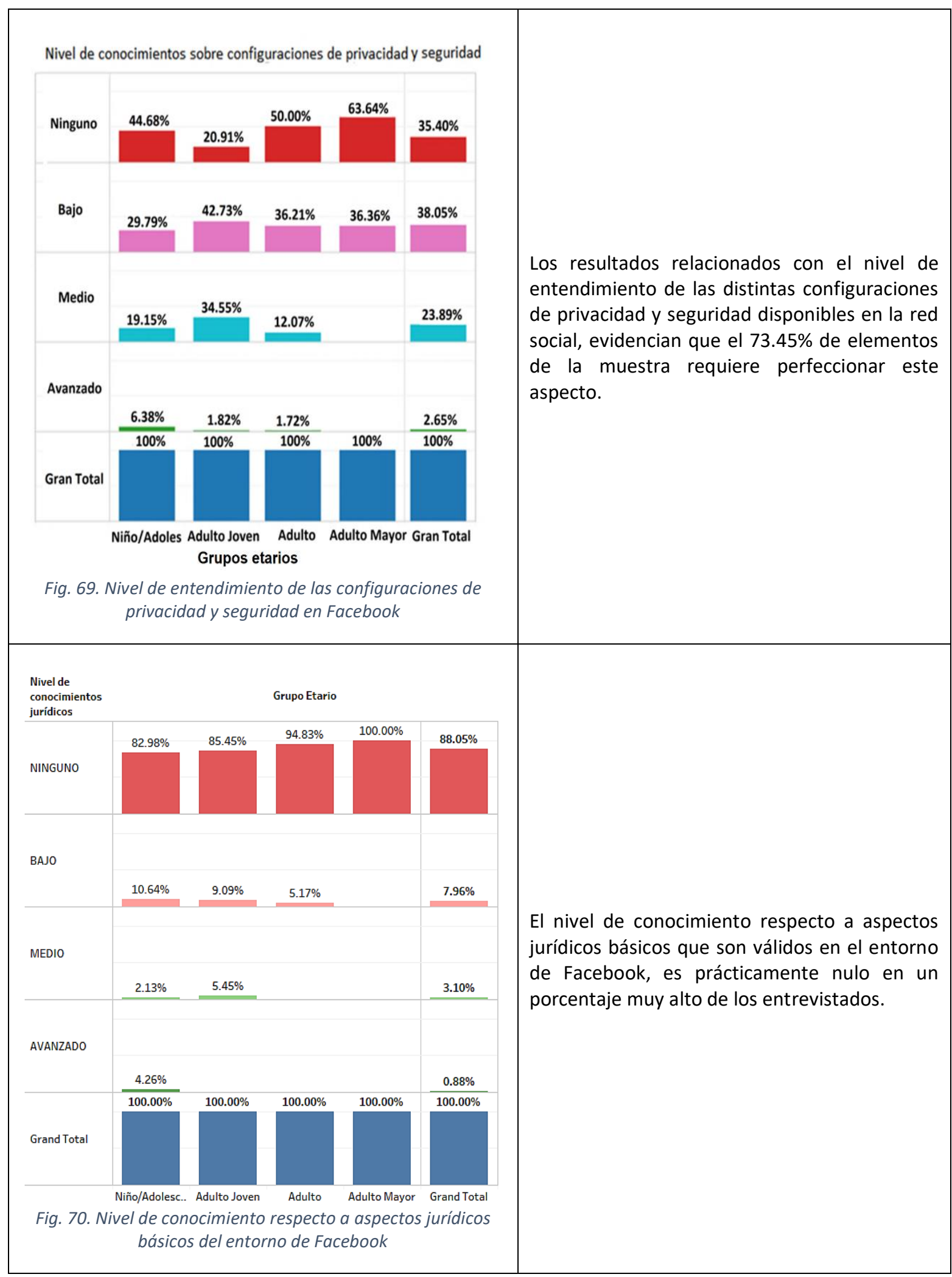

\subsubsection{Marco de referencia para conformar un entorno seguro en Facebook}

Habiéndose evidenciado la validez del proceso para estimar el nivel real de conciencia sobre privacidad y seguridad de un usuario de Facebook, y en consecuencia, también los factores 
determinantes del grado de conciencia sobre privacidad y seguridad en Facebook, se propone un marco de referencia para conformar en Facebook, un entorno seguro de interacción social virtual que apoye la inclusión familiar y social del AM, Tabla 42.

Tabla 42. Marco de referencia para conformar en Facebook, un entorno seguro de interacción social virtual que apoye la inclusión familiar y social del AM

Marco de referencia

\begin{tabular}{|c|c|c|c|c|c|}
\hline & ¿Para qué? & ¿Qué? & ¿Cómo? & $\begin{array}{l}\text { ¿A quién o a } \\
\text { qué se aplica? }\end{array}$ & $\begin{array}{c}\text { ¿Cuál es una buena } \\
\text { práctica de seguridad? }\end{array}$ \\
\hline \multirow[t]{2}{*}{1.} & \multirow{2}{*}{$\begin{array}{l}\text { Mantener la } \\
\text { confidencialidad de los } \\
\text { datos personales } \\
\text { (datos sensibles) del } \\
\text { AM. }\end{array}$} & $\begin{array}{l}\text { Ubicación, } \\
\text { datos de tarjetas de } \\
\text { crédito, } \\
\text { datos de identidad, } \\
\text { datos familiares, } \\
\text { datos de salud. }\end{array}$ & $\begin{array}{l}\text { Nunca publicar datos sensibles } \\
\text { 1. No publicar las actividades } \\
\text { actuales } \\
\text { 2. No hacer transacciones con } \\
\text { tarjetas de crédito } \\
\text { 3. No enviar o compartir copias } \\
\text { digitales de documentos de } \\
\text { identidad } \\
\text { No publicar información que } \\
\text { muestren las posesiones } \\
\text { materiales propias o de } \\
\text { familiares cercanos } \\
\text { No publicar materiales que } \\
\text { identifiquen a familiares } \\
\text { menores de edad. } \\
\text { No haga publicaciones de } \\
\text { aspectos de su vida personal }\end{array}$ & $\begin{array}{ll}\text { 1. } & \text { AM } \\
\text { 2. } & \text { Familiares y } \\
& \text { amigos del AM. }\end{array}$ & $\begin{array}{l}\text { Coordinar con familiares y amigos } \\
\text { el tipo de información que se } \\
\text { debe publicar a través de la red } \\
\text { social. }\end{array}$ \\
\hline & & $\begin{array}{l}\text { Aplicaciones y } \\
\text { servicios de terceros. }\end{array}$ & $\begin{array}{l}\text { 1. Revise periódicamente en la } \\
\text { sección de configuración de } \\
\text { aplicaciones en el perfil de } \\
\text { Facebook, los servicios o } \\
\text { aplicaciones de terceros que } \\
\text { tienen acceso a los datos de } \\
\text { su perfil. Desde esa pantalla } \\
\text { también puede eliminar o } \\
\text { restringir la aplicación. } \\
\text { Verifique si el servicio o la } \\
\text { aplicación de terceros, le } \\
\text { sirven para alguno de los } \\
\text { objetivos por los que es } \\
\text { usuario de la red social. }\end{array}$ & AM & $\begin{array}{l}\text { 1. No apruebe el acceso de } \\
\text { una aplicación al perfil de la } \\
\text { red social, porque estaría } \\
\text { dejando constancia que } \\
\text { entregó sus datos de forma } \\
\text { consciente, salvaguardando } \\
\text { los intereses legales de los } \\
\text { diseñadores de la aplicación } \\
\text { (Caso Cambridge Analytic). } \\
\text { 2. Analice si la aplicación o el } \\
\text { servicio de terceros le } \\
\text { aporta hacia sus objetivos } \\
\text { de uso de la red social } \\
\text { Facebook. }\end{array}$ \\
\hline \multirow[t]{2}{*}{2.} & \multirow[t]{2}{*}{$\begin{array}{l}\text { Ampliar la red } \\
\text { egocéntrica del AM } \\
\text { con contactos } \\
\text { confiables. }\end{array}$} & $\begin{array}{l}\text { Solicitud de amistad } \\
\text { recibida. }\end{array}$ & $\begin{array}{l}\text { 1. No acepte de inmediato el pedido. } \\
\text { 2. } \\
\text { Si la solicitud es de una persona } \\
\text { conocida, realice una verificación } \\
\text { básica del solicitante para } \\
\text { asegurarse que realmente } \\
\text { proviene de quien dice provenir. } \\
\text { 3. la solicitud proviene de una } \\
\text { persona desconocida, o ante } \\
\text { cualquier duda sobre la persona } \\
\text { conocida, real izar un análisis } \\
\text { exhaustivo. } \\
\text { 4. con el análisis exhaustivo, } \\
\text { persiste alguna duda, NO acepte } \\
\text { el pedido. }\end{array}$ & $\begin{array}{l}\text { A solicitudes de } \\
\text { amistad de personas } \\
\text { conocidas y } \\
\text { desconocidas. }\end{array}$ & $\begin{array}{l}\text { Siempre realizar un análisis } \\
\text { exhaustivo, independientemente } \\
\text { de si la solicitud proviene de un } \\
\text { conocido o desconocido. }\end{array}$ \\
\hline & & $\begin{array}{l}\text { Búsqueda de } \\
\text { conexión con } \\
\text { personas famosas, } \\
\text { políticos. }\end{array}$ & $\begin{array}{l}\text { 1. No manifieste en la red social su } \\
\text { interés por ser contacto de } \\
\text { personas famosas, ese interés } \\
\text { puede ser aprovechado por } \\
\text { personas que pueden crear un } \\
\text { perfil falso de algún famoso para } \\
\text { perjudicarlo }\end{array}$ & AM & $\begin{array}{l}\text { Incorporar a la lista de contactos } \\
\text { en Facebook únicamente a } \\
\text { personas que usted conoce } \\
\text { personalmente y que confíe en } \\
\text { ellas. }\end{array}$ \\
\hline 3. & $\begin{array}{l}\text { Evitar fraude } \\
\text { económico. }\end{array}$ & $\begin{array}{l}\text { Ofrecimiento de } \\
\text { dinero y premios por } \\
\text { parte de extraños. }\end{array}$ & $\begin{array}{l}\text { 1. No confíe en ofrecimientos } \\
\text { de extraños }\end{array}$ & $\mathrm{AM}$ & $\begin{array}{l}\text { Mantenga en mente que nadie } \\
\text { entrega algo por la red social } \\
\text { Facebook de forma gratuita. } \mathrm{Si} \\
\text { aparentemente ese es el caso, } \\
\text { significa que esa persona va tras } \\
\text { de sus datos y los valores que } \\
\text { posee. }\end{array}$ \\
\hline
\end{tabular}




\section{Marco de referencia}

\begin{tabular}{|c|c|c|c|c|c|}
\hline & ¿Para qué? & ¿Qué? & ¿Cómo? & $\begin{array}{l}\text { ¿A quién o a } \\
\text { qué se aplica? }\end{array}$ & $\begin{array}{c}\text { ¿Cuál es una buena } \\
\text { práctica de seguridad? }\end{array}$ \\
\hline 4. & $\begin{array}{l}\text { Mantener la privacidad } \\
\text { del AM. }\end{array}$ & $\begin{array}{l}\text { Publicaciones, } \\
\text { comentarios, } \\
\text { recursos } \\
\text { compartidos. }\end{array}$ & $\begin{array}{l}\text { 1. Modificar la configuración } \\
\text { de privacidad y seguridad } \\
\text { por defecto. } \\
\text { 2. Identificar y crear los grupos } \\
\text { de contactos de su red } \\
\text { social. } \\
\text { 3. Cada vez que realice una } \\
\text { publicación, seleccione los } \\
\text { grupos hacia donde se } \\
\text { difunden. }\end{array}$ & $\mathrm{AM}$ & $\begin{array}{l}\text { 1. Nunca utilizar la } \\
\text { configuración original por } \\
\text { defecto. }\end{array}$ \\
\hline 5. & $\begin{array}{l}\text { Brindar/recibir Apoyo } \\
\text { social. }\end{array}$ & $\begin{array}{l}\text { Mensajes de } \\
\text { personas haciendo } \\
\text { alusión a problemas } \\
\text { personales de } \\
\text { diferente índole que } \\
\text { requieren la ayuda } \\
\text { de otro usuario de } \\
\text { Facebook. }\end{array}$ & $\begin{array}{l}\text { 1. Si es una persona que le } \\
\text { interesa, póngaseen contacto } \\
\text { directo y brinde/reciba su } \\
\text { apoyo social. } \\
\text { 2. lo haga por Facebook, si lo } \\
\text { hace por la red social corre el } \\
\text { riesgo de dar a conocer la } \\
\text { vulnerabilidad emocional que } \\
\text { tiene, de la cual se pueden } \\
\text { aprovechar otras personas }\end{array}$ & $\begin{array}{l}\text { Al AM y los } \\
\text { miembros de su red } \\
\text { egocéntrica }\end{array}$ & $\begin{array}{l}\text { 1. Nunca difundir } \\
\text { problemas personales } \\
\text { propios o de otras } \\
\text { personas. } \\
\text { 2. No aceptar la ayuda de } \\
\text { personas desconocidas. }\end{array}$ \\
\hline 6. & $\begin{array}{l}\text { Evitar la tecno- } \\
\text { adicción. }\end{array}$ & $\begin{array}{l}\text { Alejamiento de los } \\
\text { contactos físicos } \\
\text { reales con familiares } \\
\text { y amigos debido al } \\
\text { uso de la red social. }\end{array}$ & $\begin{array}{l}\text { 1. Esté atento a los comentarios } \\
\text { de sus familiares y amigos } \\
\text { sobre su alejamiento de } \\
\text { actividades en vivo } \\
\text { 2. Póngase en contacto directo } \\
\text { con los contactos cercanos, por } \\
\text { otros medios que no sea la red } \\
\text { social. } \\
\text { Si siente que no le es posible } \\
\text { controlar su ansiedad de usar } \\
\text { Facebook, solicite ayuda } \\
\text { especializada }\end{array}$ & $\begin{array}{l}\text { Al AM y los } \\
\text { miembros de su red } \\
\text { egocéntrica }\end{array}$ & $\begin{array}{l}\text { 1. Tomar en cuenta que la única } \\
\text { conexión social con presencia } \\
\text { social absoluta es la } \\
\text { comunicación física cara a } \\
\text { cara. } \\
\text { 2. Tener presente que la red } \\
\text { social complementa las } \\
\text { relaciones interpersonales en } \\
\text { vivo, con los contactos } \\
\text { geográficamente cercanos, no } \\
\text { las sustituye. } \\
\text { Con contactos } \\
\text { geográficamente distantes, } \\
\text { Facebook es una alternativa } \\
\text { para mantener conexión social } \\
\text { con alta presencia social. }\end{array}$ \\
\hline \multirow[t]{2}{*}{7.} & \multirow{2}{*}{$\begin{array}{l}\text { Para mejorar el } \\
\text { nivel de cultura } \\
\text { de seguridad. }\end{array}$} & $\begin{array}{l}\text { Política de Facebook } \\
\text { sobre seguridad y } \\
\text { privacidad de datos; } \\
\text { y, sus } \\
\text { actualizaciones. }\end{array}$ & $\begin{array}{l}\text { 1. Asigne parte de su tiempo a } \\
\text { revisar y comprender las } \\
\text { políticas de seguridad y } \\
\text { privacidad de datos de } \\
\text { Facebook } \\
\text { 2. Analice los cambios } \\
\text { incluidos en las } \\
\text { actualizaciones de las } \\
\text { políticas de seguridad y } \\
\text { privacidad de datos que } \\
\text { publica Facebook. }\end{array}$ & AM & $\begin{array}{l}\text { Siempre dar una aceptación } \\
\text { informada de las políticas de } \\
\text { datos de Facebook y sus } \\
\text { actualizaciones. Si bien no podrá } \\
\text { modificarlas, estará al tanto de lo } \\
\text { necesario para establecer } \\
\text { restricciones mentales o por } \\
\text { configuración, a lo que comparte } \\
\text { por la red social. }\end{array}$ \\
\hline & & $\begin{array}{l}\text { Conciencia del } \\
\text { ámbito de } \\
\text { aplicación de } \\
\text { los términos } \\
\text { seguridad y } \\
\text { privacidad con } \\
\text { relación a las } \\
\text { TIC. }\end{array}$ & $\begin{array}{l}\text { Resignificar los términos } \\
\text { seguridad y privacidad, } \\
\text { para dotarles de las } \\
\text { amplias connotaciones } \\
\text { que tienen para los datos } \\
\text { personales entregados en } \\
\text { línea }\end{array}$ & $\begin{array}{l}\text { Al AM y los } \\
\text { miembros de su } \\
\text { red egocéntrica }\end{array}$ & $\begin{array}{l}\text { 1. Comprender que la concepción } \\
\text { de privacidad y seguridad en el } \\
\text { mundo real, difiere de la } \\
\text { concepción de privacidad y } \\
\text { seguridad en el mundo virtual, } \\
\text { basado en las TIC para } \\
\text { recolectar, procesar y analizar } \\
\text { información. } \\
\text { Tener presente los principios de } \\
\text { privacidad en linea: } \\
\text { a. Derecho de control } \\
\text { efectivo de datos } \\
\text { personales, esto es: } \\
\text { derecho al acceso, } \\
\text { corrección, actualización y } \\
\text { eliminación total. (OECD, } \\
\text { 2011) } \\
\text { Derecho de las personas a } \\
\text { determinar cuándo, cómo } \\
\text { yen qué medida la } \\
\text { información sobre ellas se } \\
\text { comunica a otros. } \\
\text { (UNESCO, 2012) }\end{array}$ \\
\hline
\end{tabular}




\subsubsection{Conclusiones}

Es posible afirmar que el proceso propuesto para estimar el nivel real de conciencia sobre privacidad y seguridad de un usuario de Facebook, provee datos válidos que reflejan con fidelidad la realidad.

El proceso planteado, es muy rico en datos complementarios que, interpretados correctamente, y combinados con el modelo conceptual interdisciplinario de las causas de los ciber-riesgos en el entorno de Facebook, ayudarían a plantear alternativas tendientes a mejorar los comportamientos psicosociales y la cultura de privacidad y seguridad del usuario de Facebook.

Así. por ejemplo, se concluye que el proveedor de la plataforma de la red social Facebook también puede impulsar el mejoramiento de la cultura de seguridad y privacidad de los usuarios, realizando ciertos ajustes en instancias de la interface de usuario, relacionadas con:

1) La creación de cuentas, de tal forma que un usuario sea registrado y dado de alta, solamente después de:

A) evidenciar la revisión y la comprensión de la política de datos de Facebook, por ejemplo, respondiendo un sencillo cuestionario; $y$,

B) la ejecución de una configuración básica de su privacidad.

2) La alerta de actualizaciones a las políticas de datos, para que el usuario acceda al servicio, posteriormente a una actualización de la política, solamente después de evidenciar la revisión de las modificaciones informadas.

3) Y, la presentación de la política de datos, para que el usuario cuente con las opciones necesarias para aceptar/autorizar las partes de la política con las que está de acuerdo, y rechazar las que se opongan a sus convicciones.

Para futuros estudios, es necesario incorporar en el modelo conceptual interdisciplinario de las causas de los ciber-riesgos para usuarios de Facebook, como parte del nivel de cultura de seguridad y privacidad, una vulnerabilidad adicional atribuible a los usuarios de Facebook: la tendencia de las personas a sobreestimar su nivel de conciencia sobre privacidad y seguridad en la red social.

\subsubsection{Publicación derivada de la investigación}

Tabla 43. Publicación relacionada con la investigación No.4

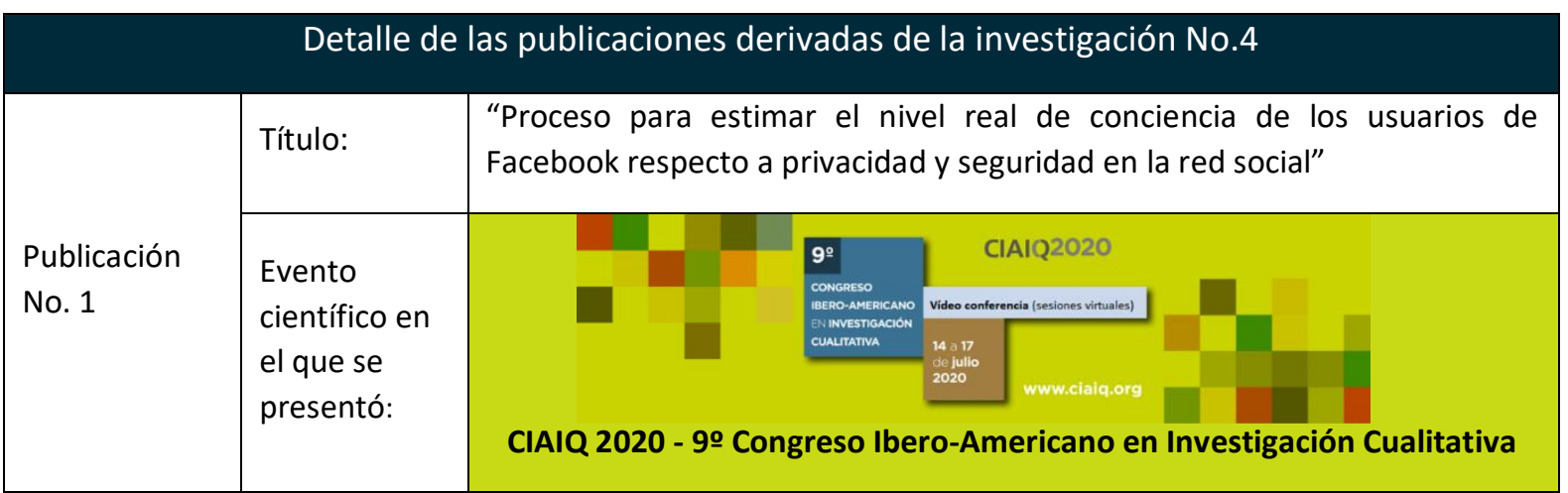




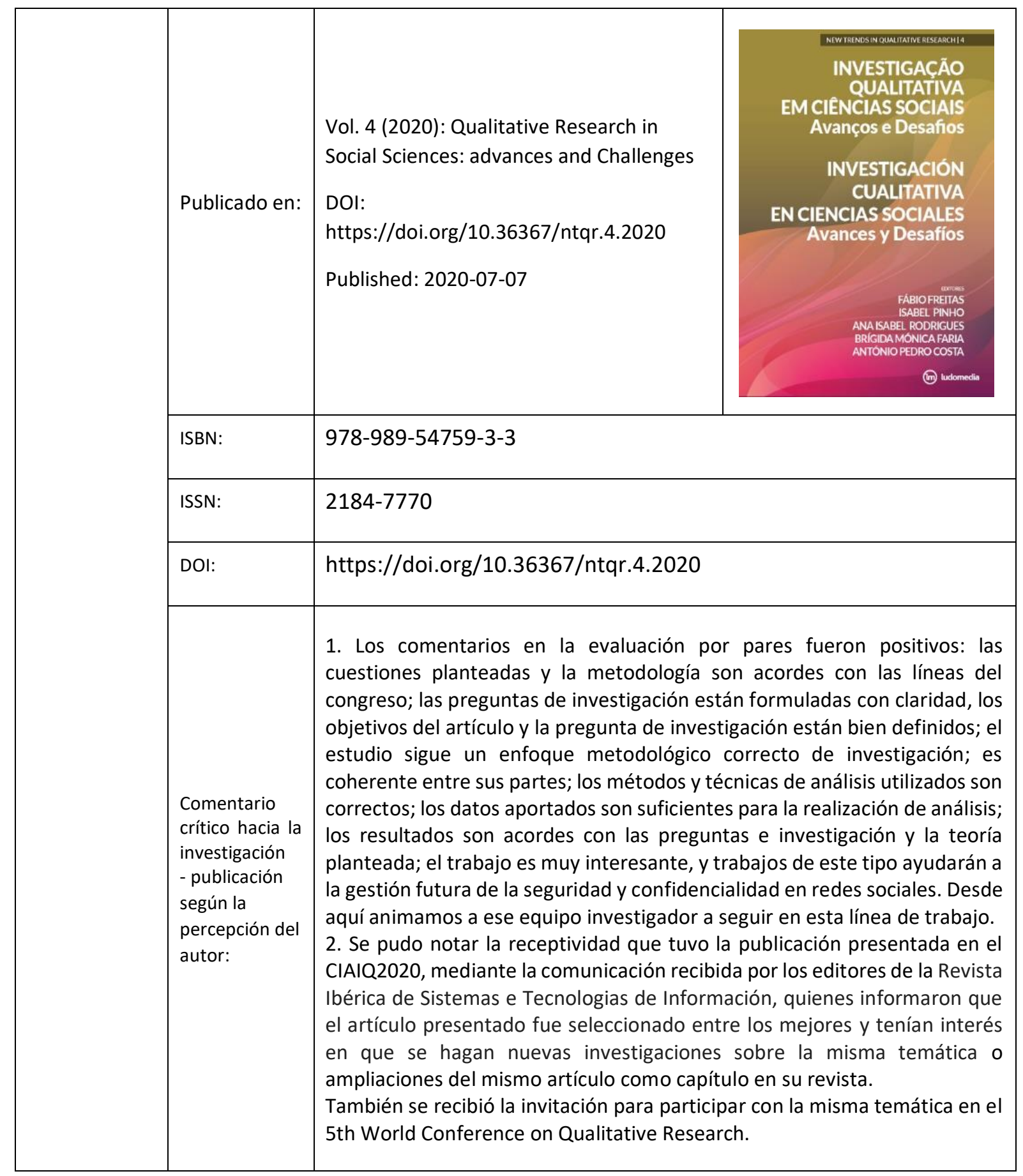




\section{CAPÍTULO 6 - CONCLUSIONES Y TRABAJO FUTURO}

\subsection{CONCLUSIONES}

1. La investigación enfocada en la tesis doctoral, perteneciente al área de computación social, transitó por todas las etapas necesarias para llegar a generar aportes al conocimiento sobre el tema de la red social Facebook como entorno seguro de comunicación para inclusión familiar y social del AM. Estas etapas son:

a) La identificación del marco teórico, con el que se recurrió a los elementos teóricos existentes para la fundamentación filosófica de la investigación, la conceptualización de los objetos de estudio: el AM, la red social Facebook y la calidad de vida del AM; la comprensión de los diferentes factores que influyen en la aceptación de tecnología y de los modelos existentes para la aceptación, uso y apropiación social de la tecnología, con los que se concretó uno de los aportes de la tesis.

b) La selección de la metodología compatible con los objetivos de la investigación y la identificación de las técnicas e instrumentos que mejor se adaptan para la interpretación de la realidad en estudio. Se determinó la necesidad de ejecutar una investigación cualitativa, complementada con investigación cuantitativa para entender el uso de Facebook por parte del AM, el impacto en las dimensiones de su calidad de vida, y las causas de los ciber-riesgos que rodean al usuario de la red social.

c) La identificación del estado del arte del AM frente a la red social Facebook, que se desarrolló desde la brecha digital concebida desde una perspectiva evolutiva hacia la apropiación de tecnología.

El estado del arte demostró la existencia de grandes beneficios del uso de Facebook en varias dimensiones de la calidad de vida del AM, y también dejó claro que es necesario tomar en cuenta las características funcionales del AM para el desarrollo de tecnología apropiada para el uso de los miembros de este segmento poblacional, que necesita apoyarse en la tecnología para superar sus limitaciones o las condiciones particulares de su vida.

d) El proceso de investigación propiamente dicho, que abarca investigación documental e investigación de campo; con análisis de datos orientados por el método de codificación de la Teoría Fundamentada, apoyados por la hermenéutica; así como también con análisis de datos cuantitativos aplicados a datos cualitativos cuantificados de los datos obtenidos con las encuestas estructuradas.

Esta etapa culmina con la difusión de los resultados y su análisis, mediante artículos presentados en eventos científicos como congresos mundiales e iberoamericanos, con los cuales se demuestra la vigencia, el interés y la novedad de la temática investigada y de los hallazgos realizados.

2. Los aportes que fueron generados en este estudio se sintetizan a continuación: 
1. El modelo de sensibilización del AM hacia el uso y la apropiación de tecnología, con el cual se plasmó el estado del arte en esta tesis. Este modelo pretende desarrollar en una persona la motivación mental y emocional para el uso de la tecnología, compatibilizando la realidad particular de la persona con los beneficios que se acreditan formalmente a la tecnología en cuestión. Posteriormente, habiendo superado la falta de motivación inicial, el modelo pretende que el potencial usuario de la tecnología conozca detalles necesarios para el acceso físico a la tecnología, es decir los equipos requeridos, las interconexiones de telecomunicaciones necesarias, sus costos de adquisición o el valor mensual a pagar por servicios de comunicaciones. Finalmente, el modelo contempla el acceso a la alfabetización digital, que se debe entender como la motivación hacia la adquisición de los conocimientos, habilidades y destrezas que se requieren para el manejo de la tecnología, y las posibilidades de adquirirlos por capacitación formal o con ayuda de confianza.

2. El proceso evolutivo de apropiación de tecnología, que se teorizó para describir las etapas lógicas que le correspondería transitar secuencialmente a una persona que teniendo una motivación desea llegar a utilizar creativamente la tecnología para alcanzar beneficios trascendentes para su vida.

3. El modelo integral de apropiación de tecnología por el AM (MIAT-AM), que fue estructurado con la integración de los dos anteriores, para describir el avance de una persona que requiere evolucionar desde la ausencia de una motivación hasta la apropiación social de la tecnología.

4. El decálogo para moldear una actitud positiva del AM hacia el uso de la red social Facebook, que surgió de la comprensión del estado del arte del AM frente a Facebook. fue desarrollado como una vía para motivar al AM a volver sus ojos hacia la tecnología de Facebook como una alternativa viable para alcanzar beneficios para su calidad de vida.

5. Modelo conceptual de las causas de los ciber-riesgos en el entorno de Facebook, que muestra claramente la naturaleza interdisciplinaria de los orígenes de los ciber-riesgos; y en el que se pueden identificar claramente las causas técnicas, tanto del ámbito de las ciencias informáticas como de las ciencias jurídicas; causas que están fuera del control del usuario de la red social Facebook. Y se observan con facilidad las causas atribuibles a los usuarios, organizadas en dos grupos: los comportamientos psicosociales; y, la cultura de seguridad y privacidad.

Estas últimas causas son las que se desarrollaron en las investigaciones finales, que con el control apropiado, pueden crear en la mente del usuario AM, la percepción de Facebook como entorno seguro de comunicación e interacción para su inclusión familiar y social; es decir un ambiente donde los ciber-riesgos si bien existen, se encuentran controlados por el usuario, a través de comportamientos psicosociales seguros; $y$, uso informado y configurado de las características de privacidad y seguridad a la medida de los objetivos que se pretendan alcanzar con la apropiación social de la tecnología de Facebook.

6. Los factores determinantes del grado de conciencia sobre privacidad y seguridad: nivel de cultura de seguridad y privacidad; $y$, nivel de riesgo generado por comportamientos psicosociales, con sus características significativas y grupos de atributos que, con un conjunto de fases sucesivas de cuantificación, fundamentaron el proceso para estimar el nivel real de conciencia de usuarios de Facebook sobre privacidad y seguridad. 
7. El proceso de estimación del nivel real de conciencia de usuarios de Facebook respecto a privacidad y seguridad en la red social, que entrega valores válidos que reflejan la realidad del usuario de Facebook con fidelidad, solamente si la entrevista estructurada No. 3, planteada en esta investigación, es respondida por el usuario de Facebook, de una manera consciente y transparente.

Este proceso resulta importante, porque no solamente estima el nivel real de conciencia, sino que arroja interesantes resultados complementarios en las etapas intermedias, que clarifican situaciones extras del usuario de Facebook, como:

- la situación de riesgo resultante de la ubicación de la persona en el plano de comparación del nivel real de conciencia con su nivel hipotético. Por la ubicación, se puede identificar otra causa adicional a la exposición a los ciber-riesgos, como la ocasionada cuando el usuario de Facebook sobreestima su nivel de conciencia, creándole una falsa confianza de lo que conoce y de su comportamiento en la red social;

- el posicionamiento dentro del mapa de caracterización del usuario de Facebook, el cual le informa gráficamente donde están sus mayores debilidades respecto a los dos factores determinantes antes citados, conocimiento que le ayudaría a la persona a buscar mejorar, de una manera más direccionada, en los ámbitos de su deficiencia;

- como complemento del punto anterior, se pueden identificar con precisión los temas específicos en los que el usuario de Facebook debe desarrollar esfuerzos de fortalecimiento, dentro de cada uno de los factores determinantes, analizando su nivel en los distintos ámbitos como: conocimientos sobre principios de seguridad y privacidad; conocimientos sobre el contenido y significado de las políticas de seguridad y de datos de Facebook; nivel de conocimientos sobre configuraciones de seguridad y privacidad; nivel de conocimientos de aspectos jurídicos básicos relacionados al entorno de Facebook.

Es importante señalar, que la realización de la encuesta No. 3 por parte del usuario de Facebook que desea conocer sus niveles particulares de cultura de seguridad y privacidad y de riesgos por comportamientos psicosociales, le aporta a la persona, con la presentación de temas que a lo mejor le resultaban desconocidos en el ámbito de la red social, lo que le conduciría ya a un mejoramiento de su conocimiento general al que tenía antes de iniciar la encuesta.

8. La propuesta de marco de referencia para conformar en Facebook, un entorno seguro de interacción social virtual que apoye la inclusión familiar y social del AM, propone un conjunto de conceptos, prácticas y criterios para reducir la exposición del usuario AM de Facebook a los ciber-riesgos del entorno de la red social, su aplicación frecuente mejorará los comportamientos psicosociales, y la cultura de seguridad y privacidad del usuario de Facebook.

3. Es pertinente afirmar que la red social Facebook, es una alternativa tecnológica para comunicación e interacción virtual que puede apoyar la inclusión familiar y social del AM, que también tiene repercusiones positivas en otras dimensiones de su calidad de vida.

Frente a todos esos potenciales beneficios para el AM, debería impulsarse su uso entre los miembros del segmento poblacional mayor a 65 años, mediante políticas públicas que favorezcan la reducción de la brecha digital en el acceso físico y en el acceso a la alfabetización digital; a través 
de la reducción de la carga impositiva a las empresas y organizaciones dedicadas a suministrar tecnología, o a proveer el acceso a Internet, o a brindar capacitación integral en la tecnología de red social Facebook, que opten por establecer planes especiales dirigidos a AM.

4. Facebook, como toda tecnología soportada en Internet, constituye un entorno con riesgos para sus usuarios, sin embargo, se puede convertir en un entorno seguro a través de esfuerzos que deberían venir desde distintas direcciones:

a) De la técnica informática, reduciendo la cantidad de datos que recopilan, la diversidad de dispositivos desde donde se recogen los datos, el tiempo de duración de esos datos en la plataforma, garantizando los derechos a la privacidad del usuario y sus datos personales, facultando al usuario para no tener que aceptar todas las condiciones contenidas en las políticas de seguridad; facilitando las configuraciones de privacidad y seguridad; no dejando una configuración por defecto tan abierta, sino que se vaya ajustando paulatinamente a la versatilidad en el uso que la persona quiere hacer con Facebook.

b) De la jurídica creando leyes que protejan los datos personales sensibles de los usuarios AM; que responsabilicen en el país de origen del usuario, a los propietarios de la plataforma de Facebook sobre la custodia de los datos que recopilan; con la creación de estudios jurídicos en las Facultades de Derecho de las universidades estatales, o en entidades gubernamentales, como por ejemplo, el Ministerio de Telecomunicaciones en el Ecuador; que asistan a los usuarios de Facebook sobre violaciones a la privacidad, o mal uso de sus datos y sus consecuencias.

c) Del propio usuario, inicialmente concienciándose del estado real de sus comportamientos psicosociales, de su nivel de conocimientos y de su cultura de privacidad y seguridad; y haciendo los esfuerzos necesarios para corregir y mejorar sus deficiencias y vulnerabilidades propias.

d) De los diversos sectores de la sociedad mundial, exponiendo a las personas, en términos sencillos, la realidad de la economía desarrollada alrededor de los datos personales de los usuarios de los servicios "gratuitos" de comunicación, como son las redes sociales y la mensajería instantánea.

En este sentido se pueden señalar los siguientes ejemplos:

1) El importante aporte que Apple realizó en los últimos días del año 2020, hacia el desarrollo de la concienciación sobre privacidad de los usuarios de los servicios de comunicación, a través del lanzamiento, en la App Store, de las etiquetas de privacidad.

Estas etiquetas de privacidad proporcionan las prácticas de datos de los productos de comunicaciones de Facebook y otras aplicaciones emergentes; haciendo que sean fácilmente visibles para todos, y evitando que permanezcan sumergidas en la letra pequeña de la política de privacidad del producto.

Estas etiquetas de privacidad facilitan la realización de estudios comparativos, que brindan interesantes conclusiones. Un ejemplo de este tipo de estudio es el publicado en (Doffman, 2021), en el cual se expone la forma en que Facebook Messenger invade la privacidad de sus usuarios y porque es más peligroso que WhatsApp. Del análisis del estudio indicado, se puede afirmar que:

i. Facebook Messenger recopila mayor cantidad de datos que WhatsApp. 
ii. Mientras WhatsApp recoge datos de sus usuarios pertenecientes a dos categorías: analítica y funcionalidad; Messenger los recoge en 5 categorías: publicidad de terceros, analítica, personalización del producto, funcionalidad, y otros propósitos.

iii. Messenger y WhatsApp mantienen una relación del número de tipos de datos recopilados, vinculados al usuario, de 14:9, es decir, Messenger colecciona un $55 \%$ más de datos, lo que le hace una aplicación más peligrosa para el usuario; encontrándose entre la variedad de campos de datos de usuario que recopila: "salud y estado físico", "información confidencial como: identificación del usuario e identificación del dispositivo, contactos y direcciones de correo electrónico, ubicación, historial de compras, información de pagos, datos de rendimiento del dispositivo", e "información financiera".

iv. Messenger, en su intento por mostrar una imagen de preocupación hacia la privacidad de sus usuarios, ha anunciado que proveerá cifrado de extremo a extremo, pero no en todas sus funcionalidades. Esto que significa que seguirá manteniendo comprometida la privacidad del usuario.

v. Otro aspecto negativo que posee Facebook Messenger y con el cual ahonda sus comportamientos invasivos hacia la privacidad de sus usuarios, aparece en (Ghoshal, 2018). En esta publicación se alerta respecto a que Facebook Messenger realiza escaneos de las conversaciones de sus usuarios, como un esfuerzo por garantizar que los usuarios sigan sus normas comunitarias, y así evitar que se propaguen mensajes que no se ajusten a sus estándares.

Estos comportamientos evidencian la débil posición del usuario frente al poder de Facebook Messenger, porque han conducido hacia acciones de censura de los mensajes que los usuarios han querido difundir, con la consecuente no difusión del material, lo que podría interpretarse como atentatorio al derecho de libertad de expresión.

2) Dando a conocer otras opciones tecnológicas, menos invasivas con la privacidad del usuario que las evidenciadas en Facebook. En este sentido, han emergido en Internet diversas alternativas tecnológicas que ofrecen servicios semejantes e incluso con mayores opciones que los ofertados a través de los productos de Facebook; que supuestamente manejan un modelo de negocio centrado en el usuario, por el que ofrecen la recolección de una cantidad mucho menor de datos de los usuarios.

Frente a estas opciones es importante advertir dos aspectos a tomar en cuenta por las personas:

i. Nadie puede garantizar, que, en el futuro, las aplicaciones emergentes que hicieron su desarrollo centrado en el usuario, asegurándole seguridad, privacidad, y funcionalidad, por necesidades económicas de sus creadores, o por los éxitos alcanzados relacionados con la penetración lograda a nivel mundial (número de usuarios, tipos de usuarios (individuales - empresariales)), o por las fuerzas del mercado; sucumban a las tentaciones de ser vendidas a grandes empresas globales, que terminen dando un giro a su modelo de negocio y se conviertan en aplicaciones demandantes de datos del usuario. 
ii. El uso y apropiación de cualquier producto de comunicación, no está supeditado únicamente a consideraciones de manejo de la privacidad del usuario, están influenciados por otros factores como popularidad del producto, facilidad de uso y funcionalidades, por lo que muchas veces, los usuarios se mantienen utilizando aplicaciones a pesar del nivel de exposición de su privacidad.

5. Por otra parte, es importante recomendar que los eventos de capacitación sobre la red social Facebook, dedicados a AM, tengan una visión amplia de contenidos, que incluyan aspectos teórico- prácticos sobre: 1) el aprovechamiento de los diferentes servicios disponibles en la red social; 2) configuraciones de seguridad y privacidad; y el 3) uso creativo de Facebook. Además, conocimientos teóricos sobre: 1) los principios de seguridad y privacidad en el entorno de Facebook, 2) de la política de datos y las actualizaciones; y, 3) comportamientos psicosociales recomendados.

Tomar en cuenta, que para que estos eventos de capacitación tengan el éxito deseado con el AM, es necesario motivarle para crear la predisposición hacia el aprendizaje, rodearle de un ambiente de confianza para superar la tecnofobia y ansiedad natural en la persona de edad avanzada que está por iniciar un proceso de aprendizaje.

6. Para finalizar, considerando que la última publicación de esta investigación, fue presentada en julio de 2020; que los resultados que se publicaron fueron con datos recopilados antes del inicio del año 2020; que en marzo de 2020 se manifiesta al mundo la existencia del nuevo coronavirus SARS-CoV-2 y su enfermedad Covid-19, con expectativas de alto riesgo para la salud de la población mundial, por lo que se establecieron nuevas normas de convivencia social que acarrearon nuevas formas de comportamiento fuera de línea; se puede afirmar que la presente tesis doctoral es una de las últimas que se cumplieron bajo las circunstancias de normalidad antes de la presencia de la pandemia generada por el nuevo coronavirus SARS-CoV-2, en la cual era factible el libre contacto físico y las relaciones cercanas cara a cara, y el uso de Facebook, se consideraba una alternativa interesante de comunicación y frecuentemente utilizada.

A partir de marzo de 2020, al haber cambiado las condiciones para las relaciones interpersonales de la población, frente al aislamiento obligatorio temporal, y la declaración del inicio de una nueva normalidad con tendencia de distanciamiento social en los contactos reales y con un incremento de los acercamientos a través de medios tecnológicos, principalmente video conferencia y los medios que aportan presencia social como las redes sociales, lo planteado en esta tesis como marco de referencia para conformar en Facebook, un entorno seguro de interacción social virtual que apoye la inclusión familiar y social del AM, cobra mayor relevancia y resulta importante para toda la población en general, usuaria de Facebook, que deberá reducir su exposición a los ciberriesgos, mientras exhiben sus manifestaciones de solidaridad, apoyo social, y utilizan la red social con otros fines particulares.

\subsection{TRABAJO FUTURO}

1. Cuantificar el efecto de Facebook sobre la calidad de las relaciones interpersonales del AM, en base a distintos parámetros como: la frecuencia con que se usan la variedad de servicios e interacciones que ofrece Facebook para la comunicación e interacción virtual; la frecuencia con que se accede a Facebook, el tiempo de duración de la conexión en Facebook, los apoyos 
sociales brindados y recibidos, la variedad de temas compartidos con los interlocutores emocionalmente importantes para el AM: familiares y amigos; la distancia geográfica donde se encuentran los contactos, los nuevos contactos recuperados o creados en la red social, las reacciones recibidas.

2. Desarrollar una herramienta informática de análisis predictivo, fundamentada en un algoritmo de minería de datos para clasificación basada en atributos, con la cual se desarrollen predicciones de las etiquetas de los niveles reales cualitativos que les correspondan a usuarios de Facebook en proceso de estudio, respecto: a los factores determinantes del nivel de conciencia sobre privacidad y seguridad en el entorno de Facebook y las características significativas que los definen; $y$, a la conciencia sobre privacidad y seguridad en la red social.

La herramienta deberá operativizar las reglas de cuantificación de los factores determinantes del nivel de conciencia real de personas usuarias de Facebook, expuestas en la investigación No. 4 del capítulo 5 .

Los datos de entrenamiento pueden ser generados a partir de los datos recopilados en el presente estudio, que constan en el archivo en formato digital que se ubica en el Anexo D, que tiene como nombre: Archivo 2.xlsx.

Los datos de prueba estarían constituidos por las respuestas obtenidas de la aplicación de la entrevista estandarizada definitiva desarrollada para la investigación No. 4 del capítulo 5, a los usuarios de Facebook en estudio.

3. La estructuración en Facebook de un entorno seguro de comunicación e interacción social para el AM, mediante la automatización del marco de referencia propuesto en esta tesis, a través de sistemas de inteligencia artificial, que interpretarían las características del AM, y las acciones que desea hacer a través de Facebook, y recomendaría las acciones seguras a cumplir para el éxito de la interacción social virtual.

4. La pérdida de credibilidad de algunos medios de comunicación tradicionales, ha hecho que las personas comunes expresen su percepción de la realidad a través de los medios actuales de comunicación, forjando muchas veces información no verificada. Por otro lado, otras personas pretenden orientar la opinión de los demás, con la intención de favorecer sus intereses, lo que ha generado gran cantidad de información sesgada con la consecuente desinformación; lo que ha dado en llamarse pos-verdad y noticias falsas.

Las personas que tienen acceso a los actuales medios de comunicación e interacción virtual, caracterizados por la inmediatez, la amplia cobertura y el acceso ubicuo, están expuestos a afectaciones debido a la pos-verdad y las noticias falsas.

Con fundamento en la teoría de la modernidad - visión dinámica expuesta en (Aranibar, 2001), en la perspectiva de Platón respecto al envejecimiento descrita en (Alfaro, 2015), y en conocimiento empírico; se pueden reconocer indicios de que las personas no tienen el mismo nivel de vulnerabilidad frente a la pos-verdad y las noticias falsas difundidas en las redes sociales, como los que se enuncian a continuación:

a) Conforme la persona transcurre sus años de vida, acumula conocimientos, actitudes y experiencias; $y$, desarrolla virtudes como la prudencia, la sagacidad, la discreción y el buen juicio; que le permiten comprender y enfrentar la realidad con mejor criterio. 
b) El año de nacimiento le ubica a la persona frente a la influencia de distintos acontecimientos y diversos recursos que le proveen una manera particular de entender e interpretar la realidad.

Las personas que viven en la época actual disponen de muchas fuentes de información, que pueden ser utilizadas para contrastar y verificar una noticia, de tal forma que será la actitud particular del usuario de las redes sociales, así como el nivel de dominio y confianza con el manejo de las funcionalidades de esas diversas fuentes de información, los que determinen el nivel de vulnerabilidad frente a la pos-verdad y las noticias falsas.

c) Por conocimiento empírico se podría presumir que la pos-verdad y las noticias falsas, pueden tener mayor influencia especialmente en grupos etarios más jóvenes que el de los AM, tomando en cuenta, la forma de procesar y apropiarse de la información, es decir, la forma en que las personas le dan sentido y significado a la información que reciben antes de actuar en base a ella.

En este sentido, las personas jóvenes, acostumbran a confiar en lo que reciben por Internet, y no manifiestan mayor esfuerzo por asegurarse o verificar si la información a la que accedieron con facilidad, es verídica o correcta.

d) Tomando en cuenta que la pos-verdad pretende aprovecharse de la sensibilidad emocional de las personas, es posible que, a más del parámetro edad, también influyan otros factores como el nivel de educación, el género.

En este contexto, se plantea como trabajo futuro, un estudio comparativo cuya pregunta de investigación sea: ¿Es el AM menos vulnerable a la pos-verdad y las noticias falsas difundidas en la red social Facebook con relación a los miembros de otros grupos etarios? Con esta investigación, se podrán identificar factores determinantes del nivel de vulnerabilidad de los usuarios de Facebook frente a la pos-verdad y las noticias falsas difundidas en la red social.

5. Estudiar el contexto del servicio de Facebook desde la perspectiva jurídica, para legislar localmente sobre responsabilidades en delitos informáticos contra las personas usuarias de Facebook debido al uso de la red social, a los datos personales recopilados y almacenados en la plataforma, a la posibilidad de que sea un delito transfronterizo, es decir que el atacante ejecute el delito desde otro país distinto del país de residencia de la víctima.

6. El uso de Facebook durante la pandemia del nuevo coronavirus SARS-CoV-2 y su enfermedad, Covid-19 es una alternativa amplia de investigación.

En el tiempo antes de que el mundo viviera la evolución de la pandemia del COVID 19, la normalidad en la convivencia diaria de las personas permitía un relacionamiento cara a cara libre de prohibiciones, y el uso de las redes sociales se consideraba una alternativa de comunicación, muy atractiva y frecuentemente utilizada.

Con el advenimiento de la pandemia, en marzo de 2020, en el mundo se estableció una nueva normalidad que se fundamentaba en el impedimento del contacto físico, con restricciones de distanciamiento social, en la que los miembros de las familias se vieron obligados a mantenerse distanciados, lo que trajo como consecuencia que las redes sociales dejen de ser una alternativa de comunicación y se convirtieron en sistemas de comunicación de uso imprescindible. 
Por la importancia que adquirió el uso de las redes sociales durante la evolución de la pandemia del Covid 19, se pueden realizar diversos estudios con distintas perspectivas de enfoque, por citar algunas de ellas: información libre frente a información censurada, análisis del manejo de la pandemia del Covid 19 en Facebook; análisis del apoyo social a través de Facebook durante la pandemia del Covid 19; análisis del uso de Facebook para el ocio y el entretenimiento durante la pandemia del Covid 19; el uso de Facebook en el emprendimiento de actividades productivas de los usuarios durante la pandemia del Covid 19; análisis de la información errónea, no verificada y oficial difundida en Facebook en la construcción de escenarios frente la pandemia del Covid 19.

7. Extender el enfoque presentado en este trabajo hacia otras redes sociales, focalizando el análisis en los grupos poblacionales que constituyan sus principales usuarios, y estableciendo comparaciones con otros grupos. 


\section{REFERENCIAS}

Abdullah, M. Y., Salman, A., Abdul Razak, N., Mohd Noor, N. F., \& Abdul Malek, J. (2011). Issues affecting the use of information and communication technology among the elderly: A case study on JENii. 2011 IEEE 10th Malaysia International Conference on Communications, MICC 2011, October, 29-32. https://doi.org/10.1109/MICC.2011.6150294

Achilleos, A. P., Mettouris, C., Papadopoulos, G. A., Neureiter, K., Rappold, C., Moser, C., Tscheligi, M., Vajda, L., Toth, A., Hanak, P., Jimenez, O., \& Smit, R. (2013). The connected vitality system: Enhancing social presence for older adults. Proceedings of the 12th International Conference on Telecommunications, ConTEL 2013, 199-206. http://www.scopus.com/inward/record.url?eid=2-s2.0-

84883701554\&partnerID=tZOtx3y1

Age UK. (2011). Technology and Older People Evidence Review (Age UK (ed.); Evidence R, Issue 1128267). Age UK. https://www.ageuk.org.uk/Documents/EN-GB/Forprofessionals/Research/Evidence_Review_Technology.pdf?dtrk=true

Agudo Prado, S., \& Fombona Cadavieco, J. (2013). Impacto De Las Tic En Las Personas Mayores En Asturias : Mejora Del Autoconcepto Y De La Satisfacción. EDUTEC. Revista Electrónica de Tecnología Educativa. ISSN 1135-9250, 1-13. http://edutec.rediris.es/Revelec2/Revelec44/pdf/Edutec-e_n44-Agudo-Fombona.pdf

Ahmad, M. I. (2014). Unified Theory of Acceptance and Use of Technology (UTAUT): A Decade of Validation and Development. In: Fourth International Conference on ICT in Our Lives 2014, 1, 1-13. https://doi.org/10.1590/0034-7612140185

Ala-mutka, K., Broster, D., Cachia, R., Centeno, C., Feijóo, C., Haché, A., Kluzer, S., Lindmark, S., Lusoli, W., Misuraca, G., Pascu, C., Punie, Y., Valverde, J. a, Ala-mutka, A. K., Broster, D., Cachia, R., Centeno, C., Feijóo, C., Haché, A., ... Punie, E. Y. (2009). The Impact of Social Computing on the EU Information Society and Economy. http://ftp.jrc.es/EURdoc/JRC54327.pdf

Aldana González, G., García Gómez, L., \& Jacobo Mata, A. (2012). Las Tecnologías de la Información y Comunicación (TIC) como alternativa para la estimulación de los procesos cognitivos en la vejez. CPU-e, Revista de Investigación Educativa, 153-166. https://www.redalyc.org/pdf/2831/283121840008.pdf

Alfaro, M. J. (2015). EL ENVEJECIMIENTO Y LA MUERTE: UN ENFOQUE FILOSÓFICO. 14, 85-94. http://www.unife.edu.pe/publicaciones/revistas/filosofia/Phainomenon/2015/6.pdf

Algarni, A., Xu, Y., \& Chan, T. (2014). Social engineering in social networking sites: The art of impersonation. Proceedings - 2014 IEEE International Conference on Services Computing, SCC 2014, 797-804. https://doi.org/10.1109/SCC.2014.108

Aranibar, P. (2001). Acercamiento conceptual a la situación del adulto mayor en América Latina. https://doi.org/ISSN: 1680-8991 
Arribas Macho, J. M. (1998). El modelo estadístico desde la perspectiva cualitativa. Empiria: Revista de Metodología de Ciencias ..., 1, 85-95. http://dialnet.unirioja.es/servlet/articulo?codigo=199621

Ayuntamiento de Vitoria-Gasteiz. (2010). Educar a los menores en el uso sin riesgos de Internet. Guía Para Madres y Padres, 53. http://www.vitoriagasteiz.org/wb021/http/contenidosEstaticos/adjuntos/es/28/95/32895.pdf

Barbosa Neves, B., Franz, R., Judges, R., Beermann, C., \& Baecker, R. (2019). Can Digital Technology Enhance Social Connectedness Among Older Adults? A Feasibility Study. Journal of Applied Gerontology, 38(1), 49-72. https://doi.org/10.1177/0733464817741369

Beuchot, M. (1999). Heurística y Hermenéutica.

Boll, F., Brune, P., \& Gewald, H. (2017). Towards your Parents' Social Network Platform: Design of a User Interface for the Age of Retirement. Proceedings of the 50th Hawaii International Conference on System Sciences (2017), 3725-3734. https://doi.org/10.24251/hicss.2017.450

Bong, W. K., Chen, W., \& Bergland, A. (2018). Tangible User Interface for Social Interactions for the Elderly: A Review of Literature. Advances in Human-Computer Interaction, 2018. https://doi.org/10.1155/2018/7249378

Bosch, T., \& Currin, B. (2015). Usos y gratificaciones de los ordenadores en personas mayores en Sudáfrica. Comunicar: Revista Científica Iberoamericana de Comunicación y Educación, 45, 9-18. http://dialnet.unirioja.es/servlet/articulo?codigo=5133303

Boyd, K., Bond, R., Nugent, C., \& Donnelly, M. (2018). EasiSocial: Recommendations in the Development and Training of Social Media Tools for Older People. https://doi.org/10.14236/ewic/hci2018.112

Bradley, J. (2009). The technology acceptance model and other user acceptance theories. Handbook of Research on Contemporary Theoretical Models in Information Systems, 277-294. https://doi.org/10.4018/978-1-60566-659-4.ch015

Camarinha-matos, L. M., \& Afsarmanesh, H. (2011). Active Aging with Collaborative Networks. IEEE Technology and Society Magazine, 30(4), 12-25.

Casamayou, A. (2016). Apropiación (es): aportes desde la sistematización y la teoría. In L. A. Rivoir (Ed.), Tecnologías Digitales en Sociedad. Análisis empíricos y reflexiones teóricas. Facultad de Ciencias Sociales. Departamento de Sociología. http://observatic.edu.uy/wp-content/uploads/2016/06/Libro-Tecnolog\%C7\%F0asDigitales-ObservaTIC-2016.pdf

Casamayou, A., \& Morales González, M. J. (2018). Personas mayores y tecnologías digitales: desafíos de un binomio Elderly people and digital technologies: a dual challenge Idosos e tecnologias digitais: desafios duplos. Conocimiento y Sociedad, 7(2), 199-226.

Chen, J. L., Ho, S. C., \& Wu, Y. Y. (2014). The impact of social psychological factors on the relationship quality of Facebook users. Proceedings - Pacific Asia Conference on 
Information Systems, PACIS 2014. http://www.scopus.com/inward/record.url?eid=2s2.0-84928614094\&partnerID=tZOtx3y1

Choi, N. G., \& Dinitto, D. M. (2013). The digital divide among low-income homebound older adults: Internet use patterns, ehealth literacy, and attitudes toward computer/internet use. Journal of Medical Internet Research, 15(5).

Chopik, W. J. (2016). The Benefits of Social Technology Use among Older Adults Are Mediated by Reduced Loneliness. Cyberpsychology, Behavior, and Social Networking, 19(9), 551556. https://doi.org/10.1089/cyber.2016.0151

Colombo, F., Aroldi, P., \& Carlo, S. (2015). New elders, old divides: ICTs, inequalities and wellbeing amongst young elderly Italians. Comunicar, 23(45), 47-55. https://doi.org/10.3916/C45-2015-05

Concha, A., Olivares, L., \& Sepúlveda, L. (2000). Redes sociales en la tercera edad. http://www.redadultosmayores.com.ar/buscador/files/DESAR017.pdf

Cordova Jorge, \& Pacheco Fernando. (2013). Uso de las redes sociales en la tercera edad. $\begin{array}{lll}\text { Ciencia Unemi, 6, 53-58. } & \text { 6, }\end{array}$ http://ojs.unemi.edu.ec/index.php/cienciaunemi/article/view/97/95

Cornejo, M., \& Tapia, M. L. (2011). Redes sociales y relaciones interpersonales en internet. Fundamentos En Humanidades, 2(24), 219-229. https://www.redalyc.org/articulo.oa?id=18426920010

Cornwell, B., Laumann, E. O., Schumm, \& Philip, L. (2009). The Social Connectedness of Older Adults: A National Profile*. National Institute of Health, 6(2), 247-253. https://doi.org/10.1111/j.1743-6109.2008.01122.x.Endothelial

Cruz, I., \& Miquel, J. (2011). Densidad, clase social y apoyo expresivo *. REDES- Revista Hispana Para El Análisis de Redes Sociales, 20, 187-203. http://revista-redes.rediris.es

Curiel, P., Pretel, I., \& Lago, A. B. (2014). Person-oriented interface transparent access to interpersonal communication services. 1-7. https://doi.org/10.1109/cisti.2014.6877036

Dasgupta, S. (2010). Social Computing: (C) (Issue June). http://www.asecib.ase.ro/mps/Social Computing [2010].pdf

De Oleo Moreta, C., \& Rodríguez Baena, L. (2012). Mayores y redes sociales en España : evaluación de la usabilidad en el proceso de registro. Ventana Informatica, 26, 129-140.

del Valle Gómez, G., \& Coll i Planas, L. (2011). RELACIONES SOCIALES Y ENVEJECIMIENTO SALUDABLE. In Envejecimiento saludable (Institut d, pp. 1-60). http://salutenvelliment.uab.cat/publicacions/docs/relacionssocialsesp.pdf

Diaz, F. J., \& Harari, I. (2014a). Estudiando la Interacción entre Adultos Mayores y las Redes Sociales en su Proceso de Aprendizaje. XX Congreso Argentino de Ciencias de La Computación.

https://pdfs.semanticscholar.org/efcd/687a1552f9f7444b21577bf3bd942932f6cf.pdf

Diaz, F. J., \& Harari, I. (2015). Del Telegrama a los Tweets : Investigación sobre la Interacción 
del Adulto Mayor con las Redes Sociales y Aplicaciones Google considerando Aspectos de Usabilidad y Accesibilidad Web Resumen Contexto Introducción Líneas de Investigación, Desarrollo e Inno. XVII Workshop de Investigadores En Ciencias de La Computación.

https://www.researchgate.net/publication/292059879_Del_Telegrama_a_los_Tweets_ Investigacion_sobre_la_Interaccion_del_Adulto_Mayor_con_las_Redes_Sociales_y_Apl icaciones_Google_considerando_Aspectos_de_Usabilidad_y_Accesibilidad_Web

Diaz, F. J., \& Harari, I. (2014b). Evaluando la usabilidad de las redes sociales por parte de Adultos Mayores. Interaction South America (ISA 14) : 6ta. Conferencia Lationamericana de Diseño de Interacción; 2014 Nov 19-22; Buenos Aires : Interaction Design Association ; Asociación de Profesionales En Experiencia de Usuario; Internet Society; Universidad Católica, Isa 14. http://bibliotecadigital.uca.edu.ar/ponencias/evaluando-usabilidadredes-sociales.pdf

Doffman, Z. (2021). Why You Should Stop Using Facebook Messenger After Privacy Backlash. Forbes.Com. https://www.forbes.com/sites/zakdoffman/?sh=634ad6c702c0 - fecha de último ingreso: 31 de enero de 2021

Durodolu, O. (2016). Technology Acceptance Model as a predictor of using information system' to acquire information literacy skills. Library Philosophy and Practice, 2016(1). https://digitalcommons.unl.edu/cgi/viewcontent.cgi?article=4029\&context=libphilprac

Elder, K., \& Retrum, J. (2012). Framework for Isolation in Adults Over 50. 48. http://www.aarp.org/content/dam/aarp/aarp_foundation/2012_PDFs/AARPFoundation-Isolation-Framework-Report.pdf

English, T., \& Carstensen, L. L. (2015). Encyclopedia of Geropsychology. In N. A. Pachana (Ed.), Encyclopedia of Geropsychology. Springer Singapore. https://doi.org/10.1007/978-981287-080-3

Espinoza, I., Osorio, P., Torrejón, M. J., Lucas-Carrasco, R., \& Bunout, D. (2011). Validación del cuestionario de calidad de vida (WHOQOL-BREF) en adultos mayores chilenos. Revista Médica de Chile, 139(5), 579-586. https://doi.org/10.4067/S0034-98872011000500003

Esset. (2011). Guía de Seguridad en Redes Sociales. https://www.welivesecurity.com/wpcontent/uploads/2014/01/documento_redes_sociales_baja.pdf

Esteban, R. C., Buils, R. F., \& Curto, R. E. (2012). Evaluation toolkit on seniors education to improve their quality of life. 2, 1-21. http://edusenior.uji.es/data/outcomes/wp2/QEduSen - WP2 - D2.1.a. - Requirement Analysis - Quality of Life - v.02.pdf

Facebook - Condiciones del servicio. (2020). Facebook. https://www.facebook.com/legal/terms - fecha de último ingreso: 31 de enero de 2021

Finn, K., \& Ph, D. (2010). Social Media Use by Older Adults. http://wiserusability.com/wpfs/wp-content/uploads/2015/07/Social-Media-Use-byOlder-Adults.pdf

Gasson, S. (2009). Employing a grounded theory approach for MIS research. Handbook of 
Research on Contemporary Theoretical Models in Information Systems, 34-56. https://doi.org/10.4018/978-1-60566-659-4.ch003

Ghoshal, A. (2018). Facebook confirms it spies on your Messenger conversations. Thenextweb.Com. https://thenextweb.com/facebook/2018/04/05/facebook-confirmsit-spies-on-your-messenger-conversations/ - fecha de último ingreso: 31 de enero de 2021

Gomes, G., Duarte, C., Coelho, J., \& Matos, E. (2014). Designing a facebook interface for senior users. The Scientific World Journal, 2014. https://doi.org/10.1155/2014/741567

Gómez Blanco, A. (2019). Las estafas más comunes en Facebook y cómo protegerse de ellas. BBVA. https://www.bbva.com/es/estafas-mas-comunes-facebook-protegerse-ellas/ fecha de último ingreso: 31 de enero de 2021

Gómez Navarro, D. A., Alvarado López, R. A., Martínez Domínguez, M., \& Díaz de León Castañeda, C. (2018). La brecha digital: una revisión conceptual y aportaciones metodológicas para su estudio de México. Entreciencias: Diálogos En La Sociedad Del Conocimiento, 6(16), 49-64. https://doi.org/10.22201/enesl.20078064e.2018.16.62611

Granovetter, M. (1973). The Strength of Weak Ties. In American Journal of Sociology (Vol. 78, Issue 6, pp. 1360-1380). https://doi.org/10.1086/225469

Grossetti, M. (2009). ¿Qué es una relacion social ? Un conjunto de mediaciones diádicas. REDES- Revista Hispana Para El Análisis de Redes Sociales, 6. http://revistaredes.rediris.es/pdf-vol16/vol16_2e.pdf

Gu, G. (2011). BotnetDetection in Enterprise Networks. In H. C. A. van Tilborg \& J. Sushil (Eds.), Encyclopedia of Cryptography and Security (pp. 166-168). https://doi.org/10.1017/CB09781107415324.004

Haris, N., Majid, R. A., Abdullah, N., \& Osman, R. (2014). The role of social media in supporting elderly quality daily life. 2014 3rd International Conference on User Science and Engineering (i-USEr), 253-257. https://doi.org/10.1109/IUSER.2014.7002712

Hartnett, Elizabeth; Minocha, Shailey; Palmer, Jane; Petre, Marian; Evans, Shirley; Middup, Christopher Paul; Dunn, Kathryn; Murphy, Brendan; Heap, Tania and Roberts, D. (2013). Older people and online social interactions: an empirical investigation. UKAIS International Conference on Information Systems (UKAIS), 18-20. http://oro.open.ac.uk/36591/1/paper12.pdf

Hendry, A., Rodriguez Mañas, L., Cano, A., Bernabei, R., Lllario, M., \& Molloy, W. (2015). Building European commitment to prevent and tackle frailty. Luxembourg: Publications Office of the European Union, 2015. https://ec.europa.eu/research/innovationunion/pdf/active-healthy-ageing/a3_decalogue_2015.pdf

Hernández Sampieri, R., Fernández Collado, C., \& Baptista Lucio, M. del P. (2010). METODOLOGÍA de la investigación (Quinta edi). McGRAW-HILL / INTERAMERICANA EDITORES, S.A. DE C.V.

Hope, A., Schwaba, T., \& Piper, A. M. (2014). Understanding digital and material social communications for older adults. Proceedings of the 32nd Annual ACM Conference on 
Human Factors in Computing Systems - CHI '14, 3903-3912. https://doi.org/10.1145/2556288.2557133

Huenchuan, S. (CEPAL/CELADE). (2013). Los derechos de las personas mayores. 1-20. http://www.cepal.org/celade/envejecimiento

INEC, I. N. de E. y C. (2018). Tecnologías de la Información y Comunicación - Encuesta Multipropósito - TIC 2018. https://www.ecuadorencifras.gob.ec/documentos/webinec/Estadisticas_Sociales/TIC/2018/201812_Principales_resultados_TIC_Multiproposit o.pdf\%0A

Innobasque, I. (2012). Envejecimiento y nuevos servicios de atención en el domicilio. In Innovación Social (p. 54). https://www.innobasque.eus/uploads/documentos/apuntes/BA51428F0E0A44049158 04AE49F3C68CDEF93EC7.pdf

Instituto de Auditores Internos de España. (2016). Ciberseguridad Una guía de supervisión (Instituto de Auditores Internos de España (ed.)). https://auditoresinternos.es/uploads/media_items/guia-supervision-ciberseguridadfabrica-pensamiento-iai.original.pdf

Játiva Espinoza, J. C., \& Jaramillo Vásconez, C. M. (2013). Servicios de Capacitación en Tecnología para Adultos Mayores [Universidad San Francisco de Quito - Colegio de Postgrados]. http://repositorio.usfq.edu.ec/bitstream/23000/3018/1/109764.pdf

Jung, E. H., \& Sundar, S. S. (2016). Senior citizens on Facebook: How do they interact and why? Computers in Human Behavior, 61, 27-35. https://doi.org/10.1016/j.chb.2016.02.080

Keil, M., \& Johnson, R. D. (2000). Feedback Channels: Using Social Presence Theory to Compare Voice Mail to E-mail. Journal of Information Systems, 13(4), 295-302. https://doi.org/http://dx.doi.org/10.1016/j.chb.2003.11.008

Keyeux, G., Penchaszadeh, V., \& Saada, A. (2006). ÉTICA DE LA INVESTIGACIÓN EN SERES HUMANOS Y POLÍTICAS DE SALUD PÚBLICA (U. N. de C. Unibiblos (ed.)). UNESCO Universidad Nacional de Colombia.

Khan, D. M., Mohamudally, N., \& Babajee, D. K. R. (2012). Towards the Formulation of a Unified Data Mining Theory, Implemented by Means of Multiagent Systems (MASs). In A. Karahoca (Ed.), ADVANCES IN DATA MINING KNOWLEDGE DISCOVERY AND APPLICATIONS (Vol. 84, pp. 3-53). InTech Janeza Trdine 9, 51000 Rijeka, Croatia. http://ir.obihiro.ac.jp/dspace/handle/10322/3933

Laing, O., \& Future Foundation. (2015). The future of loneliness. In Future Foundation (Issue July). http://www.theguardian.com/society/2015/apr/01/future-of-loneliness-internetisolation

Lappa, B. D. (2018). FACEBOOK AND GREEK RETIREES' RELATIONSHIPS A study on how Facebook usage affects Greek older adults 'social bonds. May, 1-77.

Lara, J. C., Pincheira, C., \& Vera, F. (2014). La privacidad en el sistema legal chileno. https://www.derechosdigitales.org/wp-content/uploads/pp-08.pdf 
Lehtinen, L., Kurki, M., Cuomo, S., Palmisano, E., Vainikainen, S., Pettenati, M. C., Locatelli, C., Bianco, D., Pet, T., Internal, F., \& Sillanp, M. (2011). WP 1 D1 . 1 -State of the Art Report.

Leist, A. K., Ferring, D., Klauß, K., Klein, P., Braun, A., \& Wichert, R. (2011). USER REQUIREMENTS IN ICT-BASED SOCIAL MEDIA USE: ACCEPTANCE OF A VIRTUAL COACH. In I. Bierhoff, H. H. Nap, W. Rijnen, \& R. Wichert (Eds.), Partnerships for Social Innovation in Europe - Proceedings of the AAL Forum 2011 Lecce.

León, D., Rojas, M., \& Campos, F. (2011). Guía Calidad de Vida en la Vejez - Herramientas para vivir más y mejor. http://adultomayor.uc.cl/docs/guia_calidad_de_vida.pdf

López-Bonilla, L. M., \& López-Bonilla, J. M. (2011). Los modelos de adopción de tecnologías de la información desde el paradigma actitudinal - Models of adopting information technologies from the attitudinal paradigm. 9, 176-196.

Madrigal-Martínez, M. (2010). Ingresos y bienes en la vejez, un acercamiento a la configuración de la seguridad económica de los adultos mayores mexiquenses. Papeles de Poblacion, 16(63), 117-153.

Mahmud, Y., Rahim, N. Z. A., \& Miskon, S. (2016). Social Network Site (SNS) appropriation process in family perspective based on family types. Journal of Theoretical and Applied Information Technology, 88(3), 464-475.

Majcen, K., Stocker, A., Mayer, H., Dorst, M., Dijkgraaf, P., Blümlinger, K., \& Nuñez, F. J. (2011). ELDERLY PEOPLE - NEW MEDIA ... CONTRADICTION OR CHANCE? EXPERIENCES FROM THE ALICE PROJECT. In I. Bierhoff, H. H. Nap, W. Rijnen, \& R. Wichert (Eds.), Partnerships for Social Innovation in Europe - Proceedings of the AAL Forum 2011 Lecce (Proceeding).

Marsden, P. V., \& Campbell, K. E. (1984). Measuring Tie Strength. Social Forces, 63(2), 482501. https://doi.org/10.1093/sf/63.2.482

Martínez-Salgado, C. (2012). El muestreo en investigación cualitativa. Principios básicos y algunas controversias. Ciencia e Saude Coletiva, 17(3), 613-619. https://doi.org/10.1590/S1413-81232012000300006

Me Conecto Sin Clavos, M. de G. de G. (2017). Guía ciber-riesgos educadores.

Meymo, S., \& Nyström, K. (2017). Why do elderly not use social media? An investigation of the elderly's attitudes to $\mathrm{HCl}$. https://www.researchgate.net/publication/319307162_Why_do_elderly_not_use_soci al_media_An_investigation_of_the_elderly's_attitudes_to_HCl

Moser, C., Fuchsberger, V., Neureiter, K., Sellner, W., \& Tscheligi, M. (2011). Elderly's social presence supported by ICTs investigating user requirements for social presence. Proceedings - 2011 IEEE International Conference on Privacy, Security, Risk and Trust and IEEE International Conference on Social Computing, PASSAT/SocialCom 2011, 738-741. https://doi.org/10.1109/PASSAT/SocialCom.2011.129

Myhre, J. W., Mehl, M. R., \& Glisky, E. L. (2016). Cognitive Benefits of Online Social Networking for Healthy Older Adults. The Journals of Gerontology. Series B, Psychological Sciences and Social Sciences, 00(00), gbw025. https://doi.org/10.1093/geronb/gbw025 
Neergaard, H., \& Ulhøi, J. P. (2006). Handbook of qualitative research methods in entrepreneurship. In Edward Elgar Publishing Limited. https://doi.org/10.4337/9781847204387

Nef, T., Ganea, R. L., Müri, R. M., \& Mosimann, U. P. (2013). Social networking sites and older users - A systematic review. International Psychogeriatrics, 25(7), 1041-1053. https://doi.org/10.1017/S1041610213000355

Netter, M., Herbst, S., \& Pernul, G. (2013). Interdisciplinary Impact Analysis of Privacy in Social Networks. In Y. Altshuler, Y. Elovici, A. B. Cremers, N. Aharony, \& A. Pentland (Eds.), Security and Privacy in Social Networks (pp. 1-253). Springer. https://doi.org/10.1007/978-1-4614-4139-7

Oddone, M. (2013). Antecedentes teóricos del Envejecimiento Activo. Informes Envejecimiento En Red, 4(2340-566X), 1-9. http://envejecimiento.csic.es/documentos/documentos/oddone-antecedentes.pdf

OECD. (1980). Annex to the recommendation of the Council of 23 September 1980: Guidelines governing the protection of privacy and transborder flows of personal data (Issue September).

OECD. (2011). Thirty Years After the Oecd Privacy Guidelines. http://www.oecd.org/sti/ieconomy/49710223.pdf

Organización Mundial de la Salud, G. O. de E. N. T. y S. M. (2002). Envejecimiento activo: un marco político*. 37, 74-105.

Oturakci, M., \& Oturakci, M. (2018). Developing New Technology Acceptance Model With Multi-Criteria Decision Technique: An Implementation Study. Engineering Management Research, 7(2), 43. https://doi.org/10.5539/emr.v7n2p43

Petroczi, A., Bazsó, F., \& Nepusz, T. (2007). Measuring tie-strength in virtual social networks. Connections, 27(2), 39-52. http://eprints.kingston.ac.uk/2396/

PROSIC, P. S. de la I. y el C. (2010). Los adultos mayores y las tic. Informe Anual Hacia La Sociedad de La Información y El Conocimiento, 1-33. http://www.prosic.ucr.ac.cr/informe-2010

Quinn, D., Chen, L., Mulvenna, M. D., \& Bond, R. (2016). Exploring the relationship between online social network site usage and the impact on quality of life for older and younger users: An interaction analysis. Journal of Medical Internet Research, 18(9), 1-16. https://doi.org/10.2196/jmir.5377

Quinn, K. (2018). Cognitive Effects of Social Media Use: A Case of Older Adults. Social Media and Society, 4(3). https://doi.org/10.1177/2056305118787203

Quinn Patton, M., \& Cochran, M. (2007). A Guide to Using Qualitative Research Methodology. In Medecins Sans Frontieres (pp. 1-36). http://msf.openrepository.com/msf/handle/10144/84230

Ramos, C. M. Q., Mendonça, M. M., \& Rodrigues, J. M. F. (2018). Senior users of social 
networks: Technological experience and use habits analysis. ACM International Conference Proceeding Series, 129-136. https://doi.org/10.1145/3218585.3218658

Renaud, K., \& Van Biljon, J. (2008). Predicting technology acceptance and adoption by the elderly: A qualitative study. ACM International Conference Proceeding Series, 338(October), 210-219. https://doi.org/10.1145/1456659.1456684

Rodríguez-Piñero, L., \& Huenchuan, S. (2011). Los derechos de las personas mayores. https://fiapam.org/wp-content/uploads/2012/10/Modulo_2.pdf

Rojas Crotte, I. R. (2011). ELEMENTOS PARA EL DISEÑO DE TÉCNICAS DE INVESTIGACIÓN: UNA PROPUESTA DE DEFINICIONES Y PROCEDIMIENTOS EN LA INVESTIGACIÓN CIENTÍFICA. Tiempo de Educar, 12, 277-297. http://www.redalyc.org/pdf/311/31121089006.pdf

Romo, A. C., Valencia, S. M., Romo, A. C., Valencia, S. M., \& Sampieri, R. H. (2014). Manual de introducción a ATLAS. ti 7 Manual de introducción a ATLAS . ti 7. https://doi.org/Manual de introducción a ATLAS . ti 7

Ron Revelo, O. (2016). El comportamiento del consumidor ecuatoriano desde la perspectiva psicológica (p. 15). PONTIFICIA UNIVERSIDAD CATÓLICA DEL ECUADOR SEDE MANABÍ. https://repositorio.pucesa.edu.ec/bitstream/123456789/2081/1/El Comportamiento del Consumidor.pdf

Seabrook, E. M., Kern, M. L., \& Rickard, N. S. (2016). Social Networking Sites, Depression, and Anxiety: A Systematic Review. JMIR Mental Health, 3(4), e50. https://doi.org/10.2196/mental.5842

Simplican, S. C., Leader, G., Kosciulek, J., \& Leahy, M. (2015). Defining social inclusion of people with intellectual and developmental disabilities: An ecological model of social networks and community participation. Research in Developmental Disabilities, 38, 1829. https://doi.org/10.1016/j.ridd.2014.10.008

Sinclair, T. J., \& Grieve, R. (2017). Facebook as a source of social connectedness in older adults. Computers in Human Behavior, 66, 363-369. https://doi.org/10.1016/j.chb.2016.10.003

Smithson, N. (2019). Facebook Inc.'s Mission Statement \& Vision Statement (An Analysis). Panmore Institute. http://panmore.com/facebook-inc-vision-statement-missionstatement

Teng, C. E., \& Joo, T. M. (2017). Analyzing the Usage of S ocial Media: A Study on Elderly in Malaysia. Journal of Humanities and Social Sciences, 11(3), 737-743. https://doi.org/1307-6892/10007039

Tétard, F., \& Collan, M. (2009). Lazy user theory: A dynamic model to understand user selection of products and services. Proceedings of the 42nd Annual Hawaii International Conference on System Sciences, HICSS, 1-9. https://doi.org/10.1109/HICSS.2009.287

UIT, U. I. T. (2014). Manual para la medición del uso y el acceso a las TIC por los hogares y las personas (2014th ed.). http://www.itu.int/dms_pub/itu-d/opb/ind/D-IND-ITCMEAS2014-PDF-S.pdf 
UNESCO. (2012). Global Survey on Internet Privacy and Freedom of Expression. In UNESCO series on Internet freedom. https://doi.org/ISBN: 978-92-3-104241-6

Venkatesh, V. (2003). USER ACCEPTANCE OF INFORMATION TECHNOLOGY: TOWARD A UNIFIED VIEW. MIS Quarterly, 27(3), 425-478. https://pdfs.semanticscholar.org/f444/aecb9a6cc1219d6baf81c55f23dfce3d9788.pdf? _ga=2.156085820.602289405.1585709742-414316943.1585709742

Venkatesh, V. (2012). CONSUMER ACCEPTANCE AND USE OF INFORMATION TECHNOLOGY : EXTENDING THE UNIFIED THEORY. MIS Quarterly, 36(1), 157-178. https://doi.org/10.2307/41410412

Venkatesh, V., \& Bala, H. (2008). Technology acceptance model 3 and a research agenda on interventions. Decision Sciences, 39(2), 273-315. https://doi.org/10.1111/j.15405915.2008.00192.x

Venkatesh, V., Thong, J. Y. L., \& Xu, X. (2016). Unified theory of acceptance and use of technology: A synthesis and the road ahead. Journal of the Association for Information Systems, 17(5), 328-376. https://doi.org/10.17705/1jais.00428

Verdugo Alonso, M. Á. (2004). CALIDAD DE VIDA Y CALIDAD DE VIDA FAMILIAR. http://ardilladigital.com/DOCUMENTOS/CALIDAD DE VIDA/CALIDAD DE VIDA Y BUENA PRACTICA/Calidad de vida y calidad de vida familiar - Verdugo - articulo.pdf

Verdugo Alonso, M. A., Arias Martínez, B., Gómez Sánchez, L., \& Schalock, R. (2009). Escala GENCAT: Manual de aplicación de la Escala GENCAT de Calidad de vida. http://inico.usal.es/27/instrumentos-evaluacion/escala-de-calidad-de-vida-gencat.aspx

Vilte, D., Saldaño, V., Martín, A., \& Gaetán, G. (2013). Evaluación del Uso de Redes Sociales en Ia Tercera Edad. http://conaiisi.unsl.edu.ar/2013/142-446-1-DR.pdf

Wallbridge, R. (2009). How safe is Your Facebook Profile ? Privacy issues of online social networks. ANU Undergraduate Research Journal, 1, 85-92. http://pressfiles.anu.edu.au/downloads/press/n1677/pdf/11.pdf

WHO, W. H. O. (1996). INTRODUCTION , ADMINISTRATION, SCORING AND GENERIC VERSION OF THE ASSESSMENT Field Trial Version December 1996 PROGRAMME ON MENTAL HEALTH WORLD HEALTH ORGANIZATION (Issue December).

Wong, K. (2014). Trust and Privacy Exploitation in Online Social Networks. October, 28-33. https://doi.org/10.1109/MITP.2009.1.

Zahava, G., \& Bowling, A. (2004). Quality of life from the perspectives of older people. Ziller 1974, 675-691. https://doi.org/10.1017/S0144686X03001582

Zhan, J., \& Fang, X. (2011). Social computing: the state of the art. Journal of Social Computing $\begin{array}{llll}\text { and Cyber-Physical } & \text { Systems, } & 1(1),\end{array}$ http://www.inderscienceonline.com/doi/abs/10.1504/IJSCCPS.2011.043601

Zhang, C., Sun, J., Zhu, X., \& Fang, Y. (2010). Privacy and Security for Online Social Networks: Challenges and Opportunities. IEEE Network, 24(4), 13-18. 
https://doi.org/10.1109/MNET.2010.5510913

Zhang, F., \& Kaufman, D. (2015). Social and Emotional Impacts of Internet Use on Older Adults. European Scientific Journal, ESJ, 11(17), 1-15.

http://www.eujournal.org/index.php/esj/article/view/5789 


\section{ANEXOS}

Los anexos se encuentran en archivos digitales, organizados en carpetas independientes para cada uno de ellos, acompañando el documento de la tesis.

Los anexos disponibles se detallan a continuación:

\section{ANEXO A - Publicaciones}

PUBLICACION 1: $\quad$ Decalogue for a Senior Citizen's Positive Attitude towards Facebook.

PUBLICACION 2: $\quad$ Why Should a Senior Citizen be a Facebook User? Reasons for A Senior Citizen's Positive Attitude Towards Facebook.

PUBLICACION 3: $\quad$ Comprensión de la potencialidad del contexto tecnológico del AM ecuatoriano que vive en su casa para el aprovechamiento de la interacción social a través de Internet.

PUBLICACION 4: $\quad$ Proceso para estimar el nivel real de conciencia de los usuarios de Facebook respecto a privacidad y seguridad en la red social.

\section{ANEXO B - Ejemplos de registros en las guías de observación cualitativa}

\section{ANEXO C - Entrevistas estandarizadas (encuestas) diseñadas para la investigación no experimental transversal}

ENCUESTA 1: $\quad$ Encuesta para Adultos Mayores que viven en su casa referida a sus relaciones interpersonales y el uso de las Tecnologías de Información y Comunicaciones (TIC's).

ENCUESTA 2: $\quad$ Encuesta para Adultos Mayores que viven en su casa referida a la forma en que utilizan Internet.

ENCUESTA 3: $\quad$ Encuesta para usuarios de Facebook respecto a su conocimiento sobre seguridad y privacidad en la red social.

\section{ANEXO D - Archivos digitales}

ARCHIVO 1:

ARCHIVO 2:

ARCHIVO 3:

ARCHIVO 4:
Respuestas a la encuesta No. 2 en planillas en Excel

Respuestas a la encuesta No. 3 en planilla en Excel

Planillas de cálculo para la obtención del nivel real de conciencia sobre privacidad y seguridad de los usuarios de Facebook.

Muestras de la encuesta 1 